FIIIIII

[DUL'TlinE

IN TRANSITIRN

The Unoanny Child in Transnational Cinema

Ghosts of Futurity at the Turn of the

Twenty-First Century

$$
\text { JESGICA BALANZATEGUI }
$$


The Uncanny Child in Transnational Cinema 



\section{The Uncanny Child in Transnational Cinema}

Ghosts of Futurity at the Turn of the Twenty-First Century

Jessica Balanzategui 
Excerpts from the conclusion previously appeared in Terrifying Texts: Essays on Books of Good and Evil in Horror Cinema $\Subset 2018$ Edited by Cynthia J. Miller and A. Bowdoin Van Riper by permission of McFarland \& Company, Inc., Box 611, Jefferson NC 28640.

Excerpts from Chapter Four previously appeared in Monstrous Children and Childish Monsters: Essays on Cinema's Holy Terrors @ 2015 Edited by Markus P.J. Bohlmann and Sean Moreland by permission of McFarland \& Company, Inc., Box 611, Jefferson NC 28640.

Cover illustration: Sophia Parsons Cope, 2017

Cover design: Kok Korpershoek, Amsterdam Lay-out: Crius Group, Hulshout

Amsterdam University Press English-language titles are distributed in the US and Canada by the University of Chicago Press.

$\begin{array}{ll}\text { ISBN } & 9789462986510 \\ \text { e-ISBN } & 9789048537792 \text { (pdf) } \\ \text { DOI } & 10.5117 / 9789462986510 \\ \text { NUR } & 670\end{array}$

(C) J. Balanzategui / Amsterdam University Press B.V., Amsterdam 2018

All rights reserved. Without limiting the rights under copyright reserved above, no part of this book may be reproduced, stored in or introduced into a retrieval system, or transmitted, in any form or by any means (electronic, mechanical, photocopying, recording or otherwise) without the written permission of both the copyright owner and the author of the book. 


\section{Table of Contents}

Acknowledgements

Introduction

The Child as Uncanny Other

\section{Section One Secrets and Hieroglyphs: The Uncanny Child in American Horror Film}

1. The Child and Adult Trauma in American Horror of the 1980 s

2. The Uncanny Child of the Millennial Turn

Section Two Insects Trapped in Amber: The Uncanny Child in Spanish Horror Film

3. The Child and Spanish Historical Trauma

4. The Child Seer and the Allegorical Moment in Millennial Spanish Horror Cinema

\section{Section Three Our Fear Has Taken on a Life of Its Own: The Uncanny Child in Japanese Horror Film}

5. The Child and Japanese National Trauma

6. The Prosthetic Traumas of the Internal Alien in Millennial J-Horror 


\section{Section Four Trauma's Child: The Uncanny Child in Transnational Coproductions and Remakes}

7. The Transnational Uncanny Child

8. Progress and Decay in the 21st Century

The Postmodern Uncanny Child in The Others (Alejandro

Amenábar, 2001)

9. 'Round and round, the world keeps spinning. When it stops, it's just beginning'

Analogue Ghosts and Digital Phantoms in THE RING (Gore Verbinski, 2002)

Conclusion

283

Works Cited

289

Filmography

307

Artworks

Music

Film Index

Index 


\section{Acknowledgements}

This book would not have been possible without a network of scholars, friends and family who have supported and guided its - and my own journey. My thanks especially to my incredible colleague and former $\mathrm{PhD}$ supervisor, Angela Ndalianis, who, with her seemingly illimitable knowledge, enthusiasm and creativity, has been my constant source of inspiration. I also have much gratitude for Fran Martin, whose insight and incisive feedback helped profoundly as I shaped my full draft, and for Allison Craven and Nicholas Chare, who helped me to develop my ideas in the early stages of this project in its former life as a $\mathrm{PhD}$ thesis. I thank Allison for fostering my appreciation of the aesthetic and cultural value of horror and monsters. For this I am also grateful to the Melbourne University monster club: Naja Later, Gabrielle Kristjanson, Madeleine Hunter, Tara Lomax and Leigh McLennon. Thank you in particular to Tara and to my new colleague Kaz Horsley for their wonderful work on my indexes, and to Sophia Parsons-Cope for her characteristically evocative artwork for the front cover. In addition, Adam Lowenstein and Antonio Lázarro-Reboll have influenced this monograph not only through their innovative and lively scholarship - featured in the proceeding pages - but through their thoughtful and generous feedback on an earlier version of the manuscript. I am lucky to have worked with a great team at Amsterdam University Press, including Maryse Elliott, Sarah de Waard, Chantal Nicolaes and Mike Sanders. My new colleagues and friends at Swinburne University have been a consistent source of motivation and support: thank you Julia Prendergast, Liam Burke, Jane Stadler, César Albarran-Torres, Daniel Golding, Carolyn Beasley, Andy Lynch, and Tinonee Pym. I owe a lot to my wonderful parents Peter and Jane Balanzategui, who have encouraged me throughout this project and my life. Going to Spain with them while working on this project - and in particular visiting my great-grandparents' grave in Lekeitio - was the highlight of my research. I am also very thankful for the love and support of Christine Parker, Ben Balanzategui, and Bill, Susan and Sarah Swann, and Nelson Woods. Finally, my deepest thanks to my partner Lewan Parker for his unwavering patience, care and generosity, and for always making sure our dear Samus and Spartan were fed on time. 



\title{
Introduction
}

\author{
The Child as Uncanny Other
}

\begin{abstract}
The introduction outlines the book's focus on the cinematic uncanny child, a figure that challenges normalized ideologies of childhood by interrogating the child's associations with both personal and historical time. While the uncanny child emerged as a significant presence in American horror films in the 1980 , this figure became one of the genre's key unifying tropes at the turn of the 21st century - not only in American films, but in films from around the globe, particularly from Japan and Spain. These uncanny child films are significant not just for their self-reflexive recalibration of a long-entrenched trope of the horror genre, but because they evidence a globally resonant shift in conceptualizations of childhood at the turn of the millennium.
\end{abstract}

Keywords: Uncanny child, Turn of the millennium, Futurity, Temporality, Horror film, Transnational

The child is one of the most pivotal of modernity's symbolic constructs, around which central cultural institutions such as the family and the school, and even our very conception of the adult, revolve. Yet despite this ideological centrality, defining the child remains a fraught process. Childhood continues to be demarcated by characteristics such as innocence, naivety, cuteness, and vulnerability, which define the child in terms of its vacuity and lack of form in relation to the experienced, knowledgeable, rational, and powerful adult. In addition, these characteristics naturalize the child's subordination within a family unit and stringently institutionalized processes of socialization, while existing as remnants of formative ideologies of childhood established during the Enlightenment. The key manifestations of such notions can be seen in English philosopher John Locke's famous assertion that the child is born a 'white paper' - a tabula rasa or blank slate - and is gradually filled with knowledge and experience on the journey towards adulthood (1996, xix;

Balanzategui, J., The Uncanny Child in Transnational Cinema: Ghosts of Futurity at the Turn of the Twenty-First Century, Amsterdam University Press, 2018.

DOI: 10.5117/9789462986510/INTRO 
6-24), and the Romantic ideologies of William Wordsworth and Jean-Jacques Rousseau that idealize this 'blank' child as a natural, pre-social being. These eighteenth- and early nineteenth-century concepts represent the nascent emergence of childhood's modern configuration, and remain at the core of common-sense understandings of the child - entrenched because innocence and naivety are considered to be innate, natural conditions of childhood. Thus, it is largely through the child's perceived lack of reason, socialization, and social constructedness that it is defined and established as the adult's binary opposite, and is positioned as a pivotal cultural other. While the Romantic conception that 'childhood is the sleep of reason' (Rousseau, 2007, 80) remains central to contemporary assumptions about the child, it ultimately serves to position the child as an empty and somewhat unknowable vessel, within which anxieties and ambivalence constellate. As Spanish painter Francisco Goya proclaims in a sinister amplification of Rousseau's assertion, 'the sleep of reason produces monsters' - the title of one of his most famously unsettling, gothic works.

As a result of this slippage between romanticized, innocent emptiness and the eruption of monstrosity via this very lack of knowledge and reason, the child has long been a fixation of horror cinema. The first sustained cinematic vision of a truly monstrous child occurs in THE BAD SEED (Mervyn LeRoy, 1956), which presents the murderous child as the vehicle through which a generic shift from family melodrama to horror plays out. In fact, the film ends with a message acknowledging its novelty: 'You have just seen a motion picture whose theme dares to be startlingly different.' At first a seemingly perfect child, Rhoda Penmark is gradually established as the villain of the film, as the visual and aural cues that initially construct her cuteness are distorted to become dissonant and unnerving. For instance, her performance of 'Au Clair de la Lune' on the piano shifts from signalling her innocence and sweetness into a horror cue thick with menace - infecting the non-diegetic score in discordant form - aestheticizing a point at which childishness becomes a threat to the adult characters and all the institutions that they hold dear.

Through the child, THE BAD SEED demarcates an influential shift in generic preoccupations, as from the late 1950s onwards the family comedy and melodrama started to wane just as the domestic or family-focused horror film emerged. ${ }^{1}$ Within the film, Rhoda's corruption of the security

1 This pattern of generic decline and emergence has been charted by Kathy Merlock Jackson (1986), Shelley Stamp Lindsey (1991), Tony Williams (1996), and Robin Wood (1979). That the cinematic monstrous child archetype emerged with the release of THE BAD SEED has been reinforced in the work of Dominic Lennard (2015), Merlock Jackson, William Paul (1994), and Julian Petley (1999). 
and sanctity of the nuclear family works in tandem with her provocation of the film's self-conscious generic shift. THE BAD SEED thus demonstrates the extent to which the terrible child is a key trope of the modern horror genre. As Kathy Merlock Jackson states, 'THE BAD SEED proved a real innovation for its time; never before had such an evil image of childhood appeared on the screen. [...] THE BAD SEED made its mark as a box-office success, thereby providing the germination of a filmic image that would reach its peak in the 1970s: the child-as-monster' $(1986,112)$.

THE BAD SEED's deformation of the signifiers of childish innocence and cuteness - in particular the sweet, nursery rhyme-esque refrain - had a great deal of influence upon the aesthetics of post-1950s horror film, to the extent that this device has become an oft-used and recognizable cliché of the genre. By the late 196os and early 1970s, the child became solidified as a central trope of the modern horror film via the release of the (un) holy trinity of evil child films: Rosemary's BABY (Roman Polanski, 1967), which features a baby born not as a blank slate but the devil incarnate; The Exorcist (William Friedkin, 1973), which depicts a twelve-year-old girl's possession by the devil; and THE OMEN (Richard Donner, 1976), which, like RosEmary's BABY, centres upon a child Antichrist, this time a five-year-old boy. Andrew Tudor points out that the release of these three films marks a cultural moment in which the horror genre 'transcended its specialization and attained real mass success' (1991, 63) - as Andrew Scahill observes of this phenomenon, 'one of the remarkable features of all three of these films is that the monstrosity at the centre of each text is, in fact, a child' $(2015,4)$.

Yet post THE BAD SEED's indubitably evil child, each of these possession and devil films construct the child as an empty vessel for evil to inhabit. This mechanism entails something of an evasive manoeuvre, in which all that is latently unnerving about the concept of childhood is displaced onto the figure of the devil. The horror of these films is constructed around the rather shallow tension established between the children as innocent victims of demonic possession and the evil that has come to inhabit their bodies: the innocence and naivety of the child is upheld in opposition to the power of the evil force that has assumed childhood's form. For instance, in ThE ExORCIST, while Regan's grotesque body rages against the priests who attempt to exorcise the demon, the words 'Help Me' appear inscribed on the child's flesh, illustrating a clear delineation between the body usurped by evil forces and the soul of the victimized, powerless child trapped inside. 
This book focuses not on these well-examined ${ }^{2}$ expressions of possessed, evil, or devil children, but instead on a movement that arose subsequent to these films and self-consciously modulates the child-as-vessel-for-evil trope. From the beginning of the 1980 os, a shift occurred as horror films started to feature more ambiguous images of childhood, in which the strangeness and otherness of child characters are not so simply attributable to an invasion by supernatural forces explicitly coded as 'evil' and external to the realm of the child. Foundational instances of this figure can be seen in THE SHINING (Stanley Kubrick, 1980), The Changeling (Peter Medak, 1980), and Poltergeist (Tobe Hooper, 1982), which are considered in the first chapter of this book. 20 years later, at the turn of the millennium, the uncanny child that first stirred in American horror of the 1980 s became one of the genre's key unifying tropes, not just in American films but in films from around the globe, particularly from Japan and Spain. These uncanny child films are significant not just for their self-reflexive recalibration of a long-entrenched trope of the horror genre, but because they evidence a globally resonant shift in conceptualizations of childhood at the turn of the millennium.

This book revolves around this child, not possessed or evil, but uncanny: a figure whose affects are best expressed by Freud's definition of the uncanny as an unsettling cognitive dissonance induced by the vacillation between the heimlich (homely/familiar) and the unheimlich (unhomely/unfamiliar) $(2003 \mathrm{~b}, 124)$. The horrors of these child characters are not associated with a shallow interplay of evil and innocence, but with the complex and impalpable ways in which they seem at once familiar and alien, vulnerable and threatening, innocent and dangerously indecipherable. As a result, these supernatural horror films approach the conceptual uncertainties latent within ideologies of the child, problematizing our usage of 'innocence' and 'naivety' - terms that, after all, connote emptiness - as defining qualities. Uncanny child films strip back surface understandings of the child as the pre-social, pre-rational originary stage of adulthood, a conception inevitably welded to adult nostalgia for the lost realm of purity and simplicity represented by childhood pasts. The films analysed throughout this book instead reveal the gothic underside to the romantic conceptual entanglement of childhood innocence and adult nostalgia, as childhood is positioned as the site of traumatic, imperfectly recalled pasts that haunt the adult's present in obfuscated ways.

2 These influential films and the evil child trope that they instigated have been thoroughly explored in scholarship on the horror genre, most recently in the work of Karen Jenner (2013), T.S. Kord (2016), Dominic Lennard (2015), Andrew Scahill (2015), and Adrian Schober (2004). 


\section{The Multiple Temporal Vectors of the Child's Uncanny Otherness}

Uncanny child films anxiously consider the child's complex position as a foundational but ultimately deeply paradoxical cultural other, dramatizing the dialectic tensions inherent in childhood's conceptual constitution. As Steven Bruhm suggests, 'the twentieth century has inherited - or invented - far too many contradictions in its theories about children' (2006, 98). The child can only exist in binary opposition to the adult, yet childhood also represents a past temporal stage of adulthood and is thus intimately connected to ideologies of adult identity. As childhood sociologist Chris Jenks elucidates, the child represents a:

continuous paradox, albeit expressed in a variety of forms. Simply stated, the child is familiar to us and yet strange; he or she inhabits our world and yet seems to answer to another; he or she is essentially of ourselves and yet appears to display a systematically different order of being. (2005, 2-3)

While being a subject of the present external to adult consciousness, the child is also something every adult once was, and is thus bound to teleological linear narratives of the adult self as the adult's origins and personal history. Furthermore, while childhood represents the past of the adult self, in the post-Freud era, this past psychic stage has also come to signify an ever-present but buried component of adult consciousness - almost equivalent with the unconscious - as is expressed in the popular idiom of the 'inner child'. Thus, the child is simultaneously opposed to, the past of, and a part of, the adult.

Amplifying this paradoxical constitution, through the emptiness of innocence, naivety, and unreason - the key conditions that delineate the child's otherness - the child is positioned as inherently indecipherable and enigmatic to adult consciousness. Marina Warner characterizes the child's quasi-sacred but hazardous lack of reason as a 'supernatural irrationality' $(1994,42)$, and suggests that 'childhood, placed at a tangent to adulthood, perceived as special and magical, precious and dangerous at once, has turned into some volatile stuff - hydrogen, or mercury, which has to be contained' $(1994,35)$. As Warner suggests, 'the separate condition of the child has never been so bounded by thinking, so established in law as it is today' $(1994,35)$ and many of our anxiously determined contradictions surrounding the child arise from this very 'concept that childhood and adult life are separate when they are inextricably intertwined' $(1994,48)$. By rejecting the evil child trope in favour of exploring the child's ambivalent otherness, uncanny child 
films consider the incongruities of our nebulous but symbolically charged definitions of the child as both other to and 'of' adulthood.

In so doing, these films also unveil the manner by which the child as conceptual apparatus stands at a fraught crossroads between personal and sociocultural metanarratives. In addition to being defined as a prior stage of adulthood and as the adult's binary opposite, the child is also implicated in paradigms of sociocultural progress and futurity. Constantly in the process of growing up, the child is largely conceived as a 'work in progress': as Jenks explains, 'the child has come to be understood as an unfolding project, a natural trajectory, a staged becoming, and an inevitably incremental progress into adulthood' (2001, 75). Jenks further suggests that:

the roots of such a belief run deep and integrate seamlessly with the physiological demands of medicine and the logistical demands of a society based on hierarchical stratification and hierarchical distribution of provision. This is a powerful discourse that routinely structures children's experience, their time, and how their bodies are read and managed. $(2001,75)$

This processual model of growing up is teleological in nature, as the child gradually ascends a set linear trajectory, with 'adult competence being journey's end - the modernist project writ small!' (Jenks, 2001, 75). As Lee Edelman explains, this notion of growing up is pivotal to sociocultural and political investment in teleological progression, the 'narrative movement towards a viable political future' $(2004,4)$. The child's growing up is thus welded to ideals of collective progress, as the child's journey towards both adulthood and futurity - that mythical realm beyond the horizon of present adult society - personifies 'the fantasy of meaning's eventual realisation' (Edelman, 2004, 4) through continual progress. Edelman points to standard political rhetoric that justifies present politics and ideologies in the name of 'the children', describing such child-centred investment in teleological progress as 'reproductive futurism': 'the Child has come to embody for us the telos of the social order and come to be seen as the one for whom that order is held in perpetual trust' $(2004,11)$.

While excavating the ambivalent ways in which the child is defined as other to while simultaneously being tied to adulthood, uncanny child films start to explore and deconstruct the traditionally unquestioned ways in which the child is deployed to shore up our sense of sociocultural and intergenerational continuance. These cinematic images of uncanny children thus dramatize the usually submerged paradoxical vectors that underlie 
contemporary understandings of childhood. In turn, these films expose how the child's role as embodiment of futurity - and the concomitant alignment of growing up with teleological historical continuity - sits in tension with childhood as the 'past' of adulthood, and the child as adulthood's unknowable binary opposite.

\section{The Transnational, Millennial Uncanny Child Cycle}

While the uncanny child trope surfaced as a marked trend in the early 1980 s, this figure was largely displaced from the foreground of the horror genre throughout the later 1980 s and early 1990 s in favour of the hugely successful and prolific slasher cycle. In the late 1990s and early 2000s, the ambiguously menacing uncanny child arose once again to dominate the genre. Yet, this time, it was not just North American horror films issuing forth globally pervasive visions of uncanny childhood: an assemblage of films emerged that communicated across cultural borders, as the uncanny child became central to the horror cinema of the United States, Spain, and Japan. With the release of globally successful films such as THe SiXth Sense (M. Night Shyamalan, 1999, U.S.), The DeviL's BACKBone (Guillermo del Toro, 2001, Spain), and Ringu (Hideo Nakata, 1998, Japan), the uncanny child's resonance across cultures was exposed. Of course, this is not to suggest that the U.S., Spain, and Japan were the only nations that produced films centred on eerie or threatening children during this period; ${ }^{3}$ however, from the late 1990s into the early 20oos, uncanny child films from these three sites became a concentrated, cohesive transnational body that gained global success and recognition both critically and at the box office. These films thus assembled an intercultural uncanny child trope during the transition to the 21st century that became firmly lodged in the global pop-cultural imagination: a trope with specific qualities, explored throughout this book, that interrogate the child's naturalized symbolic function.

As I chart throughout this book, this transnational assemblage of films sparked a renaissance of both the horror genre - seen during the late 1990 os to be in crisis ${ }^{4}$ - and more specifically of the supernatural subgenre. This body of films also traversed the technological transition from analogue to

3 Works from other nations include Swedish child-vampire film LET THE RIGHT ONE IN (Tomas Alfredson, 2008), French film House of Voices (Pascal Laugier, 2004), British film The Children (Tom Shankland, 2008), and Irish film Dorothy Mills (Agnés Merlet, 2008).

4 As Steffen Hantke (2010) points out in his overview of early 21st-century horror discourse, the notion that horror was 'in crisis' tended to pervade works that broadly canvassed the American horror film in the early 2000 s. 
digital filming, storage, and projection technologies. This shift underwrote the growing recognition during this period that the horror genre - previously conceived as predominantly a Hollywood genre with culturally distinct, national off-shoots - is in fact distinctly transnational, a phenomenon explored in the book's final chapters. The uncanny child trope thus became the locus for a highly visible process of transnational exchange. Suggesting the extent to which these films engage with one another cross-culturally via their child characters, North American, Spanish, and Japanese uncanny child films of the millennial turn became thoroughly entwined through transnational coproductions and remakes in the early 200os. Such films include the Spanish-American coproduction The OTHERs (Alejandro Amenábar, 2001) - one of the most critically successful and influential horror films of the new millennium - and Hollywood remakes of Japanese horror films, such as THE RING (Gore Verbinski, 2002), which is among the 20 highest grossing horror films of all time. ${ }^{5}$

A number of scholars have explored the monstrous child's expression of American cultural anxieties: for instance, Kathy Merlock Jackson (1986), Adrian Schober (2004), Robin Wood (1977), and Andrew Scahill (2015) associate terrible children with a distinctly American milieu, and the monstrous child's entwinement with American culture is implicit in the work of Dominic Lennard (2015), Bernice Murphy (2009), and even T.S. Kord (2016), who also considers a variety of non-American films. While some insightful considerations of the horror film child's significance in other cultural contexts has been carried out - see in particular the work of Karen Lury (2010), Valerie Wee (2013), and Karen Jenner (2016) - such work tends to be in the form of analyses and comparisons of particular films. No scholars have traced the overarching anxieties that shape this millennial, transnational body of films across cultures, and the precise interplay of culturally specific and globally resonant conceptualizations of childhood that these films as a body reveal. This assemblage of films illustrates with potency that the uncanny child is not an inherently American phenomenon. More specifically, close analysis of these films offers valuable insights into anxieties about the shifting ideological status of childhood at the turn of the 21st century, and reveals that these apprehensions are, to some extent, global in their broad strokes, while having specific contours that emerge from their particular cultural contexts.

I contend that this assemblage of films deploys the uncanny child to mediate the conceptual contortions surrounding millennial shift: tensions 
surrounding change, flux, and the tangling of beginnings and endings associated with the transition from the 2oth to the 21st century. As is illustrated throughout this book, the child holds a particularly central yet anxiously overdetermined position within narratives of progress and identity, both personal and national, in the U.S., Spain, and Japan. The coming of the third millennium held little literal significance in any of these nations ${ }^{6}$, but carried a great deal of symbolic weight as a sign of epochal transition. While the millennial turn was associated with specific anxieties and connotations in North American, Spanish, and Japanese contexts, in all cases this period of global transition challenged unquestioned investment in progress, historical continuance, and futurity, which in turn fomented a reexamination of the conceptual underpinnings of the child. Thus, by positioning the uncanny child as an embodiment of millennial anxieties, these films stage a direct confrontation with the pivotal but usually obscured symbolic functions of the child, interrogating the ways in which the child is simultaneously:

1. Tasked with embodying futurity and teleological progress.

2. Entwined with the adult's origins and personal past.

3. Externally situated as adulthood's inferior binary opposite.

4. Associated with a buried, enigmatic realm still lurking within the depths of the adult unconscious.

By anxiously revealing childhood's overdetermined symbolic scaffolding, this transnational body of films exposes how traditional definitions of the child started to unravel in the popular imagination with the ending of the 20 th and the beginning of the 21st century. Thus, despite the different cultural contexts from which these films emerge, they communicate

6 I do not suggest that these films interact with specific religious connotations associated with millenarianism (such as the Second Coming): even though all three countries adhere to the Gregorian calendar, the anxieties about all-encompassing change that the child characters of this period expose do not directly engage with Christian eschatological concerns. In fact, as Steven Jay Gould has suggested (writing at the height of millennial anticipation in 1997), fin de siècle anxieties about the imminent millennium represented a 'precisely arbitrary countdown' (as his book is subtitled), for which he finds little grounding in calendrics, mathematics, or even religion. In fact, while in popular culture the coming of the third millennium and 21st century was marked by the year 2000 , technically, the third millennium commenced on 1 January 2001. Yet, as these child characters illustrate, such specific underpinnings of millennial shift do not lie at the core of millennial anxieties. The uncertainty that suffused the millennial period was globally pervasive: as Hillel Schwartz points out, the Anno Domini calendar is 'used worldwide for commerce, diplomacy, and scientific exchange' and combined with typical fin de siècle concerns, the approach of the year 2000 marked 'a momentous historical divide' (1996, xiv). 
with one another through the ways their uncanny child figures express tensions surrounding this liminal period of global transition. This book revolves around the temporal disjuncture embodied by the uncanny child, for the films under discussion pivot upon an acknowledgement of the multivalent, often contradictory temporal vectors that the child is tasked with cohering.

In each of the films analysed, the uncanny child is characterized in one of two ways: as a mysterious ghost or spectre (as is the character of Sadako in RINGU), or as an 'in-between', seemingly alive yet acting as a mediator or being caught between the realms of the living and the dead, the present and the past, the material and the supernatural (as Cole is in THE SIXTH SENSE). By being associated with ghosts and a spectral realm that intrudes upon the temporal coherence of each film's 'present' diegesis, these child figures unsettle the linear flow of narrative time, drawing the past into the present and obstructing the smooth progression from present into future. As Peter Buse and Andrew Stott assert, 'anachronism might well be the defining feature of ghosts [...] because haunting, by its very structure, implies a deformation of temporal linearity' $(1999,1)$. They expound:

Ghosts are a problem for historicism precisely because they disrupt our sense of a linear teleology in which the consecutive movement of history passes untroubled through the generations [...] ghosts are anachronism $p a r$ excellence, the appearance of something in a time in which they clearly do not belong. But ghosts do not just represent reminders of the past - in their fictional representation they very often demand something of the future. [...] [The ghost] serves to destabilize any neat compartmentalization of the past as a secure and fixed entity, or the future as uncharted territory. (Buse and Stott, 1999, 14)

Either existing as spectres themselves or raising the presence of ghosts, uncanny children of transnational, millennial horror films aestheticize a breach in linear and homogenous temporal continuity. This mechanism is particularly subversive for a figure whose central sociocultural function is to ensure intergenerational and historical continuity through embodying a link to the past while existing as incubator for the future.

Furthermore, across all of the films analysed in this book, the uncanny child's association with ghosts fulfils a specific symbolic function that approaches the core of childhood's ambivalently defined otherness: the uncanny child becomes a potent embodiment of trauma. The child's connections with spectrality empower a previously repressed traumatic 
experience from the past to reemerge in, and disrupt, the present. All the films discussed throughout this book play on the traditional structure of the ghost narrative, revolving as it does around the resurfacing of repressed pasts. As Noël Carroll outlines:

ghost stories involve the return from the dead of someone who has left something unsaid or undone, who wishes something unacknowledged to be brought to light, or who wants revenge or reparation. Once the living discover this secret motive they are generally on their way to sending the ghost back to where it came from. $(1990,98)$

The child characters analysed in this book trouble this narrative trajectory and its resolution, a result, I suggest, of the ways the uncanny child layers the ghost narrative with particularly complex anxieties about trauma, progress, and futurity. As Jeffrey Weinstock suggests, 'as a symptom of repressed knowledge, the ghost calls into question the possibilities of a future based on avoidance of the past' $(2004,6)$ - a particularly symbolically charged function when associated with childhood.

In the American films, the uncanny child's association with trauma tends to be distinctly personal in nature, as the child becomes a symbolic vessel for the adult protagonist's past traumas, a process that exposes the child's continued entwinement with Freudian-inflected narratives of identity development in American culture. Yet, in the Spanish and Japanese films, the child's association with trauma takes on a distinctly and often overtly sociocultural dimension, as she becomes associated with repressed - or oppressed - historical traumas and derails politically sanctioned narratives of national progress and development. The uncanny child's association with collective traumas is then refracted in the Anglophonic remakes and coproductions of the early 21st century. It is by embodying trauma that these children challenge master narratives of personal and national progress, as is often expressed diegetically through their unravelling of the established symbolic rules of temporal continuity in the ghost narratives in which they appear. In so doing, these children subvert their status as innocent, vulnerable victims of an adult society that they are powerless to affect or change. By harnessing the painful incoherence and unruliness of a previously repressed traumatic experience, these characters simultaneously burst through the shackles of progressive teleological narratives and through definitions of the child that naturalize children's subordination, in so doing deconstructing these constrictive models of discourse. 


\section{Theorizing Uncanny Childhood}

Art, and especially cinematographic art must take part in [the] task: not that of addressing a people, which is presupposed already there, but of contributing to the invention of a people. [...] Not the myth of a past people, but the story-telling of the people to come. (Deleuze, 1997a, 217-223)

This book circulates around my conviction that in millennial horror films featuring uncanny children, conceptual tensions typically patched over by normalized ideologies of childhood dramatically emerge as a source of dread and terror. Robin Wood argues that as a genre, horror films function as 'our collective nightmares' $(1985,174)$ because 'the true subject of the horror genre is the struggle for recognition of all that our civilization represses or oppresses: its re-emergence dramatized, as in our nightmares, as an object of horror, a matter for terror' $(1985,171)$. Wood's assertion has become central to theorizations and definitions of the horror genre, which, post Wood, tends to be seen as a dramatized cultural expression of tensions surrounding conceptual otherness. Throughout this book, I follow the broad outlines of this model - maintaining that the horror films under discussion work through both ideological tensions and historical traumas that are usually repressed or obfuscated - however, I do not adhere to the Freudian orthodoxy of Wood's return of the repressedmodel, associated as it is with Freud's universalist repressive hypothesis. ${ }^{7}$

While Wood suggests that the horror genre's fixation with the monstrosity of cultural otherness is usually a sign of horror's conservative mechanisms, he also emphasizes horror's cathartic and sometimes even progressive function in exposing these usually repressed preoccupations. I would further argue that horror's working through of typically submerged anxieties surrounding otherness also signals the genre's ability to perform important cultural work, as is the case with the millennial cycle of uncanny child films. Thus, while James Kincaid proposes that we 'abandon the Gothic' $(1998,283)$ in order to overcome our ambivalent cultural obsession with childhood - because, he believes, 'most Gothic tales demand that we cease thinking as we listen and think less even as we repeat them' $(1998,285)$ - I suggest that uncanny child films enable the rethinking of our fixations with the child in productive,

7 Following Freud, Wood suggests that specific collective primitive drives and desires are repressed to ensure the smooth functioning of civilization, and that this repressed content subsequently erupts in horror film. He combines this model with the insights of Herbert Macuse to characterize this process as a collective, social repression. 
compelling ways. Emerging as they do at the millennial turn, these films suggest a mounting unease surrounding the previously naturalized ways in which the child assembles narratives of temporal continuity, models of progressive linear time that serve not the child, but the conceptual and political needs of the adult's present.

\section{Growing Sideways}

Lee Edelman and Kathryn Bond Stockton both utilize queer theory to explore the cultural politics of the child's 'growing up.' In No Future (2004), Edelman decries our intense valuing of the child as the embodiment of a mode of progress that he suggests is at its core stultifying and conservative. As he states, the child 'remains the perpetual horizon of every acknowledged politics, the fantasmatic beneficiary of every political intervention' (2004, $3-4)$, a privileging of futurity which is 'impossible to refuse' $(2004,2)$ and in fact ensures, while justifying, the continuance of present political and ideological modes: 'the image of the child [...] serves to regulate political discourse' (2004, 11). Thus, for Edelman, the child symbolizes 'the emblem of futurity's unquestioned value' $(2004,4)$, deployed in political discourse to resist radical change through the continued justification of present politics, a constitution that also relies upon history as linear narrative [...] in which meaning succeeds in revealing itself - as itself - through time' (emphasis in original, 2004, 4). Edelman conceives that the only way to resist the current social order is to eradicate our value in the child, for 'we are no more able to conceive of a politics without a fantasy of the future than we are able to conceive of a future without the figure of the child' (2004, 11).

Yet uncanny child films trouble our unthinking equation of childhood with progress and futurity, as these eerie visions of childhood instead disturb the constrictive temporal structures with which the child is usually intertwined. These horror films thus challenge the child's symbolic function as 'the emblem of futurity's unquestioned value' (2004, 4). As Stockton points out in The Queer Child, or Growing Sideways in the Twentieth Century (2009), while Edelman suggests (conceptually) 'smashing' the child, 'there are other ways to circumvent "the child". One could explore the elegant, unruly contours of growing that don't bespeak continuance' (2009, 13). For Stockton, sideways growth functions as an alternative to growing up, revealing the 'moving suspensions and shadows of growth' $(2009,13)$ that do not fit with narratives of teleological progress directed towards an imagined end in alignment with heteronormative, adult, visions of futurity. Indeed, Scahill deploys such a framework in The Revolting Child in Horror Cinema 
to illustrate how what he calls 'revolting' child characters enact 'a mass and massive rejection of heteronormative reproductive futurity' $(2015,122)$. While I do not present an explicitly queer reading of uncanny child films, I draw on the ideas of Edelman and Stockton to highlight how the horrifying qualities of uncanny child figures are located in their simultaneous resistance to national, cultural, and individual 'growth.'

Uncanny child films dramatize processes of sideways growth in various ways, as is crystallized in particular by the fact that these child characters are typically characterized as either ghosts, or as lurking in the space between the spectral and the material, the past and the present. In fact, Stockton also employs the figure of the ghost child to discuss the potential children have to destabilize models of linear development, even though her discussion centres not on horror fiction but on the experiences of queer children. She uses the term 'ghostliness' in her examination of the queer child's sideways growth, stating that "what the child "is" is a darkening question. The question of the child makes us climb inside a cloud [...] leading us, in moments, to cloudiness and ghostliness surrounding children as figures in time' (2009, 2); Stockton suggests that this ghostliness arises via the uncomfortable recognition that 'children grow sideways as well as up [...] in part because they cannot, according to our concepts, advance to adulthood until we say it's time' $(2009,6)$. Millennial horror films represent a particularly arresting moment of cloudiness and ghostliness surrounding our understanding of children as figures in time, as their uncanny children start to unsettle or even break down the narrow teleological trajectories of growth and development set for them by the adults of the present, in so doing setting off-balance the accepted hierarchy of power and knowledge between child and adult. As a result, these films problematize the ways in which the child is tasked with maintaining a coherent sense of temporal progression and historical continuance. This book exposes the aesthetic and ideological mechanisms that bind the uncanny child to these temporal incongruities.

\section{The Child as Uncanny}

As I intimated at the beginning of this chapter, my usage of the term 'uncanny' seeks to capture the child characters' vacillation between the homely and the unhomely in their maintenance of a dialectic tension between the innocent child and a figure who renders the very 'homeliness' of childish innocence disconcerting and threatening. As Freud suggests, the uncanny encapsulates the felt movement from the familiar and the homely (heimlich) to the unfamiliar and unhomely (unheimlich), a transition that unsettlingly 
reveals the entwinement of these supposedly opposed categories: 'heimlich thus becomes increasingly ambivalent, until it finally merges with its antonym unheimlich. The uncanny (das Unheimliche "the unhomely") is in some ways a species of the familiar (das Heimliche, "the unhomely")' (2003b, 134). The child in millennial horror cinema elicits the cognitive dissonance that results from this movement between familiarity and unfamiliarity, and, in so doing, she incarnates a moment in which familiar, safe visions of childhood suddenly become profoundly unnerving, a process at the heart of this film cycle's resistance to the innocence/evil dichotomy of earlier works. While I do not dwell in this book upon specific psychoanalytic models of childhood development - the films and cultural conditions examined do not suggest preoccupations with childhood psychosexual stages - what is refracted across this transnational body of films is the child's aestheticization of a tension between self and other, safety and threat. More specifically, all of these films play on the anfractuous temporal vectors between past and present that are inherent in Freud's characterization of the uncanny psychical relationship between child and adult consciousness. As I suggest in Chapter One, in its broad outlines, Freudian psychoanalysis has shaped contemporary understandings of childhood, particularly in an American context. Freudian definitions of childhood have significantly contributed to the child's overdetermined temporal function in the late 20 th and early 21st centuries - even in Eastern cultural contexts such as Japan. ${ }^{8}$

Freud famously contends that uncanny sensations are induced by the reemergence of 'something that was long familiar to the psyche and was estranged from it only through being repressed' (2003b, 148). This assertion points to the complex ways in which Freud situates childhood as the passed and 'past' temporal stage of adulthood: the symbolic site of the dark, repressed secrets from an earlier psychic stage that threaten to reemerge and disrupt the coherence of the adult's 'present' psyche. This model of child-adult psychic

8 As Nina Cornyetz and J. Keith Vincent have shown in their examination of the history of psychoanalysis in Japan, 'psychoanalysis was first introduced to Japan in a series of articles published in 1912, just seventeen years after Freud had first used the term "psychoanalysis" to describe his method of psychological interpretation' (2010, 3). Japanese psychoanalysts, most prominently Heisaku Kosawa and Takeo Doi, would go on to adapt Freud's Oedipal model and stages of psychosexual development for a Japanese context. Thus, notions of the child's intimate connections with the adult psyche have long been a facet of Japanese culture, even if the specifics of Japanese psychoanalytic narratives may vary from Freud's own theories. Indeed, Anglophonic psychoanalytic discourse contains many variations of such developmental narratives as well - while, of course, similarly working through various translations of Freud and Lacan - as is suggested by child sociologist William Kessen's assertion that 'child psychologists have invented different children' $(1983,28)$. 
relations, in which childhood is positioned as a realm partly obscured from adult consciousness but at the core of adult complexes and phobias, has had a broad influence on popular culture and conceptions of childhood worldwide throughout the 2oth century. The cultural construct has become amplified, as Kincaid has pointed out, in contemporary moral panics about the widespread repression in adulthood of sexual abuses suffered in childhood, the fractured memories of which threaten to erupt in enigmatic ways in adulthood, only to be 'recovered' with a psychological delving into the darkest depths of the adult psyche. A related component of this Freud-inflected notion can be seen in popular discourse surrounding rediscovering adulthood's lost 'inner child': as Jenks elucidates, 'psychiatric and psychotherapeutic regimes tend to be conducted through regressive narratives with individuals "finding their way" through the excavation of roots and attachments from the past - the "inner child" $(2005,111)$. This temporally clouded relationship between child and adult psyches hangs over all the films analysed throughout this book, and is, I suggest, central to the child's paradoxically constituted otherness. As Hugh Haughton points out, the uncanny 'reminds us not only that there is no place like home, but that, in another sense, there is no other place. For Freud, our most haunting experiences of otherness tell us that the alien begins at home, wherever that may be' (2003, xlix).

My usage of the term uncanny also relates to the specific ways I read these child figures as embodiments of trauma. Within the narratives of all of the films I discuss, the children are usually victims of trauma, or at least have privileged insight into traumatic experience. More than this, they come to harness this trauma and propel it back into the realm of adult experience, subverting their victimized position to become threatening and powerful through their very trauma. The uncanniness of the children in these films is thus entangled with their association with the aesthetics and temporal mechanics of trauma. Overarching this book is Cathy Caruth's influential characterization of trauma, strongly influenced by Freudian psychoanalysis and, in particular, his notion of the uncanny, as

the story of a wound that cries out, that addresses us in the attempt to tell us of a reality or truth that is not otherwise available. This truth, in its delayed appearance and its belated address, cannot be linked only to what is known, but also to what remains unknown in our very actions and our language. $(1996,4)$

In uncanny child films, the child's trauma represents a challenge to the entrenched security, coherence, and power of adult knowledge and discourse. 
In its incomprehensibility and suggestion of a submerged reality, traumatic experience in these films functions as an intensified expression of the child's 'sleep of reason', while signifying the means by which children's victimization at the hands of adult society is monstrously turned against those that oppress them.

Furthermore, in resonance with the uncanny, Caruth emphasizes the eerie temporal quality inherent in traumatic experience, in which trauma becomes known only belatedly: 'trauma is not locatable in the simple violent or original event in an individual's past, but rather in the way that its very unassimilated nature - the way it was precisely not known in the first instance - returns to haunt the survivor later on' $(1996,4)$. Caruth's deconstructionist model of trauma has been criticized by subsequent trauma scholars for its commitment to the 'unrepresentable' event: for instance, Dominick LaCapra suggests that a fixation with unrepresentability risks 'sacralising, or making sublime' the compulsive repetition of traumatic pasts $(2004,121)$. Yet, just as I do not draw on Freud in order to uncover the universal truths of childhood, I do not seek to pathologize the films I analyse: to dwell on whether they undergo processes of melancholia/ mourning, acting out/working through, and ultimately, unhealthy/healthy responses to trauma. To use Adam Lowenstein's terms, I do not wish to echo the tendency in trauma studies to 'diagnose representation as if it were a patient' $(2005,4)$. Instead, I use elements of Caruth's model - along with the insights of other scholars who discuss cinematic expressions of trauma - in order to unpack the conceptual tensions expressed by these traumatized (and traumatizing) child characters. In embodying trauma and subsequently inflicting it upon adult characters, and, by extension, the film viewer that functions as their proxy, these children incite an uncanny process of traumatic repetition which continually points to a past event that the adult protagonist is unable to perceive or understand, but which threatens their very self-identity and temporal grounding. These figures in turn throw into sharp relief the adult's belatedness to acknowledge the traumatic event, a frightening process of delayed cognizance which is built into each of these film's narratives and aesthetics in various ways, and enhances the sense that the uncanny child is privy to a layer of nonrational understanding not accessible to adult consciousness.

As is suggested by my sketching of the uncanny child's trauma and the trauma of the uncanny child, I see the child's association with trauma not only as negative and monstrous, but as the means by which the child is empowered to rebel against the strictures of linear progress and rational adult discourse. To emphasize how this occurs, my analysis often draws on 
Deleuzian conceptions of cinematic time in order to elucidate the disturbing but often productive ways that the child harnesses trauma to disrupt homogenous, progressive time consciousness. As Deleuze scholar Jack Reynolds suggests, 'Deleuze's oeuvre is best understood as a philosophy of the wound, synonymous with a philosophy of the event' $(2012,107)$, and, in resonance with the trauma theory of Caruth, Deleuze describes the temporal disjuncture of the wound or 'agonizing' event as 'always and at the same time something which has just happened and something which is about to happen; never something happening' $(2004,73)$. Deleuze's theorizations of cinematic time offer a compelling framework through which to consider the uncanny child's temporal subversions, and the way that this figure harnesses trauma to disrupt the child's typical sociocultural function of personifying intergenerational continuity.

Through their trauma, cinematic uncanny children continually puncture linear continuity, and thus can often be associated with Deleuze's 'timeimage', a mode of cinematic expression that contrasts with the norms of Hollywood continuity editing in that we are 'plunged into time rather than crossing space' (1997a, xii) when watching such images, and are forced 'beyond the purely empirical succession of time - past-present-future' (1997a, xii). By challenging linear narrative temporality and the aesthetic practices that buttress such linearity, uncanny children tend to immerse viewers and adult characters into a dimension in which, to use Deleuze's example from Hamlet, 'time is out of joint' (1997a, xi). The uncanny child's transgressive relationship to linear time (or 'clock time' in the words of Deleuze) is dramatized by the fractured temporal processes of supernatural horror film, the narratives of which are structured around the eerie revelation that an asynchronous spectral realm lurks alongside normality's linear - and previously homogenous - time consciousness. In this way, supernatural horror films tend to sustain a continual tension between the regimes of what Deleuze calls the movement-image (broadly associated with linear, continuity editing structured by the continuous bodily movements of the characters) and the time-image, and the uncanny child - the horror film's dominant fixture at the turn of the 21st century - embodies this breach in coherent continuity.

This book is constituted of four sections, each of which contains two or three chapters. Section One: Secrets and Hieroglyphs explores the uncanny children of American horror film, and sets out a model for the child's aestheticization of trauma that reverberates through subsequent chapters. In Section Two: Insects Trapped in Amber, I focus on Spanish horror films featuring uncanny children, exploring how, in post-Civil War 
Spain, the child became thoroughly embroiled with a tightly controlled narrative of national progress through the autocratic Franco dictatorship. Subsequently, the uncanny children in Spanish horror films The Devil's Backbone, The NAmeless (Jaume Balagueró, 1999), and The OrPhanage (Juan Antonio Bayona, 2007) function as terrifying but cathartic eruptions of the historical traumas that were long concealed by the claustrophobic ligatures of Francoist discourse.

In Section Three: Our Fear Has Taken on a Life of its Own, I address the explosion of globally successful Japanese horror films of the millennial turn that have become designated 'J-horror'. I consider how the child is a pivotal component of post-World War II Japanese national identity, which is buttressed by a quasi-sacred belief in rapid national progress. This competitive model of progress seeks to displace the spectres of intense national trauma, and also locks the child into an overdetermined fixation with national development, which led to pronounced anxieties about childhood when Japan's economy collapsed in what has become known in Japan as the Lost Decade, 1991-2001. Films such as RINGU and Ju-ON (Takashi Shimizu, 2000-2002) expose the traumatic extent of the child's conceptual rebellion during this period.

In the final section, Trauma's Child: Transnational Remakes and Coproductions, I consider the Hollywood J-horror remakes and Spanish-American coproductions that emerged in the early 21 st century as a response to the transnationally successful boom of uncanny child films from America, Spain, and Japan. These films self-consciously suggest the emergence of a postmodern conception of childhood that resists traditional ideas about the child's incremental, teleological progression towards adulthood and futurity.

Throughout, this book charts the complex ways in which 'the sleep of reason produces monsters' in cinematic constructions of the child at the turn of the 21st century. These supernatural horror films question the entrenched symbolic functions of the child in ways that previous cinematic models of monstrous childhood - in particular possessed and evil children - do not. Thus, I suggest that the transnational assemblage of child-centred horror films released around the millennial turn are a symptom of broader conceptual shift. These films signal a burgeoning awareness of the child's overdetermined function within narratives of identity and temporal continuity that serve the needs of the adult's present. Furthermore, they also start to point towards an understanding that, in a postmodern context in which the very status of such symbolic scaffolding is breaking apart, modernist investment in the child can no longer function as it once did, thus anxiously heralding new, more empowered visions of childhood. 


\section{Works Cited}

Bruhm, Steven. 'Nightmare on Sesame Street: or, the Self Possessed Child.' Gothic Studies 8.2 (2006): 98-210. EBSCO Host Humanities International Complete. Web. 30 Sep. 2014.

Buse, Peter and Stott, Andrew, eds. Ghosts: Deconstruction, Psychoanalysis, History. Houndsmills: Macmillan Press, 1999. Print.

Carroll, Noël. The Philosophy of Horror, or Paradoxes of the Heart. New York: Routledge. 1990. Print.

Caruth, Cathy. Unclaimed Experience: Trauma, Narrative, and History. Baltimore: The John Hopkins University Press, 1996. Print.

Cornyetz, Nina and Vincent, J. Keith. 'Japan as Screen Memory: Psychoanalysis and History.' Perversion and Modern Japan: Psychoanalysis, literature, culture. Ed. Nina Cornyetz and J. Keith Vincent. London: Routledge, 2010. 1-21. Print.

Deleuze, Gilles. Cinema 2: The Time Image. 1985. Trans. Hugh Tomlinson and Robert Galeta. Minneapolis: The University of Minnesota Press, 1997a. Print.

- The Logic of Sense. 1969. Trans. Mark Lester. Ed. Constantin V. Boundas, London: Continuum, 2004. Print.

Doi, Takeo. The Anatomy of Dependence: The Key Analysis ofJapanese Behaviour. 1971. New York: Kodansha America, 2001. Print.

Edelman, Lee. No Future: Queer Theory and the Death Drive. Durham: Duke University Press, 2004. Print.

Freud, Sigmund. 'The Uncanny.' 1919. The Uncanny. Trans. David McLintock. New York: Penguin Books, 2003b. 121-176. Print.

Gould, Steven Jay. Questioning the Millennium: A Rationalist's Guide to a Precisely Arbitrary Countdown. New York: Harmony Books, 1997. Print.

Haughton, Hugh. 'Introduction.' The Uncanny. By Sigmund Freud. Trans. David McLintock. New York: Penguin Books, 2003. vii-lx. Print.

Jenks, Chris. Childhood. $2^{\text {nd }}$ Ed. New York: Routledge, 2005. Print.

- ' 'The Pacing and Timing of Children's Bodies.' Governing the Child in the New Millennium. Ed. Kenneth Hultqvist and Gunilla Dahlberg. New York: RoutledgeFalmer, 2001. 68-84. Print.

Jenner, Karen, ed. The 'Evil Child' in Literature, Film and Popular Culture. New York: Routledge, 2013. Print.

-. Evil Children in the Popular Imagination. New York: Palgrave Macmillan, 2016. Print. Kessen, William. 'The Child and Other Cultural Inventions.' The Child and Other Cultural Inventions. Ed. Frank S. Kessel and Alexander W. Siegel. New York: Praeger Publishers, 1983. 26-39. Print.

Kincaid, James. Erotic Innocence: The Culture of Child Molesting. Durham: Duke University Press, 1998. Print. 
Kord, T.S. Little Horrors: How Cinema's Evil Children Play on Our Guilt. Jefferson: McFarland, 2016. Print.

Kosawa, Heisaku. 'Two Kinds of Guilt Feelings: The Ajase Complex.' 1931. Freud and the Far East: Psychoanalytic Perspectives on the People and Culture of China, Japan and Korea. Ed. and Trans. Salman Akhtar. Plymouth: Rowman \& Littlefield Publishers, Inc., 2009. Print. 61-70. Print.

LaCapra, Dominick. History in Transit:Experience, Identity, Critical Theory. Ithaca: Cornell University Press, 2004. Print.

Lennard, Dominic. Bad Seeds and Holy Terrors: The Child Villains of Horror Film. Albany: State University of New York Press, 2015. Print.

Locke, John. An Essay on Human Understanding. 1689. Ed. Kenneth P. Winkler. Indianapolis: Hackett Publishing Company, 1996. Print.

Lowenstein, Adam. Shocking Representation: Historical Trauma, National Cinema and the Modern Horror Film. New York: Columbia University Press, 2005. Print.

Lury, Karen. The Child in Film. London: I.B. Tauris \& Co Ltd, 2010. Print

Merlock Jackson, Kathy. Images of Children in American Film: A Sociocultural Analysis. Metuchen: The Scarecrow Press Inc., 1986. Print.

Murphy, Bernice. The Suburban Gothic in American Popular Culture. New York: Palgrave Macmillan, 2009. Print.

Paul, William. Laughing Screaming: Modern Hollywood Horror and Comedy. New York: Columbia University Press, 1994. Print.

Petley, Julian. 'The Monstrous Child.' The Body's Perilous Pleasures: Dangerous Desires and Contemporary Culture. Ed. Michele Aaron. Wiltshire: Edinburgh University Press, 1999. 87-105. Print.

Reynolds, Jack. Chronopathologies: Time and Politics in Deleuze, Derrida, Analytic Philosophy, and Phenomenology. Lanham: Lexington Books, 2012. Print.

Rousseau, Jean-Jacques. Emile, Or on Education. 1763. Sioux Falls: NuVision Publications, 2007. Print.

Scahill, Andrew. The Revolting Child in Horror Cinema: Youth Rebellion and Queer Spectatorship. New York: Palgrave Macmillan, 2015. Print.

Schwartz, Hillel. Century's End: An Orientation Manual Toward the Year 20oo. New York: Currency Doubleday, 1996. Print.

Schober, Adrian. Possessed Child Narratives in Literature and Film: Contrary States. New York: Palgrave Macmillan, 2004. Print.

Stamp Lindsey, Shelley. 'Horror, Femininity and Carrie's Monstrous Puberty.' Journal of Film and Video 43.4 (1991): 33-44. Print.

Stockton, Kathryn Bond. The Queer Child, or Growing Sideways in the Twentieth Century. Durham: Duke University Press, 2009. Print.

'The 20 Highest Grossing Horror Films of All Time.' BusinessInisder.com.au, John Lynch. 2017. Web. 30 Dec. 2017. 
Tudor, Andrew. Monsters and Mad Scientists: A Cultural History of the Horror Movie. Hoboken, NJ: Wiley-Blackwell, 1991. Print.

Warner, Marina. Managing Monsters: Six Myths of Our Time. London: Vintage, 1994. Print.

Wee, Valerie.Japanese Horror Films and their American Remakes. London: Routledge, 2013. Print.

Weinstock, Jeffrey, ed. 'Introduction: The Spectral Turn.' Spectral America: Phantoms and the National Imagination. Madison: University of Wisconsin Press, 2004. 3-17. Print.

Williams, Tony. Hearths of Darkness: The Family in the American Horror Film. London: Associated University Presses, 1996. Print.

Wood, Robin. 'The American Family Comedy: From Meet Me In St Louis to The Texas Chainsaw Massacre.' Wide Angle 3.2 (1979): 5-11. Print.

- 'An Introduction to the American Horror Film.' Planks of Reason: Essays on the Horror Film. Ed. Barry Keith Grant and Christopher Sharret. London: Scarecrow Press, 1985 164-200. Print.

- 'Yet Another Terrible Child.' London Times Education Supplement February 11 (1977): 86-9o. Print.

\section{Artworks}

Goya y Lucientes, Francisco José. The Sleep of Reason Produces Monsters. 1799. Etching, aquatint, drypoint, and burin. The Metropolitan Museum of Art, New York.

\section{Filmography}

The Bad Seed. Dir. Mervyn LeRoy. 1956. Warner Home Video, 2011. Blu-ray DVD. The Changeling. Dir. Peter Medak. 1980. HBO Home Video, 2005. DVD.

The Exorcist. Dir. William Friedkin. 1973. Warner Home Video, 2013. Blu-ray DVD. Ju-ON: The Grudge [Ju-ON]. Dir. Takashi Shimizu. 2002. Lionsgate Home Entertainment, 2005. DVD.

The Nameless [Los Sin nombre]. Dir. Jaume Balagueró. 1999. Miramax Echo Bridge, 2005. DVD.

The Omen. Dir. Richard Donner. 1976. Twentieth Century Fox, 2007. Blu-ray DVD.

The Orphanage [El orfanato]. Dir. Juan Antonio Bayona. 2007. New Line Home Video, 2008. Blu-ray DVD.

The Others [Los отros]. Dir. Alejandro Amenábar. 2001. Optimum Home Entertainment, 2011. Blu-ray DVD.

Poltergeist. Dir. Tobe Hooper. 1982. Warner Home Video, 2008. DVD. 
The Ring. Dir. Gore Verbinski. 2002. DreamWorks Pictures, 2013. Blu-ray DVD. Rosemary's Baby. Dir. Roman Polanski. William Castle Productions, 1968. Film. The SHINING. Dir. Stanley Kubrick. 1980. Warner Bros. Entertainment Inc., 2007. Blu-ray DVD.

The Sixth Sense. Dir. M. Night Shyamalan. 1999. Hollywood Pictures Home Entertainment, 2000. DVD. 



\section{Section One}

Secrets and Hieroglyphs:

The Uncanny Child in American Horror Film 



\title{
1. The Child and Adult Trauma in American Horror of the 1980 s
}

\begin{abstract}
This chapter explores how definitions of childhood post Freud have become embroiled with ideas about adult trauma, as childhood is conflated with the adult unconscious in a Western context. This constitution is amplified in North American uncanny child films of the early 1980s. The chapter charts a shift in horror film depictions of children in the 1980s, arguing that the 1980 s saw the emergence of a child character who symbolically functions as the site of the adult protagonist's past traumas and repressed anxieties. This figure is at the centre of three influential horror films of the 1980s: The Shining (Stanley Kubrick, 1980), The Changeling (Peter Medak, 1980), and Poltergeist (Tobe Hooper, 1982).
\end{abstract}

Keywords: Uncanny, Childhood, Trauma, The Shining, Freud, Unconscious

Particularly in a Western context, contemporary cultural imaginings of the child are inextricably bound up with a generalized Freudian psychoanalytic model that injects 'childhood' with intense and multivalent symbolic charge. Virginia Blum suggests that in many senses, psychoanalysis - which she describes as 'the most preeminent twentieth-century discourse about childhood' $(1995,8)$ - brought the child in its current form into being via a new 'investment in the child as the origin of the adult' $(1995,3)$. As Blum elucidates,

psychoanalysis is the story of the adult's relationships with an internalized, repudiated, but nevertheless ceaselessly desired child - not the actual child the adult has been, but rather the 'dead' child mourned by a present-tense self which is constituted on the past this child at once represents and withholds. $(1995,23)$

Balanzategui, J., The Uncanny Child in Transnational Cinema: Ghosts of Futurity at the Turn of the Twenty-First Century, Amsterdam University Press, 2018. DOI: 10.5117/9789462986510/CHO1 
This entails an uneasy conflation of 'childhood' - the originary stage of adulthood, temporally defined as the past in relation to the adult's present; and 'the child' - a being of the present external to the adult's psyche. As Carolyn Steedman suggests, between 1900 and 1920, Freudian discourse ignited a shift in the way Western societies understood childhood in relation to the concept of an interiorized self. She explains that psychoanalysis summarized and reformulated 'a great many nineteenthcentury articulations of the idea that the core of an individual's psychic identity was his or her own lost past, or childhood' $(1995,4)$. Steedman further asserts that 'the process of repression that emerged from Sigmund Freud's writing in this period theorised childhood in this sense, gave it another name as "the unconscious" or "the unconscious mind"' (emphasis in original, 1995, 4).

This alignment of childhood with the adult's unconscious - a constitution that has become entrenched in Western culture - is amplified in American uncanny child films of the early 1980 s, and is central to these films' deconstructions of conventional understandings of innocent, naïve childhood in ways that contrast with the possessed and devil child films of the late 1960 and 1970 . The early 1980 s saw the emergence of a child character - a subject of the present external to the adult protagonist - who becomes symbolically entwined with the 'past' as the site of the adult protagonist's repressed anxieties and traumas. This uncanny child figure is at the centre of three influential horror films of the 1980s, which are the focus of this chapter: The Shining (Stanley Kubrick, 1980), The Changeling (Peter Medak, 1980) ${ }^{1}$, and Poltergeist (Tobe Hooper, 1982).

\section{Childhood and the Adult Unconscious}

In Civilization and Its Discontents, Freud details an imagined Rome in which 'nothing that ever took shape passed away', constructing a spatially impossible structure in which 'all previous phases of development exist beside the most recent' $(2002,8)$ : what he describes functions like an elaborate trompe l'oeil in which particular stages of Rome's development materialize before the observer depending on the angle from which they perceive the

1 While Warner Bro.'s The SHINING is recognised as an American product, it also received support from Kubrick's British-based production company. THE CHANGELING is an AmericanCanadian coproduction, the only film produced by the Canadian company Chessman Park Productions. The film was made during the time of a tax-shelter arrangement for films produced by Canadian producers (known as the Capitol Cost Allowance). Shot in Canada and the U.S., the film is set in the U.S. and has a predominantly American cast. 
structure. Freud utilizes this image to analogize how the earliest remnants of childhood memory remain lodged, albeit submerged or repressed, within the adult mind. As he explains in 'Screen Memories', 'we must insist on the great pathogenic importance of impressions from this period of our lives' as our 'childhood experiences have left indelible traces on our inner selves' (2003a, 3). Yet, according to Freud, the shift into adulthood inevitably distances one from and blocks access to the psychic realm of childhood - the child is, after all, culturally defined as that which is other to the adult, as is reinforced by Freud's suggestion that 'the psychical behaviour of children differs fundamentally from that of adults' (2003a, 3) - in a function that, post Freud, has become synonymous with the ever-present but esoteric relationship between the conscious and the unconscious.

Freud highlights his association of childhood with the repressed content underlying adult complexes in his supposition that there are 'intimate links [...] between the mental life of the child and the psychical material of neuroses' and that investigation of childhood memories in adulthood exposes an elusive and 'unsuspected wealth of meaning [...] hidden behind their apparent harmlessness' (2003a, 8). This uncovering of the dark secrets of the adult's unconscious via the dissection of childhood memories is central to Freudian definitions of trauma, a process that is referred to in Freud's writings as Nachträglickeit. This concept became the foundation of subsequent theorizations of trauma and has been translated in various ways, most influentially as 'afterwardsness' (Jean Laplanche, 1999) and 'belatedness' (Caruth, 1996). Stockton points out that Freud's foundational model of trauma represents:

a 'deferred action', whereby events from the past acquire meaning only when read through their future consequences. Freud developed this view - sometimes called 'the ghost in the nursery' - as a way to explain how a trauma encountered in childhood - more precisely, received as an impression - might become operative as a trauma, never mind consciously grasped as such, only later in life through deferred effect and belated understanding, which retroactively cause the trauma, putting past and present ego-structures side-by-side, almost cubistically, in lateral spread. $(2009,14)$

Freud thus positions the relations between childhood and adulthood as a tangled paradox: childhood is situated as a still-somehow-present past stage of adulthood, which remains impalpable to adult consciousness while holding the key to the most urgent secrets of the adult psyche. 
This entwinement of closeness and distance is a crystallization of the (un)heimlich given anxious charge by the fact that childhood is construed as the vessel for the concealed enigmas of the adult's mind. Access to hidden impulses or traumatic memories is communicated to the adult consciousness only partially, through riddles and misleading screen memories. This process elucidates some of the most fundamental tensions existent in the ambivalently constituted differentiation between childhood and adulthood, and is self-reflexively augmented in constructions of uncanny children in 1980 s American horror.

The preoccupation with the child's uncanny conceptual constitution represents a distinct shift from child-centred horror films of the 1970s, such as THE EXORCIST, which typically feature possessed or devil children. In his study of possessed child narratives, Adrian Schober argues that depictions of children in American horror film tend to reveal an ongoing ideological conflict between Calvinism and Romanticism. Schober's thesis can effectively be applied to narratives that centralize possession, as the child in such films wavers between evil and innocence, with 'the emptiness of the child [...] filled with the knowledge of evil' (2004, 60). Yet the uncanny child films of the early 1980 s are no longer interested in dramatic constructions of the demonic invasion of the child's body, but in confronting directly the enigmas and temporal paradoxes that underlie the very 'emptiness' of the innocent child. Thus, unlike possession films, these films self-consciously draw out the deep conceptual contortions inherent to, but typically submerged beneath, Romantic understandings of childhood post Freud. As Steven Bruhm suggests, while Romantic ideals about childhood continue to hold sway in contemporary culture, 'we live in a culture haunted by Freud, for whom the child is always defined by conflicts, desires, and aggressions, instinctual drives he located in the human beings' animalistic "id"' (2006, 99). Working through the tensions intrinsic to Freudian equations of childhood with the adult unconscious, these 1980 os films are gripped by anxieties about the indissoluble but impenetrable links between the psychic states of childhood and adulthood, and the ways that this construct burdens the child with the weight of the adult's past.

Uncanny child films subsequently displace the dichotomy between Calvinist and Romantic ideologies outlined by Schober. Rather than upholding an uncertainty as to whether the child is born into sin or innocence, these films problematize Romanticized childish 'emptiness': namely innocence and its external signifier, cuteness. As Lori Merish (1996) explains, cuteness is itself a mark of otherness, and the lines between cute and uncanny can be particularly blurry when considering the child. She points out that 
as a strategy for managing the radical Otherness of the child, cuteness is [...] intimately bound up with the history of the 'freak'. There are obvious parallels between child and freak: both are liminal figures, residing on the boundaries that separate the 'fully human' from the 'less-than-human.' $(1996,189)$

In uncanny child films, the semantics that typically portray the child's cuteness and naivety - in particular, illegible or imperfect attempts at communication - become coded as threatening in their very signification of the shadowy borderlands between childhood and adulthood, implicated in the Freud-inflected model whereby childhood is associated with urgent but intangible psychic pasts and secrets.

In these films, cuteness thus morphs into threatening inscrutability, so that the child comes to precisely embody the uncanny process whereby the 'heimlich [...] becomes increasingly ambivalent, until it finally merges with its antonym unheimlich' (Freud, 2003b, 134). Thus, while Schober suggests that 'one advantage of the possession motif is that it casts the child as both good and evil, innocent and corrupt, victim and villain' $(2004,16)$, it is in the very nature of their simultaneous reflections of and disruptions to adult protagonists that uncanny child figures of the early 1980 seem at once familiar and unfamiliar, vulnerable and threatening, innocent and dangerously indecipherable. The child is no longer a possessed innocent - in which the category of innocence itself remains intact and unchallenged - but is either a ghost or a conduit between normality and an abject spectral realm, in turn becoming a symptom of or privileged witness to ghastly secrets of the past. Through evoking 'something that was long familiar to the psyche and was estranged from it only through being repressed' (Freud, $2003 \mathrm{~b}, 148$ ), childhood in these films is constructed as the receptacle for the repressed content constitutive of adult complexes, leading the uncanny child to become disruptive to linear narrative progression and symbolic coherence in ways that aestheticize the child character's threat to the adult protagonist's psyche.

Because of the child's symbolic position as an element of the adult protagonist's psyche that is at once entirely familiar yet is also inevitably ungraspable, the child, culturally defined as other to the adult through a comparative lack of knowledge and understanding, comes to expose uncanny insights beyond conventional adult rationality. Thus, the uncanny child's association with repressed secrets raises an anxiety espoused by Derrida in his discussion of the secret: 'How can another see into me, into my most secret self, without my being able to see in there myself and without my being 
able to see him in me?' (1996, 92). In symbolic parallel to a psychoanalytic journey into the depths of the unconscious, adult protagonists and viewers undergo a process of deciphering and interpreting to 'unlock' what the child conceals; thus, the secrets that the child bears radiate an enigmatic force that propels the narrative, underscoring critical turning points and moments of horror.

\section{The 1980s and the Rise of the Uncanny Child}

It is significant that the uncanny child surfaces as a key horror trope in the early $1980{ }^{2},{ }^{2}$ a decade in which distinct fissures in America's ideological fabric developed. At the cusp of the new decade, president Jimmy Carter was forced to respond to wavering sociocultural stability - the effect of an amalgamation of ongoing tribulations such as an energy crisis, stagflation, and turbulent international relations - with a speech in 1979 that acknowledged the malaise, stating:

The threat is nearly invisible in ordinary ways. It is a crisis of confidence. It is a crisis that strikes at the very heart and soul and spirit of our national will. We can see this crisis in the growing doubt about the meaning of our own lives and in the loss of a unity of purpose for our Nation. The erosion of our confidence in the future is threatening to destroy the social and the political fabric of America. (Carter, 2006, 356)

The uncanny child characters of The SHIning, The Changeling, and Poltergeist are themselves ambiguous threats to the security of meaning and the unity of subjectivity, and can thus be seen as bound to this nebulous anxiety about the wavering of ideological certainty during this period. Carter's suggestion that an erosion of confidence in futurity exists at the core of these vague tensions signals the child's implication in this sense of decline. Subsequently, the 1980 s saw a series of significant social shifts that circulated around the child.

The sociocultural conditions of the 1980 os encouraged a more intense consideration of what childhood represents, perhaps partly in an effort to

2 Some films in the 1970 contain similar visions of the child which foreshadow the constructions of uncanny childhood that erupted in the early 1980s. These include THE OTHER (Robert Mulligan, 1972) and Audrey Rose (Robert Wise, 1977): in both cases, the children are depicted as possessed, but they are in fact possessed by other child characters - a dead twin in THE OTHER and the earlier incarnation of a reincarnated child in AUDREY ROSE - indicating their straining against the possession motif. 
regain a clear vision of the future. In the words of Sarah Harwood, it was a decade 'which based its reactionary political agenda on "family values"' (1997, 2) as the family 'annealed the gap between social crisis and political mythology' $(1997,15)$. In more self-aware and overt ways in the 1980 os than in prior decades, the child became the primary justification for the family's continued ideological and sociocultural centrality. Ironically, in a decade in which both the Reagan and Thatcher governments were strongly invested in familial ideology - positioning the family as a static, idealized unit that functions as an individuated microcosm of society ${ }^{3}$ - the perceived strength and social dominance of the heteronormative nuclear family unit was disintegrating due to rising divorce rates, increasing numbers of LGBT parents seeking custody of their children or otherwise forming families (Fitzgerald, 1999, $56-8 ; 66)$, rapid increases in women's economic independence, and resultant widespread changes in family demographics. As Frances Litman suggests in an article published in 1980, 'in the United States today, a preoccupation with the changing American family is so widespread that it has become almost a national obsession' (1). The traditional, lifelong union between husband and wife could no longer be seen as the stable core of the nuclear family. In this context, the child becomes invested with a particularly important yet threatening power, figured as the thread that sutures the family together but which could also at any moment unravel it completely. Harwood points out that 'power balances, tradtionally weighted towards the father, now tipped towards the child, and the most heated debates in the 1980 s revolved around the rights of the latter' $(1997,51)$, debates which culminated in the first United Nations Convention on the Rights of the Child in 1989.

In addition to the child's increasingly ideologically charged position in unifying the politically pivotal but ever more precarious family unit in the early 1980 s was the child's newfound clout as a consumer. Stephen Kline (1995), Dominic Lennard (2015), and Juliet B. Shor (2004) have each pointed out that the 1980 s marked the beginning of a boom in children's consumer culture that saw the rapid rise in marketing aimed directly at children. In his study of the history of children's culture, Kline positions the $1980 \mathrm{~s}$ as a key turning point in understandings of childhood. As he suggests, 'during the 1980 a major transformation took place in children's [television]

3 Tellingly elucidating the way in which the family was employed in service of political ideology throughout the 1980s, one of Thatcher's most famous quotes during her tenure was 'there is no such thing as society. There are individual men and women, and there are families' (1987, 8-10) while one of Reagan's most well-known sound bites was 'If the family goes, so goes our civilization' (1982, n.p.). 
scheduling thanks to the interest of toy merchandisers' $(1995,140)$. He elucidates that 'the removal of long-established restrictions on advertising realism and tie-ins during the 1980 allowed marketers to explore new ways of communicating with children' $(1995,237)$. As Lennard points out, these shifts meant that 'throughout the 1980s, understandings of childhood were increasingly mediated by advertising and consumer culture' $(2015,137)$ as 'the specific targeting of their desires positioned the child as an active force in consumption' $(2015,136)$. Lennard argues that these new conditions can be seen as a driving influence behind the anxieties expressed in monstrous living-doll film CHILD's PLAY (Tom Holland, 1988), which positions the child's economic bargaining power within the fractured family unit as a terrifying threat.

Thus, the sense that the child was becoming empowered in new ways particularly at the expense, both literally and figuratively, of the patriarchal head of the traditional household - permeated American culture of the 1980s. The anxious awareness that the child had gained more social agency while also being tasked with unifying the family just as this politically vital institution seemed to be dissolving amplifies the Freud-inflected anxieties in The Shining, The Changeling, and Poltergeist. In these films, the child disrupts the patriarch's power in both psychic and external terms, in ways that unsettle the coherence of his identity and suggest the breakdown of long-entrenched ideological structures.

\section{'Kids Can Scare You to Death': The ShInING}

The SHINING, an adaptation of Stephen King's eponymous 1977 novel, has been extensively analysed and deconstructed. In particular, a number of precise psychoanalytic readings of the film have been produced, ${ }^{4}$ partly because Kubrick and his cowriter Diane Johnson are known to have studied Freud's 'The Uncanny' and Bruno Bettelheim's The Uses of Enchantment (1976) while developing the screenplay (Hoile, 1984, 5). Yet these studies have not suggested how, in self-consciously playing with psychoanalytic stories about childhood development, THE SHINING marks a shift in horror film visions of monstrous children by directly confronting childhood's ambivalent otherness. Furthermore, to date, almost all of these critical studies unequivocally position the child Danny as the innocent, helpless

4 See Noel Hess (2010), Christopher Hoile (1984), Robert Kilker (2006), and Ya-huei Wang (2011) on the film's Oedipal and gender anxieties. 
victim of his father Jack's monstrosity, not appreciating the extent to which Danny himself is the embodiment of the uncanny throughout the film. ${ }^{5}$ Danny's ambiguously threatening configuration and his associations with his father's trauma underline his resistance to the vacillation between evil and innocence that structured previous possessed and evil child figures. Subsequently this character has had a vast influence upon post-1980s constructions of horror film children.

Notably, in his historicist reading of the film, Fredric Jameson also suggests that Danny functions as a 'play with generic signals' (1992, 88), noting that 'we've had enough experience with horrible children (LeRoy's THE BAD SeEd [1956], Rilla's The Village of the Damned [1961]) to be able to identify sheer evil when someone rubs our noses in it' (emphasis in original, 1992, 88). He suggests that audiences are invited to misread the film's genre during its first half-hour $(1992,89)$ as it gradually becomes clear that it is not an evil child film but refracts a 'specific and articulated historical commentary' $(1992,90)$ through what Jameson categorizes as a traditional ghost story centred on Jack. While I concur that the audience is intentionally misled via Danny's early characterization, I suggest that this does not set up a shift in focus away from the child - who remains central to the narrative - but self-reflexively comments on his textual function.

There are a number of visual echoes of prominent contemporary childcentred horror films throughout THE SHINING, particularly of THE OMEN released four years prior. Danny is often seen standing in the same hands in pockets, head cocked to the side stance that has become iconic of devil-child Damien, exhibited in the final scene of THE OMEN and also featured in the film's promotional posters. Furthermore, in one particularly lengthy and now iconic scene, Danny replicates Damien's riding on a tricycle around the hallways of the Thorn household (Fig. 1), which, in THE OMEN, is a similarly drawn-out sequence that concludes with Damien pushing his mother from the house's internal balcony. Most clearly of all, Danny is introduced through his communion with 'Tony', a mysterious invisible friend. Danny's conversations with Tony echo Regan's communication with the invisible 'Mr. Howdy' in THE EXORCIST, which prefigures her possession by the devil.

While these connections to Damien and Regan underscore the vague sense of threat exuded by Danny's character, they function as a false lead. Kubrick establishes these links quite early in the film before recontextualizing them to reinforce that Danny pivots on a different conceptual axis to these possessed and evil children: Tony represents not an evil force 

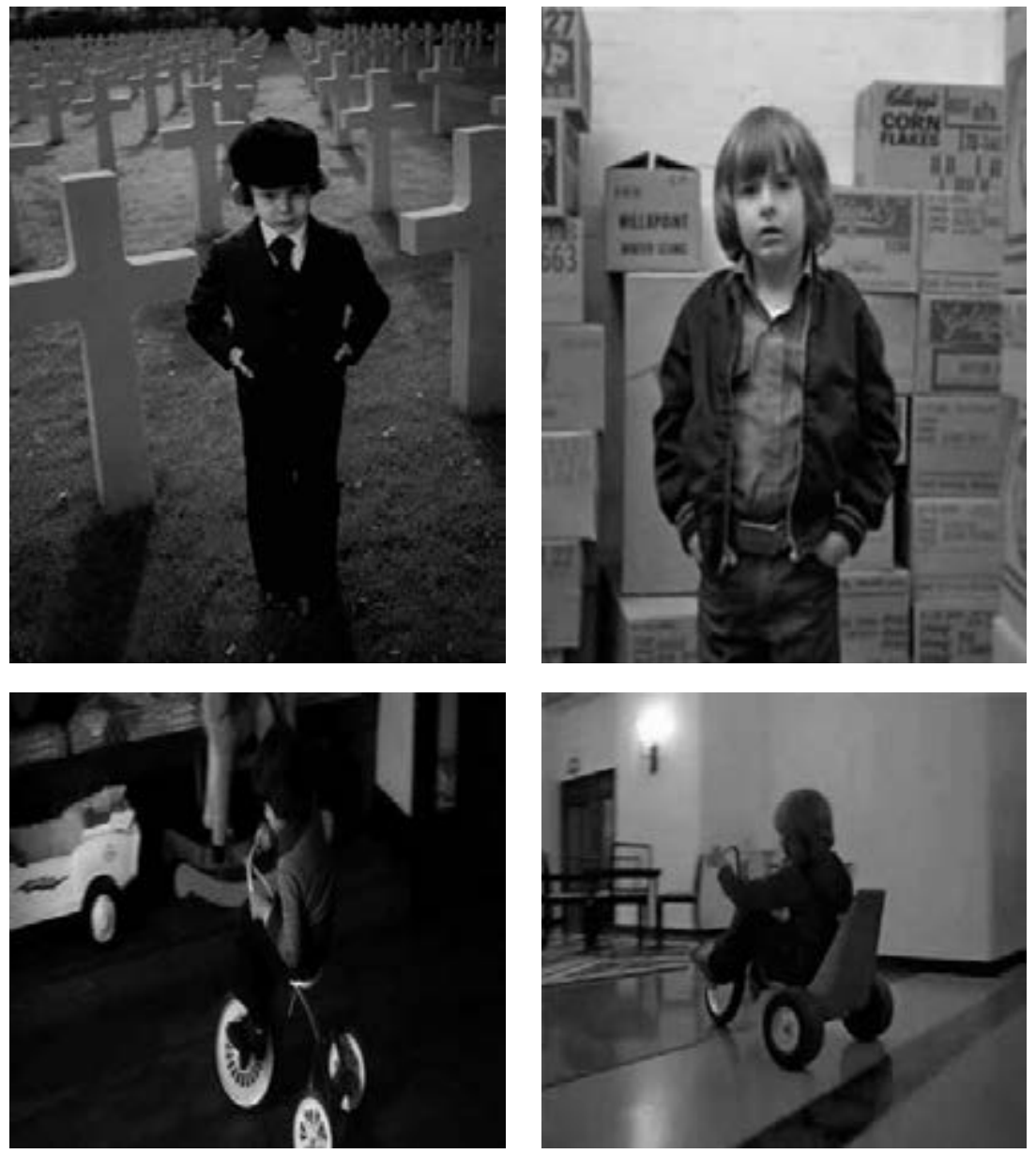

Figure 1. Visual echoes of The Omen in The Shining: Damien (left) and Danny (right). (The Omen image credit: AF Archive/Alamy Stock Photo Archive).

external to the child, but a doubling of the child himself; Danny's tricycle riding does not result in the murder of either of his parents, but merely depicts his childish means of passing the time within the vast, isolated hotel to which his family have moved. By establishing and then discarding these connections to earlier evil child films, Kubrick emphasizes the manner by which the film delves beyond the shallow tension established between the child as innocent empty vessel and the evil demon that lurks within. In The OMEN, a priest remarks of Damien 'This is not a human child', thus denying that the frightening or inscrutable qualities of the child character are anything to do with the nature of childhood itself. By contrast, in the opening of The SHINING, a doctor examines Danny 
after he has fallen into a catatonic state, and says 'Kids can scare you to death': a symbolic foreshadowing of the child's own threatening ideological status and supernatural powers, and the way they eventually result in the annihilation of Danny's father, Jack.

\section{The Psychic Entanglement of Danny and Jack}

Expressing prevalent cultural anxieties about the shifting status of the nuclear family in the 1980s, THE SHINING plays out a dramatic breakdown of the family unit: Danny, his mother Wendy, and Jack. At the beginning of the film, the Torrance family move to the isolated Overlook Hotel, where writer Jack has acquired an off-season job as a caretaker. The film circulates around the traumas of the family's past while never clearly articulating the nature of these events, except for the suggestion that Jack is a former alcoholic who has abused his son in the past, dislocating his shoulder. Jack hopes to restore the unity of his family at the isolated hotel in tandem with regaining a stable sense of his own identity by displacing the traumas of the past and resecuring his position as economically, emotionally, and mentally dominant patriarch. Yet Danny, who is able to perceive ghosts from both the past and future within the walls of the hotel, continually works against his father's attempts to restore symbolic coherence.

Through his supernatural 'shining' power, Danny unleashes the ghostly spectres of both his father's unconscious and the hotel's grisly past in ways that are inextricably entwined. Overarching the film's enigmatic narrative is Jack's belated cognizance that he shares the murderous rage and violent impulses of the previous caretaker of the hotel, Grady, who murdered his wife and twin daughters in the hotel. The paralleling of Jack and Grady takes on vague connotations as a repressed trauma within Jack's own past, as it is suggested at a number of points in the film that Grady and Jack may be one and the same. The film is not interested in clarifying a binary between the external reality of these events and their existence as the darkest impulses of Jack's mind. Instead, the hotel psycho-topographically maps out the labyrinthine corridors of both Jack's and his son's psyches, as Danny's power plunges his father (and the viewer) into the asynchronous realm of the unconscious. This is a space in which, to reiterate Stockton, 'past and present ego-structures [exist] side-by-side, almost cubistically, in lateral spread' (2009, 14), with Danny being the crucible for Jack's submerged memories, thoughts, desires, and fears. Thus, Danny's supernatural powers function to empower the site of the adult's unconscious, facilitating the monstrous eruption of his father's own repressed drives and traumas. 
As a result of Danny's power, the entire film is shot through with the aesthetics of trauma: barely explicable events double and repeat, haunting both Jack and Danny and blurring the boundaries between their psychic realms. For instance, at one point Danny finally wanders into Room $237^{6}$, a space which the psychic hotel cook, Halloran, had previously declared off-limits. While the film elides what occurs within the room, Danny emerges in a trancelike state, with bruises covering his neck, and later tells his mother (in a moment the viewer does not see) that a crazy old woman tried to strangle him there. It is notable that Danny appears before his parents in this state just as Jack is telling Wendy about a terrible dream from which he has just awoken, in which he slaughtered his wife and child. When Jack ventures to the room ostensibly to determine the source of his child's injuries and fears, the scene is at first filmed from a first-person perspective that suggests we are witnessing Danny's memories of the events that took place there, rather than sharing Jack's perspective in the film's present. This is implied by a shot of the door at the start of the sequence, which appears almost identical to the shot of the door that preceded Danny's own entrance into the room about fifteen minutes prior: it is filmed from the same low angle indicative of the child's perspective, and the door is also ajar at precisely the same angle. Furthermore, a close-up of Danny's terrified face directly follows this shot of the door. The scene subsequently plays out in first-person perspective, until a reverse medium shot reveals that it is in fact Jack's perspective that we now share: the point at which Danny's memories were replaced with Jack's present perspective remains unclear, and it is suggested throughout this sequence that the two are impossible to disentangle.

When Jack enters Room 237, he at first encounters a beautiful naked woman in the bathtub, who he embraces, only to glance in the mirror behind the woman to realize that she now appears as an old crone with flesh decaying from her bones. Jack backs away from the decomposing woman as she cackles and slowly advances towards him. These shots depicting the woman's slow but relentless pursuit of Jack with outstretched arms are intercut not only with Jack's frightened expression, but with more close-up shots of Danny's terrified face, as well as shots showing the old woman appearing as a corpse in the bathtub, slowly rising from the mouldering water. The scene thus establishes a jumbled intermingling of Jack and Danny's traumas, as Jack's own vision of the decaying woman is knotted with Danny's fractured traumatic remembrance of his previous encounter with her.

6 The elusive mysteries of Room 237 are often seen as the core of the film's enigmas, to the point that a documentary about the film's cult following and the many wild theories which purport to interpret it was titled Room 237 (Rodney Ascher, 2012). 
The psychic entanglement of Danny and Jack is further suggested by Tony, the child's invisible friend. In the Stephen King novel on which the film is based, it is revealed that 'Tony' is actually a future version of Danny. A temporality-bending double of both Jack and Danny par excellence; at this revelation, it is 'as if Tony - as if the Daniel Anthony Torrance that would someday be - was a Halfling caught between father and son, a ghost of both, a fusion' (King, 1977, 321). While Kubrick does not explicitly reinforce this connection on the level of dialogue - and it is the nature of the film, suffused with the irrationality and temporal dissonance of trauma, that very little is overtly explained - the Danny-Tony dyad also symbolically serves this function in Kubrick's film adaptation. The entwinement of Danny, Tony, and Jack incarnates a nexus of psychic identifications between father and son: the child simultaneously represents his father's other, his father's ungraspable deepest psychic realms and pasts, and the future that lies beyond the threshold of his father's death. Danny's shining power and communion with Tony unleash the repressed pasts, impulses, and conflicted desires that erode Jack's hold on his self-identity, as the child becomes embroiled with the obscure depths of Jack's psyche.

The child thus defaces clearly demarcated identities in an abject disturbance of symbolic orderliness, embodying 'the in-between, the ambiguous, the composite' (Kristeva, 1982, 4) that exists at the core of Julia Kristeva's definition of abjection, the traumatic 'place where meaning collapses' $(1982,2)$. By disturbing the secure boundaries of Jack's singular selfhood, the child precisely functions as the 'inescapable boomerang' of abjection Kristeva describes, 'a vortex of summons and repulsion [which] places the one haunted by it literally beside himself' $(1982,1)$. Unable to escape from his son within the walls of the hotel and thus forced to face the repressed psychic content that Danny both exposes and elides, 'Jack' eventually disperses into a polymorphous composite of spectres representative of his previously submerged rage, desires, and traumas: by the end of the film, Jack himself is indistinguishable from the ghost of Grady, the former caretaker of the hotel who murdered his wife and children and 'has always been' at the hotel. This point is reinforced by the film's infamous final image, which depicts Jack in the centre of a black-and-white photograph depicting the Hotel's 1921 July $4^{\text {th }}$ Ball.

Thus, while the Overlook Hotel is ostensibly positioned as the site of ghostly hauntings in THE SHINING, Danny is the vessel through which this abject realm emerges. We first become privy to the enigmatic spectral world of the hotel via Danny's perspective, yet this occurs before Wendy and Danny have even ventured to the hotel. Through a parallel-edited opening 
sequence, the psychic links between Jack and his son are established as Danny has visions of the hotel while his father undergoes an interview for the caretaker position. This sequence is introduced via a slow dissolve that momentarily overlays an image of Jack and his son. While Jack is introduced to the hotel in the course of his interview, Danny talks to Tony while looking in the mirror, in which he witnesses his first vision of the terrifying Overlook.

In this scene, we are confronted with an uncanny inversion of the Lacanian mirror stage, in which the child (mis)recognizes himself as a unified, coherent being while looking at his reflection, a process that Lacan sees as underlying the psychic constitution of one's singular self-identity. Instead of depicting the wholeness of Danny's identity, this scene moves towards the opposite vector, as the communion between Danny and his mirror image exposes him as a fragmented and splintered being even though he initially appears to us as a unified entity. Not only does the mirror serve as an intermediary between Danny and Tony, but, because this scene is parallel-edited with Jack's first encounter with the hotel, this mirrored doubling introduces Danny's own psychic imbrication with Jack. The viewer also becomes implicated in this undermining of subjective wholeness through a confrontation with the mirror, as the camera slowly tracks from an image of Danny standing before it to a shot of the mirror image itself, so that the mirror comes to fill the entire screen: the 'real' child becomes replaced with his mirror image and the viewer is placed into his position instead. However, the camera does not approach the mirror front-on, so that, although we are looking at the child's reflection, he does not meet our gaze, functioning as an imperfect reflection of the viewer that remains detached and not fully graspable.

Danny's mirror image thus evokes a subtle wavering of the permeable borders between the child character and the audience which parallels that between the child and adult protagonist, aestheticizing the child's function as the adult's own specular but ultimately disconnected self (Fig. 2). It is this uncomfortably familiar yet imperfect doubling - powerfully condensed in THe SHINING by the repeated images of the ghostly and (not quite) identical Grady twins - that underscores the uncanny child's relationship with Jack, as the father's singular identity collapses through his simultaneous entwinement with and distance from his son. While looking in the mirror, Danny first witnesses his (now iconic) recurring visions of the river of blood flowing from the hotel's elevator and the eerie Grady twins. Thus, Danny's character is introduced via his facilitation of the 'doubled, divided and interchanged' (Freud, 2003b, 141) self at the core of the uncanny - a 


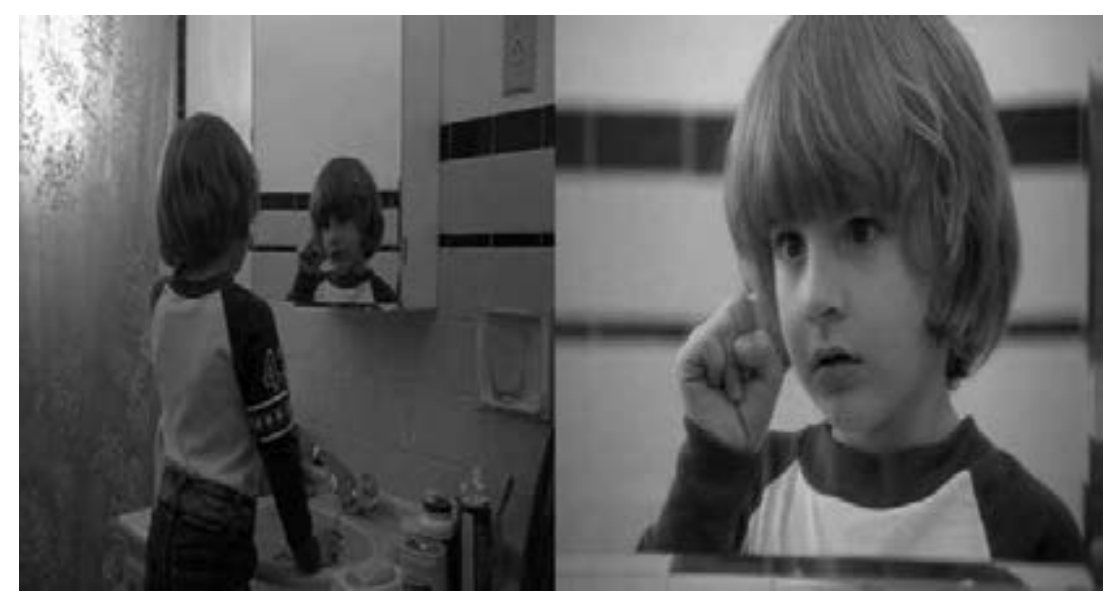

Figure 2. Danny talks to 'Tony' and his mirror image in consecutive shots.

preoccupation Freud sees expressed in dopplegänger and telepathy motifs, both of which are central to Danny's characterization. This introduction to Danny exposes how the eerie spectres of the Overlook - and Jack's own mind - are rooted in the psychic realm of the child, and in fact King's novel further elucidates this link: 'In the Overlook all things had a sort of life. It was as if the whole place had been wound up with a silver key. [...] [Danny] was that key' (King, 1977, 234-235).

\section{Danny's Abject Hieroglyphs}

As this key example shows, throughout the film, Danny's visions are expressed through obscure symbols that simultaneously prefigure and obscure the secrets underlying the Overlook Hotel's ghosts and his father's descent into madness. Thus, Danny emits vital narrative clues that are not articulated coherently in adult terms, but which exist at the core of the film's diegetic world and his father's psyche, positioning the child at the symbolic centre of the film. The subsequent narrative impulse to decipher the child's visions and his attempts at communicating them to his parents echoes the quest to uncover the hidden source of Little Hans's phobia in Freud's 'Analysis of a Phobia in a Five Year Old Boy.' In Freud's case study, Little Hans's vaguely expressed fear of horses is excavated by both Freud and Hans's own father in an attempt to resolve the enigmas of the child's language. By treating the child's communication as though it were a string of riddles to be solved, Freud seeks to unlock the secrets surrounding the repressed pasts and components of the adult psyche: the Oedipal complex 
and related stages in Freud's model of psychosexual development. As Freud explains:

When a physician treats an adult neurotic by psycho-analysis, the process he goes through of uncovering the psychical formations, layer by layer, eventually enables him to frame certain hypotheses as to the patient's infantile sexuality; and it is in the components of the latter that he believes he has discovered the motive forces of all the neurotic symptoms of later life. [...] But even a psycho-analyst may confess to the wish for a more direct and less roundabout proof of these fundamental theorems. Surely there must be a possibility of observing in children at first hand and in all the freshness of life the sexual impulses and wishes which we dig out so laboriously in adults from among their own debris - especially as it is also our belief that they are the common property of all men, a part of the human constitution, and merely exaggerated or distorted in the case of neurotics. $(2001,6)$

Thus, the process of decoding Little Hans's 'riddles' - his mysterious fear that a white horse might bite him, an obsession with horses and their 'widdlers', and his playing with dolls with knives protruding from their genitals 7 - promises to reveal the inscrutable repressed content underlying adult complexes and neuroses. Freud positions Hans's case as proof of his Oedipal model, interpreting the child's phobia and fixations as a sign that he was working through a fear that his father would castrate him for desiring his mother. Various scholars post Freud, such as Barbara Creed (1993), Melanie Klein (1975), and Lacan (2001) have presented variations on Freud's own analysis, each of them centred around careful interpretations of Hans's childish communication - his barely intelligible speech, drawings, and play - to provide evidence of the intangible (and universal) inner workings of the adult unconscious.

THE SHINING and other post-1980 uncanny child films do not refract any specific such model of infantile sexual development, but instead dwell on this very process whereby the child's insecure methods of communication are positioned as conundrums that both stand for and promise to resolve the deepest fissures of the adult's mind and existence. In Kristeva's discussion of Freud's analysis, she points out that 'the phobia of horses becomes a hieroglyph that condenses all fears, from unnameable to nameable. [...]

7 Barbara Creed (1993) famously interprets this element of the Little Hans's case as a sign of the child's fear of the castrating vagina dentata. 
The statement, "to be afraid of horses" is a hieroglyph having the logic of metaphor and hallucination' ( emphasis in original, 1982, 34). While Kristeva herself carries out an analysis of Hans's case which purports to expose clues to the universal structure of the unconscious, what is significant to my consideration of the uncanny child is that she positions the child's phobic object as inherently enigmatic, pushing at the limits of the adult's symbolic order: hence her use of the term hieroglyph.

Danny, like Little Hans, expresses, or is in fact constituted of, hieroglyphs that dimly illumine the enigmas that the adult protagonists - and viewers - are tasked with deciphering. This narrative drive entails an attempt to excavate what is uncanny and unknowable about the child and reconfigure it into a more secure symbolic framework - in so doing, domesticating his threatening alterity and restoring coherence to both the adult protagonist's existence and to the viewer's sense of narrative meaning. In this context, the child's comparatively insecure handle on language and processes of signification becomes a source of anxiety, being associated with dark secrets buried deep within the psychic realm of adulthood but just beyond the adult's perceptual capabilities. Danny's vision of the river of blood flowing from the hotel's elevator early in the film represents the first of the hieroglyphs that the child issues, one that viewers are tasked with contextualizing into a lucid symbolic pattern in an attempt to unlock the meaning or purpose underlying the spectral presences of the Overlook. The image, repeated multiple times throughout the film, functions as a condensation of 'nameable and unnameable' anxieties surrounding the continuous cycles of patriarchal violence that underlie the hotel in a similar manner to Little Hans's obscure fear of the white horse.

The other central hieroglyph in the film is Danny-Tony's ${ }^{8}$ repetitive chanting of the nonsense word 'REDRUM', and his eventual scrawling of this word upon his mother's bedroom door using her lipstick. In the process of deciphering this hieroglyph, the audience is aligned with Wendy as we are compelled to comprehend the child in order to fully recognize the murderous intentions of his father, Jack, which have so far been suggested but ultimately opaque to both Jack himself, his wife, and the audience. Wendy and the viewer share a moment of recognition as 'REDRUM' is reflected in the mirror to become 'MURDER', a meaning-securing counterpoint to the uncanny mirror-doubling of Danny seen early in the film. Like Danny's recurring vision of the river of blood, 'REDRUM' esoterically promises to resolve the

8 At this point in the film, the utterances of Danny and his invisible friend Tony meld, as Danny starts to speak only in the guttural register and repetitive phraseology of Tony. 
mysteries of the narrative, again pointing to Jack's violent impulses and to the hotel's terrible past, yet ultimately resists further clarification like Little Hans's hieroglyphic compounding of nameable and unnameable fears.

The visual construction of this hieroglyph positions it as an expression of the cuteness that delineates the borders of childhood; Danny's drawing with red lipstick on the door evokes a stereotypical image of cute childhood mischief, and his 'REDRUM' exhibits the broad scrawl, incoherence, and backwards letters that stand as signals for the child's charmingly insecure hold on language and writing. As Merish points out, 'cuteness aestheticizes the most primary social distinctions, regulating the (shifting) boundaries between Selves and Others, cultural "insiders" and cultural "outsiders", "humans" and "freaks"' $(1996,188)$. Cuteness in this context becomes realized as an anxiety-laden signifier for the unstable partition between child and adult, as 'REDRUM' emphasizes the occluded channel of communication between Danny and Wendy/the viewer, while simultaneously projecting an awareness of Jack's formerly repressed murderous rage and imminent violence.

Tony functions as a receptacle for the elusive secrets that all of these hieroglyphs simultaneously expose and conceal; he is, according to Danny 'The little boy who lives in my mouth', who remains ungraspable to the adult characters. When Danny is being examined by a doctor after first being confronted with the vision of the river of blood, she shines a torch into his eyes as if to illuminate the child's dark corners. The doctor asks if she can have a look in Danny's mouth to get a glimpse of Tony, but Danny assures her that she will not see him, because he has gone to hide in Danny's 'stomach'. The doctor's interrogation of Danny ultimately meets a dead end, as Danny abruptly halts the questioning with 'I don't want to talk about Tony anymore.' Tony thus functions as a crystallization of the inscrutable secrets that impel adult characters and viewers towards the child in their quest to understand the vaguely expressed anxieties that throb throughout the film. This constitution is further suggested by the fact that, while facilitating Danny's insight into the repressed pasts of both the hotel and his father's psyche, Tony also represents the future adult latent within Danny. Thus, the Danny-Tony dyad reinforces the overarching implications in THE SHINING that the traumas of childhood - vaguely entangled with the adult protagonist's own dark pasts - can be assembled into coherent meaning only in the 'future tense' of adulthood. Overall, the film presents a vision of childhood that is disturbing not because the child is possessed or evil - as is emphasized by the true nature of Danny's 'invisible friend' - but because the child is impossibly intertwined with yet simultaneously impenetrable to the adult's psyche. 


\section{'Why do you Remain?': Traumatic Repetition in THE CHANGELING}

Released two months prior to The SHining, The Changeling presents a different syntactic category of uncanny child to Danny, the living child who is capable of perceiving both ghosts and the darkest reaches of his father's mind. Instead, THE CHANGELING's uncanny child, Joseph, is himself a ghost. Yet, despite this key difference, Joseph exposes similar anxieties about the paradoxes inherent in the child's position as both a victimized innocent external to the adult protagonist and as a threatening symbol of the adult's past trauma and inner psychic tensions. In this film, this role is underscored by the fact that Joseph is a poltergeist, a contradictory non-presence who affects the present in a violent manner despite being a spectral remnant of a displaced past. In The CHANGELING, Joseph's status as a poltergeist drives the uncanny child's conflation with the (re)emergence of repressed pasts with particularly tangled relationships with the adult's own psyche.

In the film, ghost-child Joseph is concealed within a secret attic of the mansion in Seattle in which protagonist John, a composer, has come to live. The opening of the film depicts the sudden death of John's wife and child in a traffic accident: while John is inside a phone booth calling roadside assistance to fix the family's car, a truck strikes both his wife and daughter. The vision of their sudden deaths is omitted - the viewer only sees John's horrified reaction from within the phone booth, powerless to prevent the accident, as he bangs against the glass. This moment haunts John - and the film as a whole - in an aestheticization of traumatic experience not fully grasped in the first instance, exposing the extent to which, to use Caruth's description, 'trauma is not locatable in the simple violent or original event in an individual's past, but rather in the way that its very unassimilated nature - the way it was precisely not known in the first instance - returns to haunt the survivor later on' $(1996,4)$. John moves to the isolated mansion while grieving the death of his family, in an attempt to restart his life and recover from his trauma. Yet the ghost Joseph performs a symbolic repetition of John's trauma, and it is through this mechanism that the child-ghost and the secrets he bears expose a symbolic fissure within both the adult protagonist's psyche and the diegetic real.

Joseph, a crippled, sickly child while alive, was drowned in the bathtub by his wealthy father Richard, who feared that the child would die before his 21st birthday and would thus fail to retain the vast family fortune - inherited from his mother - within the family. Richard subsequently covered up the child's death and replaced Joseph with a healthy orphan. As a ghost, Joseph endlessly enacts a repetition of the scene of his death, which in turn functions 
as an expression of John's own compulsion to repeat the trauma that haunts him. For John, Joseph (dis)embodies the Freudian conception of traumatic neuroses in which the dream life 'continually takes the patient back to the situation of his disaster, from which he awakens in renewed terror' (Freud, $1922,9)$. Joseph's presence is first made known to John through a recurring booming that carries throughout the house at 6:0o every morning, abruptly waking him from sleep - notably, in one scene John awakes in tears as the booming emerges.

John will not accept that this sound is, as the gardener explains, a problem with the old house's furnace, responding that it is 'too loud, too rhythmic': it represents an insistent hammering upon John's own consciousness. The sound is similar to the cannon-like booming that haunts Eleanor in THE HAUNTING (Robert Wise, 1963), a sound that expresses Eleanor's ambivalent feelings towards her dead mother by monstrously inflating the sickly woman's late night banging on her bedroom door, while simultaneously evoking the rage of the ghostly spirits of Hill House. In The Changeling, the overwhelming banging stages an uncanny repetition that disturbs coherent boundaries of selfhood between John and the child-ghost. The booming relays in magnified form both Joseph's desperate banging on the sides of the bathtub as his father drowned him, and John's own frantic beating on the door of the telephone booth as he helplessly watched his wife and child get hit by a truck. The inextricable connection between the two is further suggested when John finally locates the locked door that conceals the attic within which Joseph's ghost lingers: as John starts to beat on the lock with a hammer, the spectral booming reemerges in time with his own banging. John's forcing his way into this hidden space simultaneously represents a restaging of his own trauma and an attempt to conquer and excavate the secrets of the uncanny child.

Further reinforcing his entwinement with John's trauma, Joseph functions like a blockage to John's creative development and advancement throughout the film, continually drawing him back to the past in an uncanny loop. Midway through the film, John is depicted composing a new piece, as the stages of composition are shown in abbreviated form and he proudly records the finished product. This lengthy sequence suggests that John has started to work through the traumas of his family's death, and is regaining stability as he rebuilds his identity post trauma. Later in the film, however, in a moment of déjà vu in the hidden attic, John discovers Joseph's rusted old music box, which plays the very melody he has recently 'composed' - as he remarks in disbelief, 'same key, same tempo'. It is later revealed that this song played on Joseph's music box when his father viciously drowned him; thus, John's composition represents another symbolic instance of an unconscious compulsion to repeat, driven 
by the ghost. To reinforce this, John plays the two pieces simultaneously in an eerie convergence of past and present; at this point, déjà vu actualizes the vague threats to the linear progression of time incited by the ghost's hauntings. As Nicholas Royle explains, there can perhaps be no conception of the uncanny without the impression of déjà vu, as 'Déjà vu is the experience of the double par excellence: it is the experience of experience as double' $(2003,183)$.

More than this, the experiential doubling of déjà vu constitutes a temporal layering, as time seems not to flow forwards in a homogenous, singular line, but instead suddenly appears to be comprised of strata of pastness that coexist with the present, raising the uncanny child's aestheticizaton of layers of temporality in the manner of Freud's imagined Rome cited in the introduction to this chapter. Echoing the mirror scene from THE SHINING in audio-centric form, this scene also captures Joseph's eerie entwinement with and impassable distance from John's own psyche: in his layered restaging of traumatic pasts, the child-ghost simultaneously enforces a nonlinear experience of time and a wavering of borders between the adult self and the child other. John is bewildered by the emergence of his composition on the old music box, explaining that 'whatever it is, it's trying desperately to communicate'. Thus, the child's mysteriously inarticulate attempts to communicate are again foregrounded, uncanny because they simultaneously emerge from within the adult's own consciousness and from some unknowable realm beyond the adult's perceptual grasp.

Ultimately, Joseph's invasion of John's psyche functions as a compulsion to repeat a past trauma in an effort to gain mastery over it at the interface of both of their subjectivities. By haunting John with the traumas of his death, Joseph impels John to locate his corporeal remains (hidden in the depths of a well that was built over long ago), and expose his father's crime. In so doing, Joseph leads John to dislodge the replacement 'Joseph' from his prominent position as a wealthy Senator by revealing him to be a 'changeling'. Thus, Joseph's compulsion to repeat works towards mastery via revenge, a trait Freud associates with the child's consciousness (and thus the adult's unconsciousness) when he explains traumatic neurosis via the example of child's play. In his famous example of the fort- $d a$ (gone-there) game, in which a child repeatedly throws toys from his crib only to have his guardian return them, Freud suggests that children play in a manner that repeats disagreeable experiences in order to gain mastery over these unpleasant feelings. For Freud, the fort-da game represents an empowered restaging of the child's experience of his mother leaving him alone in his crib only to have her return later, a situation over which the child has no power. Furthermore, Freud suggests that the child's compulsion to repeat during play also works to fulfil 
'the gratification of an impulse of revenge' as 'in passing from the passivity of experience to the activity of play the child applies to his playfellow the unpleasant occurrence that befell himself and so avenges himself on the person of this proxy' $(1922,14-16)$. Thus, the compulsion to repeat via child's play replays the conditions of the child's discomfort, yet places the child in an active position so that he can at once claim a sense of vengeance for his pain, while regaining power in a situation that previously left him helpless. Joseph's ghost works in this manner, as, through his repetition of trauma, he intends to empower himself, reanimating the conditions of his death in an effort to make himself heard and also to become a source of fear. Furthermore, through his hauntings, Joseph seeks vengeance upon his changeling, even though the Senator had no hand in or even knowledge of the child's death. Joseph even first makes himself known to John via a spectral version of the fort-da game: he throws a red ball down the stairs, which John picks up and subsequently throws into a nearby river. Yet, when John returns home, the soaking wet ball once again bounces down the stairs. ${ }^{9}$

Notably, this ball belonged to John's daughter, and John had previously kept it in a box with some of his daughter's other prized possessions. Joseph's eerie game of fort- $d a$ thus indicates the extent to which John himself works in simultaneity with Joseph's spectral compulsion to repeat, by questing to resolve the traumas of the ghost-child where his own trauma cannot be resolved. This connection is reinforced by the fact that John at first assumes that Joseph is the ghost of his daughter, before instead assuming, after perusing some historical records, that the ghost is that of a young girl who was struck and killed by a coal cart - a spectral proxy for his daughter. By becoming embroiled in Joseph's own compulsion to repeat, John too seeks to gain mastery over his trauma by exposing the mysteries surrounding the ghost's death and seeking vengeance for it, thus acquiring an agency not possible in response to the sudden death of his own family.

\section{Time Out of Joint: Shining Cultural Traumas}

Both The Shining and The Changeling illustrate the extent to which the uncanny child is implicated with the traumas and related repressed content of the adult protagonist's psyche. These films represent a shift in constructions of horror film children, and would go on to influence the

9 Famously, The Shining also has an incarnation of this eerie ball game. The Grady twins first reveal themselves to Danny by rolling a yellow ball down the hallway. 
films discussed in the proceeding chapter: both films can ultimately be seen as master texts that reverberate within many subsequent uncanny child films. While primary to these films is the uncanny child's entanglement with the adult character's interior psychic turmoil, a related condition of this process which comes to be amplified in late 1990s and early $2000 \mathrm{~s}$ horror cinema - particularly from Spain and Japan - is how this mechanism enmeshes the uncanny child with sociocultural traumas suppressed in present adult society.

While Danny's shining power enforces a collapse in psychic boundaries between himself and his father - and the eventual complete dissolution of his father's singular identity - the child's uncanny disturbances to temporal and symbolic coherence also afford him the ability to raise historical traumas repressed beneath the grandeur and opulence of the aptly named Overlook Hotel: he thus disturbs not only the security of his father's identity but that of America's cultural identity as well. This suggests a constructive empowerment of the child's uncanny otherness and its resistance to the rational strictures of adult discourse, beyond the negatively defined Freudian model in which the resurfacing of past traumas can be seen only through the narrow optique of adult neurosis - specifically the repetition compulsion - which must be resolved and overcome via the process of working through.

Danny's ability to re-invoke the repressed secrets of the past - to see beyond the romanticized nostalgia for the 1920 s that overcomes Jack in the hotel's 'Gold Room' - implicates him in the disintegration of linear historical narratives. That the film ends at a juncture in which the relations between the past, present, and future remain in flux lays bare the uncanny child's subversive power in layering past and present ego-structures (to return to Stockton's terms), a conceptual transgression that can be productively elucidated through Deleuzian concepts of cinematic time. Deleuze's discussion of the time-image, in which 'we are plunged into time rather than crossing space' (1997a, xii), serves to lend shape and purpose to this disturbing breakdown in linear time and the coherent chain of signification at the film's end. THE SHINING provides an example of how the uncanny child raises a time that is 'out of joint': temporality becomes so tangled that, in the final scene, Jack exists as both a dead body sitting frozen on the hotel's grounds, and as a smiling face that 'has always been' in the 1920s-era black-and-white photograph on the hotel walls.

Danny's shining ultimately, to use Deleuze's description of the timeimage, 'goes beyond the purely empirical succession of time' to reveal the 'coexistence of distinct durations, or of levels of duration: a single event can belong to several levels: the sheets of past coexist in a non-chronological 
order' (1997a, xii). As Anna Powell suggests of the film, '[i]n the Overlook, space-time's forward progression is meaningless. The viewer's own sense of time is likewise caught in the confusing knot of a temporal maze' (2006, 47). By the climax of the film, homogenous, linear temporality has collapsed as different layers of the hotel's monstrous past become visible and are overlaid: skeletons covered in cobwebs are seen in the ballroom in addition to a crowd of people dressed in 1920s-era finery, and a man in a dog suit performs fellatio on a businessman in one of the hotel rooms. Furthermore, a distant chanting that vacillates between the diegetic and non-diegetic soundtrack raises the presence of the Native Americans violently oppressed in the construction of the Overlook. Early in the film, a throwaway comment made by hotel manager about the need to '[repel] Indian attacks' while the hotel was being built vaguely gestures to the long-suppressed past of cultural genocide upon which the hotel is built. ${ }^{10}$ This violent past is activated via Danny's shining power as a certain layer of the past, one of the many to coexist with the present at the ending of the film.

Furthermore, in The ChANGeling, the resurfacing of the repressed traumas of Joseph's death are bound to a previously unacknowledged atrocity obscured by narratives detailing Seattle's history: while John scrupulously studies historical texts in his attempt to gain knowledge surrounding the circumstances of the child's death, Joseph's murder and his subsequent replacement by another child - the current Senator are elided in these official, adult-sanctioned narratives. Like Danny, by restaging a past trauma, Joseph unsettles linear constructions of history altogether, exposing a different layer of past coexistent with the present that is not contained within accepted historical discourse. Even after John has uncovered all the secrets of Joseph's death and confronted the Senator with the truth of his past, Joseph does not contentedly 'disappear', restoring clear boundaries between past and present and the onwards progression of linear time. Instead, Joseph turns into a truly monstrous poltergeist, creating a fire in the house and threatening to kill all that enter it, leading John to cry out in desperation 'Goddam son of a bitch, what is it you want? What do you want from me? I've done everything I can do! There's nothing more to do!' Like The SHINing, The Changeling thus suggests an empowerment of traumatic experience that resists the adult-centric process of working through, resolution, and displacement

10 Bill Blakemore (1987) has influentially argued that the repressed cultural guilt surrounding the genocide of Native Americans is a central element of the film. 
that characterizes both psychoanalytic approaches to traumatic 'neuroses' and traditional ghost narrative trajectories. Thus, the child's harnessing of trauma exposes the constructedness of adult-sanctioned chronological and historical time, and ultimately refuses to be re-synchronized according to a narrow temporal model that prioritizes the present existence of the adult protagonist and that in turn domesticates the subversive alterity of the child.

Another film that can be seen as part of this early 1980 s uncanny child cycle is Poltergeist (Tobe Hooper, 1982). Like The Shining and The ChANGeling, Poltergeist positions an uncanny child as the agent through which repressed traumas surface, as little Carol Anne is at first the only member of the Freeling family to perceive the 'TV people' - ghosts who communicate through the television - before eventually being sucked into their realm. However, because POLTERgeist centres on a female child, the emphasis is somewhat different: she does not become embroiled in the same manner with the darkest remnants of the male protagonist's psyche, for she is not positioned as a troublingly imperfect reflection of this patriarchal figure. Instead, her entwinement with the spectres that haunt her family raises the darkest content of all the characters' minds, as the ghosts enact what most scares each of the characters in an amplified literalization of the processes veiled in the earlier films. In so doing, Carol Anne threatens the utter dissolution of secure and stable adult identities, as is crystallized in the scene in which one of the paranormal investigators hired to cleanse the family home of spirits looks at his reflection in the mirror only for his facial features to disintegrate rapidly before his eyes (Fig. 3).

The child's eerie commune with the ghosts also works to implode the traditional sanctity and unity of the nuclear family, upon which Reaganite politics were built (and notably, the father, Steven, is at one point seen reading a book called Reagan: The Man, The President). ${ }^{11}$ After the child is rescued from the supernatural dimension and the family is seemingly reunited in domestic bliss, the psychic hired to communicate with the spirits, Tangina, triumphantly declares 'This house is clean!' Yet, subverting such neat resolutions, the ghostly realm erupts once again in the film's final moments, and is revealed to stem from the Freeling's own backyard: their house is built

11 In his article 'Blissing Out', Andrew Britton suggests that what he calls 'Reaganite entertainment' tends to produce utopian visions of a Reaganite model of society, in which patriarchal nuclear family structures are reaffirmed 'with unremitting insistence and stridency' (2009, 129): he suggests that Poltergeist incites a wavering of this unquestioned celebration, as the overt reference to Reagan serves 'to draw on and to disarticulate its audience's uncertainties at one and the same time' $(2009,149)$. 


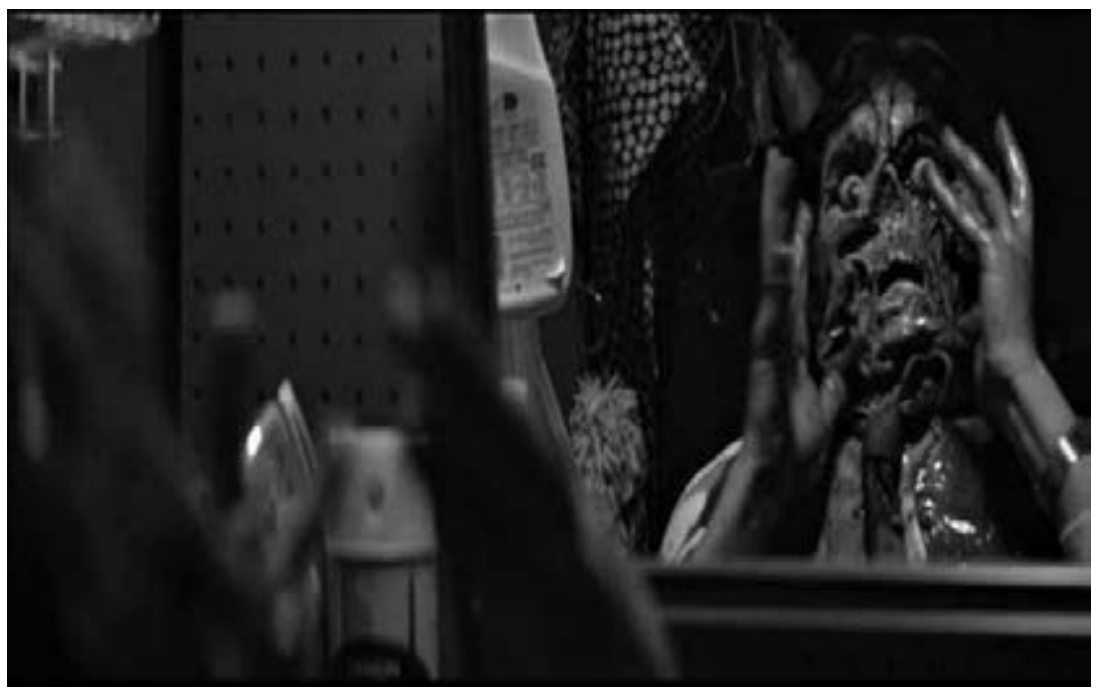

Figure 3. The paranormal investigator is confronted with the collapse of his identity upon looking at his reflection in POLTERgEIST.

upon a gravesite. Subsequently, this vision of suburban domestic bliss is literally sucked into the muddy ground by the aggrieved ghosts first raised by the uncanny child's penetrative perceptual capabilities. ${ }^{12}$

In tandem, throughout Poltergeist, the hauntings and Carol Anne's connection with them are vaguely associated with the imperilled solidity of a triumphant American historical metanarrative. The film opens with an extreme close-up of the Iwo Jima Monument, accompanied by a particularly strident brass-band version of the American national anthem. While superficially acting as a symbol of American bravery and tenacity in WWII, the history of the Iwo Jima Monument is marked by conflicting accounts and myths, as well as controversy revolving around the questionable authenticity of the famous photo on which the statue was based.13 Seemingly

12 As in The Shining, these ghosts hint at the Native American genocide upon which this suburbia is built, although the film does not explicitly draw this link. It is in fact quite notable the extent to which the now-familiar 'Ancient Indian Burial Ground' trope at first emerged in obfuscated ways in American horror films.

13 As Kirk Savage outlines in 'Monument Wars', the monument and photograph upon which it was based were initially thought to capture a heroic moment of untrammelled nationalism as a group of marines took the risk of raising the flag while under fire. The mountaintop upon which the marines are pictured was in fact captured a number of hours earlier, and a different group of marines than those involved in the original battle had returned to replace the small flag that had been placed there initially with a larger one. Thus, even the 'original' moment was reconstructed (Savage, 2009, 245). 
expressing the irresolution of this nationally sanctified but historically disputed image, POLtERGEIST's opening image erupts into thousands of tiny pixels of television snow, and the national anthem into the scratchy grain of audio static, as the camera pulls back from an extreme close-up to a medium shot that reveals that the image of the monument is displayed on a television screen. This pull back entails a gradual reveal of the borders of the television set's screen that further insinuates the constructedness of this previously all-encompassing image. It is this breaking apart of a stable image of American identity that seems to summon the child, who walks stiffly down the stairs as the rest of her family sleep and puts her hands to the television screen, beckoning these disruptive spirits that her parents are incapable of perceiving. Later she repeats this action before famously telling her mystified family, 'They're here!'

Thus, each of these films positions the uncanny child at the heart of the shifting social structures of the 1980 s, as the child's paradoxically constituted otherness - her mélange of familiarity and strangeness, victim and victimizer, innocence and threatening indecipherability - becomes a threat to formerly secure adult identities and ideologies. Via the uncanny child, these films self-consciously illuminate Vivian Sobchack's claim that horror cinema of this era suggests that 'terrorized by its own past, not able to imagine and image its own presence in the future, American bourgeois patriarchy keeps getting trapped by its desire to escape the present' $(1987,191)$. I suggest that these films expose not an impulse to escape the present, but an anxious awareness of the present's wavering, and a concomitant uncertainty about the progression from present into future. The frailty of contemporary ideological structures, particularly the unquestioned social dominance of patriarchal adult identities, is unveiled by the uncanny child in frightening but potentially constructive ways in these films. In addition, the child's association with repressed pasts that the adult protagonists have difficulty perceiving and comprehending not only unsettles the power balance between the adult protagonist and his child, but heralds the child's resistance to chronological continuity and visions of futurity sanctioned by present adult society. This figure suggests that the social institutions and models of identity so taken for granted during this period will not be seamlessly continued into the future, as the child refuses to be shaped by and inculcated into the adult's ideologies, instead empowering their subjugated position to subtly destabilize them. The uncanny child was largely displaced from the centre of the horror genre 
in the later 1980 os and early 1990 s by the vastly popular slasher cycle. ${ }^{14}$ Yet, 20 years later at the turn of the millennium - a time in which symbolic and temporal coherence were again nebulously threatened - the uncanny child reemerged as one of the horror genre's key tropes, as is explored in Chapter Two.

\section{Works Cited}

Bettelheim, Bruno. The Uses of Enchantment: The Meaning and Importance of Fairy Tales. 1976. New York: Vintage Books, 2010. Print.

Blakemore, Bill. 'Kubrick's Shining Secret: Film's Hidden Horror is the Murder of the Indian.' The Washington Post, 12 July (1987): 1-6. Web. William Blakemore. com 30 Sep. 2014.

Blum, Virginia. Hide and Seek: The Child between Psychoanalysis and Fiction. Champaign: The University of Illinois, 1995. Print.

Britton, Andrew. 'Blissing Out: The Politics of Reaganite Entertainment (1986).' Britton on Film: The Complete Film Criticism of Andrew Britton. Ed. Barry Keith Grant. Detroit: Wayne State University Press, 2009. 97-154. Print.

Bruhm, Steven. 'Nightmare on Sesame Street: or, the Self Possessed Child.' Gothic Studies 8.2 (2006): 98-210. EBSCO Host Humanities International Complete. Web. 30 Sep. 2014.

Carter, Jimmy. 'The Crisis of Confidence.' 1979. The 197os. Ed. Neil Hamilton. United States: Fact on File Inc., 2006. 356-357. Print.

Caruth, Cathy. Unclaimed Experience: Trauma, Narrative, and History. Baltimore: The John Hopkins University Press, 1996. Print.

Creed, Barbara. The Monstrous-Feminine: Film, Feminism, Psychoanalysis. London: Routledge, 1993. Print.

Deleuze, Gilles. Cinema 2: The Time Image. 1985. Trans. Hugh Tomlinson and Robert Galeta. Minneapolis: The University of Minnesota Press, 1997a. Print.

Derrida, Jacques. The Gift of Death. Trans. David Willis. Chicago: The University of Chicago Press, 1996. Print.

Fitzgerald, Bridget. 'Children of Lesbian and Gay Parents: A Review of the Literature.' Marriage and Family Review. 29.1 (1999): 57-75. Taylor \& Francis Online. Web 30 Sep. 2014.

14 However, it is important to note that the slasher film in some ways assimilated and continued this preoccupation with childhood's symbolic tethering to the darkest remnants of the adult psyche and the lingering influence of childhood trauma central to these uncanny child films. As slasher films such as the formative HALloweEn (John Carpenter, 1979) are at pains to demonstrate, the roots of the killer's psychosis lie in their childhood. 
Freeley, Dustin. 'The Monstrous Child: Replacement and Repetition in THE ShInING.'Monstrous Children and Childish Monsters: Essays on Cinema's Holy Terrors. Ed. Markus P.J. Bohlmann and Sean Moreland. Jefferson: McFarland, 2015. 160-172.

Freud, Sigmund. 'Analysis of a Phobia in a Five Year Old Boy.' 1925. The Standard Edition of the Complete Psychological Works of Sigmund Freud, Volume X. Two Case Histories: 'Little Hans' and the 'Rat Man.' Trans. Alix and James Strachey. London: Vintage, 2001. 5-21. Print.

—.'Beyond the Pleasure Principle.' 1920. The International Psychoanalytical Library, No. 4. Ed. Ernest Jones. Trans. C. J. M. Hubback. London: The International Psychoanalytic Press, 1922. 1-84. Print.

—.Civilization and Its Discontents. 1930. Trans. David McLintock. New York: Penguin Books, 2002. Print.

—.'Screen Memories.' 1899. The Uncanny. Trans. David McLintock. New York: Penguin Books, 2003a. 1-22. Print.

—.'The Uncanny.' 1919. The Uncanny. Trans. David McLintock. New York: Penguin Books, 2003b. 121-176. Print.

Harwood, Sarah. Family Fictions: Representations of the Family in 1980 s Hollywood Cinema. London: Macmillan Press, 1997. Print.

Hess, Noel. 'The Shining: All Work and No Play...' International Journal of Psychoanalysis 91.2 (2010): 409-414. Wiley Online Library. Web. 30 Sep. 2014.

Hoile, Christopher. 'The Uncanny and the Fairy Tale in Kubrick's The SHining.' Literature/Film Quarterly 12.1 (1984): 5-12. EBSCO Host Communication and Mass Media Complete. Web. 30 Sep. 2014.

Jameson, Fredric. 'Historicism in The SHInING.' Signatures of the Visible. New York: Routledge, 1992. 82-98. Print.

Kilker, Robert. 'All Roads Lead to the Abject: The Monstrous Feminine and Gender Boundaries in Stanley Kubrick's The SHINing.' Literature/Film Quarterly 34.1 (2006): 54-64. Proquest International Index to Performing Arts. Web. 30 Sep. 2014.

King, Stephen. The Shining. London: Hodder \& Stoughton Ltd., 1977. Print.

Klein, Melanie. The Psychoanalysis of Children. 1932. Trans. Alix Strachey. New York: Delacorte Books, 1975. Print.

Kline, Stephen. Out of the Garden: Toys, TV, and Children's Culture in the Age of Marketing. London: Verso, 1995. Print.

Kristeva, Julia. Powers of Horror: An Essay on Abjection. Trans. Leon S. Roudiez. New York: Columbia University Press, 1982. Print.

Lacan, Jacques. 'The Mirror Stage as Formative of the Function of the I as Revealed in Psychoanalytic Experience.' 1949. Écrits: A Selection. Trans. Alan Sheridan. London: Routledge, 2001. 1-6. Print. 
Laplanche, Jean. 'Notes on Afterwardsness.' Essays on Otherness. Ed. John Fletcher. London: Routledge, 1999. 264-269. Print.

Lennard, Dominic. Bad Seeds and Holy Terrors: The Child Villains of Horror Film. Albany: State University of New York Press, 2015. Print.

Litman, Frances. 'Introduction.' Focus on the Family: New Images of Parents and Children in the 1980's. Ed. Clifford Baden. Boston: Wheelock College Center for Parenting Studies, 1980. 5-16. Print.

Merish, Lori. 'Cuteness and Commodity Aesthetics: Tom Thumb and Shirley Temple.' Freakery: Cultural Spectacles of the Extraordinary Body. Ed. Rosemarie Garland Thomson. New York: New York University Press, 1996. 185-206. Print.

Powell, Anna. Deleuze and the Horror Film. Edinburgh: Edinburgh University Press, 2006. Print.

Reagan, Ronald. 'State of the Union Address, 1982.' The Public Papers of President Ronald W. Reagan. Ronald Reagan Library and Museum Archives, n.d. Web. 20 Dec. 2015

Royle, Nicholas. The Uncanny. Manchester: Manchester University Press, 2003. Print. Savage, Kirk. Monument Wars. Berkeley: University of California Press, 2009. Print. Schober, Adrian. Possessed Child Narratives in Literature and Film: Contrary States. New York: Palgrave Macmillan, 2004. Print.

Shor, Juliet B. Born to Buy: The Commercialized Child and the New Consumer Culture. New York: Scribner, 2004. Print.

Sobchack, Vivian. 'Bringing it all Back Home: Family Economy and Generic Exchange.' American Horrors: Essays on the Modern American Horror Film. Ed. Gregory A. Waller. Champaign: University of Illinois Press, 1987. 163-194. Print.

Steedman, Carolyn. Strange Dislocations: Childhood and the Idea of Human Interiority 1780-1930. London: Virago Press, 1995. Print.

Stockton, Kathryn Bond. The Queer Child, or Growing Sideways in the Twentieth Century. Durham: Duke University Press, 2009. Print.

Thatcher, Margaret. Interview by Douglas Keay. Woman's Own. 31 Oct. (1987): 8-10. Print.

Wang, Ya-huei. 'Archetypal Anxieties in Stanley Kubrick's The SHIning.' k@ta13.1 (2011): 112-122. Web. 30 Sep. 2014.

\section{Filmography}

Audrey Rose. Dir. Robert Wise. Sterobcar Productions, 1977. Film.

The BAd Seed. Dir. Mervyn LeRoy. 1956. Warner Home Video, 2011. Blu-ray DVD. The Changeling. Dir. Peter Medak. 1980. HBO Home Video, 2005. DVD.

Child's Play. Dir. Tom Holland. United Artists, 1988. Film.

The Exorcist. Dir. William Friedkin. 1973. Warner Home Video, 2013. Blu-ray DVD. 
Halloween. Dir. John Carpenter. Compass International Pictures, 1979. Film. The Haunting. Dir. Robert Wise. Argyle Enterprises, 1963. Film.

The OMEn. Dir. Richard Donner. 1976. Twentieth Century Fox, 2007. Blu-ray DVD. The Other. Dir. Robert Mulligan. Twentieth Century Fox, 1972. Film. Poltergeist. Dir. Tobe Hooper. 1982. Warner Home Video, 2008. DVD. Room 237. Dir. Rodney Ascher. Highland Park Classics, 2012. Film.

The Shining. Dir. Stanley Kubrick. 1980. Warner Bros. Entertainment Inc., 2007. Blu-ray DVD.

Village of the Damned. Dir. Wolf Rilla. Metro Goldwyn Myer British Studios, 1960. Film. 



\title{
2. The Uncanny Child of the Millennial Turn
}

\begin{abstract}
Chapter Two focuses on two American films released in 1999, ThE SiXTH Sense (M. Night Shyamalan) and STIR of Echoes (David Koepp) to illustrate how, at the cusp of the millennium, the uncanny child character became a precisely realized embodiment of the adult protagonist's personal trauma. These films engage with anxieties of the period: in 1999, the imminent transition into the new century - and millennium - was a strongly felt condition that unsettled a naturalized sense of temporal, personal, and historical progression. The chapter then turns to a later amplification of this trend, INsIDIOUs (James Wan, 2010), in which the uncanny child's imbrication with the adult patriarch's trauma is self-reflexively addressed.
\end{abstract}

Keywords: Uncanny, Childhood, Trauma, Secret, Millennial turn, The Sixth Sense

The uncanny child cycle was reignited in the U.S. at the cusp of the millennium by The Sixth Sense (Shyamalan) and Stir of Echoes (Koepp), released within months of each other in 1999. In particular, THE SIXTH SENSE was the second highest-grossing film of the year, earning \$293 million at the box office behind only the highly anticipated STAR WARS EPISODE 1: The Phantom Menace (George Lucas) (Kendrick, 2010, 142). As James Kendrick points out, the horror genre had not produced a blockbuster of this cultural and financial magnitude since Jaws (Steven Spielberg, 1975), and, prior to that, THE ExORCIST. He asserts that:

the cycle of films that emerged in the wake of THE SiXTH SENSE is particularly important and worthy of attention because, not only was it extremely concentrated, but it marked a decided shift in the horror genre as it was currently constituted, which served a dual function. First, in terms of 
the films themselves, it refreshed the genre by returning it to its initial emphasis on the psychological and the spiritual over the material and physical. [...] Second, in economic terms, this shift in the genre attempted to mainstream horror films (a historically marginalized genre associated with independent studios and B-level production values) by giving them a potentially broader audience via their typical PG-13 ratings and more conventional emotional resonances. $(2010,143)$

I contest Kendrick's term 'conventional emotional resonances' as this supernatural cycle of films expresses complex millennial anxieties, and STIR of Echoes is rated R (which Kendrick concedes). I concur, however, that The Sixth Sense and Stir of Echoes helped to incite a millennial boom in gothic ghost films ${ }^{1}$ that became a globally recognized, mainstream phenomenon - evidence of the extent to which this cycle resonated with contemporary anxieties. As Kendrick and others, such as Hantke (2010), have pointed out, the American horror genre was seen to be in crisis by the end of the 1990s after two decades of slasher and 'post'-slasher franchises, so the pervasive success of The Sixth SEnse heralded a new trajectory for the genre. The critical and economic success of other films discussed in subsequent chapters indicates the extent to which this late 1990s/early 200os supernatural horror revival constellated around the uncanny child.

The Sixth Sense and Stir of Echoes exhibit many of the same devices as The Shining, The Changeling, and Poltergeist, as the uncanny children and their spectral insights are entangled with the psyches of the protagonists in quite precise ways. In addition, these films emerge at a juncture in which vague fears about the solidity of reality and the transition from present into future permeated the American cultural consciousness, just as in the early 1980s. In 1999, the imminent transition into the new century - and millennium - was a strongly felt condition that unsettled a naturalized sense of temporal and historical progression. For instance, in his book published in 1998 meditating on the impending millennial shift, Joseph Natoli wonders, 'are we crawling toward our own end beyond the horizon of the New Millennium?'(6). He elucidates that 'the closer we come to the millennium the greater our sense of heading not into a dream but into an abyss' (Natoli, 1998, 12). As Kendrick suggests, this anxiety about

1 The most significant of these films are discussed in this book. Others include THE HAUNTING (Jan de Bont, 1999), House on Haunted Hill (William Malone, 1999), What Lies Beneath (Robert Zemeckis, 200o), The Gift (Sam Raimi, 200o), and Thi13Een GHosts (Steve Beck, 2001). 
the transition into the 21st century resulted in a phenomenon in which, in the final years of the 199os, 'it seemed that the entire American film industry was caught up in fin-de-siècle-inspired renewal of spirituality and religion that infiltrated virtually every genre' $(2010,150)$. While these supernatural films are not all fixated on the status of religious belief although indeed, some, such as FALLEN (Gregory Hoblit, 1999) and STIGMATA (Rupert Wainwright, 1999), pivot on this theme - they are united through their uneasiness about wavering understandings of 'the real' and the subsequent inability of adult subjects to grasp at the secrets of their own existence. This theme pervades numerous films spanning varied genres in 1999, including Fight Clu b (David Fincher), The Matrix (Lily and Lana Wachowski), The Thirteenth Floor (Josef Rusnak), Eyes Wide Shut (Kubrick's last film), MAGnolia (Paul Thomas Anderson), and EXIstenZ (David Cronenberg).

The uncanny children in The Sixth Sense and Stir of Echoes are similarly bound up with millennial anxieties about the status of cohesive self-identity and contemporary ideological structures - and whether or not these structures will continue into the new millennium, a threshold of futurity that felt eerily tangible. As Jeffrey Weinstock suggests, it is:

no coincidence that the contemporary American fascination with ghosts seems to have reached a high-water mark at the turn of the millennium. [...] The millennial explosion of supernatural cultural production [...] seems to suggest that what is as frightening as the unknown field of the future is the tenacious tendrils of a past we cannot shake. $(2004,6)$

Furthermore, these films, like The Shining, The Changeling, and PolterGEIST before them, position the spectres and the uncanny children who draw them forth as ambiguous threats to the power and primacy of patriarchal identities, illuminating the extent to which the anxieties associated with the imminent transition into the 2ooos circulated again around shifting, or, more specifically, declining, male power. As Fintan Walsh elucidates, since the 1990s, 'men have increasingly appeared across a range of social and aesthetic practices as troubled subjects, with Western masculinity repeatedly reported to be in a critical state' $(2010,3)$ a phenomenon he sees expressed in films like Fight CLUв at 'the height of the decade's deconstruction' (7).

As in the early 1980s, this felt sense of symbolic crisis was closely entwined with questions surrounding the nature of childhood. These two films from 1999 aestheticize power shifts between child and adult, centred as in THE 
Shining, The Changeling, and Poltergeist on the child's supernaturally charged insight and the ways this gift empowers the child to approach the deepest alcoves of both reality and the protagonist's psyche. This process - realized in ways more urgent and precise than in the 1980 s films - can be related to the anxieties Kincaid so powerfully charts in his Erotic Innocence, first published in 1998. As he suggests, 'few stories in our culture right now are as popular as those of child molesting' (1998, 3). Indeed, by the late 199os, the ambivalent moral panic about child abuse reached a crescendo: as Philip Jenkins suggests in his book Moral Panic, also published in 1998, by the late 1990s, one of the most entrenched 'self-evident facts in contemporary America is the belief that children face a grave danger in the form of sexual abuse and molestation' (1998, 1).

While most millennial uncanny child films do not overtly address child sexual abuse as a central theme, cultural concerns about the dark secrets possessed by adulthood's 'inner child' recharged the psychic, temporally tangled entwinement of child and adult psyches seen in uncanny child films of the early 1980s. Kincaid suggests that associated with the cultural fixation with widespread child abuse is a sense that everyone has traumatic memories from childhood hidden within the most unattainable depths of our minds. In his words, these stories thus press 'our origins into the realm of sorrow and pain - we always spring from abuse' (1998, 251). As he explains:

By expanding the story of child molesting into the past and into the recesses of all our memories, we make sure no one is left out. [...] Child molesting is an epidemic, and memory holds the secret. [...] Memory guards the vault. The fact that memory may not yield up the secrets readily licenses us to talk at greater length about hidden pasts. $(1998,244)$

Kincaid traces how the cultural fixation with this process led to an explosion in popular discourse suggesting that 'we must find that inner child and attend to its needs' $(1998,70)$ - as popularized throughout the 1990s in popular media such as Oprah Winfrey's ScARED Silent: Exposing AND ENDING CHILd ABUse, broadcast across all American television networks in 1992. This rhetoric situates the quest to uncover one's 'inner child' as a fraught but vital process synonymous with excavating the buried secrets of one's psyche. In The SixTH SENSE and STIR of EchOES, the child quite clearly functions as the symbolic vessel or 'stage' for the adult's repressed psychic content, as the protagonist's burgeoning recognition that a mysterious spectral realm underlies normality is played out through his deeply personal quest to uncover what the child character conceals. 


\section{'You've got a secret that you don't want to tell me': THE SIXTH SENSE}

In The Sixth Sense, adult protagonist Malcolm Crowe is a child psychiatrist, thus unravelling the riddles of childhood is no longer presented as a symptom of the ghost narrative but is positioned as an overtly central preoccupation. ${ }^{2}$ The dramatic twist in the final scene of the film reveals that the analysis of the child's 'phobia' leads to a revelation within the adult protagonist as well, clearly refracting the mechanics promulgated by Freud's 'Little Hans' case, discussed in the previous chapter, whereby the child's hieroglyphs are conflated with concealed truths within the adult mind. This impression is heightened by the narrative structure of THE SiXTH SENSE, in which the twist in the final scene shifts the meaning of all that has happened before. If the film's narrative 'pulling the rug out' from under the audience functions as intended, at the climax of the film, both Malcolm and the viewer simultaneously become privy to a further layer of Cole Sear's secret previously inaccessible to us: that Malcolm has been dead since the beginning of the film. Thus, the quest to uncover the child's secret becomes sewed into both the narrative and visceral experience of the film. The advertising taglines for the film played upon this process, reading 'Discover the secret of The SiXth Sense!', 'Do you believe now?', and 'Can you Keep the Secret?'

\section{Cole and Malcolm's Traumatic 'Secret'}

As in the films considered in Chapter One, the obstructed channel of communication between child and adult is a source of anxiety in THE SIXTH SENSE, for it impedes Malcolm's quest to uncover Cole's secrets. Echoing Danny's 'REDRUM', Cole issues hieroglyphs that Malcolm (and the viewer) must decode, a process emphasized in light of the twist, which reveals that many of Cole's previous statements conceal another layer of meaning. This decoding begins as soon as Malcolm meets Cole and hears him speaking in Latin, forcing him to translate the child's speech in order to comprehend it. (The child says 'De profundis clamavi ad te domine', which Malcolm translates as 'Out of the depths I cry to you, Oh Lord'). After Cole finally tells Malcolm his secret halfway through the film - that he sees dead

2 Due to its psychological theme, a number of psychoanalytic readings of the film have been produced: for a Lacanian reading see Coral Houtman (2004), on death and mourning see Marguerite La Caze (2002), and for a discussion about seduction theory and the fairy tale see Jane Thrailkill (2010). 
people - Malcolm does not truly comprehend the child's statement until he carries out his own detective, or analytic, work. Prior to this, the revelation further exposes the gulf of understanding between adult and child: when Cole asks Malcolm if he believes him, Malcolm replies 'I don't know how to answer that, Cole.' Malcolm only becomes convinced of the 'truth' of Cole's secret when he listens to the audiotapes of his sessions with former patient Vincent. Vincent first appears as a blathering madman at the opening of the film, who, having broken into Malcolm's house, suddenly appears half-naked in his bathroom and shoots Malcolm before shooting himself. He is an abject evocation of Malcolm's professional failure, to which Cole figures a return.

While listening to Vincent's session tapes, Malcolm notices a vague murmur on the recording that he had never noticed before. He rewinds the tape repeatedly, gradually increasing the volume to its maximum level, until he finally discerns a ghostly voice speaking to Vincent, partly submerged by static and crying out in Spanish: 'I don't want to die.' ${ }^{3}$ This scene represents a central turning point of the film, as Malcolm finally believes Cole's secret, and also the previously inscrutable truth behind Vincent's 'phobia'. Yet, it is not through direct communication with the child that Malcolm finally comprehends the source of Cole's anxieties, but through a technologically mediated voice from the past. Underscoring the uncanniness of both Vincent and Cole's knowledge, the audio recording from Malcolm's own past turns into a disembodied echo from another realm that reveals a layer of reality that was imperceptible to Malcolm at the time it was recorded. As in The Changeling and Poltergeist, anxieties about the uncanny child's harbouring of urgent secrets that he is unable to communicate lucidly are realized through technology's ability to allow the adult access to the child's previously elusive world, aestheticizing the uncanny amalgamation of separation and connection between child and adult psyches. The audible static that at first hides the ghostly voice metaphorizes the grainy, unclear channel of communication between the two realms.

While both the viewer and Malcolm are led to assume that they have uncovered and come to terms with Cole's secret once it becomes clear that he really does 'see dead people', the twist exposes that Cole has in fact been hiding another secret - one that is not so easily ameliorated. The last of Cole's secrets to be revealed, that Malcolm is one of these dead people, represents a repressed truth within the adult protagonist's own psyche: the hidden quest underlying the surface narrative is Malcolm's journey to understand and come to terms with submerged components of his own (non)being. 
Thus, The Sixth Sense makes overt the uncanny child's symbolic role as receptacle for the adult's repressed trauma. Cole's final secret exposes a further hole or lack within the adult protagonist that disrupts the cohesive narrative of adult fulfilment in an irreparable manner.

Cole functions like a reincarnation of the crisis that has emasculated and undermined Malcolm's coherent identity as an award-winningly successful child psychiatrist: his failure to cure former patient Vincent. Thus, Cole is like uncanny déjà $v u$ for Malcolm and the viewer, an almost literal reevocation of Malcolm's past trauma. Both Vincent and Cole have a patch of grey hair at the back of their heads, symbolizing their access to uncanny knowledge too great for their youth, and, as Malcolm explains, 'They're both so similar. Same mannerisms, same expressions, same things hanging over their head.' Vincent's taunting words at the opening of the film evoke a rupture in Malcolm's patriarchal, professional identity by hinting at his lack of awareness in comparison to Vincent's own knowledge. Notably, the film opens with a scene depicting Malcolm and his wife arriving home from an awards ceremony, where Malcolm has just been bestowed with an award from the Mayor of Philadelphia in 'recognition for his outstanding achievement in the field of child psychology'. The subsequent scene depicts Vincent appearing in the couple's bathroom: 'You don't know so many things' Vincent remarks, and sarcastically undermines Dr. Crowe's paternalistic saviour status by taunting, 'Don't you know me, hero?' Malcolm is unable to talk Vincent into putting down the gun he wields: 'you failed me', he declares before shooting Malcolm and turning the gun on himself.

Functioning as a repetition of this trauma, Cole provides Malcolm with an opportunity to discover the 'so many things' that he does not know, and also to once again become a 'hero'. Thus, Cole functions as a literalization of Malcolm's compulsion to repeat the trauma that has injured his secure conception of self and gain mastery over it. On first viewing, the audience is led to believe that this narrative is the primary one in the film, and that the film is wrapped up when Malcolm finally achieves his goal and becomes Cole's hero, helping Cole to conquer his fear of the ghosts he perceives. However, the final revelation that Cole has been keeping yet another secret from Malcolm - that he has been dead all along, and is thus one of these ghosts - reveals that Malcolm's trauma is actually irrevocable. Malcolm was in fact killed by Vincent at the beginning of the film, thus the adult's 'hole' - literalized by the gunshot wound on his back, which Malcolm realizes is still bleeding as he becomes aware that he is dead - cannot be filled or repaired. This wound is a precise incarnation of Caruth's traumatic 'wound that cries out' and 'simultaneously demands and defies our witness' (1996, 
4-5). All Malcolm can do at the close of the film is disappear, as a close-up of his face fades into the mediated image of him (now his only form of existence in the world as we know it) on the home videotapes of his wedding, which play as his wife sleeps.

\section{Childhood Traumas/Adult Traumas/Social Traumas}

As well as being intertwined with Malcolm's own trauma, Cole's sixth sense is associated with a knowledge of concealed pasts that undermine present American sociocultural structures. Magnifying the implications of the children's spectral powers in The SHINING, The ChANGeling, and Poltergeist, Cole's visions of the aggrieved dead reveal that present adult society is founded on violence and oppression, and depends upon the repression of this truth to function cohesively. Thus, Cole's statement that the ghosts he perceives 'only see what they want to see' can be applied not only to the ghosts, but to the living adults that surround him as well. As Ted Underwood points out:

[V]isually, the work is nearly as haunted by Philadelphia's past as Cole Sear is by the stories of the dead people he sees. Since the film leaves the young boy with a continuing responsibility to decode injustices reaching back to the eighteenth century, it is difficult to imagine that he will grow up to become anything but a local historian-perhaps the kind of erudite bookstore owner who is consulted in VerTigo about the meaning of masculine power in nineteenth-century San Francisco. $(2002,247)$

However, Cole's ability is represented as a good deal more disruptive than that of a knowledgeable historian, threatening because of his position as a child who sees 'too much' of what underlies adult society. As director Shyamalan states in an interview on the DVD, 'this child has knowledge way beyond what he should'. The film is permeated by the fear that the child sees too much of the adult self, a clear refraction of Freudian discourse that positions childhood as the symbolic site of adulthood's submerged psychic content.

The threat Cole's knowledge poses to adult epistemic structures is revealed in a classroom scene in which Cole confronts his teacher, Mr. Cunningham: a scene that occurs early in the film and establishes Cole's penetrative supernatural insight. The sequence also confronts how the school functions as one of the most powerful institutions of not just child socialization, but of the social othering of the child. Influential childhood theorist Philippe Ariès 
suggests that the development of the modern schooling system was integral to the formation of distinct borders of separation between the child and the adult. As he states, the development of institutions of schooling towards the end of the seventeenth century revolved around conceptions of 'the weakness of childhood [...] [but a weakness] associated with its innocence [...] and which placed education in the front rank of man's obligations' $(1962,111)$. He points out that the Romantic idea of innocence as inherent to childhood resulted in two kinds of attitudes and behaviours towards education that remain central to understandings of the child, 'firstly, safeguarding it against pollution by life, and secondly strengthening it by developing character and reason' $(1962,116)$.

The modern education system is thus structured around 'the association of childhood with primitivism and irrationalism or prelogicism' (Ariès, 1962, 116): a process of institutionalized inferiority that Marina Warner suggests has paradoxically become central to childhood's symbolic power. She asserts that the unreason of children is typically realized in the popular imaginary as an 'intimate connection, above all, to a wonderful, freefloating world of the imagination. Their observable, active fantasy life, their fluid make-believe play seem to give them access to a world of wisdom' (Warner, 1994, 37). THE SiXth SEnSE exposes the gothic underside to this myth. In the classroom scene in the film, Cole empowers his otherness: not yet inculcated into the world of adult reason, Cole's unreason affords him a spectral wisdom that penetrates beyond accepted adult discourse.

In the scene, Mr. Cunningham is teaching a history lesson about the school building, and he explains to the class that 'almost any place you go in this city has a history, a story behind it'. When questioned about what the story behind the building may be, Cole proclaims that it was used for public hangings. The visibly uncomfortable teacher rejects his answer, telling him that it is not 'correct', as if only a single historical narrative is acceptable. Cole counters the teacher, delving deeper into the grisly past of the school by explaining that 'they'd drag them in crying and kissing their families bye. People watching them would spit at them.' Cole's explanation of the school's violent past (to which the audience also later becomes witness, as we see the bodies of a hanged family swinging from a beam in the school's ceiling) is counteracted with the teacher's explanation that 'this building was a legal courthouse. Laws were passed here, some of the very first laws of this country.' The teacher thus dismisses Cole's history to replace it with a neat and clean version, one that valorizes the formation of America's symbolic reality while eliding the violence and oppression bound up with its creation. Yet, as the audience has at this point developed a burgeoning 
awareness of the extent of Cole's grisly knowledge, it is implied that the story the teacher espouses subscribes to a revisionist historical narrative that is tightly controlled by (powerful) adults in the present. Notably, images of the busts of America's presidents are neatly lined up in chronological order on top of the blackboard above the teacher's head, representative of an orderly and idealistic progression of American history.

Cole's insistent alternative answer reveals the narrowness of this history, and highlights how this historical narrative is 'correct' only because the adult teacher proclaims it is so. The teacher goes on to explain that the whole building was filled with 'lawyers' and 'lawmakers', to which Cole promptly responds, 'they were the ones that hanged everybody', subverting the paternalistic authority of the 'lawmakers' by exposing it as violently oppressive. The teacher further disallows Cole's version of historical events, telling him 'I dunno which one of these guys told you that, but they were just trying to scare you', while smirking in a way intended as comforting but which, as filmed in a low-angle shot that places the viewer into Cole's own lowly position, appears patronizing; especially in light of Cole's insights, the teacher's wielding of his position of authority now seems overbearing and disdainful. Cole responds by angrily crying 'I don't like people looking at me like that, stop it!', yet the teacher continues to advance, maintaining a condescending stare, and remarks 'I don't know how else to look.' Frustratingly for Cole, the teacher's only optique through which to perceive the child is to look down upon him as a subjugated other.

Cole continues to defy his subordinate position by further flaunting his surplus knowledge, revealing that he is also in possession of a repressed secret about Mr. Cunningham's own past: that he stuttered as a child. Thus, as occurs on a grander scale in the relationship between Malcolm and Cole, the child's association with a spectral realm becomes conflated with the reemergence of a painful past from the depths of the adult's psyche, in a simultaneous disruption to both linear historical metanarratives and to the image of a stable and superior adult self - the apparent 'end goal' of the teleological process of growing up. The teacher's repressed 'inner child' returns with a vengeance as Cole repeatedly shouts 'Stuttering Stanley!', and Mr. Cunningham starts to stutter helplessly as all the other children watch on. The stutter breaks through and erodes the teacher's imperious facade. Like trauma itself, the stutter functions as an uncontrollable blockage and repetition that metaphorizes the uncanny reemergence of 'Stuttering Stanley', and diminishes Mr. Cunningham's ability to communicate effectively as an adult. Through his parallel destabilization of the neat temporal borders of history, the adult self, and of the adult's rational chain 
of signification, Cole is again aligned with the hidden abject within the adult, a repressed psychic realm equated with the adult's traumatized inner child.

\section{Cole and the Viewer's Trauma}

This irruption of a fissure in the wholeness and coherence of the adult's subjective reality is echoed by the viewer's own experience of THE SIXTH SENSE, if the twist narrative functions as intended. While on first viewing we are led to believe that we are watching a straightforward ghost story about a paternalistic psychologist helping a young child with an uncanny 'gift', we learn in the final scene that there has been an underlying double reality haunting the surface narrative of the film all along. Central to this twist is the recognition that Cole was always aware of this second reality, but has been concealing it from Malcolm. Thus, in an amplification of the classroom scene, the film's final revelation subverts the balance of power and knowledge between the child and the adult.

Erlend Lavik discusses THE SIXTH SENSE and other twist films in terms of a particular relationship between the syuzhet (the presentation and arrangement of audiovisual information) and the fabula (the whole story/ fictional world that this syuzhet eventually creates). He explains that in such films there is a:

doubling of the syuzhet, where we are led to construct a fabula that initially seems quite straightforward until suddenly a new piece of information is introduced that subverts (or decentres) the fictional world we have created. We come to realize the presence of another fabula running parallel to the first one but 'beneath' it, hidden from view. $(2006,56)$

The revelation that Malcolm has been a ghost all along shatters the fabula that audiences are led to construct upon first viewing the film, a process that parallels Cole's own ability to overthrow accepted realities throughout the film. The impression that an eerie, previously hidden double of conventional experience has bubbled to the surface of our perceptions represents a central facet of the uncanny, enforcing a potent experience of cinematic déjà $v u$. This is of course heightened by the fact that the viewer is compelled to rewatch the film in order to construct the second, and more accurate, fabula. In doing so, the viewer experiences a 'narrative bifurcation whereby we come to notice how traces of the correct fabula were actually available to us the first time' (Lavik, 2006, 59). 
This process of rewatching the film in an attempt to see both how the director left clues to this hidden fabula and to solve the riddles of Malcolm's existence reveals the viewer's own compulsion to repeat, as we are impelled to refocus our detective work around Malcolm in a subversion of Malcolm's analysis of Cole: the exposure of the child's secret thus turns a mirror upon the protagonist and audience that exposes a fracture in the adult's subjectivity. Discussing the structure of the detective story echoed across ghost narratives - Slavoj Žižek explains that 'the detective's role is $[. .$.$] to demonstrate how "the impossible is possible" [...] that is, to$ resymbolize the traumatic shock, to integrate it into symbolic reality' $(1992,58)$. On first viewing, this process is realized through Malcolm's quest to comprehend Cole's secrets, and then to situate the abject ghosts he sees into a secure symbolic framework whereby they 'disappear' if Cole comprehends their requests and subsequently fulfils them. Yet, with the revelation that Malcolm is one of these ghosts, the coherence of the film's symbolic framework is displaced. The compulsion to rewatch the film in order to better understand how Malcolm experiences time, consciousness, and communication (or lack thereof) represents a secondary attempt to impose stable meaning upon the abject space where meaning collapses beyond rational, adult-centric discourse: to clarify the symbolic framework of the diegesis and Malcolm's position within it. However there are many irremediable gaps in Malcolm's experiences - we do not actually see him trying to pay for the bus, or meeting Cole's mother for the first time, or pondering the fact that no other human being has spoken to him for six months apart from Cole - fissures that repeat viewings cannot repair. As we shall see, a similar obstruction to tidy narrative resolution occurs in the final scene of STIR of ECHOES, a fracture again exposed by the child's uncanny knowledge.

\section{'In every mind there is a door that should never be opened': STIR OF ECHOES}

STIR OF ECHOES revolves around the Witzky family - Tom, Maggie, and their young son Jake - and follows Tom's quest to unravel the secrets behind a mysterious female ghost he begins to see after being hypnotized at a party. This ghost is Samantha, a teenage girl who was murdered accidentally in a rape attempt by two young men who live in the Witzky's neighbourhood, and whose body was hidden in the Witzky's basement before they moved in. While Tom only becomes reacquainted with his latent ability to see 
beyond the limits of linear time after being hypnotized, young Jake possesses supernatural insight that greatly exceeds the perceptual capabilities of his father. Thus, while it is the adult's quest that the film follows, it is once again the child who holds the secrets that must be unravelled to resolve the mysteries of the narrative. Jake becomes implicated in a process of uncanny doubling and déjà vu associated with both his ability to perceive multiple layers of temporality and his function as the receptacle for the enigmas of his father's own mind.

The 'stir of echoes' of the film's title is metonymized by a song that repeatedly reoccurs throughout the film in different forms. The song is associated with Jake, as he hums it in a number of scenes and, at one point, helps his father pick out the correct tabs for it on the guitar. The film opens with this song, as Jake's voice is heard haltingly humming fragments of it as the opening titles appear against a black screen. It sounds like an amalgam of melodies, with momentary hints of 'Ode to Joy' and an array of children's nursery rhymes, while never being truly discernible as any particular tune. Arising out of the black depths of the opening titles without any accompanying visuals, the cuteness and innocence of the song is threateningly undermined as the viewer is invited to question its placement in the opening of a horror movie, an effect heightened by the fragmentary tune's resistance to contextualization. In fact, it is difficult even to determine whether it is in a major or minor key, emphasizing the tune's troubling of childhood sweetness. As Stan Link explains in his discussion of children's musical performances in the diegetic world of horror films, 'at once an ingenuous and dis-ingenuous performance, in [horror films] the sound of innocence frequently announces its own end' $(2010,44)$.

Thus, the uncanny child's performance of innocence evokes suspicions about what grisly knowledge he conceals beneath his cute affectations, constructing the appearance of innocence and cuteness as merely a naive (or wishful) misunderstanding of the child on the part of the adult. In STIR OF Echoes, the vague song of the opening represents the first of the hieroglyphs that the uncanny child issues, a riddle that the viewer and adult protagonist are tasked with decoding. The song becomes the key to uncovering the dark secret of the film. Far from being an innocent nursery rhyme, it is revealed in the film's climactic scene to be the Rolling Stones's 'Paint it Black' (1966), a cover version of which (performed by Gob, 1998) was played loudly on a stereo by the young men who killed Samantha in an attempt to drown out her screams while they raped her.Jake's humming thus functions as a signifier of the child's impossible knowledge of this violent scene. The lyrics to 'Paint it Black' underscore the child's ability to perceive 
the darkest, suppressed components of adult society with lines such as 'It's not easy facing up when your whole world is black.'

That Jake hums this song in the opening seconds of the film renders his knowledge particularly uncanny when the song's context is finally revealed at the climax. Jake's humming taunts the viewer with the fact that he possessed the grim knowledge needed to solve the film's mystery all along. As if to reinforce this, when Tom finally 'witnesses' Samantha's murder after locating her corpse - experiencing a vision aided by his recently rediscovered clairvoyancy - Jake's voice becomes audible humming along with the music accompanying her death, even though he is not physically present in the scene. The child's humming gradually overcomes the diegetic music on the CD player so that, in Tom's vision, Samantha's final breaths are accompanied solely by Jake's humming of the song. Thus, in the construction of this scene, Jake is vaguely positioned as complicit in the covering up of the girl's murder by withholding this secret. This scene functions as a powerful moment of uncanny déjà vu both for the viewer and Tom, who, at multiple points throughout the film, has cried out in frustration (perhaps in alignment with the viewer) 'Why do I know this song?' and 'What is that song!' in response to Jake's humming. As it finally becomes clear what the song is and why it is significant, déjà vu's vague threats of a double reality haunting that which is visible to us finally become realized. This final and most sinister rendition of Jake's humming also unveils the child's function as an embodiment in the present of the muffled echoes of the past.

\section{'You're awake now, Daddy': Child/Adult Psyches}

The supernatural knowledge and abilities Tom comes to access are aligned with the deepest recesses of his own psyche, as his insight (re)emerges upon being hypnotized. Promotional taglines for the film read 'in every mind there is a door which should never be opened'. In the film, hypnotist Lisa makes the connection even more overt, explaining to Tom that when she hypnotized him, she 'opened a door [...] it releases repressed memories and latent abilities, whatever you got back there'. Thus, STIR OF ECHOEs makes explicit the symbiotic relationship between the uncanny surfacing of ghosts from the past and the reemergence of the adult's repressed mental content: for instance, when Tom is hypnotized, he is simultaneously reacquainted with his supernatural extrasensory perception, and his repressed childhood memories of being bullied. Once again, the child is the nexus of these traumatic resurfacings. Because Tom only sees terrifying and fractured glimpses of the supernatural, he is forced to interrogate Jake in order to comprehend 
his new insight. Thus, as in The Sixth Sense, the adult protagonist must analyse and excavate the enigmatic riddles of the child in order to resolve tensions and complexes within his own mind (and, subsequently, within the film's narrative).

In this way, Jake functions as a nebulous reoccurrence of Tom's own childhood, embodying Tom's regression into a hidden component of his mind previously inaccessible to him in adulthood. Jake's humming of 'Paint it Black' reinforces his function as a symbolic stage for the adult's submerged memories and psychic abilities. Tom is maddened by his faint memory of the song and his inability to pin it down or contextualize it (at one point, he frantically digs through his CD collection in an attempt to locate it), and his annoyed questioning of 'Why do I know that song?' simultaneously seems to be addressed both inwardly and to Jake.

Tom quickly becomes aware that his son is the key to understanding the unleashed secrets of his mind. When he first encounters the ghostly Samantha after the hypnosis 'opens' his mind, he discovers Jake has been watching him silently from the top of the stairs. 'You're awake now, Daddy', Jake tells his father as he descends the staircase. The child then touches Tom's forehead, and, while giving him a knowing look, advises 'don't be afraid of it, Daddy'. In STIR OF ECHOEs, this conflation of the adult's repressed 'inner child' with latent supernatural powers disrupts nostalgia for the innocent state of childhood, irretrievable as soon as one is an adult. When Tom's mind becomes 'opened', instead of being reacquainted with a world of naïve innocence, he (re)experiences childhood as the locus of fears, urges, and memories he had displaced in adulthood - recalling Kincaid's characterization of the inner child as a 'realm of sorrow and pain' (1998, 251) - an extension of the conceptual links drawn in uncanny child films of the early 1980 s.

Initially, it appears as though the film's quest is resolved once Tom finally uncovers Samantha's body and discovers the truth behind her murder: the ghost's secret has been revealed and those responsible have been punished, releasing the ghost Samantha from her basement tomb. Furthermore, it appears that Tom's visions have subsided, and the Witzky family have decided to move away from what has now been exposed as a corrupt neighbourhood. As we witness Tom and Maggie packing up a moving truck, the two finally seem at peace. However, in the final scene, as the family drives to their new home, the comfortable resolution of the narrative is undermined, as in all of the films covered in Section One. Tom glances at his son in the rearview mirror, and we see Jake sitting in the backseat. He is staring out the window as house after house flashes past, all red brick two-storey dwellings that 
appear ceaselessly identical in their imaging of the façade of comforting suburbia. As Jake watches the procession of houses, a cacophony of whispers overtakes the soundtrack. The whispers become increasingly desperate and vociferous, yet the words themselves remain largely indistinguishable - a carnivalesque evocation of traumatic experience. Though no single voice is particularly comprehensible in this polyphony, it is clear they are all desperate to be heard, as the whispers crescendo until they sound more like an abject babble of moans and groans. In the film's final shot, Jake slowly and calmly covers his ears in a futile attempt to shut these voices out.

Thus, the viewer is confronted with the awareness that no matter where the Witzky's move, the child will be endlessly inundated with the terrible secrets of aggrieved ghosts. It becomes clear that Jake and his father could never possibly resolve the demands of all these unquiet spirits: the process is overwhelmingly never-ending, and points to the corruption underlying adult society as a whole. As the film cuts to black, a voice before the credits commence sings the childish chant 'Na na na na na na': a taunt to the viewer that our time spent invested in Tom's quest to reinstate the delineation between past and present, the ghosts and the living, suppressed violence and domestic bliss has not successfully restored stable borders of meaning and existence. Jake is the embodiment of this lingering symbolic rupture.

\section{'It's not the house that's haunted. It's your son': Approaching The Further in Insidious}

Released ten years after Stir of Echoes and The SiXth Sense, Insidious (2010) contains the reverberations of each in its plot about a male protagonist (father Josh) being 'reacquainted' with a repressed part of his own being through uncovering his son Dalton's secrets. Insidious also self-reflexively recalls the three 1980 s films discussed in Chapter One: we are confronted with eerie female twins who look like grown-up versions of The Grady twins in The SHINING, a séance scene that closely follows a key set-piece of THE ChANGELING, and a story of a child lost in a spiritual realm that is a direct echo of that in Poltergeist (complete with an eccentric female psychic accompanied by two young male paranormal investigators armed with all manner of quirky equipment). Following the millennial wave of globally successful uncanny child films, Insidious indicates that the uncanny child trope started to become self-consciously augmented at the close of the 21st century's first decade. 
Early in the film, Dalton falls into a mysterious coma seemingly after tumbling from the stairs in the family home's attic. (However, the ominous creaking noises emanating from a dark corner of the attic suggest that the source of this noise is really behind the coma). Dalton's coma becomes the riddle that the adult protagonists, Dalton's mother Renai and his father Josh, must solve, as Dalton's body itself becomes a hieroglyph. As his parents take Dalton to the hospital, the child is positioned as an oddity to be scrutinized and decoded by the medical gaze in a similar manner to Danny in THE SHINING. As the doctor in INSIDIOUs proclaims, 'I've never seen anything like it', a horror film cliché which signals that Dalton's condition is not bound by the normal order and thus cannot be resolved through medical treatment.

The next scene is prefaced by the title ' 3 Months Later', and we learn that Dalton is still in the limbo-world of the coma and has been moved out of the hospital and back to the family home. Thus, while the everyday rhythms of time passing continue around him, Dalton remains fixed in a state of frozen a-temporality: a particularly unsettling state for a being defined according to the teleological process of growing up. The monstrousness of Dalton's bodily stasis is fetishized throughout the film. As Dalton is kept alive by feeding tubes and a life-support machine, his presence in the adult's everyday life is tied to the technological. His life is signalled by the rhythmic beeping of his life-support machine, which seems to taunt the neat chronological progression of analogous rhythms - like the large grandfather clock that stands outside his room - through marking a state of perpetual stasis. Notably, the 'ghosts' that Dalton's body invites into the family home, themselves abject images of frozen time in their stiff, doll-like aspects and aberrant movements, often appear alongside the grandfather clock as if mocking its obdurate, chronological rhythms.

Stuck in a mysterious coma, Dalton, echoing Carol Anne of Poltergeist, becomes a contradictory incarnation of the 'lost child': he is physically present, yet his mind and soul inhabit some impenetrable elsewhere to which his parents have no access. The fraught attempt to comprehend the essence of the child - that unknowable component of his otherness that threatens the adult's symbolic reality - is thus realized in this film via the quest to locate his soul. It is later explained by the psychic, Elise, that Dalton is a talented 'astral projector' and his soul has become lost in a realm of unquiet ghosts called 'The Further'. The name The Further hints at the elusive qualities of childhood in relation to the adult's psyche: it is a realm which is always just further than the adult's perceptions can reach. Elise explains that The Further is 'a world far beyond our own, yet all around us. A place without time as we know it.' Like adulthood's 'inner 
child', The Further constantly underlies the adult's present consciousness yet is simultaneously eternally beyond our grasp.

Dalton's comatose body is the portal through which signs of this place intrude upon the present. He thus displaces the process at the core of the traditional ghost story whereby the spectral world erupts at a particular site, associated with an unacknowledged trauma tied to that location, before disappearing once the traumas of the ghosts are resolved. All the films previously discussed in Section One are comprised of this structure, even though it is problematized in each by the child's eerie obstruction to cathartic narrative resolution. The deconstruction of this structure is openly dramatized in Insidious by the twist midway through (telegraphed in trailers and promotional material): as Elise explains, 'It's not the house that's haunted. It's your son.' The realm of the supernaturally charged unconscious that the child embodies and inhabits - this place where meaning collapses - cannot be escaped geographically. It is always there, just beyond the adult's view. Dalton exists as the adult's inescapable rem(a) inder of this realm.

Dalton's embodiment of the threatening return of the repressed is realized overtly through his entwinement with his father, Josh. Two-thirds into the film, we learn that Josh was also a talented astral projector as a child. As a result, throughout his childhood he was relentlessly pursued by the ghost of a decrepit old woman - the memory of which he has long since repressed. The impending reemergence of Josh's childhood memories is suggested by recurring grainy, black-and-white shots of Josh as a child sleeping as the camera floats upwards and towards his bedroom window. In fact, the film opens with such a shot, signalling that the father's own return to his buried past is a central quest of the film, albeit submerged until the third act. Josh's concealed inner child is evoked by a box of childhood photographs his mother has kept hidden from him throughout his adulthood. As Josh discovers when his mother shows him these photographs, the old woman's ghost appears in every photograph of Josh as a child.

The photographs thus literalize the uncanny resurfacing of Josh's inner child. A scene in which he and his wife Renai nervously pore over these longforgotten childhood photos reflects Damien Sutton's Deleuzian discussion of photography: 'like memory, photography constitutes a past as an other, and as with memory, we enter the photograph's "pastness" in order to make sense of the collapse of the "then" and "now" that it represents' (emphasis in original, 2009, 54). The faded tones of the photographs and their depiction of Josh as a child staring knowingly back at himself as an adult - an image of himself back 'then' casting an immobile yet penetrating gaze at 
Josh as he is 'now' - presages the imminent collision of these seemingly distinct realms. The 'then' of Josh's childhood and the 'now' of adulthood are bound to each other - Josh is, after all, the same person as the boy in the photographs - yet they are also impenetrably distant from each other. As Josh stares at the photographs and Renai asks if he remembers what is depicted in them, Josh blankly shakes his head and mutters 'No. I don't.' The ghostly figure in the photographs enhances the threatening otherness represented by his inaccessible former self. The ghost initially appears as an ambiguous distortion of the image, gradually becoming more visible in each successive photograph Josh looks at. Her gaze, while literally veiled, seems to be simultaneously directed towards both the child-Josh within the photograph and outwards towards the adult-Josh looking at the photographs. The ghost's gaze thus penetrates beyond the 'then' and 'now' border, auguring a simultaneous collapse in temporal and subjective boundaries.

The Further spatially represents adulthood's inner child. Dalton's soul has been trapped within The Further throughout the film, and, as we see when Josh first enters this shadowy dimension at the film's climax and comes face-to-face with himself as a child, it is also in these murky black depths that Josh's inner child resides. The Further is characterized by indeterminate spaces with no borders: Josh wanders through its inky gloom until he reaches the façade of the former family house, in which Dalton fell into the coma in the film's early scenes. In The Further version of the house, the dark, cavernous spaces and labyrinthine structure do not emit a direct reflection of the house with which we have already become familiar, although the structure and positioning of the staircase and rooms are the same. This is particularly apparent in the attic in which Dalton is trapped - a small, cramped space in the opening of the film, it now appears impossibly wide and high, a red-hued cavern with no clear borders. The house as it appears in The Further is an image of the unhomely par excellence, the familiar rooms now appearing as capacious spaces littered with exaggerated realizations of Dalton's childhood drawings, such as an elaborate rocking horse. Thus, the house reflects a dreamlike image of the past childhood realm with which Josh has just become reacquainted: a precise conflation of the adult's unconscious, his childhood past, and the uncanny child character external to him - his son - who exists as the crucible for both realms. Reinforcing The Further's existence at the interface of Josh's and Dalton's psyches, Josh's physical body is actually sleeping as he ventures into The Further - his journey is punctuated by shots that draw us back into the diegetic present in which his sleeping 
body jerks and jolts - suggesting that Josh has gained access to The Further through a process of hypnosis that peels back the conscious layers of his psyche. This is also a precise instance of the 'slackening of the sensorymotor connections' (Deleuze, 1997a, 3), which invites the emergence of the cinematic time-image.

The Further's status as an unconscious zone of pastness beyond progressive adult clock-time is highlighted by the different layers of the past which coexist within the same space. The space thus functions in a similar way to The Overlook hotel in THE SHINING. Dimly lit Elizabethanstyle paintings adorn the walls, while a child dressed in Victorian garb runs amok, and a doll-like 1950s-era family sit frozen in a neighbouring room. Appearing like mannequins with caricature-like grins, this family seem to stem from a stereotypical child's drawing like those that adorn Dalton's bedroom walls. Extending the personal implications of the child's uncanniness into the realm of the sociocultural, just as the innocence of Dalton's drawings appears menacingly disingenuous, the mannequin-esque 1950s family disrupt cultural nostalgia for an innocent lost past in their maniacal exaggeration of a traditional nuclear family. Furthermore, they monstrously empower the temporal disjunction of The Further. This is aesthetically rendered through these beings' defiance of coherent sensory-motor connections and bodily movement: they evoke in threatening form Deleuze's 'emancipation of time, which ensures the rule of impossible continuity and aberrant movement' (1997a, 39). When Josh desperately asks one of the doll-like female twins about the whereabouts of Dalton, the camera closes in on his face, and although he does not break eye contact with the apparition, she suddenly appears in the room behind him. Similarly, as Josh backs away from the family in horror, they remain fixed in their positions, only to suddenly appear standing before him without moving through a jump cut. The abject leers that appear on their faces also emerge through a jump cut, a violation of linear continuity in which the facial movement required to change from one expression to the other is omitted (Fig. 4).

The film as a whole eventually becomes consumed by The Further's threats to homogenous, linear clock-time. When Josh and Dalton finally escape The Further and make it back to the present, the family seem to be happily reunited and the spectral realm displaced. However, in the film's final moments, psychic Elise becomes suspicious of Josh and takes a photograph of him (as photography again becomes the intercessor between temporal and subjective realms). The viewer is not shown this photograph, but Elise is clearly terrified by what she sees. Josh becomes so enraged that 


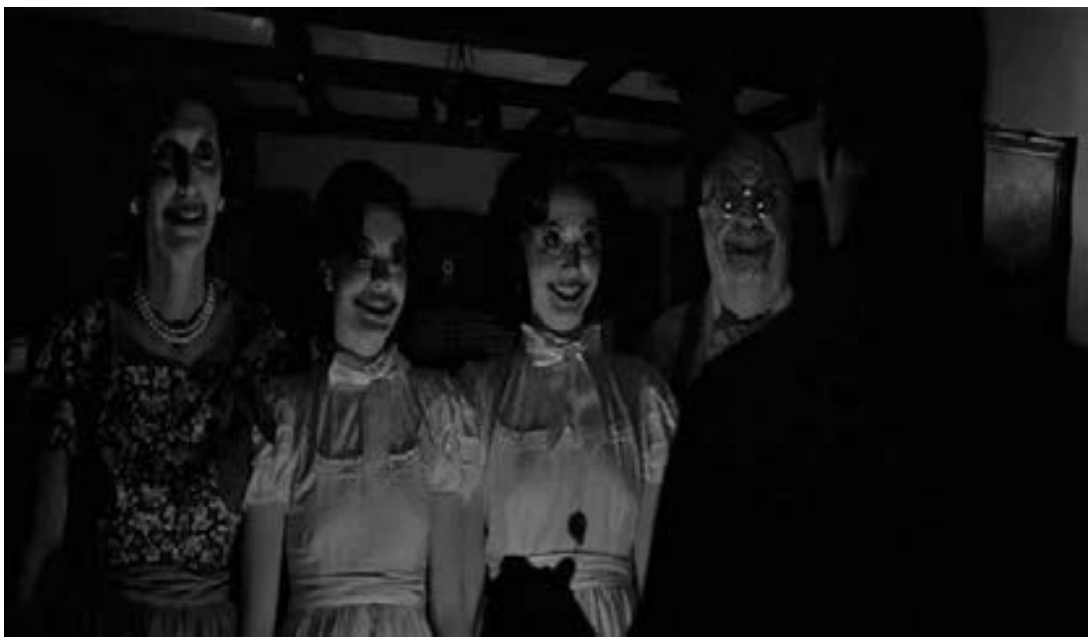

Figure 4. The doll-like 1950s-era family leer at Josh in The Further (INSIDIOUS).

Elise has taken his photograph without permission that he strangles her, leaving her face frozen in an expression of fear that aligns her with the immobile postures of the beings in The Further. When Renai enters the room and picks up the camera she is able to see the frightening vision that the photograph revealed to Elise: the ghostly old woman who haunted Josh's childhood has taken over Josh's adult self, as an image of the ghost's visage is superimposed upon his own face. Josh has been consumed by the childhood traumas - signified by the ghost woman - that were previously locked inside his repressed inner child.

The film ends abruptly on a close-up of Renai's terrified face as she turns around to face Josh, before cutting to an extended black screen. From this black screen, the film's title emerges, identical in appearance to that which opened the film and accompanied by the same dissonant violin shrieks. Prior to this, the movement in the close-up on Renai's face slows down to the point that the shot almost becomes a freeze-frame. This, coupled with the cut to black and sudden reversion to the film's first few seconds, enunciates with finality the threat to chronological continuity evoked initially by the child's coma. In the final moments, the film seems to become 'stuck' before looping back to its opening moments. Actualizing the breakdown in linear time threatened by the coma-frozen Dalton, The Further, the ghost from Josh's childhood past, and the photographs throughout the film - and the subsequent dissolution between the borders of 'then' and 'now' - the film's own chronological narrative progression abruptly comes undone in the final shot. 


\section{Conclusion}

While the narratives of each of these films attempt on a surface level to resolve the enigmas of their uncanny children, these characters somehow resist functioning as riddles that can be solved by the adult protagonists and viewers, their vaguely threatening otherness preserved just outside the bounds of a secure symbolic framework. In more overt and precise ways than in the 1980s films, in The SiXTh SenSe, Stir of Echoes, and Insidious, the uncanny child character reawakens the adult's traumatized inner child, suggesting a tangled relationship between child and adult subjects that in turn unsettles the boundaries between past and present. Drawing back to Freud's discussion of an imagined Rome in which all developments of the past stand alongside those most recent - outlined in Chapter One - Freud remarks that:

if we wish to represent a historical sequence in spatial terms, we can do so only by juxtaposition in space, for the same space cannot accommodate two different things. Our attempt to do otherwise [...] show[s] how far we are from being able to illustrate the peculiarities of mental life by visual means. $(2002,9)$

These ambiguously eerie children actualize such spatio-temporal 'peculiarities', imaging the process in which, to reiterate Stockton, 'past and present ego-structures [are put] side-by-side, almost cubistically, in lateral spread' $(2009,14)$.

Thus, these films suggest the extent to which contemporary American understandings of childhood continue to entangle the child with Freudinflected mythologies of the adult's unconscious. Yet, by self-reflexively augmenting this association, these films also imply that the child draws both a disruptive and constructive power from this seemingly adult-centric paradigm. These late 2oth- and early 21st-century American films start to consider the implications of the uncanny child's empowerment of traumatic temporalities that strain against adult-centric models of progressive chronological time - a particularly potent process amidst the uncertainties of millennial transition, as is further explored in Section Four. In their disruptions to linear narrative time and concomitant exposure of the illusory permanence and solidity of adult subjectivity, these uncanny children reconceptualize teleological conceptions of growth that place adulthood as a secure, complete end point to childhood's empty, naïve origins. In the next section discussing Spanish horror films, I demonstrate how the uncanny 
child also unhinges historical chronology in frightening but potentially liberating ways, as the child's spectral insight is extended into the realm of collective memory and national identity.

\section{Works Cited}

Ariès, Philippe. Centuries of Childhood: A Social History of Family Life. Trans. Robert Baldick. New York: Alfred A. Knopf, 1962. Print.

Caruth, Cathy. Unclaimed Experience: Trauma, Narrative, and History. Baltimore: The John Hopkins University Press, 1996. Print.

Deleuze, Gilles. Cinema 2: The Time Image. 1985. Trans. Hugh Tomlinson and Robert Galeta. Minneapolis: The University of Minnesota Press, 1997a. Print.

Freud, Sigmund. Civilization and Its Discontents. 1930. Trans. David McLintock. New York: Penguin Books, 2002. Print.

Hantke, Steffen, ed. 'They Don't Make 'Em Like They Used To: On the Rhetoric of Crisis and the Current State of American Horror Cinema.' American Horror Film: The Genre at the Turn of the Millennium. Jackson: The University Press of Mississippi, 2010. vii-xxxii. Print.

Houtman, Carol. 'Questions of Unreliable Narration in The SIXTH SENSE.' Scope: An Online Journal of Film Studies Nov. 2004: n.p. Web. 30 Sep. 2014.

Jenkins, Philip. Moral Panic: Changing Concepts of the Child Molester in Modern America. New Haven: Yale University Press, 1998. Print.

Kendrick, James. 'A Return to the Graveyard: Notes on the Spiritual Horror Film.' American Horror Film: The Genre at the Turn of the Millennium. Ed. Steffen Hantke. Jackson: The University Press of Mississippi, 2010. 142-159. Print.

Kincaid, James. Erotic Innocence: The Culture of Child Molesting. Durham: Duke University Press, 1998. Print.

La Caze, Marguerite. 'The Mourning of Loss in The SiXth Sense.' PostScript:Essays in Film and the Humanities 21.3 (2002):111-121. Web. 30 Sep. 2014.

Lavik, Erlend. 'Narrative Structure in The Sixth Sense: A New Twist in Twist Movies?' The Velvet Light Trap 58 (2006): 55-64. Project Muse. Web. 30 Sep. 2014.

Link, Stan. 'The Monster and the Music Box: Children and the Soundtrack to Horror.' Music in the Horror Film: Listening to Fear. Ed. Neil Lerner. New York: Routledge, 2010. 38-54. Print.

Natoli, Joseph. Speeding to the Millennium: Film and Culture, 1993-1995. Albany: State University of New York Press, 1998. Print.

Stockton, Kathryn Bond. The Queer Child, or Growing Sideways in the Twentieth Century. Durham: Duke University Press, 2009. Print.

Sutton, Damien. Photography, Cinema, Memory: The Crystal Image of Time. Minneapolis: The University of Minnesota Press, 2009. Print. 
Thrailkill, Jane F. 'Sigmund Freud, Pedophile Priests, and Shyamalan's Filmic Fairy Tale (The Sixth Sense).' Critical Approaches to the Films of M. Night Shyamalan: Spoiler Warnings. Ed. Jeffrey Weinstock. New York: Palgrave Macmillan, 2010. 139-158. Print.

Underwood, Ted. 'Romantic Historicism and the Afterlife.' PMLA. 117.2 (2002): 237-251. JSTOR Arts and Sciences III. Web. 30 Sep. 2014.

Walsh, Fintan. Male Trouble: Masculinity and the Performance of Crisis. New York: Palgrave Macmillan, 2010. Print.

Warner, Marina. Managing Monsters: Six Myths of Our Time. London: Vintage, 1994. Print.

Weinstock, Jeffrey, ed. 'Introduction: The Spectral Turn.' Spectral America:Phantoms and the National Imagination. Madison: University of Wisconsin Press, 2004. 3-17. Print.

Žižek, Slavoj. Looking Awry: An Introduction to Jacques Lacan Through Popular Culture. Cambridge: MIT Press, 1992. Print.

\section{Filmography}

The Changeling. Dir. Peter Medak. 1980. HBO Home Video, 2005. DVD.

EXISTenZ. Dir. David Cronenberg. Alliance Atlantis Communications, 1999. Film. Eyes Wide Shut. Dir. Stanley Kubrick. Warner Bros., 1999. Film.

FALLEN. Dir. Gregory Hoblit. Atlas Entertainment, 1999. Film.

Fight Club. Dir. David Fincher. Fox 2000 Pictures, 1999. Film.

The Gift. Dir. Sam Raimi. Lakeshore Entertainment, 200o. Film.

The Haunting. Dir. Jan de Bont. DreamWorks SKG, 1999. Film.

House on Haunted Hill. Dir. William Malone. Dark Castle Entertainment, 1999. Film.

Insidious. Dir. James Wan. 2010. Icon Film Distribution, 2011. Blu-ray DVD.

Jaws. Dir. Steven Spielberg. Universal Pictures, 1975. Film.

Magnolia. Dir. Paul Thomas Anderson. New Line Cinema, 1999. Film.

The Matrix. Dir. Lily and Lana Wachowski. Warner Bros., 1999. Film.

Poltergeist. Dir. Tobe Hooper. 1982. Warner Home Video, 2008. DVD.

Scared Silent: Ending and Exposing Child Abuse. Dir. Melissa Jo Peltier, Perf. Oprah Winfrey. Arnold Shapiro Productions, 1992. TV Movie.

The Shining. Dir. Stanley Kubrick. 1980. Warner Bros. Entertainment Inc., 2007. Blu-ray DVD.

The SiXth Sense. Dir. M. Night Shyamalan. 1999. Hollywood Pictures Home Entertainment, 2000. DVD.

Star Wars Episode I: The Phantom Menace. Dir. George Lucas. Lucasfilm, 1999. Film. 
Stigmata. Dir. Rupert Wainwright. Metro-Goldwyn Myer, 1999. Film.

StIR of EchoEs. Dir. David Koepp. 1999. Lionsgate Home Entertainment, 200o. DVD. Thi13een Ghosts. Dir. Steve Beck. Warner Bros, 2001. Film.

The Thirteenth Floor. Dir. Josef Rusnak. Columbia Pictures, 1999. Film.

What Lies Beneath. Dir. Robert Zemeckis. DreamWorks SKG, 20oo. Film.

\section{Music}

Gob. 'Paint it Black' (Rolling Stones Cover). Comp. Mick Jagger and Keith Richards. How Far Shallow Takes You. Nuttwerk America, 1998. CD.

The Rolling Stones. 'Paint it Black.' Comp. Mick Jagger and Keith Richards. Aftermath. ABKCO Records, 2002. CD. 



\section{Section Two}

Insects Trapped in Amber:

The Uncanny Child in Spanish Horror Film 



\title{
3. The Child and Spanish Historical Trauma
}

\begin{abstract}
Chapter Three establishes the cultural context for the late 1990s/early 2000s wave of Spanish horror films featuring uncanny children. The chapter demonstrates how childhood became entangled with a tightly controlled narrative of national progress in post-Civil War Spain through the autocratic Franco regime. In the heavily censored film industry of Franco's 36-year reign (1939-1975), the cinematic child became a conceptual tool of Francoist propaganda, positing a sense of continuity between pre-Republican Imperialist Spain and postwar Franco fascism. Thus, the child came to hold a particularly significant but precarious ideological role in late 2oth-century Spanish cinema. This context positions the uncanny child of millennial Spanish cinema as an important tool of collective memory that challenges Spain's previously dominant historical narrative.
\end{abstract}

Keywords: Childhood, Spanish Civil War, Collective memory, Spanish cinema, Franco, History

In the American films analysed in the previous section, the child is embroiled in the imperilled selfhood of adult protagonists, unmasking an adult-centric preoccupation with childhood as symbolic of the adult's past and unconscious. In turn, the children in these films become bound up with the adult protagonist's own repressed memories, troubling the solid distinctions between present and past, self and other in a process that mirrors Freudian models of trauma. The uncanny child also became a central recurring feature in Spanish horror films of the millennial turn. These gothic supernatural films ${ }^{1}$ are similarly fixated with the child's paradoxically constituted other-

1 The Spanish uncanny child films analysed in this book belong to a fertile mode of postmillennial Spanish filmmaking that Xavier Aldana Reyes (2017) defines as part of a continuing 'Spanish Gothic' tradition.

Balanzategui, J., The Uncanny Child in Transnational Cinema: Ghosts of Futurity at the Turn of the Twenty-First Century, Amsterdam University Press, 2018.

DOI: 10.5117/9789462986510/CHO3 
ness and association with a supernatural, traumatic dimension. Instead of embodying the inner child of the individual adult psyche, however, the uncanny child is often explicitly intertwined with historical trauma in the Spanish films. In these films, signs of the child's Freudian entanglement with the past traumas of adulthood are evident - after all, as the previous section indicates, this mythology has infiltrated popular culture on a broad scale. However, the thematic emphasis in these films is no longer the child's disruptions to the present self-identity of adult protagonists. In these films, the child's spectral empowerment of suppressed traumas allows a reconsideration of entrenched teleological narratives not only of growing up, but of national progress and accepted history.

Thus, rather than disturbing individual selfhood, the children of millennial Spanish horror embody the repressed spectres of the collective cultural memory, and unravel the constrictive ligatures of national identity that previously worked to obscure the cultural wounds of post-Civil War Spanish society. Helen Graham and Jo Labanyi explain that:

The history of twentieth-century Spanish culture is - as the Civil War made particularly apparent - the history of a struggle between different ways of interpreting the world, and different ways of interpreting Spanish society in particular: a battle of meanings which shaped individual and collective identities, and affected the material conditions of individual and collective existence. $(1995,6)$

For reasons discussed throughout this chapter, from the 1940s onwards, Spanish cinema has been bound up with the projection and configuration of the national narrative, and thus tied to the battle of meanings Graham and Labanyi describe in intricate ways. In particular, films in the decades following the war - many of which functioned as fascist propaganda - often anchored their ideological projects to the child.

As this chapter demonstrates, in the postwar period cultural mythologies of the child became deeply entwined with Francoist trajectories of national progress that worked to suppress the cultural traumas of the Civil War (1936-1939) and dictatorship (1939-1975). Yet this overdrawn sociopolitical function positions the child as a site of resistance in dissident horror and art films that emerged towards the end of Franco's regime, a crucible for the unacknowledged cultural tensions that threaten Francoist ideals of smooth national progress. Subsequently, the following chapter consists of a close analysis of The DeviL's BACKBone (Guillermo del Toro, 2001), THe NAMELESS (Jaume Balageuró, 1999), and The OrPhANAGE (Juan Antonio Bayona, 2007), 
metonymic examples of millennial Spanish horror films featuring uncanny children that are particularly precise and forceful in their interweaving of the aesthetics of trauma with the uncanny child. However, these films are by no means the only examples of recent Spanish horror films featuring uncanny children. ${ }^{2}$ In each of these films, the uncanny child invokes the (re)emergence of trauma in a particularly powerful manner in a Spanish context, as a result of childhood's tethering to narratives of progress that attempt to cover over or figure a break from unsavoury recent pasts.

In Spain, this relentless looking forward at the expense of adequately assimilating the past has become a defining condition of modernity, both in the period directly following the Civil War and again after the long-anticipated collapse of the Franco dictatorship after his death on 20 November 1975 . Particularly in the decades following the Civil War, the child became knotted with Francoist processes of national mythmaking, precisely instituting the function outlined by Edelman in which the child 'remains the perpetual horizon of every acknowledged politics, the fantasmatic beneficiary of every political intervention' $(2004,3)$. The uncanny child of late 2oth- and early 21st-century Spanish horror troubles this overdetermined Francoist function by subverting the child's sociocultural position as incubator for the future, instead exposing the extent to which suppressed pasts coexist with the present in ways that threaten notions of progress or 'moving on'. As will be explored in Chapter Four, through the child, these films play out in sociopolitical terms the dreadful belated recognition at the core of traumatic experience. Enhancing the unsettling affects of this device, the broad trajectories of postwar Spanish cinema are themselves characterized by the same temporal belatedness that suffuses the diegesis of these millennial horror films: the traumas of the Civil War were not played out

2 Other child-centred Spanish horror films of the early 21st century include THE DARK Hour (Elio Quiroga, 2006), ShIver (Isidro Ortiz, 2008), and PAInless (Juan Carlos Medina, 2012). Another very similar film is PAN'S LABYRINTH (Guillermo del Toro, 2006), a particularly noticeable omission from this chapter, for it has been one of the most successful Spanish exports of the 21st century, having won three Academy Awards and having grossed $\$ 83$ million, the highest ever for a Spanish-language film. Yet while this film indeed associates the child with an otherworldly realm with clearly established allegorical links with the turbulent Civil War period, it is a work of fantasy rather than a gothic supernatural film - and in turn it deals with temporality in different ways to the films discussed throughout this book. In addition, the audience is invited to identify in a more unproblematic way with the central child protagonist than in most films of the transnational uncanny child cycle, in which the child is a figure to fear as well as a figure with which to empathize. Yet PAN's LABYRINTH does indeed draw on the themes of the uncanny child cycle. In particular, the film engages with THE DeviL's BACKBONE, del Toro's earlier film - in fact, he calls these two films his 'brother and sister pieces' (2006, n.p.). 
on film until the final years of Franco's regime, and even then in muddied, opaque forms.

\section{Spanish Horror and Collective Memory}

Millennial Spanish horror films thus draw on processes of collective memory in complex ways, augmenting the psychically rooted, Freudian mechanisms of the American films previously discussed. French sociologist Maurice Halbwachs established the concept of collective memory, suggesting that:

it is in society that people normally acquire their memories. It is also in society that they recall, recognize and localize their memories. [...] It is in this sense that there exists a collective memory and social frameworks for memory; it is to the degree that our individual thought places itself in these frameworks and participates in this memory that it is capable of the act of recollection. $(1992,38)$

Halbwachs thus suggests that individual memory constantly interfaces with collectively assembled memories and the national identities with which these collective processes interact: 'the individual remembers by placing himself in the perspective of the group, but one may also affirm that the memory of the group realizes and manifests itself in individual memories' $(1992,40)$. As Rafael F. Narváez elucidates, Halbwachs makes a 'famous distinction between history and collective memory, where history belongs to a dead past and collective memory lives organically in the present' (2013, 11). Collective memory thus suggests that cultural imaginings of national pasts shift according to contemporary context, challenging concepts of a fixed and linear national history and revealing 'that the past is organically connected to the collective order, and thus anchored within the present. It means that the past is thus actualized, acted out and re-presented by the individual and by the social group' (emphasis in original, Narváez, 2013, 11).

Unlike official histories, collective memory is a continually developing consideration of the past and its relationship with the present, which can retrospectively reconfigure or deconstruct entrenched historical narratives. Media representations are central to this process of collective memory building - as Alison Landsberg suggests in Prosthetic Memory (2004), a text central to my analytical framework in Section Three, cinema has the potential to facilitate a process of collective memory formation even amongst individuals who did not live through the pasts represented. Thus, films - particularly those that self-reflexively engage with their cultural 
context - can build upon and recompose the collective memories embedded within concepts of national identity. In turn, particularly affective cinematic representations, like those that populate horror cinema, may become knotted to an individual's identity in the form of potent personal memories. This process illustrates the interplay between individual and collective memories involved in shifting concepts of national identity. As Landsberg suggests, 'the cinema offers spectators from diverse backgrounds and ancestries a shared archive of experience' (2004, 14).

In her book The Child in Spanish Cinema (2013) - the first text to broadly chart the child's significant role in Spanish cinema - Sarah Wright links children in Spanish cinema to such processes, suggesting that 'the child has emerged as a central figure in the politics of memory' and is therefore 'symbolic not only of the loss of historical memory and its recuperation after a time-lag but also it is often a site of trauma in contemporary memory wars' $(2013,14)$. Through the child, Spanish horror films of the millennial period tend to explore how the contemporary reconfiguration of the collective memory, sparked by belated traumatic recollection, works to unsettle established historical narratives - an especially resonant fixation because national identity was carefully manufactured through child characters in post-Civil War films.

Later in this book, in Section Four, I examine another uncanny child film released in the same year as THE DeviL's BACквоNE that is also often delineated as Spanish - The Oтнers (Alejandro Amenábar, 2001). As I will show, unlike the films analysed in this section, THE OTHERs is placed squarely in-between specific cultural contexts because it is performed in (British) English, was coproduced with the Hollywood production company Cruise/ Wagner Productions (which received top-billing over Spanish company Sogecine), and was positioned as a Hollywood product to external markets. As a result, the Spanish origins of this transnational film may not have been acknowledged by the majority of viewers outside of Spain, and, as it is not set in Spain, it does not set out to engage directly with Spain's history and collective memory. By contrast, The Devil's Backbone, The Nameless, and ThE ORPHANAGE were filmed and are set in Spain, and are performed in Spanish. The NAmeless and The OrPhanage were developed by Spanish directors and production companies, while BACквONE was a SpanishMexican coproduction with a Mexican director. Although BACKBONE and The OrPhANAGE in particular were, like THE OTHERs, marketed for and appropriated by global audiences, ${ }^{3}$ central to the aesthetic and thematic

3 Antonio Lázaro-Reboll illuminates the transnational properties of BACKBONE (2007), a point to which I will return in Section Four. 
constitution of each of these films is their complex, often allegorical exploration of the national narrative, and the ways that processes of collective memory reconfigured the relations between Spain's past and its present in the late 2oth- and early 21st century. Thus, unlike The OTHERs, these films establish a clear relationship with the Spanish cultural context from which they emerge, and their visions of childhood are strongly influenced by - and engage with -50 years of Spanish film history.

\section{The Horror Genre in a Spanish Context}

Despite going through a boom period between 1968 to 1975 - during which exploitation films flourished, many of which were produced, directed, and/ or written by schlock auteur Jesús Franco - Spanish horror cinema was a largely marginal genre both locally and abroad until the genre's revival in the late 1990s. In the first and, to date, only comprehensive study of Spanish horror cinema written in English, Antonio Lázaro-Reboll points out that while the horror films of the 1960 s and early 1970 sere often commercially successful, they were 'reviled by contemporary critics, film historians and scholars, who consigned horror titles to the margins of Spanish film history' $(2012,5)$. Furthermore, Lázaro-Reboll notes that while horror films of this period were released in both domestic and external markets, due to strict censorship 'Spanish audiences continued to consume the squeaky-clean, censored versions of films whose more explicit originals were exported for international consumption' $(2012,20)$. In his study of the Spanish Gothic mode, Xavier Aldana Reyes describes the horror films of this period as 'a survivor type of cinema, staying afloat' - in spite of censorship conditions - 'thanks to its moderate success' $(2017,191)$. In order to work around censorship, these films usually foreground foreign settings and actors, rather than establishing overt or clear links with their local context. ${ }^{4}$

Following this boom in exploitation pictures, the horror genre was largely displaced from the late 1970s to the early 1990s, a result of a complex series of events subsequent to the death of Francisco Franco in 1975: namely, the decline of his despotic regime and subsequent lifting of media censorship in late 1977, and the introduction of a film legislation by the new Socialist Government in 1983 (known as Ley Miró). As Andrew Willis suggests, horror's marginality 'was heightened when democracy was restored and critical

4 Although Lázaro-Reboll points out that, while 'the coding of the source of horror as foreign $[\ldots]$ was a must $[. .$.$] specific elements did often connect the film with the Spanish landscape,$ for many locations are recognisably Spanish' $(2012,22)$. 
interest began to focus on how film-makers would negotiate and engage with that historical moment. The horror film and its place in Spanish film history quickly became forgotten. Arguably, that would not change until the end of the twentieth century' (2004, 238). Throughout the transition period and early stages of democracy, the horror genre was antithetical to the national project of rapid modernization, and a boom of prestige historical and political films largely displaced domestic horror output. Lázaro-Reboll explains that this period saw an intense focus on 'the production and distribution of "quality" films - that is, auteurist, middle-brow and high-brow products, which were based mainly on literary and historical sources. The serious art-film [...] was instituted as the new brand of official cultural cinema, bringing to an end a specific type of genre filmmaking' (2012, 176).

Thus, just as THE SIXTH SENSE sparked a new cycle of supernatural horror cinema in America following its release in 1999, the Spanish cycle emerged to revive the horror genre around the millennial turn, and a number of major works in this horror renaissance circulated around the uncanny child. The DeviL's BACKBone was particularly influential: the film that helped to launch del Toro's career as a horror and fantasy auteur, BACKBONE has received widespread critical acclaim while being commercially successful in both domestic and global markets. It was nominated for awards at a number of regional and global genre festivals such as the USA Academy of Science Fiction, Fantasy and Horror Films, The International Horror Guild, and The American Latino Media Arts Awards, and won the Grand Prize at the Amsterdam Fantastic Film Festival and Special Prize at the Festival international du film fantastique de Gérardmer. Through its global recognition, the film helped to ignite a wave of gothic Spanish horror films. Lázaro-Reboll concurs that 'for decades, horror has been the outcast genre of Spanish cinema' $(2012,5)$, while the 1990s and 2000 s 'have witnessed the commercial, critical and cultural renaissance of the horror genre in Spain' (2012, 6). Throughout the first decade of the 21st century, Spanish horror films dominated the local box office - Lázaro-Reboll points out that Spanish-produced horror films drew the highest box-office earnings in Spain in 2001, 2007, and 2009, beating stiff competition from Hollywood blockbusters such as Pirates of the CARIBbEAn: At WorLD's End (Gore Verbinski, 2007, 199). ${ }^{5}$ This explosion in the production and popularity of

5 Notably, two of these films, The Others (2001) and The OrPhANAgE (2007) revolve around uncanny children. While the third, JuLIA's Eyes (Guillem Morales, 2010), does not feature a child, the film deals with repressed pasts and their relationship to the passed developmental stage of 'childhood' in a manner which resonates strongly with the uncanny child films. In fact, the 
local horror cinema during the millennial turn and early 21st century suggests that during this period, the genre became an intensely charged locus for expressing the tensions that have moulded contemporary Spain. The cultural significance of this horror revival is illuminated when considering the extent to which film has sculpted the national narrative post Civil War.

\section{Spanish Cinema Under Franco}

While concealed beneath a blanket of Francoist and, later, transitional narratives of successful national progress, the course of modernity in Spanish culture has been particularly incongruous and uneven. This can be seen as an effect of the Civil War between the liberal Republicans loyal to the established Spanish republic and the conservative, Franco-led Nationalists, and the subsequent Franco dictatorship. Resulting in approximately 500,000 deaths and exposing an impassable ideological fissure between what has become known as 'the two Spains', the Civil War was, in the words of Peter Besas, 'one of the most violent conflicts of [the $20^{\text {th }}$ ] century' $(1988,13)$ which left Spain 'in ruins, exhausted, depleted' $(1988,15)$. However, the acute national trauma associated with the war and subsequent dictatorship has almost totally eluded cultural expression up until quite recently.

The articulation of national trauma was actively suppressed by the fascist government throughout Franco's reign. Censorship laws were extremely strict under Franco, who strived to tightly control all cultural production in order to regulate national consciousness and the national narrative. Franco's government carried out such ideological work in order to quash Republican discourse and thus to superficially paste over the cleft that continued to separate the 'two Spains', and to position the Civil War - instigated by a violent coup against the democratically elected Republicans - as a necessary, justifiable act for the good of Spain. Central to this process was the repression of the very recent past, both that of the Republican-governed Spain and the violence of the Civil War, and the subsequent attempt to construct a smooth continuum between the new fascist regime and the Imperial Spain of a bygone era. Tatjana Pavlović et al. explain that during the period directly after the Civil War - known in Spain as the anos de hambre (years of hunger) due to a financial crisis and widespread unemployment - Franco set about

film stars Belén Rueda, who also plays the adult protagonist of THE ORPHANAGE, and her role as a woman constantly affected by the lingering spectres of repressed childhood trauma echoes the earlier film. 
securing the foundations of his oppressive ideology, "with its exaltation of the fatherland, uncritical celebration of "Spanishness", promotion of the military ethos, and repressive assertion of order and social control' (2009, 55). Franco regarded cinema as a vital tool in propagating his doctrine; Raymond Carr points out that, in the decades following the Civil War, Spain 'was a nation of cinema addicts' $(1980,164)$, with more cinema chairs per capita than any other European country. Subsequently, as Franco and his government were well aware, the films that Franco sanctioned following the Civil War represented the 'only images most Spaniards had of their country's recent history' (Virginia Higginbotham, 1988, 18), exposing the extent to which cinema in Spain engendered the formation of post-Civil War cultural consciousness and set in place a national metanarrative.

\section{Cinema in the Post-Civil War Period}

Spanish cinema in the years directly following the Civil War largely consisted of quasi-propaganda films that legitimized the war and cast the Nationalist cause as heroic, although often in indirect ways that avoided representing the war directly. While the Civil War was rarely explored on film even in its immediate aftermath, Marvin D'Lugo notes that there was a 'tendency toward the aggrandizement of the heroic, militant values of The New Era even in films unrelated to the theme of the war' as a number of films emerged in the postwar years that 'did not deal explicitly with the war but connected with it by exalting the army and militarism directly' $(1997,11) \cdot{ }^{6}$ Following the war, Spain's fascist regime faced ostracism from most of Europe and the rest of the world, a segregation that deepened through Franco's enforcement of the politics of autarky. As Pavlović et al aptly assert, 'in this isolated climate the legitimization of the new Nationalist dictatorship was tied to the validation of what was deemed to be the "authentic" Spain' $(2009,61)$. In an effort to valorize Spain's cultural and economic isolation, Franco aimed to utilize cinema to champion an independent, exalted Spain that should be insulated from the 'sullying' influences of other cultures. As a result, much of Spanish cinema became consumed with projecting a mythologized Spanish cultural unity, constructing a teleological national master narrative as the singular correct one. This cinema is characterized by the celebration of pre-Republican, Imperial Spain in order to express, as

6 Notable examples are The Legion's For Me! (Juan de Orduña, 1942) and Martyrs of the Philippines (Antonio Román, 1945). 
articulated by Graham, an 'idealized, highly tendentious image of Spain's imperial past as a model for its present' $(1995,237){ }^{7}$

Intertwined with Franco's construction of this national narrative was an emphasis on restoring the overarching power of Catholicism and the fortitude of patriarchal family values. As Marsha Kinder points out, the fascist melodramas that dominated the film industry after the Civil War privilege 'the family as the primary site where ideological issues can be displaced and naturalized', as this genre 'acknowledges and politicizes the connection between the domestic and public realms. [...] it proclaims the family as a legitimate site for effective political action, mobilizing "the people" around universal issues of morality, generation, and gender that cut across class lines' $(1993,72)$. In this context, the child becomes deeply entangled with Franco's ideological project, figured as a particularly vulnerable and precarious sociopolitical unit that must be carefully moulded for the successful advancement of Spanish society. As Wright suggests, 'in the sense that Francoism was based on conservative family values, bolstered by religious imagery, as a way to sustain patriarchy, the aura surrounding the child fitted perfectly' $(2013,31)$. As Franco himself stated, cultural solidarity necessitated 'the total education of children in a political creed that is based on eternal truths: the law of God, service to the Fatherland and the general wellbeing of the Spanish people' (cited in Wright, 2013, 31). Subsequently, 'the children of Franco' - a term explored by Marsha Kinder $(1983,57)$ and explicated in Chapter Four - have become an intensely overdetermined and multidirectional category, reflecting a great deal about the ways the child is enmeshed with considerations of national trauma in contemporary Spanish cultural discourse.

The importance of the child and the nuclear family as microcosms of Spanish society in Francoist ideology is evidenced in the film that Franco himself scripted and produced, released soon after the end of the Civil War: RAZA (RACE, José Luis Sáenz de Heredia, 1941). Pavlović suggests that, with RAZA, Franco 'is simultaneously erasing and rewriting Spanish history, while obsessively recounting his own family story' $(2003,30)$. The film details the story of a military family across a $5^{0}$-year time period, focusing on three sons who all traverse differing life paths following the declaration of the Spanish Republic in 1931. One brother grows up to become a priest and is executed by Republicans; another abandons the Nationalist ideals of his family (with disastrous results, as he is shot and killed by his Republican comrades); while

7 Examples include InÊS DE CASTRo (José Leitão de Barros, 1944), EugENIA DE MontiJo (José López Rubio, 1944), and The Madness of Love (Juan de Orduña, 1948). 
the third brother, a thinly veiled, fictionalized reconstruction of Franco himself, becomes a Nationalist hero in the Civil War - the climax depicts him marching in a victory parade, which instigates the glorious reunification of the remaining members of his family. Central to this triumphant scene is the war hero's little nephew, who proudly watches his uncle from the crowd and signals the continuation of his grand legacy. Thus, as Pavlović et al articulate, the film 'conflates family unity with national accord. In this way, historical discourse is embodied in the experience of this "exemplary family"' (2009, 71).

To project its didactic message, RAzA rather anxiously emphasizes the importance of the correct development of the child under the nuclear family, establishing a comparison between the trajectories of the three brothers to ensure that the most worthy life path is illuminated. Thus, the film constructs the child's growing up as paralleling the progression of a Spanish grand narrative. In rigorous and drawn out detail, RAzA sets out a strict linear vector for the progression from childhood to adulthood that consciously parallels the teleological post-Civil War national narrative according to Francoist ideology, a trend that would continue throughout Franco's regime. As Wright suggests, 'if Francoist cinema might be described as an exercise in the "mass mobilisation of affect", then the child rose up as an affective key, twinning culture and politics' (2013, 31-32).

\section{Marisol and the cine con niño}

Besides military films, the other variety of films to project idealized visions of childhood in service of the national narrative was the cine con niño (child-centred cinema), which became particularly popular throughout the 1950 s and 1960s. Spain developed its own autochthonous child star system during this period, which produced huge stars such as Pablito Calvo, Joselito, and Marisol (often known as the 'Spanish Shirley Temple'). The vehicles for these child prodigies - which include The Miracle of Marcelino (Ladislao Vajda, 1955) and AN ANgel HAS AppeAred (Luis Lucia, 1961) depict perfect children who embody the exultant national homogeneity central to Francoist constructions of post-Civil War identity. Referring to perhaps the most famous of these child stars, Marisol, Peter Evans explains that 'in her all-singing, all-dancing, all-talking vivacity [Marisol embodies] the hectic expression of a nation's sham illusion of utopian festivity' (2004, 129). In many of these films, the children are orphans, an all-too common reality in post-Civil War Spain. However, as Wright suggests, by the mid 1950s, the child war-orphan was no longer a social reality, yet 'the rhetoric 
of the child orphan and child martyr continued to hold sway' $(2013,24)$. Notably, despite their fixation with orphans, the cine con niño does not employ this device to acknowledge the many children orphaned by the Civil War, nor to consider the conceptual threat such children may pose to Francoist models of seamless patriarchal, intergenerational progress. These films instead suppress such tensions by displacing the Civil War: for instance, in AN ANGEL HAS APPEARED Marisol is left an orphan after her father, a fisherman, drowns at sea. Instead, the films tend to position the orphaned child as a martyr of the Nationalist cause who embodies a break with the recent past - the Civil War never being overtly referenced in such films - instead seeming to spawn from a romanticized, often indeterminate folkloric past.

The Civil War itself is thus elided as the precocious child constructs an illusory continuity with a pre-Republican, Imperial Spain and the post-Civil War present. As Wright elucidates, 'if Francoism had to do with a yearning to recover a lost mythical state of grace now brought into the realm of politics, then the child, always caught between nostalgia and the future, encapsulated this longing' (2013, 31). The national significance of this mythic cultural past is succinctly conjured by the popular Spanish folk songs warbled by the child in all of the Marisol films. Marisol's folk performances craft a sense of cultural pride and triumph for Franco's Nationalist present through conjuring an 'authentic' cultural past, and suggesting a smooth continuity between the two temporal realms. It is of course significant that this constructed sense of cultural continuity is mobilized by the figure of the perfect child, who also anticipates the glory of Spain's impending future. Wright points out that the 'implicit narrative encapsulated in Marisol's persona was the move towards modernity' $(2013,71)$ despite the fact that these films, and in fact Marisol's star persona as a whole, emphasize her roots in traditional, rural Spain. For instance, Celestino Deleyto suggests that by the mid 196os, Marisol films suggest an imminent new era of tourism and capitalist prosperity after the isolation and economic hardship of the postwar years, heralding 'a golden future in which foreign nations [...] will come to envy [Spain] and recognise the superiority of its ideological doctrine' (1994, 243). Thus, the cine con niño projects in extremely narrow, utopian form the process described by Edelman whereby the child embodies 'history as linear narrative [...] in which meaning succeeds in revealing itself - as itself - through time' (Edelman, 2004, 4). Evidently, the child in this context expresses an overdetermined relationship to time and the Spanish national narrative, which barely conceals the anxieties surrounding the child's portentous ideological position in Francoist Spain. 


\section{Cinema in the Final Years of the Regime}

It is exactly this rigid association of the child with linearity and national master narratives that oppositional cinema created towards the end of Franco's regime starts to destabilize. In the early 1970s, Franco's death seemed imminent due to a prolonged battle with Parkinson's disease (among other illnesses). Furthermore, the impending decomposition of his regime was politically marked by his designation of Prince Juan Carlos de Borbón as his heir-apparent in 1969, and his surrender of prime ministerial function in 1973. The gradual disintegration of his regime was heralded by his death in November 1975. Throughout this uncertain period, subtly dissident art films began to emerge, in which the child and childhood become the sites of the as yet unfathomable collective trauma that had been denied in Francoist cinema. The formative and most influential of these art films are The Spirit of the Beehive (Victor Eríce, 1973), ANA AND the Wolves (Carlos Saura, 1973), Cousin Angelica (Saura, 1974), and RAISE RAvens (Saura, 1976), all of which feature child characters who ambiguously suggest a delayed cultural response to the wounds of the Civil War and oppressive dictatorship.

\section{Horror Film and the New Spanish Cinema}

Due to ongoing censorship that prevented filmmakers from overtly examining the Civil War or the Republican cause - and also a lack of resources and political certainty during this precarious period - a fair proportion of the films released throughout this period were these elusive art films and cheaply made, lucrative, B-grade horror films. ${ }^{8}$ These horror films were often made possible through international coproduction and tended to be released in Spain in vastly censored, truncated forms (yet distributed internationally with all their blood and gore intact). By contrast, the seminal art films of the early 1970s directed by auteurs Victor Eríce and Carlos Saura were released at the tail end not only of Franco's dictatorship, but also of a politically sanctioned project aimed at raising the perceived quality of Spanish cinema both domestically and abroad. Both types of films were made possible by the loosening of censorship. As Willis explains, 'following a period of arch-conservatism after the nationalist victory in the Civil War, Spanish cinema in the 1960 s is marked by a clear liberalization of the

8 Such horror films include Vampyros Lesbos (Jesús Franco, 1971), Tombs of The Blind Dead (Amando de Ossorio, 1972), and Night of the Howling Beast (Miguel Iglesias, 1975). 
government's attitude towards films that might be seen as critical of the regime' $(2003,72) \cdot{ }^{9}$

In 1962, the regime created a body led by José María García Escudero aimed at developing a 'New Spanish Cinema' with artistic merit. In an attempt to rescue Spain's failing film industry, Escudero instituted changes including increases in government funding for 'special interest' films, an overhaul of the censorship board, and developments to the Escuela Oficial de Cine (Madrid's Official Film School). As has been outlined in the work of John Hopewell (1986), Kinder (1993), and Willis (2003), while The New Spanish Cinema led to the production of films that would have previously been approached with caution, censorship, or even outright banning by the authorities - as was the case with Luis Buñuel's internationally lauded but domestically banned VIRIDIANA (1961) - this institutionalized, carefully monitored art movement sought to facilitate more prestigious, internationally visible cultural products. Eríce attended the Official Film School in the 1960s, while Saura (who attended the school prior to the changes ushered in by Escudero) benefitted from the support of the New Spanish Cinema to release The Hunt (1966) and PEPPERMint Frappé (1967), both of which fulfilled the project of the New Spanish Cinema by winning Silver Bears for Best Director at the seventeenth and eighteenth Berlin International Film Festivals. However ultimately, the New Spanish Cinema was an economic failure. As Lázaro-Reboll points out:

between 1968 and 1975 the Spanish film industry - never very healthy - was witness to the closure of one-third of its total number screens [...] and a decrease in the sector's income. By 1968, therefore, the Spanish film industry was in a critical state [...] and the NCE [New Spanish Cinema] was practically defunct. $(2012,19-20)$

Yet directors such as Saura and Eríce continued to receive critical acclaim following the initial support of the New Spanish Cinema: THE SPIRIT OF The Beenive won the prestigious Golden Seashell at the San Sebastian Film Festival, and RAISE RAVENS received the Cannes Film Festival Special Jury prize.

9 However, Labanyi suggests that this period was short-lived, as, by 1973 (the year of SPIRIT OF THE BEEHIVE's release), 'hard-line, repressive censorship returned' due to the assassination of Franco's prime minister - and suspected planned successor - Luis Carrero Blanco by Basque terrorist group the E.T.A. $(2007,97)$. 
Ultimately, it is important to consider that, throughout the final years of Franco's reign, the two dominant film trends were:

1. Art film attempts to approach the cultural traumas of the Civil War and dictatorship through an elliptical structure that skirted the line between subversiveness and politically sanctioned art, often through the obscure and confused perceptions of a child (as is the case with two of the most successful and culturally significant products to emerge out of the New Spanish Cinema, BeEHIVe and Ravens).

2. Outlandish, often extremely violent horror films that did not have the Civil War on their thematic radar yet nevertheless expressed the wholesale unleashing of repressed tensions following three decades of oppressive censorship. As Lázaro-Reboll suggests, these films were 'a barometer of the decades' contradictorily overt conformism and latent dissent, a time when the repressed was on the verge of making a return, in monstrous form' $(2012,12)$.

Thus, both types of film respond to the uncertainty of the early 1970s via a still nascent consideration of long-denied cultural trauma. As will be seen in the next chapter, in their similarly eerie and shocking confrontations with cultural trauma, the child-centred horror films of the late 1990 and early 200os draw together the two prevailing styles of the liminal 1970s.

\section{Who Can Kill a ChILD?}

Of particular note during this period is horror film WHO CAN KILL A CHILD? (Narciso Ibáñez Serrador, 1976), which can be seen as a forebear to the horror cycle of the late 1990s and early 2000s. The film depicts the story of an English couple on a visit to a quaint Spanish island, which they discover is inhabited by maniacally violent children. Released only five months after Franco's death, the film erupted at a particularly uncertain sociopolitical moment. Lázaro-Reboll points out that the film sparked controversy, with many commentators dismissing it as a shallow provocation that was low-grade and derivative: 'in many instances, the director himself and his work were the subjects of disapproval and derision' $(2012,121)$. Yet in fact, the film edges towards the concealed ideological domain of the art films of this period, openly expressing the horrific effects of war and oppression upon the figure of the child, both as concept and as living member of Spanish society.

The film opens with a montage of documentary footage and images depicting children left wounded and starving as a result of various wars 
and cataclysmic historical events, with figures indicating the number of children left dead in their wake. In accordance with the lingering bounds of censorship, Spain's own Civil War is not included in this montage, but eerily overarches it through its absence. The children are a monstrous subversion of the perfect orphan martyrs of the cine con niño: while the adult protagonists initially assume that the children on the island are innocent orphans, they come to learn that the children killed all the adults on the island out of an apparent impulse for revenge. The terrifying antagonism of the children is enhanced by the fact that they speak Spanish, but the adult protagonists only speak and understand English - in part due to the film's positioning for international markets - sustaining an impenetrable gulf of untranslatability between them. Both protagonists eventually die at the hands of the children: most dramatically, female protagonist Evelyn is murdered from within her own body by her unborn child. The film ends as some of the murderous youngsters journey across the ocean on a motorboat to mainland Spain. In the film's final lines, a little girl asks 'Do you think the other children will start playing the way we do?', to which a young boy - the children's leader - replies, 'Oh yes. There are lots of children in the world. Lots of them.' Thus, the film overtly positions the children as a powerful, monstrous force finally enacting their vengeance against an adult society that has violently oppressed them.

The children's rage is presented in the film as a generalized antipathy towards adulthood, in a conscious effort to prevent the already controversial subject matter from being perceived as an outright political attack. Thus, while a mutation of the innocent, pure children of the cine con niño is played out, this occurs in generalized terms that sidestep the specifics of cultural context, as is reinforced by the film's largely English dialogue, and the isolated setting on Almanzora island. Upholding this vague generality, director Serrador stated at the time of the film's release 'I don't like talking about the message of a film but I think [in the case of my film] this is easy to understand. If the children are cruel and they rebel against the adults, they are not to blame; we are to blame' (cited in Lázaro-Reboll, 2012, 119). However, the war and dictatorship are implicated in obfuscated ways: absent from the narrative and opening montage, the war and subsequent Francoist oppression loom over the entire film as probable causes of the children's mutation, in a potent enactment of the 'complex ways that knowing and not knowing are entangled in the language of trauma and in the stories associated with it', a crisis marked by 'the ways it simultaneously demands and defies our witness' (Caruth, 1996, 4-5). Despite its forceful expression of trauma, WHo CAN KILl A CHILD? was largely displaced from Spain's 
cultural consciousness with the transition to democracy - as was the general tendency with Spanish horror films of this period - and in fact the film was largely unavailable for home viewing until the millennial Spanish horror boom, via a 2007 DVD release by Dark Sky Films.

\section{Child-Centred Art Cinema}

Unlike the exploitation horror films that symbolically play out cultural trauma via their gore and violence (plentiful in WHO CAN KILL A CHILD?), the art films that emerged in the final years of the dictatorship are permeated by the historical fractures of a postwar context. Yet these art films approach this trauma in such esoteric, uncanny ways that their style has become known as the esthetica franquista, the 'Francoist aesthetic' or what Higginbotham describes as the 'aesthetic of repression' $(1988,129)$. The two seminal art films considered in the next chapter, THE SPIRIT OF THE BEEHIVE and RAISE RAVENS, represent the apotheosis of this aesthetic. As will be seen, the use of the child in this framework has particularly compelling resonances with Caruth's description of trauma as an event 'experienced too soon, too unexpectedly, to be fully known' $(1996,4)$ : the child characters are forced to confront distressing situations that they are not yet equipped to comprehend or contextualize. This process allegorically refracts the deferred processes of recognition inherent in Spain's cultural response to the traumas of Civil War, not explored in popular culture until decades after it occurred. Unlike the largely overlooked WHO CAN KILL A CHILD?, ${ }^{10}$ The SPIRIt of the BeEhive and RaISe RAVENS are among Spain's most well-known and culturally revered cinematic releases, and their usage of the child as witness of trauma vastly influences later horror films. ${ }^{11}$

10 The film has gradually amassed cult status following screenings by cult/genre festivals and clubs (for instance, Cinefamily's and Spectrevison's 2014 screening in Los Angeles of the only remaining $35 \mathrm{~mm}$ print of the film), and its recent DVD release.

11 BEEHIVE in particular is considered a master text of both Spanish cinema and child-centred cinema. As David Martin-Jones suggests, it has become metonymic of a 'child film format', which uses a child character to consider historical upheaval (2011, 81-82). Furthermore, scholars such as Labanyi (2007), Perriam (2008), and Wright (2013) have examined the ways in which the film explores the politics of memory and cultural trauma through little Ana. As Perriam states in his eloquent description of the film:

It stages a series of possible reactions to and interpretations of the state of Spain, on the one hand, and a state of mind, on the other hand, connected to horror, nightmare, vicarious remembrance, the loss of innocence [...] In a manner whose obscurity, temporal discontinuity, illogicality, and ungraspability are appropriate to the symptoms of trauma, the film sporadically crossmatches Ana's crisis to a nation's crisis. $(2008,67)$ 
As I chart in detail in the next chapter, the powerful incoherence of the child's trauma in these art films challenges linear narratives of national progression - so bound to childhood's Francoist function - a process selfconsciously magnified in temporally complex ways in millennial horror films. Gestating within the children of the art films are as yet unfathomable fissures that threaten to erupt in monstrous and destructive ways in the future - a 'future' that millennial horror films claim, in relation to these art film inter-texts, as their own present. Thus, the uncanny child of millennial horror first stirs in these art films as an arcane and ominous embodiment of national trauma, of which the deep ramifications for Spanish national identity cannot yet be fully articulated but incubate within the child, to erupt in an unknowable future.

Ultimately, both the art and B-grade horror films of the 1970s may seem generically worlds apart, yet they express an intersecting cultural function. While the horror films function as a violent but wilfully indirect acting out of long-simmering national trauma, the horror-tinged art films ${ }^{12}$ figure a conscious, but concealed, attempt to work through it. By drawing these 1970s modes together, often self-consciously, millennial horror films accord with Adam Lowenstein's assertion that the horror genre's potent allegorical mediations of historical trauma often challenge 'the binary oppositions that tend to govern the study of trauma and its representation: melancholia/ mourning, acting-out/working through' by instead maintaining 'a productive tension between' such responses $(2005,3)$. As Lowenstein rightly suggests, such binary oppositions tend to sustain hierarchical value distinctions between art and genre films, with the art films considered to elicit historically responsible responses to trauma, while genre films are considered to express conservative, historically irresponsible responses (2005, 7-9). Especially given the complexities of their relationship to their sociopolitical context, all of these cinematic responses to Spain's cultural trauma are too multifaceted to neatly assign into binary categories of 'healthy'/'responsible' or 'unhealthy'/'irresponsible' traumatic representation.

It was not until over 30 years after the Civil War that these initial cinematic expressions of trauma began to emerge; subsequently, they anxiously express the temporal delay in responding to the wounds inflicted by the

Yet Perriam's work also aligns with the general tendency of scholars to suggest that Ana is somehow not really a child, but a metaphoric cipher, advocating that we see Ana 'not so much as a child but as a maternal aura' $(2008,73)$. I suggest instead that Ana's status as a child is central to her subversive function.

12 Wright in fact refers to these films as 'art-house horror'. 
war. In her work on trauma and horror films, Linnie Blake suggests that such films productively explore 'trauma by remembering it and repeating it in the form of diagetically mediated symbolisations of loss' (2008, 2). As she outlines, films that dwell on the eerie or disturbing processes of collective trauma - in ways both overt and symbolic - articulate:

a willingness on behalf of audiences to work through the anxiety engendered by trauma, but a willingness also to undertake a fundamental questioning of those ideologically dominant models of individual, collective and national identity that can be seen to be deployed across post-traumatic cultures, as a means of binding (hence isolating and concealing) the wounds of the past in a manner directly antithetical to their healing. $(2008,2-3)$

The horror exploitation pieces and ambiguously subversive art films of the 1970 s both construct such diegetic worlds permeated by loss, dread, and fear, and, through these violent or uncanny aesthetics, start to carry out the cultural function outlined by Blake, utilizing expressions of trauma to loosen the oppressively tight post-traumatic bindings of Francoist discourse. Furthermore, their temporal belatedness is inextricable from their indirectness and opacity, in an aesthetic expression of a long unassimilated traumatic experience that finally starts to surface in veiled, oblique forms.

\section{Cinema in the Transition Period}

Even after Franco's death and the commencement of the transition to democracy - a liminal period that would last until the 1982 election of the Spanish Socialist Worker's Party - Spanish film expressed a lingering reluctance to confront the traumas of the war. As a number of scholars have pointed out, throughout this period there was a continuing official sensitivy within the governing agencies of the film industry resulting from a reluctance to challenge or stress newly established democratic institutions (Higginbotham [1988, 128], Eloy Merino and Rosi Song (2005, 11-15)]. Such resistance was crystallized by the pacto del olvido, or 'pact of forgetting' - enshrined in the 1977 amnesty law that pardoned all political crimes committed during the war and dictatorship - whereby all parties agreed to essentially forget the Civil War in order to break with the conflicts of the past and ensure a smooth transition to democracy. This officially sanctioned sensitivity to the past was also bound up with anxieties surrounding Spain's new-fledged 
ideological status as one of the most successful latecomers to democracy: other countries admired and sought to emulate the 'Spanish model', 'the paradigm of a peaceful transition from an authoritarian to a democratic regime' (Paloma Aguilar, 2001, 93). It was not until the mid 1980s - nearly ten years after Franco's death - that films started to emerge with some level of regularity that directly confronted the Civil War. ${ }^{13}$

Even this trend was short-lived: writing in 1988, Spanish film scholar Roman Gubern opines that 'the judgement of the industry was that, now that the initial curiosity was over, the public had decided to forget and close its own unpleasant past [...] therefore, it was necessary to offer the market evasion and euphoria, escapism and optimism' (cited in Higginbotham, 1988 , 133). Labanyi adds that the cultural break with the oppressive past delineated by the transition period sparked a frantic process of catching up with the lifestyles and cultural hallmarks of Western modernity. She explains that 'such lifestyles were conceived as requiring the excision of all reference to the past' $(2007,94)$. This impulse saw the launch of a public relations campaign (1982-1996) aimed at projecting modern, progressive Spanish cultural products abroad - like the films of Pedro Almodóvar - as the 'promotion of an outrageous hypermodernity prevailed' (Labanyi, 2007, 95). The compulsion in Spanish film to express a newly established cultural modernity is thus motivated by anxiety about a return to or repetition of Spain's traumatic past. Aguilar elucidates that 'fear was present throughout the transition largely because of a traumatic memory of the Civil War given renewed impetus by fears of a military or right-wing reaction against emerging democratic forces' (2001, 94). As a result, the post-Franco trends in Spanish cinema continued to sustain the temporal conditions of trauma, in which narratives of successful linear progress perilously cover up a fissure not yet assimilated or synthesized. As Sarah Leggott puts it, 'Spain's transition to democracy [...] was characterised by the silencing of the more painful and polemical aspects of the preceding decades in the interests of national reconciliation' $(2010,120)$.

In her study of popular culture, class and constructions of national narratives in modern Spain, Valis characterizes the frenzied expressions

13 Such films include Bicycles are for Summer (Jaime Chávarri, 1984), The Death of Mikel (Imanol Uribe, 1984), and THe Heifer (Luis Garciá Berlanga, 1985) - which was the first (very black) comedy made about the Civil War. This period also saw the release of IN A GLASs CAGE (Agustí Villarona, 1987), a controversial art film with strong horror elements featuring a monstrous vengeful child. The film, perhaps tellingly, elides any direct reference to Spain's Civil War yet features a sadistic former Nazi doctor, and can be seen to bridge an important gap between child-centred art films of the 1970 s and the recent crop of uncanny child films. 
of Spain's progressiveness post Franco as the 'relentless insistence on the present as a refusal and inability to come to terms with the past' (2002, 282 ), which paradoxically points to an underlying cultural rupture between past and present yet to be addressed. Up until the end of the $20^{\text {th }}$ century, Spanish cultural discourse had largely failed to acknowledge the ways that the unacknowledged traumas of the past reverberate in the present, a recognition that would unsettle fixations with rapid national progress. Thus, according to Valis, submerged beneath a cultural obsession with the present and future is 'a displaced, ruptured narrative of identity diffusely structured through complexly ambivalent feelings' $(2002,285)$. The cultural rupture outlined by Valis (re)emerges in monstrous forms through the millennial uncanny child, in ways that threaten the illusory stability of post-Franco Spanish culture. As will be outlined in Chapter Four, these films thus figure a literal return of the repressed disruptive to national homogeny in their dismantling of narratives of cultural progress and smooth transitions to a post-Franco hypermodernity.

\section{Works Cited}

Aguilar, Paloma. 'Justice, Politics and Memory in the Spanish Transition.' The Politics of Memory: Transitional Justice in Democratizing Societies. Ed. Alexandra de Brito, Carmen Gonzaléz-Enríquez, and Paloma Aguilar. Oxford: Oxford University Press, 2001. 92-118. Print.

Aldana Reyes, Xavier. Spanish Gothic: National Identity, Collaboration and Cultural Adaptation. London: Palgrave Macmillan, 2017. Print.

Besas, Peter. Behind the Spanish Lens: Spanish Cinema under Fascism and Democracy. Denver: Arden Press, 1988. Print.

Blake, Linnie. Wounds of Nations: Horror Cinema, Historical Trauma and National Identity. Manchester: Manchester University Press, 2008. Print.

Carr, Raymond. Modern Spain, 1875-1980. New York: Oxford University Press, 1980. Print.

Caruth, Cathy. Unclaimed Experience: Trauma, Narrative, and History. Baltimore: The John Hopkins University Press, 1996. Print.

Del Toro, Guillermo. Interview by Mark Kermode. 'Guillermo del Toro.' The Guardian.com, The Guardian News and Media. 21 Nov. 2006. Web. 22 May 2015.

Deleyto, Celestino. 'Rewriting Spain: Metafiction and Intertextuality in Saura's Carmen.' Journal of Hispanic Research. 2.2 (1994): 237-247. Print.

D'Lugo, Marvin. Guide to the Cinema of Spain. Westport: Greenwood Publishing Group. 1997. Print.

Edelman, Lee. No Future: Queer Theory and the Death Drive. Durham: Duke University Press, 2004. Print. 
Evans, Peter. 'Marisol: The Spanish Cinderella.' Spanish Popular Cinema. Ed. Antonio Lázaro-Reboll and Andrew Willis. Manchester: Manchester University Press, 2004. 129-151. Print.

Graham, Helen. 'Popular Culture in the "Years of Hunger." Spanish Cultural Studies. Ed. Helen Graham and Jo Labanyi. Oxford: Oxford University Press, 1995. 237-245. Print.

Graham, Helen and Labanyi, Jo, eds. 'Culture and Modernity: The Case of Spain.' Spanish Cultural Studies. Oxford: Oxford University Press, 1995 1-20. Print.

Halbwachs, Maurice. On Collective Memory. 1925. Ed. and Trans. Lewis A. Coser. Chicago: University of Chicago Press, 1992. Print.

Higginbotham, Virginia. Spanish Film Under Franco. Texas: University of Texas Press, 1988. Print.

Hopewell, John. Out of the Past: Spanish Cinema After Franco. London: British Film Institute, 1986. Print.

Kinder, Marsha. Blood Cinema: The Reconstruction of National Identity in Spain. Berkeley: The University of California Press, 1993. Print.

-.'The children of Franco in New Spanish Cinema.' Quarterly Review of Film Studies 8.3 (1983): 57-76. Taylor \& Francis Journals Complete. Web. 30. Sep. 2014 Labanyi, Jo. 'Memory and Modernity in Democratic Spain: The Difficulty of Coming to Terms with the Spanish Civil War.' Poetics Today 28.1 (2007): 89-116. JSTOR Arts and Sciences III. Web. 30 Sep. 2014.

Landsberg, Alison. Prosthetic Memory: The Transformation of American Remembrance in the Age of Mass Culture. New York: Columbia University Press, 2004. Print.

Lázaro-Reboll, Antonio. Spanish Horror Film. Edinburgh: Edinburgh University Press, 2012. Print.

—.'The Transnational Reception of El espinazo del diablo (Guillermo del Toro 2001).' Hispanic Research Journal 8.1 (2007): 39-51. Maney Online. Web. 30 Sep. 2014.

Leggott, Sarah. 'Representing Spain's $20^{\text {th }}$-century Trauma in Fiction: Memories of War and Dictatorship in Contemporary Novels by Women.' Trauma, Media and Art: New Perspectives. Ed. Mick Broderick and Antonio Traverso. Cambridge: Cambridge Scholars Publishing, 2010.120-131. Print.

Lowenstein, Adam. Shocking Representation: Historical Trauma, National Cinema and the Modern Horror Film. New York: Columbia University Press, 2005. Print. Martin-Jones, David. Deleuze and World Cinemas. London: Continuum International Publishing Group, 2011. Print.

Merino, Eloy E. and Song, Rosi H., eds. Traces of Contamination: Unearthing the Francoist Legacy in Contemporary Spanish Discourse. Lewisburg: Bucknell University Press, 2005. Print.

Narváez, Rafael F. Embodied Collective Memory: The Making and Unmaking of Human Nature. Lanham: University Press of America, 2013. Print. 
Pavlović, Tatjana; Alvarez, Inmaculada; Blanco-Cano, Rosana; Grisales, Anita; Osorio, Alejandra and Sánchez, Alejandra. 100 Years of Spanish Cinema. Oxford: Wiley-Blackwell, 2009. Print.

Pavlović, Tatjana. Despotic Bodies and Transgressive Bodies: Spanish Culture from Francisco Franco to Jesús Franco. New York: State University of New York Press, 2003. Print.

Perriam, Chris. 'El espíritu de la colmena (Víctor Eríce, 1973).' Burning Darkness: A HalfCentury of Spanish Cinema. Ed. J.R. Resina. New York: SUNY Press, 2008. 61-82. Print.

Valis, Noël. The Culture of Cursilería: Bad Taste, Kitsch and Class in Modern Spain. Durham: Duke University Press, 2002. Print.

Willis, Andrew. 'From the Margins to the Mainstream: Trends in Recent Spanish Horror Cinema.' Spanish Popular Cinema. Ed. Antonio Lázaro-Reboll and Andrew Willis. Manchester: Manchester University Press, 2004. 237-249. Print.

—.'Spanish Horror and the Flight from Art Cinema.' Defining Cult Movies: The Cultural Politics of Oppositional Taste. Ed. Mark Jancovich, Antonio Lázaro-Reboll, Julian Stringer, and Andy Willis. Manchester: Manchester University Press, 2003. 71-83. Print.

Wright, Sarah. The Child in Spanish Cinema. Manchester: Manchester University Press, 2013. Print.

\section{Filmography}

Ana And the Wolves [Ana y los lobos]. Dir. Carlos Saura. Elías Querejeta Producciones Cinematográficas S.L., 1973. Film.

An Angel has Appeared. [Ha llegado un Angel]. Dir. Luis Lucia. 1961. Richard Bradley distribuciones, 2009. DVD.

BiCyCles ARe for Summer [LAS biCicletas son PARA El verano]. Dir. Jaime Chávarri. In-Cine Compañía Industrial Cinematográfica, 1984. Film.

Cousin Angelica [La PRima AngéLICA]. Dir. Carlos Saura. Elías Querejeta Producciones Cinematográficas S.L., 1974. Film.

The Dark Hour [La hora fría]. Dir. Elio Quiroga. Eqlipse Producciones Cinematográficas S.L., 2006. Film

The Death of Mikel [La Muerte De Mikel]. Dir. Imanol Uribe. Aiete Films S.A., 1984. Film.

The Devil's Backbone [El Espinazo Del Diablo]. Dir. Guillermo del Toro. 2001. The Criterion Collection, 2001. Blu-ray DVD.

Eugenia de Montijo. Dir. José López Rubio. Manuel del Castillo, 1944. Film.

The Heifer [LA vaquilla]. Dir. Luis García Berlanga. In-Cine Compañía Industrial Cinematográfica, 1985. Film. 
The Hunt [LA CAZA]. Dir. Carlos Saura. Elías Querejeta Producciones Cinematográficas S.L., 1966. Film.

In a Glass Cage [Tras el CRistal]. Dir. Agustí Villaronga. T.E.M. Productores S.A., 1987. Film.

InÊs DE CAstro. Dir. José Leitão de Barros. Faro Producciones Cinematográficas, 1944. Film.

Julia's Eyes [Los ojos de Julia]. Dir. Guillem Morales. Antena 3 Films, 2010. Film. The Legion's For Me! [¡A Mí LA LEgion!]. Dir. Juan de Orduña. Compañía Industrial Film Español S.A. (CIFESA), 1942. Film.

The Madness of Love [Locura de Amor]. Dir. Juan de Orduña. Compañía Industrial Film Español S.A. (CIFESA), 1948. Film.

Martyrs of the Philippines [Los úlitmos de Filipinas]. Dir. Antonio Román. Alhambra-Cea, 1945. Film.

The Miracle of Marcelino.[Marcelino pan y vino]. Dir. Ladislao Vajda. Chamartín Producciones y Distribuciones, 1955. Film.

The Nameless [Los sin nombre]. Dir. Jaume Balagueró. 1999. Miramax Echo Bridge, 2005. DVD.

Night of the Howling Beast [LA maldición de la Bestia]. Dir. Miguel Iglesias. Profilmes, 1975 .

The Orphanage [El orfanato]. Dir. Juan Antonio Bayona. 2007. New Line Home Video, 2008. Blu-ray DVD.

The Others [Los otros]. Dir. Alejandro Amenábar. 2001. Optimum Home Entertainment, 2011. Blu-ray DVD.

Painless [Insensibles]. Dir. Juan Carlos Medina. Les Films d'Antoine, 2012. Film. PAN's LAByrinth [El LABERINTo DEL FAuno]. Dir. Guillermo del Toro. Estudios Picasso, 2006. Film.

PePpermint Frappé. Dir. Carlos Saura. Elías Querejeta Producciones Cinematográficas S.L., 1967. Film.

Pirates of the Caribbean: At World's End. Dir. Gore Verbinski. Walt Disney Pictures, 2007. Film.

RACE [RAZA]. Dir. José Luis Sáenz. Cancilleria del Consejo de la Hispanidad, 1942. Film.

Raise Ravens [Cría cuervos]. Dir. Carlos Saura. 1976. The Criterion Collection, 2007. DVD.

Shiver [Eskalofrío]. Dir. Isidro Ortiz. A Punto la Postpo, 2008. Film.

The Spirit of the Beehive [El Espíritu de la colmena]. Dir. Víctor Eríce. 1973. The Criterion Collection, 2006. DVD.

Tombs of the Blind Dead [La noche Del terror ciego]. Dir. Amando de Ossorio. Interfilme, 1972.

Vampyros Lesbos. Dir. Jesús Franco. CCC Telecine, 1971. Film. 
VIRIDIANA. Dir. Luis Buñuel. Unión Industrial Cinematográfica (UNINCI), 1961. Film. Who Can Kill a Child? [¿QuiÉn PUEde Matar a Un NiÑo?]. Dir. Narciso Ibáñez Serrador. 1976. Dark Sky Films, 2007. DVD. 



\title{
4. The Child Seer and the Allegorical Moment in Millennial Spanish Horror Cinema
}

\begin{abstract}
Chapter Four presents an analysis of Spanish horror films THE DEviL's BACKBONE (Guillermo del Toro, 2001), THE NAMELESS (Jaume Balagueró, 1999), and The Orphanage (Juan Antonio Bayona, 2007) to show how these films position their uncanny children as terrifying but cathartic eruptions of the historical traumas that were long concealed by the ligatures of Francoist discourse. Using Adam Lowenstein's framework of the 'allegorical moment', the chapter demonstrates how these uncanny children utilize trauma to break through their symbolic bounds in a Spanish context. In addition, the chapter outlines how these films engage with Franco-era art films SPIRIT OF THE BeEhIVE (Víctor Eríce, 1973) and RAISE RAVEns (Carlos Saura, 1976).
\end{abstract}

Keywords: Childhood, Allegorical moment, Trauma, Child seer, Collective memory, Spanish horror film

During the millennial turn, Spanish culture finally became consumed with an impulse to reconfigure the collective memory in order to account for the trauma of the Civil War. As Sally Faulkner articulates, the war became a 'newly urgent question for 2000 s Spain' $(2013,253)$ : harnessing the conditions of felt historical transition incarnated by the shift into the 21st century, cultural discourse turned to uncovering and assimilating the traumas long suppressed in Spain's historical narrative. This excavation of the collective memory became the project of the Association for the Recuperation of Historical Memory, formed in 2000, which seeks to collect oral and written testimonies of victims of the war and Francoist regime, and also coordinates the opening of mass graves. Subsequently, a number of other groups emerged

Balanzategui, J., The Uncanny Child in Transnational Cinema: Ghosts of Futurity at the Turn of the Twenty-First Century, Amsterdam University Press, 2018.

DOI: $10.5117 / 9789462986510 / \mathrm{CHO} 4$ 
aimed at reclaiming suppressed pasts and reshaping the national narrative, such as the Forum for Memory and the Spanish Civil War Memory Project.

This mounting cultural interest in the darker facets of Spain's past eventually led to the Historical Memory Law, passed in 2007 by Prime Minister Josè Luis Zapatero. The law recognizes victims on both sides of the war, while formally condemning the Franco regime, including removing plaques commemorating the war and dictatorship from public buildings. The controversy surrounding the law - the passage of which was opposed by both the Republican Left of Catalonia and the conservative Popular Party - illustrates, in the words of Leggott, the 'complex relationship between remembering and forgetting in a society in which the articulation of the past has been forbidden' $(2010,122)$. The war and dictatorship are thus not historical pasts distanced by the passage of time: as Leggott asserts, 'the recent dictatorial past continues [...] to hold deep significance in contemporary Spain' $(2010,122)$. The painful reshaping of the collective memory is most affectively expressed in the horror films that erupted in tandem with these organizations aimed at recuperating these long-suppressed pasts.

The spectral children in the films analysed in this chapter - THE NAMELESS (Jaume Balagueró, 1999), The Devil's BACKbone (Guillermo del Toro, 2001), and The OrPhANAGE (Juan Antonio Bayona, 2007) - are caught between death and life, past and present. From this liminal position, they enact the resurgence of repressed collective memories from the traumatic post-Civil War period. Chapter Four thus outlines how the cultural return of the repressed is mobilized through the figure of the uncanny child, who is faced with a traumatic encounter while too young to comprehend or respond to it effectively. As a result, the unassimilated trauma incubates within the child, to be unleashed in monstrous disruptions to symbolic coherence suggestive of a volatile future: a complex temporal process that evocatively captures the anxieties of Spain's millennial milieu. Adding to the temporal complexity of these cultural expressions of trauma, these films draw on tropes established in dissident art cinema of the 1970s - namely, the eerily insightful child characters in THE SPIRIT OF THE BEEHIVE (Victor Eríce, 1973) and RaISE RAVENs (Carlos Saura, 1976). Through the figure of the uncanny child, temporal belatedness becomes sewed into the narrative and aesthetic of these horror films with a melancholic yet ultimately helpless urgency, a belatedness bound to the films' preoccupations with the delayed recognition of past traumas.

These child characters ostensibly embody Caruth's characterization of trauma as 'a breach in the mind's experience of time, self, and the world' caused by an event that 'is experienced too soon, too unexpectedly, to be 
fully known and is therefore not available to consciousness until it imposes itself [...] repeatedly [...] in [...] nightmares and repetitive actions' $(1996,4)$. Yet these children come to relish this traumatic breach in homogenous time and meaning, in turn gaining a voice outside of the constrictive pressures of a politically ordained futurity. Through postwar Francoist efforts to validate the Nationalist cause and subsequent transitional fixations with rapid progress and hypermodernity, the child has long been implicated in Spain's resistance to consider the past in favour of crafting utopian visions of the future, in a way that precisely refracts 'the pervasive invocation of the Child as the emblem of futurity's unquestioned value' (Edelman, 2004, 3). However, if futurity is violently divorced from childhood - as is the case in these horror films - such narratives of historical progression are thrown into disarray, as the child instead disturbs the constrictive temporal structures that she usually buttresses. Exigently bound up with the tragedies papered over in narratives of historical progress, the ghostly children of millennial Spanish horror embody transgressions of spatiotemporal coherence coded as both monstrous and powerful. As a result, these characters expose the revolutionary potential of childhood outlined by Walter Benjamin and described by Alison Landsberg, a potential that emerges from 'the child's ability to see through and question the reified structures of society, to imagine new possibilities, new social constellations' (2004, 89).

These child figures are thus monstrous in the Deleuzian sense: they become 'the pure unformed' $(2004,107)$, embodying a breakdown in accepted (adult) regimes of meaning to generate new ways of approaching disturbing situations. Monstrosity can thus be understood as a 'sense-producing machine, in which nonsense and sense are no longer found in simple opposition, but are rather co-present within a new discourse' (Deleuze, 2004, 107). I consider how these ghostly children raise a monstrous new discourse in this chapter by situating them as incarnations of the 'child seer', a concept Deleuze outlines alongside his introduction of the time-image in Cinema 2 (1997a, 2-7). Deleuze argues that the child seer first emerged in Italian neorealist films as a response to the massive cultural rupture of World War II. According to Deleuze, the seer becomes trapped in the traumatic gap between perception, understanding, and decisive action, yet, while entombed in this in-between state of physical and cognitive incapacity, the seer gains a powerful insight beyond the limits of linear time (1997a, xi-xii; 2-7).

Caught in the past while shaping the flow of the present, the characters in the films analysed manifest powerful 'allegorical moments' - a term coined by Adam Lowenstein to describe an intersection in certain horror 
films that exposes 'our connection to historical trauma across the axes of text, context, and spectatorship [...] [through the mobilization of] the unpredictable and often painful juncture where the past and present collide' $(2005,9)$. Lowenstein characterizes the allegorical moment as a 'shocking collision of film, spectator and history where registers of bodily space and historical time are disrupted, confronted and intertwined' (2005, 1). He draws on Walter Benjamin's discussion of Jetztzeit to conceptualize this moment as a collision which 'blast[s] open the continuum of history' (Benjamin cited in Lowenstein, 2005, 16) in a manner that is both confrontational and liberating. Through Benjamin, Lowenstein links the 'betweenness' that characterizes allegorical representations with the agonizing 'betweenness' of historical trauma, as is potently expressed in Benjamin's discussion of the death's head:

For Benjamin, the image of the death's head, or the corpse, reveals the sorrow behind a false redemptive face of history, just as it reveals the fragments behind a mirage of unified individual identity. Benjamin designates this mode of revelation as allegorical, where 'meaning' is glimpsed between the dead corpse and the living body, between individual interiority and historical exteriority. $(2005,146)$

Lowenstein suggests that 'allegory honors representation's promise that trauma can be communicated - its commitment to the image of death is simultaneously a commitment, however conflicted and provisional, to recognition, to the past's value for the present' $\left(2005,15^{-16}\right)$.

Frightening images of death are, of course, a key preoccupation of the horror genre. Hereby, Lowenstein seeks to analyse the 'allegorical confrontation between past and present' that emerges when horror cinema reveals to us the extent to which 'traumatic events lodged in the past' have 'echoes [that] resonate in the present' $(2005,177)$. The uncanny children of millennial Spanish horror ignite such a process, which Lowenstein describes as 'a return of history through the gut' $(2005,48)$. Furthermore, the allegorical moment encapsulates the uncanny child's challenge to entrenched historical master narratives: as Lowenstein suggests, 'allegory resists fantasies of strictly teleological history in favour of fleeting instants where "meaning" is forged between past and present' $(2005,15)$. By raising or even embodying allegorical moments, the child characters in the films under discussion unravel paradigms of national progress that previously worked to mask the cultural wounds of post-Civil War Spanish society. That these figures have clear roots in the enigmatic children of 1970 art cinema enhances 
the affects and implications of their traumatic allegorical moments, evoking a confrontation between past and present that extends beyond the films' diegeses. These figures thus incite particularly layered instances of Lowenstein's allegorical moment. They expose that the apparently distinct relations between Spain's past and present are much more tangled than teleological conceptions of progress - themselves remnants of Francoist discourse - dare to acknowledge.

\section{Seething Mutations in the Children of Franco: THE SPIRIT OF THE BEEHIVE and RAISE RAVENS}

Before examining these horror film children, I will turn to their progenitor, the child seer in 1970s art films BEEHIVE and RAISE RAVENS. The gaze of the children in these films destabilizes inflexible constructions of temporality in ways that are intertwined with the directors' methodological projects: these child characters are able to see through the stiff and dogmatic narratives of nationhood that characterized Francoist propaganda. Thus, in a practical sense, the child seer is a vehicle through which Eríce and Saura critique such cultural metanarratives in ambiguous ways, allowing them to evade censorship.

Deleuze explains that the seer surfaces when a powerless and confused child character experiences a disorienting breakdown in the sensory-motor schema, a condition he associates in the opening of Cinema 2 with the uncertainty of the post-World War II period. This sensory-motor collapse forces the child to experience a 'purely optical or sound situation' (1997a, 5) that is divorced from the relentless progression of linear time. As a result, these children perceive the loss of a clearly defined, coherent meaning system - or what Deleuze terms an 'encompassing situation' (1997a, 57) - a loss that resonates with the moments of national uncertainty and transition depicted in BEeHIVE and RaVENS.

The children of BEEHIVE and RAVENS are trapped within unsavoury situations that they are unable to change or interact with physically: confused and largely ignored in the liminal period characterized by the immediate aftermath of the Civil War in BEEHIVE, and in the months preceding the death of Franco in RAVENS, they are continually forced to wait and watch rather than act. These arcane moments incarnate Caruth's 'breach in the mind's experience of time, self, and the world' (1996, 4). Yet the child characters' penetrative gaze upon these inscrutable situations - not a gaze that seeks to master the situations it confronts, as in Laura Mulvey's (1975) seminal essay, 
but to take in their fissures and opacity - comes to be the very source of their eerie yet generative power. In his insightful exploration of the Deleuzian child seer in world cinema, David Martin-Jones explains that 'the child seer encounters something "intolerable and unbearable", something [...] beyond their power to act upon' $(2011,74)$. He suggests that 'these are characters directly encountering contemporary social and political mutations, and who are mutating along with these historically shifting contexts' (2011, 74). Both BEEHIVE (1973) and RAVENs (1976) were made and released towards the end of Franco's protracted period of illness, which lasted from 1962 until his death in 1975, a prolonged liminal moment saturated with uncertain anticipation. As Pavlović articulates, 'Franco's slow and interminable dying and agony [...] deeply marked the [...] decade and were accompanied by the gradual and final decomposition of his regime' (2003, 70). Absorbing the agonizing sense of in-betweenness that permeated this cultural context through their contemplative gaze, the child characters in both BEEHIVE and RAVENs hover on the threshold of a mutation into something other.

The central motif of both BEEHIVE and RAVENS is the child's huge, staring eyes. The child is played in both films by Ana Torrent and her character is also called Ana in each, solidifying her position as a metaphorical every-child around which the anxieties of the period constellate. The emphasis on Ana's huge eyes highlights her role as seer whose watchful look penetrates the situations in which she finds herself, and her stare is central to each film's narrative and visual landscape. Yet, in both films, Ana is markedly powerless to affect her situation. Thus, she usually appears in the frame as a silent observer, ignored or unheeded by all but the camera. Ana is unable to act upon the situations she witnesses because many of the things she sees are too painful to synthesize in the present moment, a powerlessness further enhanced by her status as a child. Deleuze claims that the child in particular is equipped to become a seer in traumatic conditions because 'in the adult world, the child is affected by a certain motor helplessness, but one which makes him all the more capable of seeing and hearing' (1997a, 3). In Deleuze's conception, unendurable situations generate an extended gap between perception, understanding, and action that the adult is wont to repress but which the child, denied full access to context and information, is forced to accept, undermining the totalizing dominance of the sensorymotor chain of action.

For instance, RAVENS continually draws back to one of Ana's memories from her recent past, in which Ana's mother lies on her deathbed, screaming and writhing in agony. Ana's only response is to stare at her mother in horror before silently backing away, an action that fails to vanquish the 


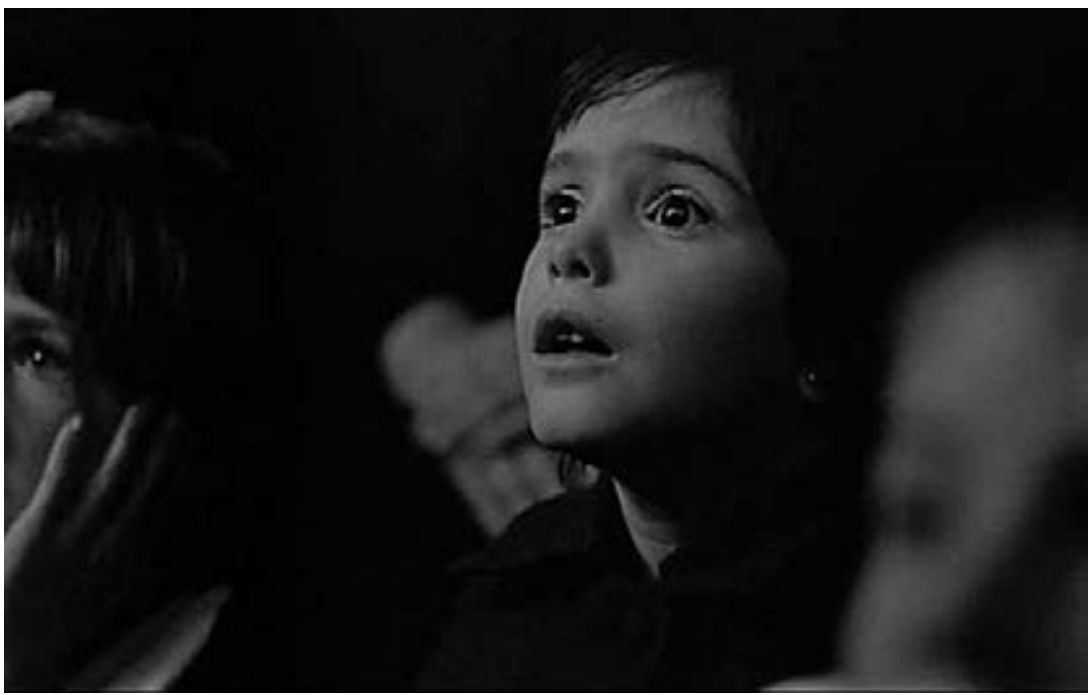

Figure 5. Ana's horrified gaze at the little girl's death in Frankenstein in SPIRIT of the BeeHive.

disturbing image of her agonized mother. This moment haunts the entire film, repeatedly invading the narrative in truncated form, signalling that Ana remains trapped in the gap between perception and decisive action evoked by the sight of her mother's suffering. In BEEHIVE, the intolerable situation is metaphorized by the horror film, FRANKEnSTEIN (James Whale, 1931), which Ana watches at the beginning of BEEHIVE when a mobile cinema brings the film to her village. As Ana watches the scene that traumatizes her throughout BEEHIVE, in which Frankenstein's monster throws the little girl into the lake, the camera focuses not on the scene itself but on Ana's horrified, yet transfixed, expression as she watches it (Fig. 5). Like the scene of Ana's mother's death in RAVEns, Ana becomes obsessed with this traumatic moment and it repeatedly intrudes upon the film in various ways, culminating in the dreamlike restaging of the scene at the film's climax, with Ana occupying the position of the little girl. It is notable that the actual moment in which the monster hurls the child into the lake is never depicted in BEEHIVE - and in fact never appeared in the original release of FRANKENSTEIN, having been removed by censors - forcing both Ana and the film to circle around this frightening vision rather than confront it directly. This response can be seen as a symptom of the Franco-era obstructions to the recognition and assimilation of postwar trauma, while also being inherent to the ways in which, to return to Caruth, it is trauma's very unassimilated nature, 'the way it was precisely not known in the first instance' (1996, 4), which haunts the sufferer. 
Ana's viewing of this scene from FrAnKEnSTEIN functions as Deleuze's pure optical situation, which cannot be acted upon but merely gazed at in fear. In this case, a 'cinema of seeing replaces action' (Deleuze, 1997a, 9); Ana's horrified viewing of FRANKENSTEIN in BEEHIVE and of her mother's death in RAVENS aptly metonymizes the overarching structure of the films themselves. This 'cinema of seeing' constructs the conditions of trauma: as Caruth points out, the traumatic experience constellates around a paradox of vision in which 'the most direct seeing of a violent event may occur as an absolute inability to know it', which in turn engenders the repetitive intrusion of the traumatic event upon the victim's sight, drawing forth 'the belatedness and incomprehensibility that remain at the heart of this repetitive seeing' $(1996,92)$. Although Ana is unable to comprehend or physically engage with these situations, the child's source of power lies in this horrified, repetitive seeing - while she recognizes and even invites the intrusion of this unassimilated trauma, the adult characters remain steadfastly blind to it. That these confused visions of trauma, such as the death of Ana's mother, repeatedly invade the narratives and collapse the boundaries between the diegetic past and present crystallizes the children's vision beyond homogenous time. The Anas appreciate that these dark pasts coexist with the present in ways that the adult characters refuse to understand, as is highlighted by Ana's aunty in RAVENS repeatedly telling the child that her visions of her dead mother are simply 'nightmares' that are not 'real'.

These child seers both literally and figuratively inhabit the 'any-spaceswhatever' outlined by Deleuze: liminal zones he associates with derelict post-World War II spaces that could no longer be adequately understood or traversed, leaving inhabitants at a loss as to how to define them or physically interact with them (1997a xi-xii; $5 ; 8-13)$. In Spain, at the time the films were released, any-spaces-whatever held both material and emblematic prominence in the form of lingering remnants of the Civil War - decaying structures such as abandoned Republican headquarters and homes stood as haunting, but officially unacknowledged, rem(a)inders of the conflict. Such spaces unsettle triumphal, teleological historical discourse. As Lowenstein suggests, 'the ruin [...] has a privileged potential for generating the shock of the allegorical moment' $(2005,108)$. Furthermore, both BEEHIVE and RAISE RAVENS were released during liminal gaps in the national narrative - figurative any-spaces-whatever - deepening the implications of the adult characters' uncertainty as to how to 'progress'.

As outlined earlier, BEEHIVE was produced in 1973 towards the end of Franco's prolonged period of illness, while RAVENS was made in the summer 
of 1975, as Franco lay on his deathbed, and was first released in January 1976, barely two months after his death. At this point, despite the death of the dictator the process of transition had yet to commence; thus, the film was released during a juncture in which Spain remained entombed by the ghost of the Franco dictatorship despite the imminent prospect of a political overhaul. These liminal situations enforce the temporal conditions of trauma in a way that resonates with Deleuze's conception of the any-space-whatever, producing a situation that cannot be assimilated or navigated in the present moment. Both films employ the child's confluence with any-spaces-whatever-metaphorized within the diegesis as deserted, crumbling spaces - to confront the cultural trauma that threatens to (re) surface at the time of their production, and as a means of resisting the linear metanarratives that enable its suppression.

Deleuze describes any-spaces-whatever as 'deserted but inhabited, disused warehouses, waste grounds, cities in the course of demolition or reconstruction. And in these any-spaces-whatever a new race of characters was stirring, a kind of mutant: they saw rather than acted, they were seers' (1997a, xi). While the adult characters in both RAVENS and BEEHIVE attempt in vain to act upon their situations, the children represent such stirring mutants, choosing to welcome and inhabit the any-space-whatever. In RAVENS, Ana appears happiest when she plays with her doll in a decaying, emptied swimming pool, as her adult guardians watch on incredulously. In BEEHIVE, Ana continually visits an abandoned, disused barn, where an exiled Republican soldier hides briefly until he is killed by the Francoist police. She is also drawn to a crumbling old well - at one point, she calls into the well to summon the spirit of Frankenstein's monster (Fig. 6).

Both the ex-soldier who attempts (and fails) to hide in the abandoned barn and the juddering, decaying monster evoke the adult's disintegration in the face of this postwar break down of both smooth national progression and the sensory-motor schema. Higginbotham describes the use of Frankenstein's monster in BEEHIVE as an allegorical caricature of Spain under Francoist mythology, as 'a monster that has lost its memory' $(1988,116)$, which, as a result, 'has no moral sense and, thus, can behave kindly and then kill' $(1988,120)$. In addition, the mindless, relentlessly forward-moving stagger of Frankenstein's monster parallels the adult characters' desperate hold on ideals of national progress: they rely on triumphal discourse about fascist military heroes (applied to Ana's father in RAISE RAVENS) and Spanish glory or authenticity in order to elide the cultural ruptures of war. While the adults flounder in their vain attempts to maintain teleological temporal progression when faced with the loss 


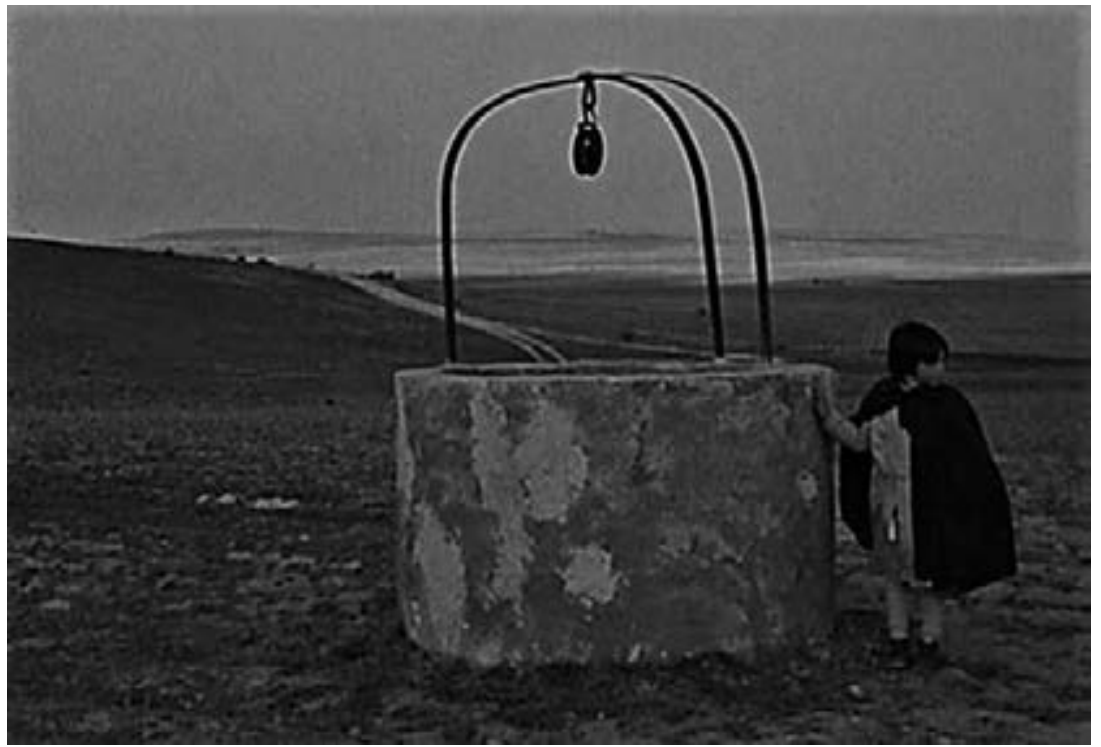

Figure 6. Any-spaces-whatever: Ana plays with the well with which she has become fixated in SPIRIT of THE BeEHIVE.

of a coherent encompassing situation, Ana draws her power from the loss. This is particularly emphasized in the final scene of BEEHIVE, in which Ana stands staring out an open window in a white nightgown, whispering repeatedly to the night sky 'I am Ana.' She appears like the mysterious spectres that haunt later horror films, standing on the threshold of, and summoning, a new, unpredictable situation.

Further linking these child seers with their horror movie successors, in each film, Ana's consciousness is intertwined with a supernatural force not perceived by the adult characters: in BEEHIVE, the amorphous spirit of Frankenstein's monster, and in RAVENS, the mysterious spectre of Ana's dead mother. The child seer's attachment to these ghostly figures invokes the relentless collision of the recent past and the present. This subverts the narrative traditions of mainstream Spanish cinema of prior decades, in particular the cine con niño, which tend to manufacture a break with the recent past in favour of positioning the child as the vessel for a utopian future. By contrast, both Anas welcome the intrusion of these spectres and the subsequent dislocation from linear time that they invoke.

Ultimately, BEEHIVE and RAVENS use the child seer's harnessing of traumatic temporal dissonance to covertly destabilize teleological narratives of victory and progress under Franco. In alignment with this aim, there is also a practical component to the way these films make use of nonlinear time. 
As Saura points out, 'for me and my compatriots, to make the stories we wanted to do, we had to use indirect methods. For example, we couldn't use a linear structure or the ideas would be too clear' (cited in Kinder, 1979, 16). In RAVENS and BEEHIVE, the child seer and her ability to access nonlinear perspectives functions in coalition with the filmmakers need to use indirect methods to evade censorship in their critiques of Francoist dogma. Thus, Ana in both Saura's and Eríce's films represents stirring mutations within the officially sanctioned cinematic children of Franco, subtly disturbing the homogeneity of the national narrative.

It is important to note at this juncture that the directors themselves have been described - and saw themselves - as irrevocably damaged children of Franco. This involves a rethinking of romanticized, utopian understandings of childhood, as is made explicit in Saura's suggestion that RAVENS expresses his belief that:

childhood is one of the most terrible parts in the life of a human being. What I'm trying to say is that at that age you've no idea where it is you are going, only that people are taking you somewhere, leading you, pulling you and you are frightened. You don't know where you're going or who you are or what you are going to do. It's a time of terrible indecision. (cited in Rob Stone, 2002, 102)

Saura thus positions childhood itself as an unnavigable any-space-whatever, rather than a time of growth toward futurity and adulthood. Born in 1931, Saura was a young child during the Civil War, while Eríce, born in 1940, grew up in its aftermath. As Kinder explains, these two directors came to see themselves as:

emotionally and politically stunted children who were no longer young; who, because of the imposed role of 'silent witness' to a tragic war that divided country, family and self, had never been innocent; and who, because of the oppressive domination of the previous generation, were obsessed with the past and might never be ready to take responsibility for changing the future. $(1983,58)$

Thus, the Francoist 'aesthetic of repression' is manifested through the directors' artistic praxis, whereby the political need to use indirect methods melds with their personal expression of a child's powerless and as yet unfathomable experience of national trauma: a trauma that simmers and incubates within these quietly subversive children of Franco. 


\section{The Mutant Child Seer in Millennial Horror Cinema}

Of course, millennial Spanish horror films no longer have to deal with such strict political censorship; thus, the child seers' ability to see beyond linear time is no longer intertwined with the films' methodology. Engaging with these seminal art films as key intertexts, the spectral children of Spanish horror retain the powers of the child seer, however in an exaggerated form, as their ability to see beyond the adult's present is taken to uncanny and threatening extremes. In these films, the child seer mutates into a source of horror. Lowenstein suggests that while art cinema and the horror genre are typically considered to be 'diametrically opposed' $(2005,10)$, in fact, through their expressions of historical trauma, these forms are 'often engaged in interactive exchange' $(2005,10)$. Drawing self-reflexively from the seminal 1970s art films, the children's physical powerlessness to act upon their situations in The Devil's Backbone, The Nameless, and The ORPHANAGE has been brought to its utmost conclusion and resulted in their demise. However, through their deaths (whether literal, as in THE ORPHANAGE and BACKBONE, or figurative and vague, as in THE NAMELESS), these child seers escape the confining bounds of linear time entirely and become powerful figures to fear. As Lowenstein argues, due to its generic intentions to invoke shock, dread, and fear, the 'horror film may well be the genre of our time that registers most brutally the legacies of historical trauma' $(2005,10)$ : this is true of millennial Spanish horror films in particularly multilayered ways.

These uncanny child characters expose awful secrets that, like the return of the repressed in Freud's uncanny, 'ought to have remained hidden but have come to light' (2003b, 241). Yet, in so doing, the children evoke Lowenstein's allegorical moment, in which 'an image of the past sparks a flash of unexpected recognition in the present' $(2005,14)$. By raising previously submerged traumas from the recent past, these children force a renegotiation of narrative and - via allegory - national time in the present. As a result, they menacingly trouble the distinctions between the past and present, yet do so in a way that interrogates with potent force the dominant ideological models of teleological progression that have been operational throughout post-Civil War Spanish society. By finally raising and acting out the unassimilated traumas of the Civil War and dictatorship, these children dismantle constrictive visions of national identity, allowing space for their reformation from the rubble of a post-traumatic context. 


\section{The DeVil's BACKBone}

Like its predecessor BeEHIVe, The Devil's BACKBone is set in the direct aftermath of the Civil War: a liminal period in which the advancement of the national narrative is threateningly uncertain, and adult characters are left unsure of how to engage with their situations. Unlike BEEHIVE, however, BACKBONE is able to confront this period in a direct and retrospective way, so this moment of cultural metamorphosis is figured as a mutation that has already occurred: a repressed spectre in the national consciousness. This is suggested by the montage that opens the film - consisting of a bomb being dropped from a plane, an unconscious child drowning, and a foetus with a malformed backbone floating in stagnant water - and the dialogue that accompanies these images, which recurs at the end of the film:

What is a ghost? A tragedy doomed to repeat itself time and time again? An instant of pain, perhaps. Something dead which still seems to be alive. An emotion suspended in time. Like a blurred photograph. Like an insect trapped in amber.

The opening scenes thus self-consciously establish the film as a whole as an allegorical moment, a confrontation with a traumatic period of time - an instant of pain - which, through its ghostly suspension and repetition, interacts with the present.

A number of critics have considered the ways in which BACKBONE deploys the ghost story to consider national trauma: for instance, Labanyi suggests that the cultural function of the haunting trope 'becomes explicit' (2007, 101) in BACKBONE, a 'literal ghost story as the narrative format' $(2007,101)$ to express historical trauma $(2007,102)$. Anne Hardcastle contends that the film 'dramatizes this confrontation with the past in a way that encourages a reconsideration of the contemporary "reality" of Spain's historical trauma' $(2005,126)$, which in turn helps Spanish audiences 'to overcome the traumatic legacy of the Civil War' from the perspective of 'a stable, successful democracy interested in creating a new meaning for its history' $(2005,129)$. Yet, as Lázaro-Reboll aptly asserts, such a reading tends to 'reiterate and reinforce official historical discourses on contemporary democratic Spain, which have endorsed reconciliation, compromise, and consensus in an exercise of collective amnesia' $(2007,47)$. Furthermore, such a reading positions this trauma as distanced and immobilized through being history, the past. In fact, the mutant child seer of the film, via his embodiment of a potent allegorical moment, challenges such 'collective 
amnesia', instead suggesting that Spain's past lurks alongside its present via the belated temporal frameworks of trauma.

The film is set in an orphanage for young boys from Republican families whose parents were killed or captured in the Civil War. These children thus counter the orphan martyrs of the Franco-era cine con niño, who embody a clean break from the recent Republican and Civil War past and herald a glorious future. The orphanage itself is detached from civilization in the middle of the desert, with an unexploded bomb sitting in the courtyard. The bomb has apparently been defused, however the children are not fully convinced that this is true: as one of the oldest children, Jaime, says at one point, 'They say it's switched off, but I don't believe them. Put your ear against her, you'll hear ticking.' Constantly looming over the children, the bomb mocks the adult's downplaying of the traumatic effects of the war upon the children. Deterritorialized from society, the film's setting functions as the epitome of the any-space-whatever, as is emphasized by the immobile bomb which constantly threatens to detonate; the orphanage's young inhabitants are unable to affect this situation, yet are enraptured by its unnavigable power, and are constantly shown gazing helplessly at the bomb throughout the film (Fig. 7).

As well as being haunted by this unexploded bomb, the orphanage is also haunted by a child ghost, Santi, a former inhabitant of the orphanage who disappeared on the same night that the bomb landed in the orphanage's grounds. As del Toro says of the bomb in the DVD audio-commentary, 'all the stories, occurrences are tied around the bomb, this constant looming reminder of a terrible past'. The young children, the deserted products of a political movement all but vanquished by Franco and his Civil War, also exist as rem(a)inders of this past. Thus, these orphans, through their very existence, trouble Franco's postwar efforts to suppress any remnants of the Republican's cause and set in place a triumphal narrative of national progression. Subsequently, while figuring a monstrous past, the unexploded bomb and the ghost Santi simultaneously suggest a disastrous future: just as the bomb constantly threatens to explode, virtually the only words Santi is heard uttering throughout the film are 'Many of you will die.' By embodying the 'constant looming reminder of a terrible past' which is simultaneously prophetic of a volatile future, Santi and the bomb evoke an allegorical moment that comments on the way in which the past traumas represented by the film continue to seethe beneath the extra-diegetic present.

The scene of Santi's death, shown in full late in the film, is the apotheosis of the seer's physical incapacity, signifying his mutation from innocent child into powerful, monstrous seer. As we learn two-thirds into the film, Santi 


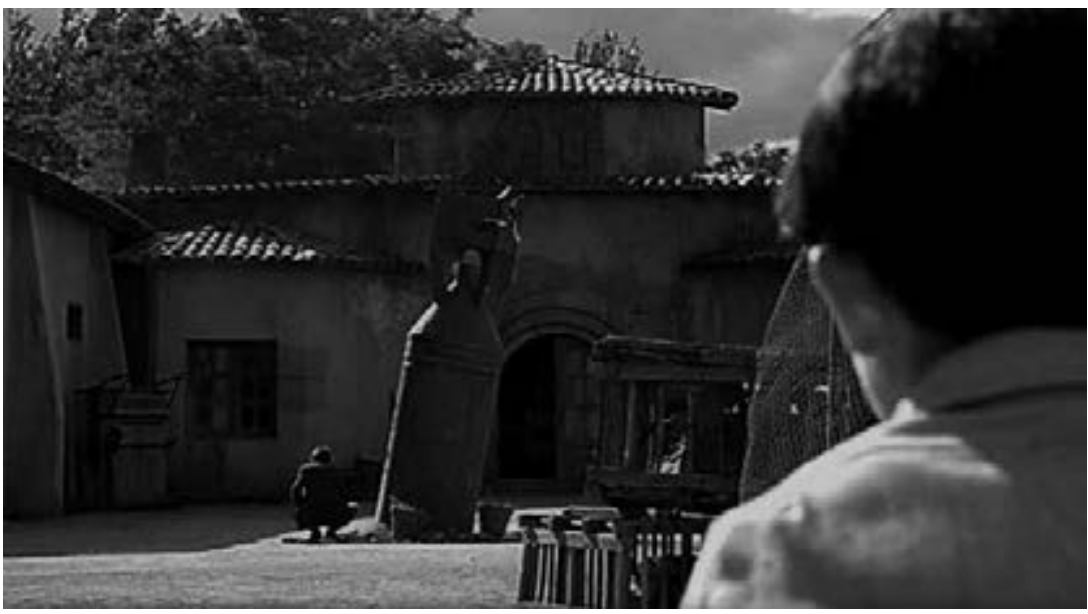

Figure 7. The children gaze at and hover around the unexploded bomb in The DeVIL'S BACKBONE.

was caught playing near the cistern in the orphanage's cellar late at night by the violent and angry young janitor, Jacinto, who was covertly searching for gold he believed to be hidden somewhere on the orphanage's grounds. Jacinto is a former inhabitant of the orphanage who has been inexorably damaged by his experience, and thus represents a parallel realist figuration of the child deformed by wartime turmoil. Furious about encountering the child during his furtive search for gold, Jacinto struck Santi, injuring his head and rendering him unconscious. In a panic, Jacinto then placed the motionless boy into the cistern of amber water. His body immobile, Santi was unable to swim and drowned in the murky water. This amber water, which appears like an infinite void as Santi is filmed in a tight close-up sinking into its depths in slow-motion, epitomizes the unnavigable qualities of the any-space-whatever. Through this death, the ultimate extreme of sensory-motor helplessness, Santi is transformed. He becomes an 'insect trapped in amber': a ghost whose consciousness is fused to the any-spacewhatever represented by the seemingly endless depth of the amber water.

As a ghost, Santi comes to exist fully outside of linear time. The 'amber' that he is trapped within can also be likened to Deleuze's 'crystal of time', a cinematic moment in which the sensory-motor link becomes completely severed, enforcing a collapse in the distinctions between the 'actual' past as a specific point on a chronological line - a 'dead' present that has already passed - and the 'virtual' past which 'coexists with the present that it was' (1997a, 79). The crystal of time can thus be viewed as an aesthetic that mobilizes the allegorical moment, as meaning is formed in the intersices between temporal and subjective boundaries instead of within them. 
Through his death, Santi comes to embody this glimpse of a crystal of time, becoming forever fused to the moment of his drowning so that, through his presence, the past, present, and even the future, refract one another. This is enhanced by the fact that the shot of Santi drowning is shown multiple times throughout the film, including in the opening montage, before the audience has any context through which to understand it or to assign it a clear place in the film's narrative chronology. Ultimately, this allegorical moment, activated by a cinematic 'crystal', ungrounds the linear progression of cinematic and historical narratives that position the cultural rupture of the Civil War as a remnant of the past that has successfully been overcome. Santi's death refuses to remain lodged in an immobilized historical past - a present that has passed - but remains forever alongside the present as a traumatic past that is. At the moment of his death, Santi's subjectivity escapes its corporeal, present-grounded confines, as is indicated by the way his spectral presence visually warps the ether around him. No longer bound to the flow of linear time or the physical encasing of selfhood, Santi's mutation to a ghost renders his penetrative gaze all the more powerful, as he harnesses the power of this 'breach in the mind's experience of time, self, and the world' caused by an event that 'is experienced too soon, too unexpectedly, to be fully known' (Caruth, 1996, 4).

The ghostly Santi is visually constructed as a broken porcelain doll (Fig. 8), with cracks visible all over his body, emphasizing his physical fragility; however, in his ghostly form, it is this very fragility that becomes threatening. The film presents this postwar mutant child as a being who has been shattered whilst undergoing the delicate process of being formed: an eerie incarnation of a trauma that has occurred 'too soon' to be properly integrated. On the DVD commentary, del Toro explains that he wished to express 'how unsafe it is to be a child', before discussing his memory of witnessing children growing up in unstable conditions attempting to kill each other. Del Toro's comment about the danger of childhood - which echoes Carlos Saura's characterization of his childhood - thus suggests a vulnerability that is perilous, as sinister social forces invoke a transfiguration of the child's as yet unformed subjectivity into something monstrous. Recalling Deleuze's definition, this is the monstrosity of the 'pure unformed' $(2004,107)$ that cannot be contained by the existent symbolic order. Accordingly, after his mutation, Santi functions as a fissure in the coherence of the film's diegetic world. Subverting the rational relationship of the body with space-time, wherever he goes, Santi appears to be underwater, with the blood from his head wound constantly floating upwards. Fused to the any-space-whatever of his death, Santi now exists forever as an expression of his past trauma, 


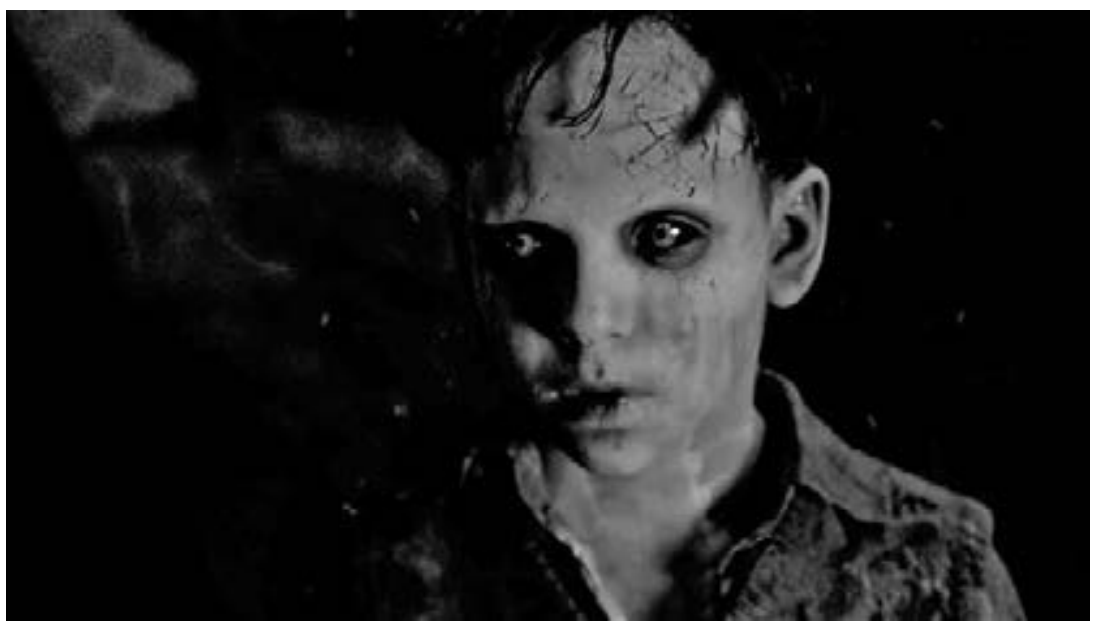

Figure 8. The ghostly Santi in The DeviL's BackBone.

caught in the inescapable gap between perception, understanding, and action. His haunting thus invokes an allegorical moment that impels other characters - and viewers - to experience the frisson of this previously repressed traumatic encounter. As Lowenstein suggests, the allegorical moment enacts a 'complex process of embodiment where film, spectator and history compete and collaborate to produce forms of knowing not easily described by conventional delineations of bodily space and historical time' $(2005,2)$ - a viscerally allegorical process of interaction also incarnated by Santi's gaze.

Santi's most prominent feature is, like Ana of the 1970s art films, his dark, staring eyes. The large shadowy pools of Ana's eyes, however, have mutated into something monstrous in the character of Santi: the entire surface of his eyes is dark and intensely reflective. His eyes accentuate the uncanny penetration of his gaze, while simultaneously establishing an opaque barrier to those who look back into them. In his discussion of the cinematic gaze, Lacanian film theorist Todd McGowan (2003) counters Mulvey's influential suggestion that the gaze of the viewer identifies with the characters and situations on-screen in a way that is pleasurable through its scopophilic mastery. McGowan instead explores the gaze's potential to confront the viewer with a traumatic sense of powerlessness. He suggests that, when watching a film, our perceived scopic mastery over the film's diegesis can be directly challenged by the impenetrability of another character's gaze, which lends this figure a deeply uncanny power by 'exposing a blank spot in the subject's look' (McGowan, 2003, 33). The security and mastery of the viewer 
is threatened when she is unable to pinpoint the other's gaze at the exact spot from which it (appears to) look back at her. As McGowan explains, 'even when the subject sees a "complete" image, something remains obscure; the subject cannot see the Other at the point at which it sees the subject' (2003, 33 ) - the subject being either the audience or their character proxy on-screen. Santi's reflective eyes incarnate such impenetrability: as he advances upon other characters and the viewer, his blank eyes reflect the image of those who gaze upon him, an effect that is particularly uncanny when he stares directly at the camera (and viewer). This reflective, inscrutable gaze raises anxieties about what the child represents once he has mutated under the upheavals of war and fascist oppression, while suggesting the ways in which his traumas reflect and reverberate with the present - both that of the film's diegesis and that inhabited by the viewer.

The spectre raises the ominous possibility that the trauma of Spain's recent past may return within the mutant child to engulf the future. Santi's repetitive uttering of the single ominous phrase, 'Many of you will die' is revealed to be accurate by the film's climax, as a conflict incited by Jacinto within the walls of the orphanage results in the death of all of the adult staff. Santi's accurate prediction crystallizes his ability to perceive the volatility of the future - an undermining of 'futurity's unquestioned value' (Edelman, $\mathbf{2 0 0 4}, 3$ ) which functions as a comment on Spain's present, the 'future' in relation to the film's historical diegesis - while he remains forever bound to his traumatic past. The final scene of the film depicts the threshold of this volatile future, as the orphaned children stand as a group staring out at the endless expanse of desert beyond the orphanage's bounds unsure of how to proceed, the adult characters having killed each other in a microcosm of the Civil War.

\section{The Nameless}

Unlike BACKBONE, THE NAMELESS is set in the present and contains no overt references to the Civil War or Franco. However, like BАсквоNE, the film is consumed by the power of the allegorical moment to unsettle the security of Spain's present: the film's opacity amplifies the Franco-era aesthetics of repression seen in BEEHIVE and RAVENS, ensuring that Spain's grisly past eerily permeates the film through the very absence of direct references. In a similar - but more malevolent - manner to BАсквоNE's Santi, the film's uncanny child Ángela personifies a perpetual traumatic encounter. Ángela cannot be classified as a ghost in the same way as Santi: she resists categorization according to boundaries of life/death, present/past, setting her 
completely outside the bounds of adult frameworks of reason and temporal progression. Augmenting the subversive ambiguity of the Anas, the entire film revolves around the impalpable enigma of Ángela's presence as an embodiment of suppressed trauma.

The opening scene suggests that young Ángela was murdered under mysterious circumstances, depicting the excision of her remains from a well in an abandoned factory (an any-space-whatever, of which there are many in The NAMELESS). The child's body has been severely burnt by sulphuric acid, to the point that the corpse can only be identified as 'Ángela' because one of its legs is shorter than the other. After this gruesome opening, the film then jumps forward five years, demonstrating that Ángela's grieving mother, Claudia, is effectively moving forward with her life after enduring a period of intense mourning. Claudia has separated from her husband, Ángela's father, and appears to have a successful career. However, in a sudden disruption to this proficient working through of trauma, Claudia starts to receive mysterious phone calls from a young girl claiming to be her daughter - in a small, desperate voice, the child utters 'Mummy, it's me.' In another call, the child impels her mother to come and rescue her from a derelict sanatorium on a beach where Ángela, her mother, and father used to play.

Up until this point, Claudia has been shown watching a home videotape of her and her former husband playing with little Ángela on this very beach, replaying the tape over and over again. As Claudia receives this second phone call from the child, the videotape remains paused, flickering and juddering ever so slightly, on a shot of Ángela's face smiling at the camera. Looming in the background, behind the cherubic face of the 'innocent' child, is the dark outline of the sanatorium in which, according to the phone call, Ángela is supposedly currently trapped. The repetitive replaying of a supposedly joyous moment from the past is thus suddenly injected with an uncanny charge with this phone call - accentuated by the image of the child's direct gaze at both Claudia and the viewer - as the past's previously ossified, nostalgic relationship with the present shifts on its axis in an uncomfortable manner. Intertwined with the child's eerie shift from heimlich to unheimlich in this moment is the sudden awareness that the past that she inhabits is not dead and gone.

As a result, while Ángela herself appears on-screen very little, the haunting power of her contradictory (non)presence looms over the film. As is suggested by the images of the child on the home videotape, Ángela's power over her mother and the narrative is, like Santi's, manifested by the uncanny penetration of her gaze. The film opens with a disorientating, rapid-fire 
montage consisting of barely discernible shots of a child dressed in white staring directly at the camera, her arms outstretched. With her blonde hair, bright, dimpled smile, and fine features, Ángela is a clear echo of Marisol, poster child of the 1950s-196os-era cine con niño - yet Ángela's inexplicable appearance in this unsettling opening montage, immediately followed by a shot of the child's decaying corpse, subverts the utopian connotations carried by the angelic Marisol. Such images of Ángela reoccur throughout the film - and subsequently depict the child with her white dress soaked in blood - suddenly puncturing the diegesis at unexpected, seemingly random moments (Fig. 9). Intermingled with these images are flashes of a 'not dead' sign written in blood and glimpses of a snuff movie. These shots are accompanied by pounding, jarring sounds that seem to meld a human scream with a camera shutter - implying that the omnipresent eye of the camera is intertwined with Ángela's own gaze - which aurally assault the viewer in parallel with the violent visual fragmentation of the images. Lázaro-Reboll aptly points out that these images 'suggest the interminable replay of Claudia's traumatic loss' (2012, 250). Furthermore, this inexplicable intrusion of disturbing images of the child, an abrupt disturbance to the film's visual and narrative logic, crystallizes the mutant child seer's violent disruption of a coherent encompassing situation.

The child's mysterious phone calls motivate a quasi-detective narrative, as Claudia enlists the help of a detective and, eventually, an expert on the occult in the desperate search for her daughter. Their investigation leads them to an orphanage and similar cases of missing children, revealing that Ángela's apparently unique case may actually be widespread, a sinister fact somehow suppressed from the public's knowledge. Their investigation starts to suggest that Ángela may not have been murdered after all, but abducted by a cult whose members aim to inflict as much pain and trauma upon the Spanish general public as possible. This cult, called 'The Nameless' - a telling resistance to labelling that characterizes the film's allegorical mechanisms ${ }^{1}$ - is led by an imprisoned madman called Santini. In a conspicuous side-stepping of Spain's own past, Santini was a prisoner in a Nazi concentration camp while a child, a traumatic experience that has damaged him beyond repair. He is in jail for a series of child kidnappings in Spain in the early 1980 s, a decade that marked the final stages of Spain's transition period and is thus representative of the nation's very

1 The NAmeless is based on an eponymous book by British horror novelist Ramsey Campbell, but I suggest that Balagueró's transferral of the story to a Spanish context establishes these allegorical links. 


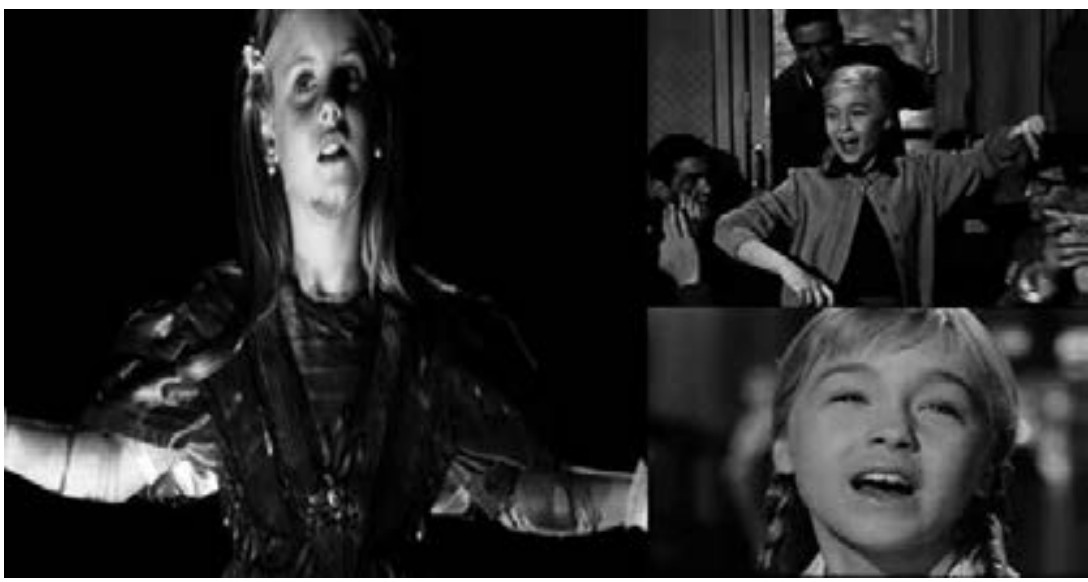

Figure 9. Ángela as she appears in the disturbing montage, which slices the diegesis of THE Nameless (left), Marisol in An Angel has Appeared (top right), and A Ray of Light (Luis Lucia, 1960) (bottom right).

rapid advancement to modernity and democracy post Franco. Thus, the kidnapping of Spanish children, receptacles for the future, by a malevolent cult leader at this point in Spanish history threatens teleological narratives that emphasize the successful progress of this period and the resultant hypermodernity and national unity of the present.

Santini's cult promotes torture, suffering, and terror, as he tells Claudia from the confines of his cell, and is called The Nameless so that they can 'reject the idea of name. As long as they're the nameless ones they can reject human morality.' The impetus behind this sadistic cult recalls the allegorical role of Frankenstein's monster in BEEHIVE, who, lacking memory or any clear sense of identity, was similarly free to reject morality. Furthermore, Santini cryptically suggests that the cult abducts and converts young children because they do not yet have a secure and fully formed sense of self, and are thus easily inculcated into the cult's amoral doctrine. The Nameless is thus a ghastly product of an unassimilated past childhood trauma that aims to engulf and distort Spanish children on a mass scale, allegorically suggesting the wholesale perversion of Spanish childhood.

In the final minutes of the film, Claudia finally thinks she has found her lost child, now a teenager, at the cult's mysterious headquarters - the now abandoned hotel where Ángela was conceived. Both Claudia's sleuthing partners are swiftly killed by cult members, yet, just as it seems all is lost, she is unexpectedly confronted with her ex-husband. He reveals that he has always been a member of the cult, and that he had claimed their daughter for the cult at the moment of her birth: 'a pure child to be perverted from 
the beginning. Thus, the film constructs a toxic vision of contemporary Spain, in which the perpetual cycle of barely repressed trauma ensures that, from the moment of their birth, children are mutated into crucibles for pain and suffering as result of the dogma force-fed to them by malicious and oppressive fathers. There is no escape for the child in this allegorical collapsing together of Spain's Francoist past and the supposedly liberated present.

Despite this bleak twist, the film momentarily seems to have reached a cathartic conclusion with the long anticipated reunion of mother and child. Claudia's husband introduces her to the now teenaged Ángela, and instructs the child to kill her mother. While it seems initially that Ángela will comply, she suddenly breaks down in tears when her mother symbolically reinstates her identity by repeatedly calling her Ángela, and shoots her father instead. Yet, just as it seems that the film has reached a satisfying resolution with the embrace between mother and child, Ángela suddenly tells her mother to stop calling her Ángela. She states 'I have no name', and proclaims that her sole purpose in life is to perpetuate her mother's traumatic loss ('you'll suffer more this way'), before putting a gun to her own mouth. The film then cuts to black and ends with the sound of a gunshot.

It is first signalled to the viewer that there may be something horribly wrong with the seemingly exultant mother-daughter reunion when Ángela opens her eyes while embracing Claudia and focuses a cold stare directly to the camera, behind her mother's back (Fig. 10). While suggestive of her malevolent intent, Ángela's gaze is threatening in that it appears to abruptly break the boundary between the real of the viewer and the fictional diegesis of the film; as the other suddenly stares back, the viewer's imagined mastery over and distance from the world of the film collapses, a particularly uncanny, layered incarnation of Lowenstein's allegorical 'flash of unexpected recognition in the present' $(2005,14)$ which implicates the viewer in the film's traumas. Before putting the gun in her mouth, Ángela says to her distraught mother, 'I'll call you again sometime.' Thus, in the final seconds the neat resolution - and in fact the entire quest narrative laid out in the film - is overturned. It becomes impossible to discern if this girl truly was Claudia's daughter, and the film ends with the suggestion of a volatile future in which Claudia will be tormented endlessly by a chain of 'nameless' children posing as Ángela. At the end of the film, both Claudia and the viewer are trapped in a perceptual gap incarnated by the child's subversive ambiguity - a monstrous amplification of the enigmatic quality of the Anas. This threatening ambiguity can be elucidated using Deleuze's conception of 'indiscernibility', which he associates with the 


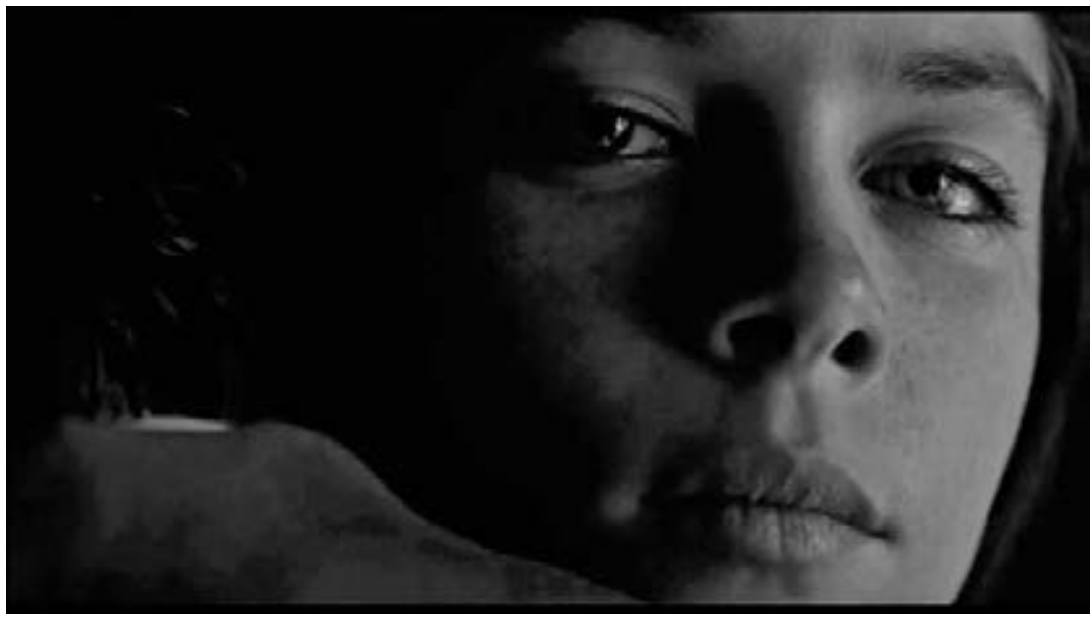

Figure 10. 'Ángela' directs a cold stare at the viewer behind her mother's back in THE NAmELESS.

child seer's inability to establish a sensory-motor link between perception, understanding, and action: 'we no longer know what is imaginary or real, physical or mental, in the situation, not because they are confused, but because [...] there is no longer even a place from which to ask' $(1997 \mathrm{a}, 7)$. The child in THE NAMELESS forces the adult to inhabit an inescapable position of indiscernibility, as the final scene suggests that Claudia will be forever entombed by the any-space-whatever of traumatic loss.

Thus, THE NAmELEss positions the mutant child seer as a seething, infectious threat to contemporary Spanish society. That a single figurative child character is replaced in this film with an amorphous group of nameless beings (which could constitute any number of children), echoes Who CAN Kill a CHILD? (Serrador, 1976) in its suggestion that children as a subjugated social group have become threateningly indecipherable and unpredictable in the post-traumatic collectivity of contemporary Spain. In a similar manner to Santi's cracked body in BACKBONE, Ángela posits a dangerous fragility that can all too easily be permeated by trauma and malicious ideologies, and, via a 'nameless' cult, this process is allegorically extended to the category of Spanish childhood wholesale. This anxiety is crystallized when Claudia explores the abandoned sanatorium by the beach (the site of supposedly happy memories with her young daughter), which is filled with decayed and deformed images of childhood, such as broken dolls in bizarre positions melding with dead animals hanging from the walls - an image that suggests a macabre children's mobile. THE NAMELESS thus implies that the conditions of innocence and purity that traditionally 
define childhood have long since mutated in contemporary Spain, as the child's growth is perverted by the simmering undertow of unassimilated past traumas rather than progressing towards a utopian future.

\section{The Orphanage}

The child seers in THE ORPHANAGE are nowhere near as actively malevolent as Ángela; however, they similarly engage the protagonist and viewer in the sensation of being fused to the traumatic any-space-whatever between perception and action. They thus similarly challenge teleological models of both narrative and, via allegory, historical progression. The film selfconsciously echoes BACкBONE: it was released six years after del Toro's film, and del Toro produced the film. Exposing the film's allegorical preoccupation with the power of concealed traumatic pasts, a medium enlisted to inspect the film's haunted house for ghosts explains to protagonist Laura: 'When something terrible happens, sometimes it leaves a trace, a wound that acts as a knot between two timelines.' THE ORPHANAGE is set in the present in a building that was once an orphanage, but is now the home of a former inhabitant, the now middle-aged Laura, and her family. By featuring a haunted former orphanage that is now a grand and imperious house, the film, like BACKBONE, engages with and rewrites Francoist mythologies of the orphan martyr, who embodies a split from the recent past and functions as an 'emblem of futurity's unquestioned value' (Edelman, 2004, 3). Laura herself was one of the oprhans who once inhabited the property, and by returning to the home of her childhood is unable to break from her trauma-soaked past. The film thus depicts the relations between Laura's childhood and adulthood as circular and reciprocal, rather than constructing a teleological progression from child to adult.

The seer of the film is Simón, Laura's adopted son. The cycles of orphanhood and adoption that overarch the film suggest the troubling of a seamless process of intergenerational continuity. Furthermore, Simón is afflicted with HIV: he is the helpless victim of a disease passed down from the preceding generation, again evoking a fractured intergenerational continuation and a vulnerability to adult malaise that comes to be figured as a threat. Throughout the film, Simón's huge dark eyes are continually emphasized, echoing the Anas. Like Santi, Simón's death is brought about by a situation of sensory-motor helplessness through being entombed within an anyspace-whatever: Laura unknowingly traps young Simón in a cavernous cellar hidden beneath the house early in the film, after placing some heavy bars against the cellar's door, which has been concealed by new layers of 
wallpaper. Thus, the dark secrets of the orphanage's past have literally been papered over in the quest for a fresh start. The heavy bars obstruct Simón's way out and his parents do not hear his screams in the huge house, leaving him powerless to do anything but wait in the cellar to be found. The film follows Laura's quest to find her adopted son - she at first thinks he may have been abducted or run away. When Laura finally finds him trapped within her own house, he is already dead.

It is revealed that Simón has been engulfed by the concealed traumas of the past, sharing the fate of a 'friend' he has made within the haunted orphanage: little Tomás, the ghost of a child who, while alive, was an inhabitant of the orphanage at the same time as Laura. An illegitimate child afflicted with a facial deformity, Tomás was concealed and isolated in the cellar by his mother, a nurse at the orphanage. One day, the other children (with the exception of Laura, who had recently been adopted) discovered Tomás in the secret space, and teased him by leading him to a nearby cave by the ocean and running away. Tomás remained frightened and alone within the cave as the tide came in. Unable to comprehend the situation in time and thus physically powerless to escape it, echoing Santi, Tomás drowned. Tomás's grieving mother, traumatized and furious at the other orphaned children, placed poison in their food - they too were thus killed by a violent event that occurred too soon for them to recognize it taking place, and, like Tomás, became ghosts forever trapped in the any-space-whatever between perception, understanding, and action. Underscoring this agonizingly elongated temporal interval, in a dramatic moment in which the medium ${ }^{2}$ encounters these ghosts, the children cannot be seen but are heard shouting 'We are sick! Please help us, why are we sick?'

Laura was not even aware of Tomás's existence during her time at the orphanage, and she does not realize that all of her childhood friends are dead until she uncovers their remains in a concealed incinerator within a boat shed on the orphanage's grounds. The dramatic scene in which she retrieves these previously hidden, unacknowledged remains - a moment both tragic and horrifying - allegorically reflects anxieties about Spain's long-unacknowledged Republican dead, whose memories and corpses were finally exhumed in early 2000 s Spain. Notably, ThE OrPHANAGE was

2 The medium is played by Geraldine Chaplin, who also played both the adult Ana and Ana's dying mother in RAISE RAVENS. That Chaplin performed both roles in RAISE RAVENS constitutes an often indiscernible folding together of the child's traumatic past and her future. Chaplin's role in ThE ORPHANAGE thus establishes a conscious link to the earlier art film, and ThE OrPHANAGE echoes the depiction in RAISE RAVENS of a woman eternally trapped by unassimilated childhood traumas. 
released in 2007, the same year that the Historical Memory Law was passed. Laura's inability to fully recognize the hidden traumas lurking alongside her childhood past is what ultimately kills Simón. She initially insists that Tomás is imaginary, and, despite growing up in the building, she does not know that the room within which Simón is stuck exists. As a result, the tragedies of the past are repeated, and Simón too becomes caught in an inescapable gap between perception and action. The child is caught in this room for almost the entire duration of the film: particularly on second viewing when the spectator is aware of the lost child's whereabouts, time is felt in its full force while Simón remains trapped in this space of waiting, and the fruitless detective narrative driven by Laura simply accentuates the viewer's awareness of agonizing temporal protraction. Although Laura ostensibly 'solves' the mystery of Simón's disappearance at the film's climax, discovering Simón's body in the cellar, in a painfully felt undermining of narrative progression and resolution, she is unable to act upon the situation, for he is already dead.

Throughout the film, the past is mobilized by the (supposedly) passed temporal state of childhood, as the adult's childhood becomes entangled with this tragic repetition of unassimilated trauma. Immediately prior to her discovery of Simón's body and subsequent suicide, Laura experiences a particularly uncanny moment of collision between her past and her present, which is extended to the viewer via cinematic repetition. The film's opening scene shows Laura as a child playing a game with her friends at the orphanage: Laura incants 'one, two, knock on the wall' with her back to the other children, who quietly creep up behind her, freezing whenever she turns around. Even this opening scene, filmed in a bright wide shot outside on the orphanage grounds, seems eerie: the orphaned children, shrouded in shadow, stalk Laura from behind and stiffen like immobile dolls whenever she attempts to catch them in the act. This childish game comes to metonymize how Laura's childhood friends stimulate shifting relations between past and present through their mutation into ghosts. For much of the film, these dead children seem to be frozen in the past as tragic remnants of recent history, as is depicted through their dusty appearance in sepia-toned photographs and by their aged and cracked porcelain dolls, both of which Laura pores over nostalgically. However, through the children's ever-escalating hauntings, this seemingly immobile past is activated and lurks ever closer to the present.

This process is foregrounded in the sequence immediately prior to the scene in which Laura finds Simón's body, which echoes the film's opening shot. In an attempt to compel the ghostly children to materialize, Laura has 
dressed up in a replica of her childhood orphanage uniform, and starts to play the game of her childhood. The game signals the impending collapse of Laura's past childhood into her present adulthood, a subjective breakdown of temporal boundaries that parallels the film's overarching knotting together of past and present, reflecting Lowenstein's commentary on how the allegorical moment creates meaning via the intersections 'between individual interiority and historical exteriority' $(2005,146)$. Laura nervously chants 'one, two, knock on the wall' - this time in a darkened room - as the ghostly children start to creep up behind her. In contrast to the opening wide shot, the camera now shares Laura's obstructed view of the children approaching her from behind through a tight close-up on her face. Thus, the viewer shares her dread as an unknown force sneaks ever closer outside of our field of vision, as the ghosts appear like fixed shadows whenever the camera, in conjunction with Laura's point of view, whips around to catch them in motion. One of the film's final scenes shows Laura's own ghost sitting on a windowsill with all the other ghostly children - including Simón - suggesting that Laura's childhood past and her adult present have now well and truly folded together following the initial frisson of this collision.

Similarly, the uncanny gaze of the child seer is marked by a lack of distinction between the lost child of the present, Simón, and Tomás, the ghost from the past. Tomás wore a sack mask while alive to conceal his facial deformity, which Simón subsequently finds. Both children are seen wearing the mask at various points in the film; by covering the child's real face, the mask confounds Laura's and the viewer's ability to differentiate the two children (Fig. 11). The mask thus erodes the boundaries between the two boys as singular identities. When Simón/Tomás appears masked, staring ominously at Laura (and the viewer), the point from which his real eyes stare back is disguised. Returning to McGowan's discussion of the inscrutability of the other's gaze, the child's look in this context has become a traumatizing threat in that 'the gaze of the object gazes back at the subject, but this gaze is not present in the field of the visible. [...] [the gaze] constantly eludes our grasp [...] because it gives body to a void' (2003, 33-35). In this case, the oscillation between Simón and Tomás created by the mask ensures that both children revolve around a void of indiscernibility. Furthermore, the blurring of boundaries between the ghost of a child who died decades ago and a child who disappeared only weeks ago constitutes a particularly uncanny allegorical moment; the eerie mask simultaneously provokes the commingling of both two separate identities and the past and the present, as the children collapse 'conventional delineations of bodily space and time' (Lowenstein, 2005, 2). Simón consciously enforces this 


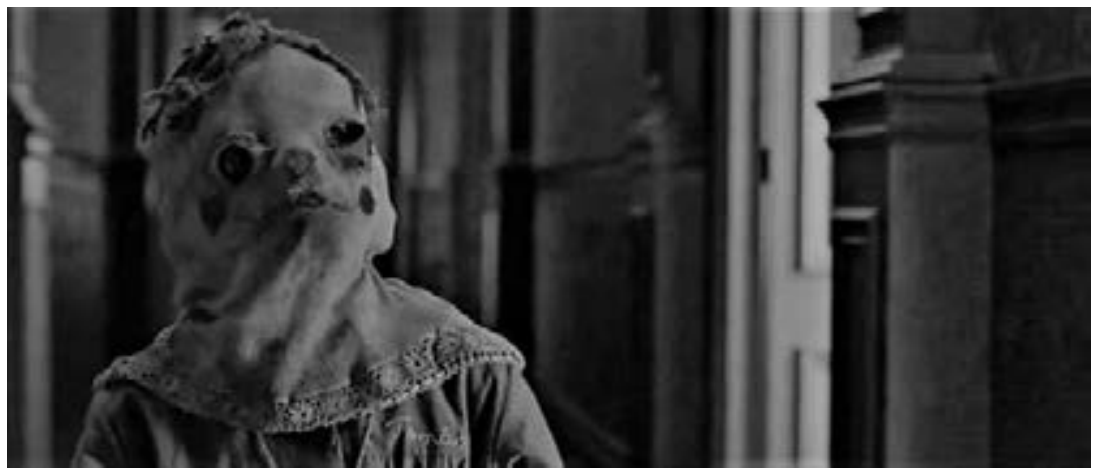

Figure 11. Símón/Tomás simultaneously disturb the boundaries between their singular selfhoods and the past and the present through the adornment of the dead child's mask in The OrPHANAGE.

indiscernibility by not only dressing in the dead Tomás' clothing, but by deciding to dwell in what he calls Tomás's little house' - the cellar in which Tomás spent the majority of his short life, concealed and alone. Thus, the children in THE ORPHANAGE function as the loci for concealed traumas of the past, disallowing teleological narrative progression and preventing the adult protagonist from blindly papering over recent history.

\section{Conclusion}

The cultural rupture represented by the war - violent in both its disruption to cultural unity through solidifying the fissure between the 'two Spains', and in its vast loss of life - was typically uneasily patched over throughout the mid to late 2 oth century in the quest to maintain cohesive conceptions of national identity. This mechanism was perfected and institutionalized by the Franco regime. Even in early 21st-century Spain, a time in which memorials were finally being constructed to recognize and honour the Republican dead, the traumas of war and the oppression of Franco were often neutralized by being positioned at specific points on the continuum of history: as tragic moments of the past, immobilized and defused by the progression of time.

However, Santi's, Ángela's, and Símon's/Tomás's overdetermined relationship to temporality ensures that these uncanny children resist being locked in a frozen historical past that is irretrievably distanced from the present. Instead, these 'insects trapped in amber' suggest the organic de- and reconstructions of collective memory, raising allegorical moments that evoke the collision of past and present and in turn 'blast open the continuum of history' 
(Benjamin cited in Lowenstein, 2005, 86). These child characters create an uncomfortable flash of recognition of the extent to which Spain's past lives within its present - a device literalized extra-diegetically by the fact that those who grew up as stunted 'children of Franco' are now adult filmmakers, political leaders, and constituents of Spanish society. The uncanny child in this context points to the danger inherent in misrecognizing national history as a present that has long since passed, instead of as a past that $i$. Through their position of powerlessness, these children become fused to the anyspaces-whatever in which they died or disappeared, incorporating fissures in spatiotemporal coherence into their beings and drawing their supernatural force from this fusion. Thus, through their deaths, Santi, Ángela, and Simón/ Tomás come to inhabit the any-space-whatever permanently, maintaining an existence outside the rational bounds of linear time and physical space. It is these children's status as insects trapped in amber that ultimately lends them their uncanny power, as they escape the confining bounds of linear teleological progression and return to bring about its destruction.

\section{Works Cited}

Caruth, Cathy. Unclaimed Experience: Trauma, Narrative, and History. Baltimore: The John Hopkins University Press, 1996. Print.

Deleuze, Gilles. Cinema 2: The Time Image. 1985. Trans. Hugh Tomlinson and Robert Galeta. Minneapolis: The University of Minnesota Press, 1997a. Print.

-.The Logic of Sense. 1969. Trans. Mark Lester. Ed. Constantin V. Boundas, London: Continuum, 2004. Print.

Edelman, Lee. No Future: Queer Theory and the Death Drive. Durham: Duke University Press, 2004. Print.

Faulkner, Sally. A History of Spanish Film: Cinema and Society 19ı-20oo. London: Bloomsbury Academic, 2013. Print.

Freud, Sigmund. 'The Uncanny.' 1919. The Uncanny. Trans. David McLintock. New York: Penguin Books, 2003b. 121-176. Print.

Hardcastle, Anne. 'Ghosts of the Past and Present: Hauntology and the Spanish Civil War in Guillermo del Toro's The DeviL's BACKBone.'Journal of the Fantastic in the Arts 15 (2005): 119-131. EBSCO Host Humanities International Complete. Web. 30. Sep. 2014.

Higginbotham, Virginia. Spanish Film Under Franco. Texas: University of Texas Press, 1988. Print.

Kinder, Marcia. 'Carlos Saura: The Political Development of Individual Consciousness.' Film Quarterly 32.3 (1979): 14-25. JSTOR Arts and Sciences III. Web. 30 Sep. 2014. 
—.'The children of Franco in New Spanish Cinema.' Quarterly Review of Film Studies 8.3 (1983): 57-76. Taylor \& Francis Journals Complete. Web. 30. Sep. 2014. Labanyi, Jo. 'Memory and Modernity in Democratic Spain: The Difficulty of Coming to Terms with the Spanish Civil War.' Poetics Today 28.1 (2007): 89-116. JSTOR Arts and Sciences III. Web. 30 Sep. 2014.

Landsberg, Alison. Prosthetic Memory: The Transformation of American Remembrance in the Age of Mass Culture. New York: Columbia University Press, 2004. Print.

Lázaro-Reboll, Antonio. Spanish Horror Film. Edinburgh: Edinburgh University Press, 2012. Print.

—.'The Transnational Reception of El espinazo del diablo (Guillermo del Toro 2001).' Hispanic Research Journal 8.1 (2007): 39-51. Maney Online. Web. 30 Sep. 2014.

Leggott, Sarah. 'Representing Spain's $20^{\text {th }}$-century Trauma in Fiction: Memories of War and Dictatorship in Contemporary Novels by Women.' Trauma, Media and Art: New Perspectives. Ed. Mick Broderick and Antonio Traverso. Cambridge: Cambridge Scholars Publishing, 2010. 120-131. Print.

Lowenstein, Adam. Shocking Representation: Historical Trauma, National Cinema and the Modern Horror Film. New York: Columbia University Press, 2005. Print.

Martin-Jones, David. Deleuze and World Cinemas. London: Continuum International Publishing Group, 2011. Print.

McGowan, Todd. 'Looking for the Gaze: Lacanian Film Theory and its Vicissitudes.' Cinema Journal 42.3 (2003): 27-47.JSTOR Arts and Sciences III. Web. 30 Sep. 2014.

Mulvey, Laura. 'Visual Pleasure and Narrative Cinema.' Screen 16.3 (1975): 6-18. Oxford University Press Journals. Web. 30 Sep. 2014.

Pavlović, Tatjana. Despotic Bodies and Transgressive Bodies: Spanish Culture from Francisco Franco toJesús Franco. New York: State University of New York Press, 2003. Print.

Stone, Rob. Spanish Cinema. London: Routledge, 2002. Print.

\section{Filmography}

An Angel has Appeared. [Ha llegado un Angel]. Dir. Luis Lucia. 1961. Richard Bradley distribuciones, 2009. DVD.

A Ray of Light [Un Rayo De LUZ]. Dir. Luis Lucia. 196o. Tribanda Pictures, 2009. DVD.

The Devil's Backbone [El espinazo del diablo]. Dir. Guillermo del Toro. 2001. The Criterion Collection, 2001. Blu-ray DVD.

Frankenstein. Dir. James Whale. Universal Pictures, 1931. Film.

The Nameless [Los Sin nombre]. Dir. Jaume Balagueró. 1999. Miramax Echo Bridge, 2005. DVD. 
The Orphanage [El orfanato]. Dir. Juan Antonio Bayona. 2007. New Line Home Video, 2008. Blu-ray DVD.

Raise Ravens [Cría cuervos]. Dir. Carlos Saura. 1976. The Criterion Collection, 2007. DVD.

The Spirit of the Beehive [El espíritu de la colmena]. Dir. Víctor Eríce. 1973. The Criterion Collection, 2006. DVD.

Who Can Kill a Child? [¿QuiÉn PUede Matar a Un NiÑo?]. Dir. Narciso Ibáñez Serrador. 1976. Dark Sky Films, 2007. DVD. 



\section{Section Three}

Our Fear Has Taken on a Life of Its Own:

The Uncanny Child in Japanese Horror Film 



\title{
5. The Child and Japanese National Trauma
}

\begin{abstract}
Chapter Five considers how the child became a pivotal component of post-World War II Japanese national identity, which is buttressed by a quasi-sacred belief in rapid national progress. The chapter contends that this competitive model of progress conceptually locks the child into an overdetermined fixation with national development. The inextricable entwinement of childhood and national progress led to powerful anxieties about the child when Japan's economy collapsed in what has become known in Japan as the 'Lost Decade', 1991-2001. The chapter reads the boom of child-centred 'J-horror' cinema around the millennial turn as an expression of widespread cultural anxieties that national progress was coming undone.
\end{abstract}

Keywords: Childhood, Progress, Japanese cinema, Lost Decade, National identity, World War II

Parallel to the Spanish horror films discussed in the previous section, the child characters of Japanese horror of the millennial turn problematize a narrow ideal of national progress. At the approach of the turn of the millennium, the release of RINGU (Hideo Nakata, 1998)' ignited a transcultural obsession with the uncanny child. The film incited a franchise that remains one of Japan's most commercially successful domestic film products. ${ }^{2}$ Sadako,

1 For the sake of clarity, I will refer to the original film throughout as 'Ringu', and the franchise as a whole as 'Ring.' In fact, the title 'Ringu' is somewhat problematic as it was not the original translation given to the film's title (which was initially simply 'Ring'). The Romanization 'Ringu' came in use to differentiate Nakata's film from the American remake.

2 In fact, Mark Cousins suggests that RINGU was 'the most commercially successful [film] ever released in [Japan]' $(2013,354)$; however, this claim is inaccurate, particularly two decades after the film's release. But, as Mark Kermode (2000) reinforces, at the time of release, RinGU

Balanzategui, J., The Uncanny Child in Transnational Cinema: Ghosts of Futurity at the Turn of the Twenty-First Century, Amsterdam University Press, 2018.

DOI: $10.5117 / 9789462986510 / \mathrm{CHO} 5$ 
the terrible aggressor of RINGU, has become perhaps the most recognizable horror icon of the new century: a strange but telling paradigm for this moment of global transition, considering that she functions as a harbinger for the collapse of chronological progress. Sadako wears a long, tattered, white dress evocative of the tarnished burial gowns adorned by the vengeful spirits of premodern Kabuki and Noh plays. Furthermore, like the grotesque female spirits depicted in Edo-era ukiyo-e, Sadako's face is obscured by her lank black hair, suggesting but never entirely revealing an unspeakably abject visage. Sadako haunts her victims from within the well in which she died, recalling the ancient Japanese folktale 'Banchō Sarayashiki' ('The Dish Mansion at Banchō') in which a young woman, thrown into a well by her Samurai master and left to die, returns to haunt him from her watery sepulchre.

Yet, while she evokes traditional Japan, Sadako uses technologies such as VHS tapes, televisions, cameras, and computers as the vessels for her supernatural curse. Even her use of technology, when considered on its own terms, speaks of unstable, liminal temporalities: when Sadako first infected a VHS videotape in late 1998, VHS - a triumph of Japanese technological innovation - dominated the home entertainment sector. Yet, DVD had emerged only a year before, and by the time RINGU attained global popularity, VHS was on the brink of obsolescence. Sadako's videotape curse thus surfaces not only in the midst of millennial transition, but in the fold between analogue and digital storage. Emerging from the grainy analogue snow of the VHS image, Sadako advances towards her victims slowly and deliberately, recalling the measured motions of Noh dance, yet her contorted, painfully spasmodic movements suggest those of Butoh, an intentionally abject form of performance art that emerged in the 196os, in part as a protest against Noh and other highly structured, traditional forms of Japanese dance. Sadako's eruption through the television screen which projects her image encapsulates in potent form all of these temporal dissonances, as her previously spectral being suddenly takes on corporeal form within her victim's own present, physical space. Clearly, this eerie creature is polysemically and disruptively asynchronous - as are all the uncanny children from Japanese horror of the millennial turn.

was Japan's most successful domestic horror film, with a worldwide gross of approximately \$13 million. Mitsuyo Wada-Marciano (2009) points out that the sequel RINGU 2 (Nakata, 1999) doubled RINGU's sales, and the franchise continues to expand, with recent sequels SADAKO 3 D and SADAKO 3D 2 (Tsutomu Hanabusa, 2012; 2013) earning a combined worldwide gross of approximately $\$ 20$ million. 
Sadako has become the synecdoche for the uncanny child on a grand scale. She appeared initially in the original novel Ring by Koji Suzuki (1991) (which Suzuki has followed with four sequels); and has since featured in eight Japanese feature films to date (as well as two successful American remakes, an American reboot, and a Korean remake), two Japanese television series and a telemovie, eleven manga, two videogames, a radio drama, and in 2014 joined Sanrio's extremely popular 'Hello Kitty' franchise, which released merchandise such as dolls, stickers, mugs, and pencil cases depicting Sadako emerging from the well in which she died or crawling through a television screen (the most iconic moments of the original film). After the immense success of RINGU, so-called 'J-horror' became metonymic of an entire national cinema. As I outline in this chapter, at the cusp of the new millennium, childhood in Japan became implicated in anxieties surrounding the 'Lost Decade' - a time of economic stagnation after decades of successful postWWII progress - in such deep and complex ways as to enforce a wholesale consideration of what childhood 'means' to Japanese national identity.

\section{The Horror Genre in a Japanese Context}

Many of Japan's most respected and well-known contemporary directors, including Takashi Miike, Sion Sono, Kiyoshi Kurosawa, Takashi Shimizu, and Ringu's Hideo Nakata worked primarily within the horror genre in the final years of the 1990 and first decade of the 2000s. Many of these directors secured their global auteur status through their internationally successful horror releases, and continue to work within the genre or employ horror aesthetics in more conventionally prestigious genres such as period drama and art films (as seen, for instance, in Miike's critically acclaimed period drama HARA-KIRI: DEATH OF A SAMURAI [2011]). Thus, such generic boundaries are often blurred in a Japanese context. As a result, critically acclaimed horror films tend to be assured a place in canonical paradigms of Japanese national cinema - a phenomenon which particularly dominated Japan's film industry during the J-horror boom of the millennial period. In fact, unlike in Spain, the recent influx of globally successful Japanese horror films do not represent a sudden horror 'golden age' following many decades of being relegated to the margins - horror has long been a central and dominant presence in the landscape of Japanese film. However, as Mitsuyo Wada-Marciano (2009) has noted, even though many films produced during Japanese cinema's golden age during the 1950s and 196os are now taken for granted as canonical horror films - including Ugetsu (Kenji Mizoguchi, 1953), GHost Story of YotsuYa (Nobuo Nakagawa, 1959), KwAIDAN (Masaki 
Kobayashi, 1964), and ONIBABA (Kaneto Shindô, 1964) - they were not necessarily considered as such at the time of their production and original release.

Despite the fact that such films of the 1950s and 196os centre upon their eerie atmosphere and an intention to ignite dread and terror in audiences, as Wada-Marciano suggests, they were usually considered art, period and/ or folktale films (known as minwa-mono) at the time of their release (2009, 35-36). Such prestige connotations relate to how these films were marketed for Western film festivals such as the Cannes and Venice Film Festivals, but also reflect their association with time-honoured Japanese theatre traditions Kabuki and Noh ${ }^{3}$ - which themselves draw on ghost folklore known as kaidan - indicating that in Japan, horror aesthetics are not considered to be marginal or inferior. It could in fact be argued that after the successful export of some of these horror-suffused art films to international festivals and audiences, the deployment of horror aesthetics in period pieces and artistic mediations of historical trauma became a distinctive technique of Japanese cinema in which directors took great pride. ONIBABA and KWAIDAN are both foundational instances of this framework, both being supernatural period pieces that raise the spectre of premodern Japan to consider postWWII traumas allegorically. Both films played at the 1965 Cannes film festival, with KWAIDAN being awarded the Special Jury Prize. Ghost tales are ultimately a central facet of Japanese reflections on pre-modernity and ancient traditions - often used to express more recent historical tensions, as in KWAIDAN and ONIBABA - which goes some way towards explaining the prevalence of horror aesthetics in both low and high Japanese film genres. Thus, in Japan, horror's symbolic power and its subsequent ability to work through sociocultural anxieties has long been explicitly recognized.

While supernatural horror has long held an important place in Japanese culture, during the millennial turn and throughout the first decade of the 21st century, the specific subgenre designated J-horror - the transnational classification for these recent Japanese films - came to reshape the landscape of global horror film. As Wada-Marciano points out, the prefix ' $\mathrm{J}$ ' is 'thoroughly connected with the media distributor's strategy of marketing

3 For instance, UGETSO is based on Ueda Akinari's seminal Edo period ghost story collection Ugetso Monogatari (first published in 1776). The film won the Silver Lion Award for Best director at the 1953 Venice Film Festival. GHOST STORY of YotsuyA is a direct retelling of a famous folktale Yotsuya Kaidan, and is based in particular upon the nineteenth-century Kabuki version of the story written by Nanboku Tsuruya. KwAIDAN is an anthology of different ghost tales, drawn from Lafcadio Hearn's collection Kwaidan: Stories and Studies of Strange Things. This film was nominated for the Best Foreign Film at the Academy Awards in 1965, and was awarded the Special Jury Prize at the Cannes Film Festival. 
their product both inside and outside Japan' $(2012,29)$. Subsequent to the release of RINGU, J-horror films began to generate global recognition: as Chi-Yu Shin (2009) suggests, the international success of J-horror was sparked in part by London-based VHS and DVD publisher Tartan developing and globally positioning its 'Asian Extreme' label, which soon led to blockbuster Hollywood remakes of particularly popular films such as RINGU (THE RING, Gore Verbsinki 2002) and Ju-ON (Takashi Shimizu, 2002) (remade as THE GRUDGE, Shimizu, 2004). As a result, J-horror tropes and aesthetics quickly came to suffuse Hollywood horror generally. Such global influence in turn injected J-horror with a particularly heightened domestic cultural currency. For instance, in 2002, the year in which the American remake of RINGU was released, a ritual burial ceremony was held for Sadako in Tokyo to commemorate her passage from a Japanese to an American context - an acknowledgement that, in buying the rights to the RiNG films, Hollywood had on some levels claimed ownership of Sadako. ${ }^{4}$

This strong cultural currency ensures that J-horror's uncanny children have a more direct relationship with mainstream culture than those of the American and Spanish horror films. As both Chika Kinoshita (2009) and Thy Phu (2010) suggest, the term 'J-horror' does not denote simply a nationalized film genre but, to use Kinoshita's term, more of a 'movement' $(2009,104)$. During the shift into the 21st century, a series of ideological and structural contortions were reshaping Japanese culture, many of which spiralled from the bursting of the bubble economy - the effects of which will be explored in more detail below. As Wada-Marciano points out, the stagnation of the economy in the 1990 s resulted in significant restructuring of the film industry. As she suggests, the Lost Decade ushered in a 'reconfiguration at all levels of production, distribution, and reception' (Wada-Marciano, 2009, 16) underpinned by the rapid uprising of digital technologies and home viewing. In fact, she contends that 'J-horror grew out of the specific context of the contemporary Japanese film industry - the disintegration of the studio system and a levelling of competition, even increasing affiliations among "major" and "independent" film productions' (Wada-Marciano, 2009, 18).

The uncanny children that populate J-horror function as expressions of the unease surrounding such industrial and cultural shifts. These figures play out a frightening dissolution of the previously unquestioned ideological braiding of childhood with national identity, and thus the child's growing up

4 The ceremony was held at LaForet Museum, Harajuku; Ring author Koji Suzuki was in attendance (Landry, 2015). 
with national progress. The horrors of the uncanny children in many ways exceed the fictional realm of the films in which they appear, exposing the magnitude of the cultural work they perform: since the beginning of the 21st century, the characters of J-horror have invaded theme parks, city streets, and even sporting matches. A key horror set piece in many J-horror films consists of a technologically mediated image of the child-ghost drawing ever closer to the horrified spectator (diegetic and otherwise), before finally escaping the bounds of her technological housing to overwhelm the human subject: a particularly thrilling theme when depicted in real-life amusment attractions or events. For instance, Sadako has been the subject of a parade at Shibuya crossing (Muir, 2012), threw the first pitch at three major baseball games at Tokyo Dome, and has been the subject of five walk-through horror attractions at indoor theme park Sega Joypolis in Odaiba, Tokyo. ${ }^{5}$ This pervasive cultural performativity goes some way towards elucidating the powerful and lasting cultural influence of the uncanny child in Japan.

\section{The Internal Alien}

Because J-horror was such a ubiquitous pop-cultural phenomenon of the millennial transition, much insightful criticism ${ }^{6}$ has been written about this explosion of transnationally popular Japanese horror films. Yet surprisingly, aside from nuanced analyses by Karen Lury (2010) and Valerie Wee (2013) - the insights of whom I build upon in this section - to date this work has largely elided or understated the significance of the uncanny child, which, along with haunted technologies, is the most tellingly new commonality that underpins this assemblage of films. Much of the scholarly discourse about millennial J-horror focuses on the figure of the onryō (vengeful ghosts, usually female) or broader category the yürei (ghost), and suggests that the monstrous spectres of millennial J-horror are primarily a continuation of the adult female ghosts featured in postwar art-horror (such as the aforementioned GHOST STORY OF YoTSUYA), themselves carried over from Japanese traditional art and kaidan (YoTsuYA being a direct retelling of one such folktale) (Balmain [2008], Blake [2008], Hand [2006], McRoy [2005;

5 For a report on a recent Sadako Joypolis attraction, see Lynzee Lamb (2013).

6 See in particular Colette Balmain (2006; 2008), Linnie Blake (2008); Richard Hand (2006), Chika Kinoshita (2009), Bliss Cua Lim (2009), Adam Lowenstein (2009; 2015), Karen Lury (2010), Jay McRoy (2005; 2008), Thy Phu (2010), Ramie Tateishi (2003), Mitsuyo Wada-Marciano (2009; 2012), and Valerie Wee (2011a; 2011b; 2013). 
2008], and Wee [2011a]). While the legacy of the vengeful female onryō looms over millennial J-horror, the child characters in these films are constituted of a new set of ideological and aesthetic motivations.

While the onryō and yürei are clearly major influences upon contemporary J-horror children (most of which are female), another important precedent to these figures is the eerie, knowing child of Japanese fantastic literature. Awareness of this grounding sheds much light on the cultural and textual mechanics of these characters, while also exposing the extent to which they modulate the long entrenched onryō/yürei archetypes. As Susan Napier (1995) has demonstrated in her work on Japanese fantastic fiction, the eerie child has figured heavily in the Japanese imaginary since the shift to modernity represented by the Meiji Restoration (1868). ${ }^{7}$ In the literary fiction she analyses, Napier describes a trope she designates the 'internal alien': a being, often a child or associated with childhood, who embodies inner psychic turmoil incited 'not by some alien outside force but through some frightening power inside [the protagonist's mind]' (Napier, 1995, 110). Across the examples Napier analyses, the internal alien exists at the interface between the ' $I$ ', the 'Other', and the collectivity at the same time as it exists between the past, present, and future (Napier, 1995, 110-128). She suggests that 'it is this polysemic potential which is so disturbing and enthralling to the reader' (Napier, 1995, 97). Emerging as it did following Japan's tumultuous transition to modernity, the literary trope of the creepy child who thematically and symbolically defies its proper place is deeply bound up with anxieties about national progress: a key feature of millennial J-horror children.

As Napier demonstrates, while the internal alien appears in a great deal of literary fiction post Restoration, ${ }^{8}$ a formative example appears in the short story by Natsume Sōseki from his collection Ten Nights' Dreams (first published in 1908). In the 'Dream of the Third Night', a man is walking through a forest at night with a six-year-old child on his back. The man

7 As is charted in the work of Anne Allison (1996), Napier (1995), Brian Platt (2005), Stefan Tanaka (2004), and many others, 1868 is commonly held as the date of the Meiji Restoration, as it was during this year that practical imperial rule was restored under Emperor Meiji, and Japan's political structure become configured and consolidated under his rule. The period spanned 1868-1912, and, during this time, Japan shifted from a feudal economy to a market economy, underwent a rapid process of industrialization, opened to Western trade, and strengthened its military. The period thus represented an extremely rapid process of modernization as Japan started to establish itself as a significant global agent.

8 Some works Napier analyses as part of the 'internal and ideological alien' trend include Kappa (Akutagawa 1927), Inter Ice Age 4 (Abe 1958), 'Agwhee the Sky Monster' (Ōe 1964), and The Pinch Runner Memorandum (Ōe 1976) and a number of works in Haruki Murakami's oeuvre. 
is aware that the child is his own, and also that the child is blind, but, in a hopeless undermining of adult agency and progress, he knows nothing else, not even to where he is walking or why. Even though the man knows the child is his son, he is afraid of him, for 'with this weird creature on my back, I felt something horrible was about to happen to me' (Sōseki, 200o, 10). As the man aimlessly trods ever onwards through the forest, the child remarks 'I will be heavier soon' (Sōseki, 2000, 10). The forest grows denser and darker, but, in the darkness, the child begins to reflect 'like a mirror, every tiny thing in my past, present, and future' (Sōseki, 2000,11) to the point at which the man 'couldn't stand it anymore' (Sōseki, 2000, 11). Finally, as they stop under a tree, the child tells his 'father' that it has been '100 years since you killed me here!' (Sōseki, 2000, 13); it suddenly dawns on the man that he once killed a blind man under this very tree, a memory he has long since repressed. As he 'realized for the first time that I was a murderer, suddenly the little one on my back became much heavier than before, like a jizō stone child' (Sōseki, 2000, 13).9

The internal alien thus exists at the interface of the man's interior and exterior worlds: the child upon the man's back is the prosthetic vessel for the trauma and guilt he has until now refused to acknowledge consciously. Napier illuminates the multilayered ways eerie moments of recognition such as this are shared by the reader:

Reactions [to the horror] can range from intellectual admiration of and pleasure in the intensity of aesthetic effect [...] to the enjoyable frisson of terror that the reader vicariously experiences. [...] Underlying these obvious emotions [...] are more subtle and complex ones, most importantly the sense of excitement stemming from the liberation of sublimated fears and taboos. (1995, 96)

I suggest that the uncanny children of J-horror represent a contemporary remodelling of the internal alien. This figure has clear parallels with the American uncanny children analysed in Section One, resonating with Freudian myths about childhood's simultaneous entwinement with and distance from the inner depths of the adult psyche. Indeed, as Napier points out, the internal alien trope is connected with shifting ideas about selfhood

9 A 'jizō' is a bodhisattva or Buddhist 'saint' who helps others reach paradise by providing them with enlightenment and insight into their own lives, and is also a protector of children. Jizō is frequently represented throughout Japan as a small, childlike stone statue. For a detailed discussion of jizō, see Jan Chozen Bays (2002). 
throughout the Japanese transition to modernity, as premodern notions of the Japanese self came into contact with Western notions of identity: 'the fantastic Other may be seen as an important means by which postRestoration Japanese began to construct a Westernized sense of self [...] working out their explorations of the self against such textual elements as dreams, ghosts, monsters and dopplegangers' (Napier, 1995, 97). As Nina Cornyetz and J. Keith Vincent have shown in their examination of the history of psychoanalysis in Japan, Freudian psychoanalysis was introduced in Japan in 1912 and spawned a vibrant body of scholarly and cultural Japanese commentary and debate (2010, 3-5).

Freud-inflected notions of childhood as a crucible for adulthood's darkest repressed secrets reverberate in millennial, cinematic incarnations of the internal alien - particularly because the seminal American films of the early 1980 s considered in Chapter One are clear influences on millennial J-horror. Yet, as is indicated by Sōseki's tale, the internal alien functions in a more direct and embodied way than the uncanny children of American horror film, rendering clear and overt some of the complex symbolic mechanisms charted in the first section of this book. Perhaps it is partly because of the internal alien's potent intensification of Freud-influenced mythologies of childhood that this figure, as represented in J-horror, resonated so powerfully with Western audiences and became so conducive to American remakes in the early 2000s. Like the internal alien in Sōseki's tale, the millennial J-horror child raises within adult characters - and viewers - an uncomfortable combination of fear stemming from a seemingly external source, and deep, internal psychic guilt and dread.

These affects are directly related to the sociocultural tensions permeating Japan at the liminal moment represented by the transition into the 21st century, tensions which parallel those surrounding the nation's rapid shift to modernity during and post Restoration. Nowhere more than Japan is the child so anxiously defined as a receptacle for national futurity according to the processual condition of growing up: as Lury suggests, in Japan, the child tends to symbolize 'the continuation of the nation state itself. The child acts to stabilize the inherent instability of modernism. [...] [a]nd seemingly [embodies] the potential for progress' (2010, 26). As will be explored in detail in the next chapter, the uncanny children of J-horror rail against this linear mode of temporality, disassembling the central ontological pillars that have long delineated childhood in Japan. The current chapter proceeds to examine the sociocultural contexts that fostered these millennial anxieties about childhood's subversive potential in Japan. 


\section{The Lost Decade and the Collapse of Progress}

In Japan, the period from the late 1990 s into the 2000 s was particularly fraught due to the Lost Decade, ${ }^{10}$ as the rapid economic growth of the $1960 \mathrm{~s}$ until 1989 suddenly slumped dramatically. Scholars in Japan and around the globe ${ }^{11}$ are still picking apart the ruins of the Lost Decade to determine its causes. The economic recession and subsequent stagnation resulted in wholesale changes to the structure of employment and industry in Japan, as previous models of lifelong employment within a single company have shifted with the increase of flexible, short-term contracts. The reconfiguration of employment has such far-reaching socio-ideological consequences that Anne Allison has characterized it in terms of the 'liquidization' of work and life structures $(2013,8)$. The bursting of the economic bubble thus had just as potent symbolic effects on Japan's national identity as it did tangible ones. As Allison states, 'in liquefied Japan a change in the logic of work seeps into everyday relationality: relations once valued for their sturdiness in space (staying in one company or neighbourhood for decades) and durability over time (lifelong marriages, group memberships, and jobs)' (2013, 8).

The anxieties surrounding this liquidization of seemingly solid spatial and temporal structures are related to the ways in which Japanese cultural identity has become cleaved to notions of national progress. Of course, the quest for progress is intertwined with the national ideology of most countries, however, as Napier points out: 'what makes Japan unique is the remarkable involvement at every level, on the part of the government, private citizenry, business, and educational institutions, in a highly conscious ideology of progress' (1995, 142). Japan's rather astonishing socioeconomic development following the nation's traumatic World War II defeat and subsequent Allied Occupation has long been held as a model for progress to be admired and emulated. As Napier puts it, postwar Japan has 'become something of a myth if not a full-blown fantasy' $(1995,2)$, and the epic qualities of Japan's postwar success story further injected the Lost Decade with the aura of a catastrophic downfall. Fletcher and von Staden explain that 'the experience of the Lost Decade has been traumatic for Japan. [...] Observers no longer claimed that Japan was "number one"'(2012, 275). They further state that 'the effects of the economic stagnation linger as the nation has not found a

10 In fact, this term is often revised to be 'the two Lost Decades', as Japan struggles to overcome this period of economic stagnation.

11 See Miles Fletcher and Peter von Staden (2012); Zuzana Stuchlíková (2012); Christopher Wood (1992); and David Weinstein, A. K. Kashyap, and Hamada Kōichi (2011). 
way out of its economic purgatory of slow growth over the past two decades' (Fletcher and von Staden, 2012, 275). Narratives of rapid national progress started to disintegrate throughout the 1990s, resulting in a wavering of the national confidence that had been successfully reassembled post war. The sociocultural collapse represented by the Lost Decade is particularly traumatic considering the extent to which Japan was required to repress or side-step its own past in order to adopt Westernized modes of progressive time consciousness, a repudiation of Japan's own cultural identity with roots in the Meiji Restoration of 1868 but further enforced throughout the Allied Occupation. Thus, Japan's Westernized, capitalistic progress and the economic rewards reaped through it were particularly high stakes.

In fact, from the time of the Meiji Restoration onwards, the quest for modernity, while overtly successful, has been underpinned by an unstable series of dichotomies. As Kevin Doak elucidates, 'modernity was defined in a variety of ways (and therefore tended toward obscurity): at times it represented a foreign influence - the West; at other times it referred to the Meiji state and its ideology of "civilization and enlightenment"' (1994, xvi). Narratives of rapid national progress attempted to reconcile this discordant constellation of principles, and, in some ways, uneasily suppressed them. Following Japan's traumatic defeat in World War II, fixations with progress were resurrected with deepened exigency and impetus, yet became even more overdetermined due to an inherent association with Japan's victimization: following the bombings of Hiroshima and Nagasaki in 1945, Japan's surrender and the subsequent Allied Occupation (1945-1952), progress became characterized as a valorous quest to overcome the nation's victim status. Yet, this emphasis on valiant progress surged firmly in the opposite direction from reflection on the multilayered extent of Japan's trauma. Involved in this renewed preoccupation with progress and futurity was an avoidance of culpability for the nation's own part in the war. Some disturbing cultural memories of wartime itself were thus quickly repressed and obfuscated.

Yoshikuni Igarashi (2000), Beatrice Trefalt (2003), and Bruce Suttmeier (2010) have demonstrated that accounts of Japanese aggression and violence during the war only began emerging in Japan in the late 196os and early 1970s, and even then in micro-form. As Suttmeier explains: 'for over two decades, the Japanese remembered the war largely through scenes of domestic deprivation and suffering, scenes that acknowledged the horrors of war even as they allayed the central anxieties concerning Japanese wartime activities' $(2010,31)$. Suttmeier elucidates this disavowal through a discussion of the 'triumphant' return in 1972 of Japanese solider Shōichi Yokoi, who had been hiding in a jungle in Guam for the previous 28 years, believing the 
war to be ongoing. His discovery and return to Japan was met with great fascination, and he became a media sensation. While Yokoi was initially valorized for his tenacity and fortitude - qualities that effectively paralleled the dominant discourse on Japan's postwar resilience - he gradually became a much more ambivalent figure. He delivered conflicting accounts about what happened to the two comrades who perished while living with him in the jungle, arousing suspicions about the circumstances of their deaths, and his persistent habit of referring to 'his Majesty the Emperor' excavated the memory of extreme prewar nationalism and Japanese wartime atrocities. Suttmeier suggests that, while Yokoi was initially perceived as 'the image of a victimized, resilient Japanese citizen', this impression was 'increasingly clouded by darker, more threatening scenes that spoke to an aggressive, brutalizing legacy' (2010, 32).

Such undercurrents of suppressed guilt continue to tug at Japanese notions of progress, particularly in recent years following the collapse of the bubble economy now that the veil of rapid progress has worn thin. The Japanese government continue to enact controversial and ambivalent responses to the war. In March 2017, Prime Minister Shinzo Abe's cabinet released a statement approving the use of the 'Imperial Rescript on Education' - issued by Emperor Meiji in 1890 - in Japanese classrooms. Children would recite this edict in school to pledge their allegiance to the Emperor and Japanese nation. The Imperial Rescript was declared null and void after WWII because its celebration of patriotism and national loyalty over individual subjectivity was thought to underpin Japanese military aggression. ${ }^{12}$ In 2013, the Osaka mayor at the time, Torū Hashimoto, claimed that wartime sex slaves (euphemistically known in Japan as 'comfort women') were necessary to ease the suffering and tension experienced by Japanese soldiers, ${ }^{13}$ and in December 2013, Prime Minister Abe visited Yasukini Shrine, which includes among its honourees fourteen convicted war criminals. ${ }^{14}$ In his discussion of Hashimoto's statements, Walden Bello suggests that such actions indicate that Japan 'has yet to come to terms with its actions in World War II' (2013, n.p.). The uncanny child in J-horror tends to raise these tensions in abstracted form: as will be detailed in the next chapter, the child is often characterized as a misunderstood victim before suddenly being exposed as a monstrous aggressor in a climactic twist. In all cases, the J-horror child disturbs narratives of progress and the status of victimhood, 
exposing the long-suppressed guilt and trauma that haunts contemporary Japan. The J-horror movement thus suggests that the Lost Decade forced the unease underlying ideologies of progress to surface, impelling a renewed interrogation of Japan's investment in progress and the uneasy relationship with the nation's past that lurks beneath mythologies of rapid national advance.

\section{Modernity and Childhood}

The J-horror child's disassembling of coherent, progressive time is deeply frightening in a Japanese context because the child sustains the linear logic at the core of conceptions of modernity and progress. As Stefan Tanaka explains, in Japan the child has become:

a site where the ambiguities and contradictions of modernity are ameliorated into a coherent whole personified through the child. [...] Childhood has become a symbol for several aspects of modernity: of a new progressive society, one looking forward to a seemingly better future; of temporariness, that idealized past or originary state that must be guided and transformed; and of immanence, the constant regeneration of that pure originary state. $(1997,22)$

Education for children was central to the national project of industrial and economic advancement during the Meiji Restoration, a project which was exhumed following the traumatic ruptures of WWII, albeit aligned along exigent new axes. The emergence of childhood as a distinct social category in Japan is inherently bound up with Japan's rapid shift to modernity.

Although influenced by many factors, the Meiji Restoration was largely sparked by Japan's opening up to Western trade with the arrival of the American navy led by Matthew C. Perry in 1853. This 'Arrival of the Black Ships', as it is known in Japan, exposed the nation to the most advanced of Western technologies. Subsequently, the Meiji period involved a highly conscious process of catching up with the West's technological developments: one of the most central shifts, as Morris Low points out, was that 'the Japanese literally had to learn to live by the clock' (2009, 134). Intrinsic to the swift transition to modernity were 'new ideas about time. Time became less rooted in nature and more closely aligned with machines and clocks' (Low, 2009, 134). Most central to this new living by the clock' was the movement away from a heterogeneous, plural time consciousness to a homogenous, socially unified temporal model driven by an ideal of collective 
linear progress. As Naofumi Nakamura explains, 'people in the Edo period (1500-1867) lived by what is called a variable hour system, which arbitrarily established that sunrise was 6 a.m. [...] and sunset was 6 p.m'. $(2002,14)$, a localized model of time which tied communities to the immediate conditions of their environment.

The Meiji Restoration saw the gradual introduction of a fixed hour system, the Gregorian calendar, and the Western Common Era model. As Tanaka points out, 'the significance of this new time is that it is abstract; it opened up the possibility for the transformation of myriad communities that had somehow coalesced into a "Japan" into a unified nation-state that is rational, scientific and efficient' $(2004,6)$. Greenwich Mean Time was officially sanctioned in 1888 , finalizing the process whereby Japan's time consciousness was integrated into the Western model. This new model of homogenous, national time quickly became embedded into the national consciousness in large part due to the carefully managed punctuality of the new, heavily populated train network, as 'people were forced to experience time in minutes, which they had never even considered before; if they were even a minute late, they would miss their train' (Nakamura, 2002, 16).

A reconfiguration of the concept of childhood was at the heart of the nation's temporal overhaul. By embodying futurity, the child cohered the new model of homogenous national continuity. Tanaka suggests that, in premodern and early modern Japan, children 'did not exist as future citizens, but as members of their locale. Childhood was not a unifying category that represented [...] an early stage of linear growth' $(1997,25-26)$. Prior to the Meiji shift to modernity, childhood was a diverse category associated with the particular seasonal cycles and working habits of the communities in which children grew up. This pluralism was rapidly stripped back during the Meiji Restoration, as the child became constituted as a unitary social category upon which the linear development of the nation was inscribed. As Kathleen Uno states, since the Meiji Restoration:

national salvation depended upon the socialisation of ordinary Japanese children. [...] most advocates of Japan's progress expected that private and municipal day-care centres would function as the allies of adult members of households, public schools, and other state-sponsored organizations in shaping children who would loyally serve the needs of national advancement and the imperial state. $(1999,8)$

Uno explains that for centuries leading up to the Meiji period, the Japanese family was structured around the ie system, which ties the family 
to household dynasties. Children were essential to the continuation and immortality of the $i e$ : intergenerational progression, and thus investment in the child as a vessel for the successful continuation of the family, was an underpinning facet of the $i e$ structure. However, as intimated by Tanaka's comments above, the child did not represent a specific social unit and future national citizen; instead children functioned as receptacles for plural and localized forms of cross-generational futurity.

The ie structure underwent rapid change throughout the 2oth century, particularly following the Allied Occupation, as families became increasingly structured along Western lines. The family quickly became positioned as a social institution grounded by the central aim to socialize and educate children in service of the nation's future, rather than that of specific ie dynasties. A number of J-horror films analysed in the next chapter, particularly Ju-ON (Shimizu, 2002), lament the falling away of the extended community support and individual agency represented by the $i e$ structure. This is realized through depictions of small and toxically claustrophobic family units that disintegrate or tear each other apart, almost literally. Since the mid 1990s, Japan has had one of the world's lowest birth rates, with an average below 1.5 children born to a woman during her lifetime, ${ }^{15}$ another contributing factor to heightened anxieties about children and changing family dynamics in the late 199os.

In conjunction with the diminishing of the ie structure, central to the Meiji Restoration was the dismantling of Japan's feudal class system and the restructuring of communities in order to facilitate the process of rapid catch-up industrialization. This necessitated the repositioning of the child as not just a symbol of futurity for individual ie units, but for the entire nation. As Brian Platt puts it:

Japanese leaders during the early decades of the Meiji period (1868-1912) believed that the source of Western power and the key to Japan's national survival in the face of Western imperialism lay in the nation-state's capacity for mobilizing human resources. When they set about creating institutions to accomplish this goal, they recognized the particular importance of the school, which extended the project of mobilization to Japanese children. In turn, they opened up the child to public inquiry, generating within an emerging mass society a new awareness of childhood. [...] the modern concept of childhood was 'created' in the context of Japan's encounter with modernity. (2005, 965-966) 
This investment in the child as a vital sociocultural unit that must be effectively mobilized for rapid national progress escalated as the 2oth century progressed. The research of Roger Goodman (2000), Platt (2005), and Uno (1999) has revealed that daycare and school institutions rapidly became ubiquitous throughout the 2 oth century, as urbanization resulted in groups of children roaming the streets, no longer employed with physical labour in service of the $i e$. This new anxiety started to consume modern Japanese leaders: in 1925, the Home Ministry's Social Bureau Chief went as far as to declare that 'the social weaknesses regarding children are the root of all social problems' (cited in Platt, 2005, 979). As Uno elucidates, 'if idle children grew up to be useless as workers, soldiers, and citizens [...] the nation would face a dismal future' $(1999,17)$. She further suggests that 'heightened concern for the character of children as future citizens established a basis for receiptivity to day-care centres', in large part because 'progress-minded Japanese came to see day-care centres as a means of cultivating habits of industry and economy, which would boost national productivity by resocializing a group of morally deficient citizens' (Uno, 1999, 17). Instilling patriotic and dutiful morals in children through school and even daycare systems became of primary importance, as the future success of Japan's industrial, technological, and ideological revolution was contained within them.

In alignment with this repositioning of the child to become the nucleus of the modernization process were the significant ideological reforms of Japan's education system during the Meiji period. The previously mentioned Imperial Rescript on Education (1890) was an officially sanctioned nationalized system of education, which, as Norma Field (1995) and Tanaka (1997) point out, explicitly positioned education as a gradual ascendance through a hierarchical system of knowledge and loyalty with the Emperor at the apex. Furthermore, Gerald Figal (1999), Tanaka (1997), and Tateishi (2003) point to education ideologue Tetsujirō Inoue's discourse on 'monsterology', which emerged in tandem with the Rescript and sought to remodel the curriculum to eliminate reference to supernatural folklore in favour of a more rational ideology in line with that of the West. Figal explains that monsterology aimed to 'attack obstinate beliefs at their roots and [argued] that this eradication of superstition (meishin taiji) was instrumental for the constitution of a healthy, modern Japanese state' (1999, 87). Tateishi expands: 'coded as illogical and chaotic, and thus antithetical to the project of modernisation, such elements were targeted as the embodiments of those qualities that needed to be eliminated in the name of progress' (2003, 296). 
This new curriculum based upon nationally sanctioned models of both Westernized rationality and Japanese patriotism was tied to the inculcation of the child into the incipient model of globally positioned, linear national time. As Tanaka states:

Inoue [describes] the space of childhood, a temporal site in which deferred work, the acquisition of knowledge, is not considered wasted time, but an asset more important than material resources. [...] By placing a value on time, Inoue is sacralising the child [...] Inoue, who is considered a conservative ideologue, is working within a progressive linear concept. The child who goes to school does not represent uselessness but deferred gratification, improvement, functionalization, and rationality. $(1997,33)$

Thus, post Restoration and throughout the first half of the 2oth century, the child became the locus through which new temporal and ideological paradigms were tested and played out, becoming tied to the relentlessly forward-looking chronology of modern time consciousness: in effect, the child's growing up became coiled to the 'growing up' of the nation itself.

\section{The Child and Postwar Consciousness}

In the years subsequent to World War II, the emotional valences that tied childhood to national development became increasingly polyphonic, as the project of reestablishing a distinctly Japanese identity from the ruins of the war and Japan's forced surrender became symbolically intertwined with the victimized child. Julie Rauer eloquently explains that the war resulted in a traumatic tearing of Japan's national identity: 'tragically splintered by defeat, subjugation, humiliation, and inconceivable horrors - unable to command a return to a unified monolithic persona, the ordered cerebral imperative and societal dignity of pre-nuclear innocence [...] World War II left indelible stains on the Japanese psyche' (2005, n.p.). After the war, images of the traumatized, scarred faces and bodies of women and children became embedded in the Japanese cultural consciousness. Lowenstein suggests that the image of the victimized woman became a potent postwar symbol of suffering and hardship that played into mythologies of Japan's victimization, a vision of trauma that also functions as a disavowal of responsibility (2005, 86). Lowenstein's assertion is reinforced by the research of Lisa Yoneyama, who states that 'the memories of Hiroshima [...] [sustained] at least in the dominant historical discourse, a national victimology' $(1999,13)$, and that 'postwar Japanese womanhood became fully implicated in sustaining the 

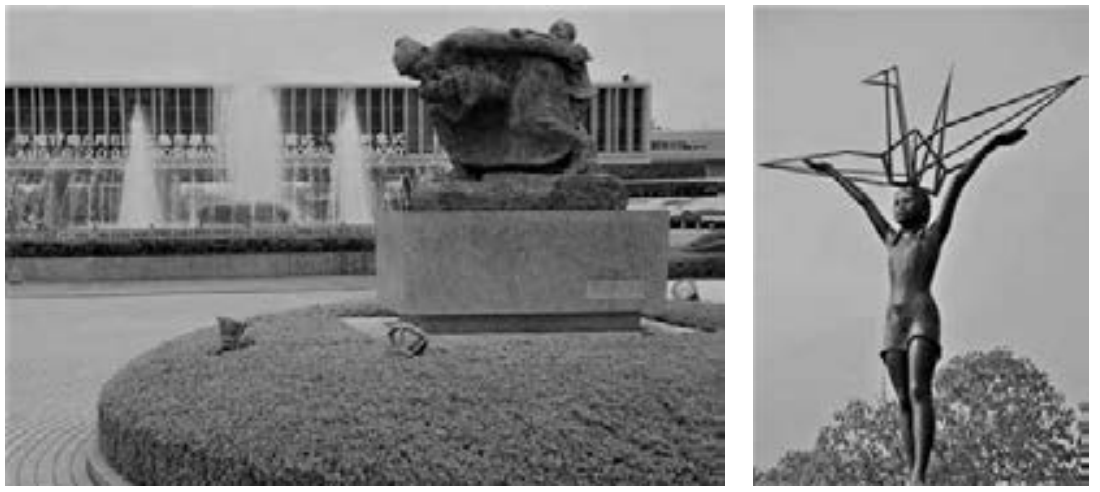

Figure 12. Left: Statue of Mother and Children During the Storm, Hiroshima Peace Park. Bronze, Shin Hongo, 1960; photograph by Fg2. Right: Children's Peace Monument, Hiroshima Peace Park. Bronze and Concrete, Kazuo Kikuchi and Kiyoshi Ikebe, 1958; photograph by Lewan Parker. The child on top of the monument represents Sadako Sasaki holding a large paper crane.

myth of national innocence and victimology' (1999, 38). The child became bound up in such mythology in particularly affective ways. In fact, images of orphaned children and of widows holding their children amongst the ruins of devastated cities became some of the most potent signifiers of Japan's postwar suffering and victimization. ${ }^{16}$

The image of the suffering child has become one of the key defining features of the Hiroshima Peace Park and Museum. Two significant sculptures at the Peace Park are the Statue of Mother and Children During the Storm and The Children's Peace Monument (Fig. 12), which depicts Sadako Sasaki, a young girl who died of radiation-induced leukaemia. Sasaki has since become the most recognizable symbol of the postwar valiant victim: on her deathbed, she endeavoured to fold one thousand paper cranes in an effort both to survive and to promote world peace. When she died before finishing this task, fellow students finished folding the cranes for her. The story of 'Sadako and the Thousand Paper Cranes' has attained mythic proportions in Japan, having been retold in numerous films, television programmes, and children's books. ${ }^{17}$ Thousands of origami cranes are placed around

16 See, for instance, the photograph of the terrified woman hiding in a cave with her children, taken during the Battle on Saipan island (Robertson, 1944), and the image of a charred mother and child on the streets of Tokyo following the 'Operation Meetinghouse' bombing in 1945 (Ishikawa, 1945).

17 For instance, the children's novel Sadako and the Thousand Paper Cranes (Eleanor Coerr 1977) and shortened illustrated version Sadako (Coerr and Ed Young 1993), Children of the Paper Crane: The Story of Sadako Sasaki and Her Struggle with A-bomb Disease (Masamoto Nasu 1991), and the animated film On A PAPER Crane: Tomoko's Adventure (Arihara Seiji 1994). 


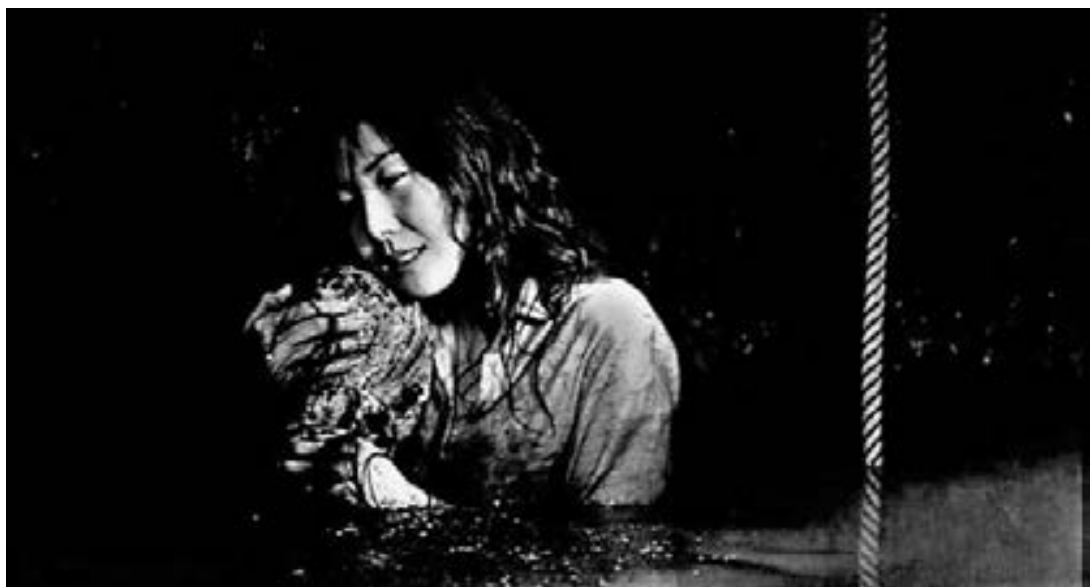

Figure 13. Reiko holds Sadako's decaying corpse to her breast in RINGU.

The Children's Peace Monument in honour of Sasaki each day. An entire section of the Hiroshima Memorial Museum is dedicated to Sasaki and other child victims of war, in which some of her paper cranes are on display. The most intensely affective part of the museum - as is emphasized by its positioning near the exit and dim lighting ${ }^{18}-$, this section also displays a burnt lunchbox, tricycle, and school uniform; children's drawings depicting their experiences of wartime trauma; and children's remains, such as hair and charred skin.

It is surely no coincidence that the archetypal J-horror child shares Sasaki's first name, a pointed reference to Sadako of RINGU's monstrous undoing of the valiant victim myth. RINGU seems to have reached a cathartic conclusion once the protagonist, Reiko, discovers Sadako's decaying corpse within the well in which she died. At this moment near the end of the film, Reiko clutches Sadako's corpse to her breast and begins to cry, accompanied by the swelling of warm, melancholy music (Fig. 13). Yet, while the film positions this sequence as Sadako's redemption - as the monstrous, violent ghost is at this moment domesticated into a helpless victim -, her status as a wronged victim is overturned in the climactic scene, when she emerges through Reiko's ex-husband Ryuji's television screen to kill him, acting out her curse even though he helped to uncover the circumstances of her murder and exhume her corpse. The scene also indicates that Sadako will continue to spread her curse throughout Japanese society indiscriminately,

18 At the time of writing, the museum is undergoing renovations, so it remains to be seen if this layout will remain. 
regardless of whether or not people like Reiko and Ryuji honour her memory or attempt to restore her humanity.

By the later decades of the 2oth century, the extremely successful and rapid manner whereby Japan had reclaimed economic and cultural independence had come to define Japan's postwar identity, and the pressure upon the child - both as concept and lived experience - had become acute. As Field (1995) and Allison (1996) have shown in their examinations of Japan's education system, part of Japan's extreme postwar success can be attributed to the locking of childhood into an increasingly linear system of national advancement in which education leads almost seamlessly into future employment. Writing in 1992 and drawing on conclusions from research conducted in the late 1980 s and early 1990 (the nascent emergence of the Lost Decade), Field explains that 'school and work are becoming increasingly continuous, such that the goals of education fail to suggest even a modicum of autonomy from the goals of the economy' $(1995,62)$. Field discusses the wider implications of this system on childhood, pointing to such materials as cofounder of Sony Masaru Ibuka's instructional child development books Why age zero? Life is decided at age zero (1989) and The Fetus is a Genius: Life begins before birth (1992), to outline the extent to which child development was seen to function in tandem with the capitalist progress of the nation throughout the 1980s and early 1990s. She suggests that the pressurized and claustrophobic ways in which children were hemmed in to this process has 'produced suffocating conditions over the past several decades' (Field, 1995, 62).

Allison reinforces Field's work, suggesting that:

the post-war educational model in Japan exceeds being 'merely' a school system and extends into a regime of test-taking that produces and centers the Japanese self. [...] [I]t is academic performance that has increasingly become the common standard of value in the economy. This means that in the marketplace of careers and jobs, it is the test scores and schools attended as youths that operate as the currency of exchange for adults. (1996, xvii)

It is important to emphasize that both authors write at the beginning of the Lost Decade, which had begun reshaping Japanese economic and social structures by the time both works were published. ${ }^{19}$ Thus, Field's and Allison's works provide valuable insight into the stifling entwinement of childhood 
and national progress as Japan approached long-term economic stagnation, in turn illuminating the extent to which a breakdown in national progress logically became associated with a failure in childhood development. ${ }^{20}$

\section{Progress Dismantled: The Strange-changed Child of the Lost Decade}

Central to this perceived meltdown of the fusion of childhood and national progress were two seemingly contradictory, yet intersecting, moral panics. The first was the 'discovery' in Japan of child abuse, which, until the 1990s, was considered to be a feature of Western modernity that Japan had managed to escape. Up until the late 1980 s, it was widely believed that the absence of child abuse in Japan set it apart from the West (Yoshiko Ikeda, 1995), and 'the apparent absence of abuse was generally explained in terms of the stability of the Japanese family, community, and wider society' (Goodman, 2000, 160). As Goodman points out, the discovery that child abuse occurred with regularity in Japan was in fact a result of clarifications and changes to the definition of what constituted abuse, after a number of surveys and the introduction of the U.N. Convention on the Rights of the Child (brought forth in the mid 1990s and ratified in Japan in 1998, the same year that RINGU was released). Nevertheless, amongst the ruptures of the Lost Decade, the sudden realization that Japan was not immune to child abuse became characterized as a concern that modern Japanese family and community structures were coming undone.

Spiralling from the discovery of child abuse was increasingly focused attention on the pressure placed upon the child in school. The intense education system previously celebrated as the locus of Japan's postwar

20 Although she does not make a connection to the horror films that emerged during the period (having presumably written her essay just prior to their emergence), Andrea G. Arai's 'The Wild Child of 1990s Japan' (2006) presents an insightful discussion of the simmering anxieties surrounding children and their relationship to educational and social structures in the mid 199os, focusing in particular on Princess Mononoke (Hiyao Miyazaki, 1997). First published in 2000, Arai finishes her essay with the questions:

How will the mass-mediazation of [images of wild children] interact with the new socioeconomic and historical concerns of the nation in the twenty-first century? How will these once again add to the reconfiguring of this site of the child in Japan, and how will 'the child' be positioned to make up for the deficits at the more crucial level of the representative force of the nation? How will this affect the social realities of the historical subjects themselves? $(2006,232)$

Arai suggests the extent to which the child was embroiled with anxieties about epochal shift represented by the transition into the 21st century, while raising some questions that I hope this section will start to address. 
success became cause for concern, particularly in the wake of research by sociologists such as Field that revealed the extent to which school children were suffering from physical and mental health issues as a result of stress. ${ }^{21}$ As Lury puts it, such revelations presented 'evidence that the national project was questionable, even malign' $(2010,27)$. Anxiety that Japan's school system was on the brink of disaster was reflected in the widespread emergence in the popular imagination of the term gakkyū hōkai (classroom collapse, the breakdown of order in the classroom). The phenomenon even became the subject of a best-selling book by teacher-turned-social commentator Ryoichi Kawakami, titled Gakkō Hōkai (School Collapse, 1999). The mythos of the resilient valiant victim had swirled around the child since the end of the war, yet ideas surrounding Japan's victimization and subsequent rising up from the ashes of the war - via the figure of the industrious child - had always positioned this victimization as the result of an external force that could be overcome with hard work. This new discourse on widespread child abuse and extreme pressure on students repositioned the child as a previously unacknowledged victim of Japanese society, eroding the boundaries between traumas inflicted from without and those that emerge from within.

The second but related moral panic revolves around a perception that childhood was mutating incomprehensibly, a panicked response to a string of violent juvenile crimes throughout the 199os and into the early 2000s. As Arai outlines, Kawakami and other Japanese commentators have described this fear as kodomo ga hen $d a$ (the strange-changed child, or the child is turning strange): in fact, Arai points to an informal collection of essays published by Kawakami in 1995 bearing this title, which 'describe how the Japanese child (much like the nation itself) had become unknowable and unrecognizable' $(2013,186)$. Professor of criminal psychiatry and social commentator Akira Ishii expresses the sudden shift in attitude towards modern family structures that accompanied the increase in juvenile crime: 'The breakdown of community and family traditions in modern Japan has seen [a rise in juvenile] crime without clear motives' (cited in Kakuchi, 2003, n.p.). One of the worst of these shocking crimes was a double murder committed by a fourteen-year-old from Kobe, known in the media as 'Boy A', who beheaded an eleven-year-old boy and killed a ten-year-old girl at his

21 Field (1995) cites a survey of Japanese grammar school children from 1990, which showed that $63.2 \%$ of children suffered high cholesterol, $36.2 \%$ from ulcers, $22.1 \%$ from high blood pressure, and $21.4 \%$ from diabetes. She refers to reportage of high levels of stress-related hair loss, eczema, and constipation. 
junior high school. The crimes were accompanied by lengthy notes, which referred to the murders as 'the beginning of the game' and justified them as social vengeance, claiming it was 'compulsory education which formed me, an invisible person' (Wetsch, 2005, n.p.). As a result of this vicious and unsettling crime, the age of criminal responsibility was lowered from sixteen to fourteen in 2000. Expressing oft-repeated sentiments of the time, Prime Minister Ryutaro Hashimoto questioned on national television 'Where did we go wrong?' and politician Shizuka Kamei claimed in despair 'Adults should be blamed for this' (Lev, 1997, n.p.). Of these strange-changed children, Kawakami lamented in a personal interview with Arai 'We can't get through to these children, they're incomprehensible (tsujinai; wakaranai) and we don't have a clue what they're thinking' $(2013,186)$.

A range of similar murders occurred in $2000,{ }^{22}$ the very year the age of criminal responsibility had been lowered in an effort to deter such crimes. In 2003, a twelve-year-old boy pushed a four-year-old from the roof of a shopping complex, resulting in the child's death: in response to the crime, the Asia Times reported that 'Shock and soul-searching gripped Japan' and quoted a businessman who lamented 'Whatever has happened to the peaceful and harmonious Japan we knew?' (Kakuchi, 2003, n.p.). The above are just some in the long list of violent juvenile crimes that occurred in Japan from the mid 199os to the mid 200os, most of which, as reported by the media, seemed shockingly incomprehensible. A constant cycle of media reportage emerged detailing the ways in which previously normal, calm children became possessed by kireru (sudden fits of rage). More shocking still was that the biggest rise in violent juvenile crime was acts committed by children under the age of fourteen. Not only did this moral panic about juvenile crime have a wide reach throughout Japan, but the phenomenon was frequently reported on in global media, further dissolving former pride in the child-centred national project: with headlines such as 'Juvenile Crime No Longer Rare in Japan' from the American Broadcasting Corporation (Litke, 2003), and 'Youth Violence Has Japan Struggling for Answers' from The Washington Post (Faiola, 2004).

These vessels for the future, held up as a symbol of national pride and rapid progress for so long in Japan, were turning strange in ways that could not be understood or contained. As Arai suggests, 'the child problem displaced the troubles of economic downturn and the fissures the downturn opened

22 A fifteen-year-old boy who had been bullied at school stabbed three people to death; a seventeen-year-old boy hijacked a bus, which led to the death of one woman; and another seventeen-year-old turned himself into the police after killing an elderly woman. 
up in national identification onto the young' $(2016,7)$. Yet, underlying this monstrous mutation was a delayed recognition of children's long-standing victimization: as is evident among much reportage of the kodomo ga hen da or kireru phenomenon in Japan, it was believed that children were finally enacting their violent revenge upon a society that had oppressed them in service of Westernized modes of capitalistic progress. The proliferation of child-centred horror films during the millennial turn is symptomatic of this multilayered cultural trauma, and represents a way for Japanese audiences to acknowledge and work through it, in similar ways to the internal alien in Sōseki's tale who rouses his father's intermingled guilt and trauma, yet on a collective scale. As will be seen in Chapter Six, the multivalent traumas raised by the J-horror uncanny child are deeply bound up with adult guilt associated with the sudden realization that the child's suffering stems from within Japan's cultural cocoon: a result of long-entrenched fixations with progress, productivity, and futurity.

\section{Works Cited}

Abe, Kobo. Inter Ice Age 4. Trans. Dale Saunders. 1958. New York: Perigee Books, 1981. Print.

Akinari, Ueda. Ugetsu Monogatari, or Tales of Moonlight and Rain. 1776. Trans. and Ed. Leon M. Zolbrod. London: George Allen \& Unwin Ltd., 1974. Print.

Akutagawa, Ryunosuke. Kappa. 1927. Trans. Geoffrey Bownas. London: Peter Owen Publishers, 2009. Print.

Allison, Anne. Permitted and Prohibited Desires: Mothers, Comics and Censorship in Japan. Berkeley: University of California Press, 1996. Print.

-.Precarious Japan. Durham: Duke University Press, 2013. Print.

Arai, Andrea G. 'Notes to the Heart: New Lessons in National Sentiment and Sacrifice from Recessionary Japan.' Global Futures in East Asia: Youth, Nation and the Economy in Uncertain Times. Ed. Ann Anagost, Andrea Arai, and Hai Ren. Stanford: Stanford University Press, 2013. 174-196. Print.

—.'The Wild Child in 199os Japan.' Japan After Japan: Social and Cultural Life from the Recessionary 199os to the Present. Ed. Tomiko Yoda and Harry Harootunian. Durham: Duke University Press, 2006. Print.

-.The Strange Child: Education and the Psychology of Patriotism in Recessionary Japan. Stanford: Stanford University Press, 2016. Print.

Balmain, Colette. 'Inside the Well of Loneliness: Towards a Definition of the Japanese Horror Film.' Electronic Journal of Contemporary Japanese Studies. 3 May (2006): n.p. Web. 30 Sep. 2014. 
-.Introduction to Japanese Horror Film. Edinburgh: Edinburgh University Press, 2008. Print.

Bays, Jan Chozen. Jizō Bodhisattva: Guardian of Children, Travelers and Other Voyagers. Boston: Shambhala Publications, 2002. Print.

Blake, Linnie. Wounds of Nations: Horror Cinema, Historical Trauma and National Identity. Manchester: Manchester University Press, 2008. Print.

Bello, Walden. 'The Hashimoto Controversy and Japan's Failure to Come to Terms with its Past.' Foreign Policy in Focus, Institute for Policy Studies. 22 May (2013). Web. 27 Oct. 2014.

'China protests at Japanese PM's latest WW2 shrine tribute.' TheGuardian.com, The Guardian News and Media. 17 Oct. (2014). Web. 30 Dec. 2014.

Cousins, Mark. The Story of Film. London: Pavilion, 2013. Print.

Doak, Kevin. Dreams of Difference: The Japan Romantic School and the Crisis of Modernity. Berkeley: University of California Press, 1994. Print.

Faiola, Anthony. 'Youth Violence Has Japan Struggling For Answers.' The Washington Post.com, The Washington Post. 9 Aug. (2004). Web. 30 Sep. 2014.

'Fertility Rate Total (Births Per Woman).' Worldbank.org. The World Bank. 2015. Web. 30 Jan. 2015 .

Field, Norma. 'The Child as Laborer and Consumer: The Disappearance of Childhood in Contemporary Japan.' Children and the Politics of Culture. Ed. Sharon Stephens. Princeton: Princeton University Press, 1995. Print.

Figal, Gerald. Civilization and Monsters: Spirits of Modernity in Modern Japan. Durham: Duke University Press, 1999. Print.

Fletcher III, W. Miles and von Staden, Peter W. 'Epilogue: retrospect and prospects: the significance of the 'lost decades' in Japan.' Asia Pacific Business Review. 18.2 (2012): 275-279. Taylor and Francis Journals Complete. Web. 30 Sep. 2014.

Goodman, Roger. Children of the Japanese State: The Changing Role of Child Protection Institutions in Contemporary Japan. Oxford: Oxford University Press, 2000. Print. Hand, Richard J. 'Aesthetics of Cruelty: Traditional Japanese Theatre and the Horror Film.' Japanese Horror Cinema. Ed. Jay McRoy. Edinburgh: Edinburgh University Press, 2006. 18-29. Print.

Hearn, Lafcadio. Kwaidan: Stories and Studies of Strange Things. 1904. New York: Start Publishing LLC, 2012. Print.

Ikeda, Yoshiko. 'Child Abuse and Child Abuse Studies in Japan.' Pediatrics International 37.2 (1995): 240-247. Wiley Online Journal. Web. 30 Sep. 2014.

'Imperial Rescript on Education making slow, contentious comeback.' JapanTimes. co.jp, Japan Times. 12 April 2017. Web. 21 April 2017.

Igarashi, Yoshikuni. Bodies of Memory: Narratives of War in Postwar Japanese Culture, 1945-1970. Princeton: Princeton University Press, 2000. Print. 
'Japan PM Shinzo Abe visits Yasukuni WW2 Shrine.' BBC.com, BBC World News. 26 Dec. 2013. Web. 30 Sep. 2014.

Kakuchi, Suvendrini. 'Youth murder shocks Japan.' AsiaTimes.com, Asia Times. 15 July 2003. Web. 25 Oct. 2013.

Kawakami, Ryoichi. Gakkō Hōkai [School Collapse]. Tokyo: Bungei Shunju, 1999. Print. Kermode, Mark. 'Review of RIngu.' Sight and Sound, British Film Institute. Sep. 2000. Web. 30 Sep. 2014.

Kinoshita, Chika. 'The Mummy Complex: Kurosawa Kiyoshi's Loft and J-Horror.' Horror To the Extreme, Ed. Jinhee Choi and Mitsuyo Wada-Marciano. Hong Kong: Hong Kong University Press, 2009. 103-123. Print.

Lamb, Lynzee. 'Tokyo Theme Park Offering Creepy Sada ko 3D 2 Menu.' Anime News Network, Anime News Network, 28 July 2013. Web. 30 Sep. 2014.

Landry, Jess. 'SADAKo 3D: Super Scary Fun Time Challenge Extreme! Part 1.' Dirge Magazine, Dirge Magazine. 21 April 2015. Web. 1 May 2015.

Lev, Michael A. 'Beheading Arrest Plunges Japan Into Despair About Its Kids.' ChicagoTribune.com, Chicago Tribune. 4 July 1997. Web. 30 Sep. 2014.

Lim, Bliss Cua. Translating Time: Cinema, the Fantastic and Temporal Critique. Durham: Duke University Press, 2009. Print.

Litke, Mark. 'Juvenile Crime No Longer Rare in Japan.' ABC News.com, American Broadcasting Corporation. 28 Nov. 2003. Web. 30 Sep. 2014.

Low, Morris. 'Technological Culture.' The Cambridge Companion to Modern Japanese Culture. Ed. Yoshio Sugimoto. Melbourne: Cambridge University Press, 2009. 130-146. Print.

Lowenstein, Adam. 'Ghosts in a Superflat Global Village: Globalization, Surrealism and Contemporary Japanese Horror Films.' Post-Script. 28.2 (2009): 59-72. EBSCO Host Humanities International Complete. Web. 30 Sep. 2014.

—.'Globalized Spectatorship: Ring Around the Superflat Global Village: J-Horror Between Japan and America.' Dreaming of Cinema: Spectatorship, Surrealism and the Age of Digital Media. New York: Columbia University Press, 2015 · 79-116. Print.

- Shocking Representation: Historical Trauma, National Cinema and the Modern Horror Film. New York: Columbia University Press, 2005. Print.

Lury, Karen. The Child in Film. London: I.B. Tauris \& Co. Ltd., 2010. Print.

McRoy, Jay, ed. 'Case Study: Cinematic Hybridity in Shimizu Takashi's Ju-on: The GRudge.' Japanese Horror Cinema. Edinburgh: Edinburgh University Press, 2005. 175-184. Print.

- Nightmare Japan. Amsterdam: Rodopi, 2008. Print.

Muir, Bob. 'Latest SADAKO 3D marketing flooding the streets with Sadako.'Japanator, Modern Method. 5 Aug. 2012. Web. 30 Sep. 2014.

Nakamura, Naofumi. 'Railway Systems and Time Consciousness in Modern Japan.' Japan Review. 14 (2002): 13-38. JSTOR Arts and Sciences III. Web. 30 Sep. 2014. 
Napier, Susan. The Fantastic in Modern Japanese Literature. Tokyo: The Nissan Institute/Routledge Japanese Studies, 1995. Print.

Nasu, Masamoto. The Children of the Paper Crane: The Story of Sadako Sasaki and Her Struggle with A-Bomb Disease. Trans. Elizabeth W. Baldwin. London: Routledge, 1991. Print.

Ōe, Kenzaburō. 'Aghwee the Sky Monster.' 1964. Teach Us to Outgrow Our Madness. Trans. John Nathan. New York: Grove Press, 1994. 221-328. Print.

-.The Pinch Runner Memorandum. 1976. Trans. Michiko N. Wilson and Michael K. Wilson. London: Routledge. 1994. Print.

'Osaka Mayor Toru Hashimoto: Sex slaves in World War Two were necessary to "maintain discipline" for Japanese army.' The Independent.co.uk, The Independent UK. 14 May 2013. Web. 30 Sep. 2015.

Phu, Thy. 'Horrifying adaptations: RINGU, THE RING, and the cultural contexts of copying.' Journal of Adaptation in Film and Performance. 3.1 (2010): 43-58. Print.

Platt, Brian. 'Japanese Childhood, Modern Childhood: The Nation-State, the School, and $19^{\text {th }}$-Century Globalization.' Journal of Social History. 38.4 (2005): 965-985. JSTOR Arts and Sciences VII. Web. 30 Sep. 2014.

Rauer, Julie. 'Persistence of a Genetic Scar: Japanese Anime, Manga, and Otaku Culture Fill an Open National Wound.' AsianArt.com: The on-line journal for the study and exhibition of the arts in Asia. 13 June 2005. n.p. Web. 30 Sep. 2014. Shin, Chi-Yu. 'The Art of Branding: Tartan "Asia Extreme" Films.' Horror to the Extreme: Changing Boundaries in Asian Cinema. Ed. Jinhee Choi and Mitsuyo Wada-Marciano. Hong Kong: Hong Kong University Press, 2009. 85-100. Print.

Sōseki, Natsume. Ten Nights' Dreams. 19o8. Trans. Takumi Kashima and Loretta R. Lorenz. London: Soseki Museum in London, 2000. Print.

Stuchlíková, Zuzana. 'Japan's Lost Decade: On the Development of The Japanese Economy in the 1990s.' Journal of International Relations. 4 (2012): 129-152. HeinOnline Law Journal Library. Web. 30 Sep. 2014.

Suttmeier, Bruce. 'Speculations of Murder: Ghostly dreams, poisonous frogs and the case of Yokoi Shoichi.' Perversion and Modern Japan: Psychoanalysis, Literature, Culture. Ed. Nina Cornyetz and J. Keith Vincent. Oxon: Routledge, 2010. 22-39. Print.

Suzuki, Koji. Ring. Trans. Robert B. Rohmer and Glynne Walley. New York: Vertical, 2004. Print.

Tanaka, Stefan. 'Childhood: Naturalization of Development in a Japanese Space.' Cultures of Scholarship. Ed. Sarah C. Humphreys. Ann Arbor: The University of Michigan Press, 1997. 21-56. Print.

-.New Times in Modern Japan. Princeton: Princeton University Press, 2004. Print. Tateishi, Ramie. 'The Japanese Horror Film Series: Ring and Eko Eko Azarak.' Fear Without Frontiers: Horror Cinema Across the Globe. Ed. Steven Jay Schneider. Godalming: FAB Press, 2003. Print. 
Trefalt, Beatrice. Japanese Army Stragglers and Memories of the War in Japan, 1950-75. London: RoutledgeCurzon, 2003. Print.

Uno, Kathleen. Passages to Modernity: Motherhood, Childhood, and Social Reform in Early Twentieth Century Japan. Honolulu: University of Hawai'i Press, 1999. Print.

Wada-Marciano, Mitsuyo.Japanese Cinema of the Digital Age. Honolulu: University of Hawai'i Press, 2012. Print.

-.'J-Horror: New Media's Impact on Contemporary Japanese Horror Cinema.' Horror To the Extreme: Changing Boundaries in Asian Cinema. Ed. Jinhee Choi and Mitsuyo Wada-Marciano. Hong Kong: Hong Kong University Press, 2009. 15-39. Print.

Wee, Valerie. Japanese Horror Films and their American Remakes. London: Routledge, 2013. Print.

-.'Patriarchy and the Horror of the Monstrous Feminine: A Comparative Study of RIngu and The Ring.' Feminist Media Studies 11.02 (2011a): 151-165. Taylor and Francis Journals Complete. Web. 30 Sep. 2014.

-.'Visual Aesthetics and Ways of Seeing: Comparing Ringu and THE Ring.' Cinema Journal 50.2 (2011b): 41-6o.JSTOR Arts and Sciences III. Web. 30 Sep. 2014.

Weinstein, David E., Kashyap, A. K., and Hamada, Kōichi.Japan's Bubble, Deflation and Long-term Collapse. Cambridge: MIT Press, 2011. Print.

Wetsch, Elisabeth. 'Kobe School Killer.' Crimezzz.net, Elisabeth Wetsch. 2005. Web. 30 Sep. 2014.

Wood, Christopher. The bubble economy: The Japanese economic collapse. London: Sidgwick and Jackson, 1992. Print.

Yoneyama, Lisa. Hiroshima Traces: Time, Space and the Dialectics of Memory. Berkeley: University of California Press, 1999. Print.

\section{Filmography}

Ghost Story of Yotsuya [Tôkaidô Yotsuya KaIdAn]. Dir. Nobuo Nakagawa. Shintoho Film Distribution Committee, 1959. Film.

The Grudge. Dir. Takashi Shimizu. Sony Pictures Home Entertainment, 2005. DVD. Hara-Kiri: Death of A SAMurai [ICHIMEI]. Dir. Takashi Miike. Sedic International, 2011. Film.

Ju-ON: The Grudge [Ju-ON]. Dir. Takashi Shimizu. 2002. Lionsgate Home Entertainment, 2005. DVD.

KWAIDAN [KaIdAn]. Dir. Masaki Kobayashi. Bungei, 1964. Film.

On a Paper Crane: Tomoko's Adventure [Tsuru ni notte: Tomoko no bOUKen].

Dir. Arihara Seiji. Peace Anime, 1994. VHS Videotape.

Onibaba. Dir. Kaneto Shindô. Kindai Eiga Kyokai, 1964. Film. 
Princess Mononoke [Mononoke-Hime]. Dir. Hayao Miyazaki. Studio Ghibli, 1997. Film.

RINGU. Dir. Hideo Nakata. 1998. DreamWorks Video, 2000. DVD.

RINGU 2. Dir. Hideo Nakata. 1999. DreamWorks Video, 2005. DVD.

The RING. Dir. Gore Verbinski. 2002. DreamWorks Pictures, 2013. Blu-ray DVD.

SADAKo 3D. Dir. Tsutomu Hanabusa. Kadakowa Pictures, 2012. Film.

SADAKo 3D 2. Dir. Tsutomu Hanabusa. Kadakowa Pictures, 2013. Film.

Ugetsu [Ugetsu monogatari]. Dir. Kenji Mizoguchi. Daiei Studios, 1954. Film.

\section{Artworks}

Coerr, Eleanor. Sadako. Illust. Ed Young. New York: G.P. Putnam's Sons, 1993. Print.

-.Sadako and the Thousand Paper Cranes. 1977. New York: Puffin Books, 1999. Print.

Fg2. Children's Peace Monument. 2005. Photograph. Wikimedia Commons. Web. 30 Jan. 2015 .

Hongo, Shin. Statue of Mother and Children During the Storm. 1960. Bronze. Hiroshima Peace Park, Hiroshima City.

Ishikawa, Kouyou. Charred mother and child after the Operation Meetinghouse bombing. 1945. Photograph. C. Peter Chen, World War II Database. Web. 30 Sep. 2014 .

Kikuchi, Kazuo and Ikebe, Kiyoshi. Children's Peace Monument. 1958. Bronze and concrete. Hiroshima Peace Park, Hiroshima City.

Parker, Lewan. The Statue of Sadako Sasaki. 2015. Photograph.

Robertson, Corporal Angus. A Member of a Marine Patrol on Saipan found this family ofJaps hiding in a Hillside Cave. 1944. Photograph. National Archives and Records Administration, Archives.gov. Web. 30 Sep 2014. 



\title{
6. The Prosthetic Traumas of the Internal Alien in Millennial J-Horror
}

\begin{abstract}
Chapter Six presents an analysis of the RINGU (Hideo Nakata, 1998-1999; Norio Tsuruta, 2000) and Ju-ON (Takashi Shimizu, 2000-2002) franchises alongside considerations of other influential J-horror films to illustrate the traumatic extent of the child's conceptual rebellion in these films. The chapter employs Alison Landsberg's 'prosthetic memory' and Angela Ndalianis's 'horror sensorium' to elucidate the particularly visceral ways that these children inflict 'prosthetic trauma' upon their audiences. In so doing, the uncanny child in these millennial J-horror films functions as a powerful - even traumatic - agent of counter-memory, dismantling the imagined coherence of Japan's national narrative.
\end{abstract}

Keywords: Childhood, Ringu, Internal alien, Prosthetic trauma, Countermemory, Progress

In resonance with the American and Spanish films previously discussed, the J-horror uncanny child's symbolic entanglement with deep national traumas erupts in a challenge to 'the pervasive invocation of the Child as the emblem of futurity's unquestioned value' (Edelman, 2004, 3). In the films analysed in this chapter - the RING and JU-ON cycles - the uncanny children defy and deconstruct the particularly claustrophobic welding of childhood to national progress in Japanese culture. These films have been chosen as metonymic and influential examples of J-horror; however, many other films of the millennial transition feature similarly subversive constructions of childhood, such as DARK WATER (Nakata, 2002), the ONE Missed CAll franchise (Takashi Miike, 2003), The Locker (Kei Horei, 2004), and REINCARNATION (Takashi Shimizu, 2005). In all of these films, the J-horror child's traumatic temporal dissonance reconfigures the constrictive teleological model of national time that dominated the Japanese cultural

Balanzategui, J., The Uncanny Child in Transnational Cinema: Ghosts of Futurity at the Turn of the Twenty-First Century, Amsterdam University Press, 2018.

DOI: 10.5117/9789462986510/CHo6 
imaginary prior to the ruptures of the Lost Decade. Thus, their function is similar to the uncanny children of Spanish horror, who emerged at the turn of the millennium in tandem with social groups that aimed to reshape the collective memory. Yet, beyond sparking an allegorical moment that enforces a reconsideration of the relations between the historical past and the present, the child characters in J-horror raise something akin to what Foucault calls 'counter-memory', a form of collective memory that challenges the dominant historical discourse by enacting 'a transformation of history into a totally different form of time' $(1977,160)$. J-horror children unmask the ambivalence and tensions that have long lurked beneath Japanese narratives of post-Restoration and postwar progress, the very narratives that the child is tasked with cohering. Counter-memory represents a mode of resistance against linear conceptions of time by raising a disruptive pluralism that stands against a homogenous official discourse of progress and history. As José Medina explains, counter-memory is 'not a pluralism that tries to resolve conflicts and overcome struggles, but instead tries to provoke them and to re-energize them. [...] This is a pluralism that focuses on the gaps, discontinuities, tensions and clashes among perspectives and discursive practices' (2011, 24).

In the Japanese context, pluralism disruptive of homogenous, historical time has specific resonance with the nation's quite recent, premodern temporal plurality, in which children were tied to their ie and immediate locale rather than national progress. Via their temporally dissonant traumas, J-horror children reinvigorate this suppressed plurality. They raise countermemories not only through their embodiment of long-suppressed traumas, but by invoking visceral traumatic experiences for those with whom they come into contact - both other characters and audiences alike. At the crux of the narrative of each of the films considered in this chapter - and of many other J-horror films - is the adult protagonist's quest to synthesize the child's trauma into some semblance of coherent, linear narrative: essentially, to uncover the narrative kernel of lucid memory that elucidates the circumstances of the child's death, and the reasons for her subsequent vengeful rage. But these figures resist having their painful counter-memories resituated into a unitary narrative that coherently reorganizes chronological time and domesticates them as helpless victims - a resistance to linear progression provoked by the temporal incongruence of their trauma.

For this reason, Alison Landsberg's conceptual framework of prosthetic memory is a useful means by which to examine the affects and cultural work of these characters. As I outlined in Chapter Three, Landsberg's prosthetic memory describes the effect of films which are able to form powerful 
personal memories about past events within audience members who did not experience them directly. As Landsberg points out, there is a stark difference between apprehending a historical narrative about the past and subjective memories of past events we ourselves have experienced. Prosthetic memory 'emerges at the interface between a person and a historical narrative about the past, at an experiential site such as a movie theatre' (Landsberg, 2004, 2 ), as the affective register of the movie-viewing experience encourages spectators 'to not simply apprehend a historical narrative but [to take] on a more personal, deeply felt memory of a past event through which he or she did not live. The resulting prosthetic memory has the ability to shape that person's subjectivity and politics' (Landsberg, 2004, 2). Via her embodiment of trauma and subsequent sensory attack upon viewers, the J-horror child forges intersubjective relationships with characters and viewers in alignment with Landsberg's concept of prosthetic memory.

In fact, the eerie transfer of memory from ghostly child to those she haunts, and the subsequent tangling of the dead child's traumatic memories with those of her victims, is a major theme of millennial J-horror, mirroring the extra-diegetic manner by which the eerie affects of this fictional child become prosthetic memories for the viewer. Yet, in these films, it is not specific historical narratives that are rendered, as all of them are ostensibly set in the present - albeit an unstable present that is continually displaced by the weight of the past. These films instead impel audiences to experience the traumas lurking beneath the national narrative, traumas which disrupt historical continuity in such a way as to disallow the simple revisiting of history from the (supposedly) safe vantage point of the present. As Bliss Cua Lim points out in her discussion of temporality in Asian supernatural cinema, 'haunting, or the spectre's act of returning from death, is a refusal to complete the sentence, a worrying of historical knowledge' (2009, 160). The J-horror child not only refuses to finish the sentence started by dominant historical narratives of Japan's miraculous postwar progress, he folds the sentence back onto itself, suggesting that it was misguided from the beginning. The J-horror child thus raises in concentrated form what Landsberg refers to as 'the indigestible material of history' $(2004,47)$, inciting not just prosthetic memories, but prosthetic traumas.

Landsberg explains that memory is 'a sensuous phenomenon experienced by the body, and it continues to derive much of its power through affect' $(2004,8)$, and it is through this corporeal connection that film has 'the power to "suture" viewers into pasts they have not lived' $(2004,14)$. This suturing power is pivotal to both the aesthetics and the narratives of the films under discussion in this chapter, as the ghostly children trap characters and viewers 
within the cyclical replay of their traumatic deaths - or, more precisely, within the feelings of pain, terror, and powerlessness that underwrote their experience of dying. While Landsberg emphasizes the primacy of memory in her own work, she points out that 'prosthetic memories, like an artificial limb, often mark a trauma' (2004, 20). As millennial J-horror expresses, memory and trauma are cyclically entwined, as trauma itself represents an inability to fully synthesize, and thus to move beyond, a painful memory: an assertion at the crux of Caruth's suggestion that trauma 'is an experience not fully assimilated as it occurs' $(1996,5)$, which thus occurs largely retrospectively. As Giorgia Dona elucidates, trauma represents the abject space in which 'the remembered, the forgotten and the unspeakable coexist. Trauma politics and aesthetics go hand in hand' $(1999,18)$. The uncanny children of J-horror impel a realization that the very act of remembering is confounded by trauma: the aesthetics of their trauma thus figure a political intervention. The trauma both evoked and experienced by the Japanese uncanny child unsettles processes of remembering, especially the ways in which coherently assembled memories anchor secure personal and national identities.

Consequently, these children do not merely haunt those in their wake; instead, they inject their own traumatic experiences into the corporeal and subjective experience of those around them. This affect characterizes much J-horror film: as Wee states, dread elevates to horror in the genre 'when the boundary between Self/human and Other/monster collapses [...] when the Self and Other are largely indistinguishable' $(2013,209)$. The polysemic erosion of boundaries is also at the core of the internal alien outlined in the previous chapter; this precedent to the contemporary uncanny child, a common trope of post-Restoration Japanese fantastic literature, simultaneously embodies deep-seated anxieties within the psyches of adult protagonists while also existing as a monstrous, unknowable being external to them. The internal alien thus personifies prosthetic trauma. The eerie child carried on the back of the protagonist in Sōseki's seminal tale 'Dream of the Third Night' - considered in Chapter Five - is paradoxically both the man's actual, physical progeny and the embodiment of his repressed guilt over a murder he committed a century ago, raising the spectre of the murdered man. Echoing this tale, a common visual theme in J-horror consists of a ghostly child clinging to the body of his victim: a monstrously inescapable prosthesis upon the adult's body to which only the audience is privy. In addition, the traumas of the ghost are transported across physical space and time via technological portals such as videotapes, computers, televisions, and mobile phones. Through these technologies, the ghost's trauma-stained spaces 
are ungrounded from both temporal and geographical ties and invade the realities of other characters even when they are not in the vicinity of the child's death. These devices thus become vehicles for prosthetic trauma, not just for other characters but for the viewer as well, as the ghost threatens to transverse the seemingly impermeable boundary between reality and fiction and enter the space inhabited by the viewer.

Such an all-encompassing breakdown in spatiotemporal boundaries marks quite a point of difference from the films previously discussed in this book. In the American and Spanish films, the child compels us periodically to experience moments of frisson with traumatic pasts that rattle neat formations of linear, homogenous time both personal and cultural. Yet, the J-horror child, to use Lim's explanation of ghostly time in Asian cinema, forces 'characters (and those spectators who identify with them) to experience time with the ghost' (emphasis in original, 2009, 161). The unbridled temporalities of millennial J-horror thus delve fully into the deep implications that are ultimately displaced in most ghost films: if the existence of the ghost exposes the fallacy of linear, historical chronology, then the notion that time can be neatly reorganized once the ghost's requests are fulfilled may, in fact, be an all-too-hopeful mirage. In J-horror films of the millennial turn, progressive chronology cannot be restored once the ghostly child has unveiled its falsity.

\section{Prosthetic Trauma and the Horror Sensorium}

I consider the prosthetic traumas of the J-horror child via Angela Ndalianis's concept of the horror sensorium, which helps to understand the kind of experiences the senses mediate and give meaning to in our encounter with contemporary horror cinema' $(2012,30)$. Ndalianis's sensorium elucidates the way in which cognition, emotion, and sensation are fused in the horror experience, a conception of the relations between film and audience that allows consideration of the deep entwining of the cognitive and the visceral involved in the J-horror child's mechanics. While Ndalianis associates this process with the horror genre as a whole, I suggest that the films of this chapter foreground and revolve around the manner by which they interface with audiences, accentuating our conscious acknowledgement of the space where 'the medium and the human body collide' (Ndalianis, $2012,3)$. This heightened awareness of our coalescence with the events and beings on-screen is a primary reason for the child-ghost's effectiveness in invading the audience's psyche and body, and the resultant lingering of these affects long after the film has finished - residues of prosthetic 
trauma that crystallize the formation of prosthetic memory. The concept of the sensorium effectively demonstrates the ways in which the J-horror child incites cognition and sensation in a way intended to 'make me feel less secure in the actual space I occupy both while I'm watching the film and in the aftermath [...] the memory of it still lingering and eerily invading my everyday reality' (Ndalianis, 2012, 163).

In her final chapter, Ndalianis uses the climactic scene from RINGU to elucidate the extent to which horror films can engage the sensorium: she states that it is 'one of the creepiest horror scenes I've experienced' (2012, 163) as she, like Ryuji on-screen:

squirmed at the possibility of [Sadako crawling through her own screen]. Sure I knew it couldn't really happen, but that didn't stop the feeling that it might. [...] One of the most powerful effects that horror has is to be able to affect the sensorium in such a way that it perceptually collapses the boundaries between reality and fiction. $(2012,163)$

Here, Ndalianis raises the spectre of prosthetic trauma, as the viewer is confronted with a powerfully disquieting sense that her own reality has been punctured by the horrors on-screen. While I do not suggest that film-induced prosthetic trauma such as this is equivalent to that suffered directly, I do claim that these films launch an attack on the audience's sensorium so as to simulate the effects of trauma. I employ Ndalianis's sensorium in order to analyse the particularly visceral ways that the J-horror child provokes simulated traumas for the spectator. Because this affectual engagement with viewers invites a seamless merging of sensation and cognition, I use the term 'ideo-aesthetic' in the course of my analysis to articulate how these films quite powerfully intertwine aesthetics with ideology to elicit particular affects. Drawing back to Dona's point about the interlacing of trauma aesthetics and politics, the ideological agendas of these films are delivered via their complex aesthetic expressions of cultural trauma.

Consideration of how these films induce prosthetic trauma via their interaction with the audience's sensorium also helps to elucidate J-horror's lasting power not just in Japan, but transnationally, in a way almost unprecedented among foreign-language horror cinema produced outside of Hollywood - particularly remarkable considering the small production and marketing budgets of the films that sparked this trend, RINGU and JU-ON. As Landsberg explains, through the technologies of mass culture, 'prosthetic memories are transportable and therefore challenge more traditional forms of memory that are premised on claims of authenticity, "heritage", and 
ownership' (2004, 2-3). The sensory attack of J-horror resonates beyond audiences local to Japan: during the millennial turn, global audiences were compelled to experience the traumas ignited in a Japanese context but that can also be strongly felt within other personal and sociocultural contexts as prosthetic trauma. In the words of Caruth, "trauma itself may provide the very link between cultures: not as a simple understanding of the pasts of others but rather, within the traumas of contemporary history, as our ability to listen through the departures we have all taken from ourselves' $(1995,11)$.

\section{'Do kids die too?': The RING Cycle}

Spanning the turn of the millennium, the RING cycle undergoes a complex meditation on the collapse of progress through its depiction of a ghostly child who harnesses the trauma of her death to unbolt both history and the process of growing up from linear time. While each of the original RING films projects a different overarching narrative - the first details an investigation into Sadako's videotape curse; the second centres on the scientific attempt to understand and contain the curse via a range of technologies; the third is a prequel detailing the circumstances of Sadako's death -, all three revolve around the affective kernel that is Sadako's trauma and the trauma that is Sadako.

The mythemic nucleus central to all three films, always knotted around the overarching plot as a painful yet vaporous past (and, in the prequel, as both the past and an impending future) is as follows: ${ }^{2}$ Sadako was a young girl with powerful psychic powers inherited from her mother, Shizuko. Tension is upheld throughout the cycle as to whether Sadako's father is Dr. Ikuma - Shizuko's lover who sought to prove to the general public that her powers were legitimate - or if she is the progeny of Shizuko's unholy union with a mysterious oceanic sea spirit. At a demonstration of Shizuko's psychic powers presented by Dr. Ikuma, a journalist interrupted the demonstration to declare vehemently that Shizuko is a fraud. Sadako employed her own

1 Quote from Ringu: upon his cousin's death at the hands of Sadako, Reiko's young son Yoichi plaintively questions the mortality of children.

2 The time structures of the films are complex, with multiple layers making up the diegetic past (Sadako's childhood past, the moment of her death, the time before Sadako's birth). For the purposes of this section, I take my cue from the films themselves and use the past tense in descriptions of Sadako's childhood and the events depicted in the cursed tape: moments that are always treated in the films as a particularly traumatic fork in time that hovers over the events in the overarching narratives. 
psychic powers to strike him dead. An indeterminate period of time after this event, Shizuko took her own life, and Ikuma, presumably threatened by Sadako's powers, hit her across the back of the head and tossed her into a well, closing the lid to prevent Sadako's escape and leaving her to die. From her watery sepulchre, Sadako projected her fractured memories onto a VHS videotape, suturing her trauma into the present in the form of a supernatural curse: anyone who watches this videotape is doomed to die within a week unless they copy the tape and show it to another, to ensure, in the words of one of the young children who brightly explains this process at the beginning of RINGU, 'It never ends. It just goes on and on.' Sadako thus unleashes prosthetic trauma on a mass scale, and via a process of unstoppable contagion.

Existing analyses of RING tend to be characterized by an imprecision as to whether Sadako is a child, adolescent, or adult, ambiguity that is understandable for it is reflected in strange but telling ways throughout the RING cycle. ${ }^{3}$ Even Lury, who presents an insightful analysis of how RINGU's temporal subversions express anxieties about childhood in Japan, concludes of Sadako and other J-horror child-ghosts that 'the terrible deeds they commit and the secrets they know mean that we can no longer consider these ghastly figures children' $(2010,40)$. As is refracted in indirect ways in the scholarship on RING, Sadako's ambiguous oscillation between childhood, adolescence, and adulthood is central to the anxieties projected by the films and the way they interface with our sensorium, as will be explored in detail later in this chapter. It is particularly notable that the directors, Nakata and Tsuruta (RINGU o), and the screenwriter, Hiroshi Takahashi, chose not to depict the collapse in gender boundaries central to Koji Suzuki's book series, upon which the films are based. In Suzuki's first novel, Ring, Sadako is unambiguously depicted as a young adult, and the climactic twist occurs when she is revealed to be a hermaphrodite. Shifting the emphasis of the book to reflect the tensions underlying the millennial shift in Japanese attitudes towards childhood, the films' creators place the horrors of the films not along gender lines, as in Suzuki's books, but along temporal ones.

In fact, Sadako herself is barely present in the first two films of the cycle, despite looming over both as the monstrous aggressor - it is largely via her

3 A number of works on RING tend to resist classifying Sadako using age-suggestive terms, leaning instead upon the broad classification 'female' (see Richards, 2010; Wada-Marciano, 2009; and Wetmore, 2009), while some refer to Sadako as a 'child' or 'girl' (see Balmain, 2006; Lowenstein, 2009, 2015; Lury, 2010; McRoy, 2008; Tateishi, 2003; White, 2006), others refer to her as a 'teenager' or 'young woman', (See Wee, 2011a, 2011b, and Hand, 2006) and certain works largely position her as a 'woman' (see Haque, 2010 and Balmain, 2008). 
brief cursed videotape that her (non)presence is manifested in both RINGU and RINGU 2. She thus functions quite precisely as Caruth's traumatic 'wound that cries out' $(1996,4)$, which 'simultaneously demands and defies our witness' $(1996,5)$. Indeed, trauma's paradox of vision elucidates J-horror's overarching aesthetic of visual suspense, in which the power of the viewer's gaze is relentlessly undermined: Sadako crystallizes the manner by which the child-ghosts lurk on the edges and at the lower corners of the frame, making their presence known while refusing full capture within the visual field of both viewers and other characters.

\section{Sadako's Cursed Videotape and the Ideo-aesthetics of Trauma}

As I intimated in the opening of Chapter Five, it is significant that the VHS tape is the vessel for Sadako's curse, for this technology was intertwined with the sense of Japan's declining progress in the Lost Decade. As Lowenstein suggests, 'by having its curse recorded and played on videotape, RING [...] allegorically suggests that the electronic products that epitomized Japan's national strength in the 1980s, such as televisions, VCRS and videocassettes, no longer "work" in the recessionary 1990s' $(2015,89)$. At the pinnacle of Japan's rapid economic progress from the late 1970s to the beginning of the 199os, VHS videotape was one of Japan's key emblems of technological success, having been invented by the Victor Company of Japan. The company had attained celebrated postwar success, including developing subsidiaries in the U.S. and Europe in the late 1960s and 1970 (a reversal of its original status in the late 1920 s as a subsidiary of an American company). As Phu points out, the VHS tape sealed in 'its victories with competing developments such as Betamax [another Japanese development], the laserdisc and electronic disc, Japan's much envied stature as a technological superpower' and became associated with the 'dominance of a "national" innovation' (2010, 53). VHS was the success story of a Japanese company that won the hard-fought battle for technological domination of the home entertainment sector at that time. Yet, while VHS was ubiquitous at the time of RINGU's domestic release in 1998, the mechanics of Sadako's curse quickly seemed antiquated with the rapid replacement of VHS by DVD: as Caetlin Benson-Allott charts, DVD was launched in America in 1997 and, by 2001, DVD sales exceeded those of VHS $(2013,14)$. Thus, in 1998, Sadako infected an analogue device that symbolized Japanese technological supremacy at the very moment when it was tipped to be overcome by the technological paradigm shift to digital storage: an uncanny evocation of stalled progress that resonates with the anxieties of the Lost Decade. By entwining Sadako's curse with degraded 
VHS technology, RINGU raises a premature, but seemingly prescient, uncanny nostalgia for the fitful, grainy qualities of analogue video. In fact, even in 1998, Nakata consciously endeavoured to enhance the imperfection of the analogue image by passing it through a computer to enhance the washed-out, snowy quality (Nakata, 2000, n.p.).

All three Ring films revolve around the eerie images contained on Sadako's cursed videotape, which is threatening in its incoherence and lack of clarity. RINGU follows the attempts of protagonists Reiko and Ryuji to decode the tape in an effort to lift the fatal curse, a task that they learn, all too late, is impossible. Even after they analyse the tape's mysterious images to locate Sadako's corpse at the bottom of the well and provide her remains with an appropriate burial, Sadako still mechanistically enacts her curse, erupting from Ryuji's television screen and striking him dead with her monstrous gaze. Aesthetically paralleling Sadako's own fluctuation between child, teenager, and adult, the cursed tape enacts a plurality of different temporal modes that strain against one another. Such temporal plurality aligns with Lim's Deleuze-inflected concept of 'immiscible times': 'multiple times that never quite dissolve into the code of modern time consciousness, discrete temporalities incapable of attaining homogeneity with or full incorporation into a uniform chronological present' $(2009,12)$. In so doing, the horrors of Sadako's trauma, to use Deleuze's terms, 'plunge viewers into time rather than through space' (1997a, xii) in quite marked ways that resonate with the child-centred anxieties of the millennial turn in Japan.

The images on the tape occur in a disconnected string, which, in each RING film, withstands the protagonists' and viewers' attempts at contextualization; each strange image cuts to another before we have a chance to comprehend fully what we have witnessed, and, in total, the tape - while threateningly looming over all of the RING films - is just under a minute long. The surreal imagery on the tape includes: a man peering into a well (filmed from within the depths of the well), spatially indistinct traditional interiors, floating kanji characters (which seem to spell 'Eruption'), a mass of people writhing on all fours, a man with a towel on his head standing before the ocean, a reflection of a sedate woman in a kimono brushing her hair in an oval mirror (revealed in RINGU to be Sadako's mother Shizuko), a strangely shaped eye - both human and horse-like - with the Japanese character for 'Sada' (which means 'chaste child' or 'pure one') reflected upon its surface, and finally, a well in a forest clearing. The soundscape of the tape indiscernibly melds machinic and organic sounds, including a cacophonous, low rumbling - which suggests an incoherent babble of human voices as well as audio static - and a rhythmically intermittent, high-pitched 
scraping sound: a harsh sound that evokes the buzzing of insects as well as the mechanical screeching of magnetic tape speeding through a spool. In its disorienting resistance to ontological characterizations and narrative structure, Sadako's video pollutes the symbolic coherence of all the RING films, which set out to follow traditional ghost mystery arcs in which the precise details of Sadako's traumatic death are uncovered and her unquiet spectre is satiated. The tape thus renders both the intensity and enigmatic corrosion of traumatic memory, while constituting a challenge to the narrative process of domesticating memories of past traumas via linear and cathartic narrative resolutions.

In contrast to the smooth, muted colour palette of each film's overarching diegesis, the VHS imagery is characterized by a degraded, snowy aesthetic that incites the spectator's sensorium through a gradually intensifying cognitive engagement - specifically, a building awareness of delayed recognition, as will be detailed - facilitated by an eerie, haptic quality. As RINGU progresses, the tape's grainy aesthetic comes to constitute a threat, for it conceals Sadako's gradual appearance from within the well in which she died, which is depicted in the tape's final shot. Each time the tape is replayed as Reiko and Ryuji attempt to decode its imagery, Sadako hauls herself slightly further over the rim of the well before this final image erupts into static and the video ends. The floating grain thus obscures the spectre's gradual emergence from the well between progressive viewings of the tape. In some of the earlier instances in which the tape's final shot is shown, the viewer may notice some odd flicker of movement near the well's rim - actually the appearance of Sadako's hand - but associate it with the grain of the degraded image. It is only when Sadako crawls out of the well and erupts through the television screen in Ryuji's living room in the climactic scene that it becomes clear what the grain concealed.

The decaying quality of the image thus belatedly impels spectators to consider their relationship to the screen. As Laura Marks points out, aesthetics of image decay such as graininess 'discourage the viewer from distinguishing objects and encourage a relationship to the screen as a whole' $(2000,172)$. This affect becomes particularly potent when Sadako is pictured climbing through the diegetic television which projects her image at the film's climax, as our felt proximity to the screen is belatedly registered as a threat. The images on the tape are haptic in that that visual grain compels our eyes to graze their surfaces, troubling the simple engagement engendered by crisp, clean images and encouraging 'a more embodied and multisensory relationship to the image' (Marks, 2000, 172). This embodied mode of engagement in RINGU provokes a reflection on the way our own 
memories interface with and give meaning to the tape's images: as Sadako finally pulls herself out of the well and then escapes the bounds of the television screen at the end of the film, the audience is impelled to sift through their memories of the previous depictions of the cursed tape's final shot in an attempt to pinpoint when they may have first experienced a flicker of cognizance that the spectre was emerging. The grainy imagery thus aestheticizes the paradoxical power and intangibility of traumatic memory, in which much of the discomfort arises from being unable to remember coherently, and also the frisson involved in realizing too late the extent of the threat with which one has been confronted - a potent evocation of trauma's belatedness. Audiovisual television static heralds Sadako's imminent appearance throughout RINGU, to the point that spectators are primed to dread the sudden, piercing hiss of television snow, even before they are aware of the nature of the threat that it issues. The eruption of this audiovisual static into the coherently assembled shots that constitute the film's narrative is a compelling aesthetic metonym for the disruptive incoherence of Sadako's trauma.

\section{The Traumatic Curse of Counter-memory}

Through her cursed tape, Sadako activates a particularly uncanny form of counter-memory for Japan's past that disrupts historical narratives structured around growth and progress. The tape reshapes comforting nostalgia for traditional Japan and furusato (meaning 'hometown' or 'native place' and connoting traditional rural farm villages) ${ }^{4}$ and suffuses it with dread. The images on the tape are shot using muted frontal lighting, which makes the spaces and images appear almost impossibly flat, recalling the frontal lighting and resultant flattened aesthetics of Kabuki theatre and very early Japanese film, which was mimetic of Kabuki. ${ }^{5}$ This vague aesthetic of

4 Nostalgia for furusato is in fact a major trend in Japan, even though a vast percentage of Japanese have lived all their lives in cities and do not have a rural hometown to which to return. Nostalgia for an imaginary furusato represents an attempt to forge some sort of connection with an 'authentic' traditional Japan: as Jennifer Robertson states, furusato is 'a cogent and compelling signifier for, and symbol of, things Japanese' $(1988,495)$ and the continued craving for it in the present is motivated by 'a nostalgia for nostalgia, a state of being provoked by a dissatisfaction with the present on the grounds of a remembered, or imagined, past plenitude' $(1988,495)$.

5 In The Aesthetics of Shadow, Daisuke Miyao (2013) details the development of Japanese lighting techniques, and points out that early film techniques were much indebted to the flat aesthetic of Kabuki theatre. In fact, as Miayo explains, there was much resistance in the early decades of the Japanese film industry to three-point Hollywood lighting techniques, so integral was this flat aesthetic to ideas of Japanese cultural authenticity. 
pastness is further reinforced by Reiko and Ryuji's realization in RINGU that there is an outmoded regional dialect submerged in the staticky, hissing soundscape of the tape, which leads them to Oshima island off the coast of Tokyo, where Sadako grew up. Oshima is depicted as an isolated fishing village in a state of economic decline due to a history of volcanic eruptions (vaguely suggested on Sadako's tape by the word 'Eruption') and an ageing population - an atavistic community left behind by the rapid progression of urban Japan. While on Oshima, Reiko and Ryuji stay in Sadako's childhood home, inserting themselves into the spatial manifestation of cultural pastness represented by the traditional house that appears in flat, fragmented form on Sadako's tape. In the present, it is an unbearably quiet and still space inhabited only by Sadako's aged, distant relatives. Reiko and Ryuji discover that Sadako was murdered in Izu, an island province near Tokyo, which, like Oshima, is part of the Izu peninsula. Izu is currently a popular tourist destination, but, as depicted on the tape, was a rural area at the time of Sadako's death. The well in which Sadako's corpse has festered for 30 years has since been built over by a holiday resort - Reiko and Ryuji have to crawl underneath a cabin to locate the well - further emphasizing Sadako's entwinement with past modes of Japanese existence rapidly built over in the quest for rapid economic progress. Thus, as mediated through the decaying aesthetics of a soon-to-be outmoded technology, the video eerily depicts a mode of existence that is quickly becoming past in progress's wake.

Further resisting linear historical constructs, the recent pasts conjured by Sadako's degraded tape collapse into the more distant pasts suggested by the video's Kabuki-esque aesthetics. Similarly, the tattered gown that Sadako wears points to multiple temporal sheets. Throughout the first two films, her brief appearances evoke the onryō of traditional Noh, Kabuki, and ukiyo-e through her long white burial gown and the dark, lank hair that covers her face: the typical hallmarks of the onryo who traditionally returns from death to seek vengeance or because proper burial rights were not completed. ${ }^{6}$ Yet in RINGU o, it is revealed that Sadako wears this white gown because she was performing in a play, aptly named 'The Mask', on the day that she died in the late 196os. The play seems to draw on modern Western traditions, in particular the musical The Phantom of the Opera (Andrew Lloyd Weber, 1986) and French horror film Eyes Without a FACE (Georges Franju, 1960), more than ancient Japanese ones.

Yet, when she is paired with the image of the decaying well in her tattered gown, Sadako's recent (and strongly Western-influenced) past reverberates 
with much more distant ones: the well is a particularly potent signifier of premodern Japan, recalling folktales such as 'Banchō Sarayashiki' (a direct influence on RINGU's narrative, as outlined in Chapter Five), as well as the famous autobiographical story 'The Fox' by early modern author Nagai Kafū, first published in 19og. Like the RING films, 'The Fox' filters a meditation on haunted nostalgia through the lens of troubled memories from childhood: the story details Kafü's childhood fears of a well at the centre of an abandoned traditional garden below his father's modern house. In 'The Fox', this well seems to be the eerie, foreboding vessel for the premodernity that the country is in the process of displacing in the name of progress. The well through which Sadako emerges similarly functions as a spectral rem(a)inder of deep layers of suppressed pasts throughout the RING cycle. That Sadako is depicted erupting through two thresholds simultaneously in RINGU's most famous sequence - that of the well and that of the television screen - thus suggests dual layers of temporal transgression, as a girl who died 30 years ago thrusts her presence and experience into the present, while also stirring the cyclical, numinous temporalities of premodernity.

Because they raise such a layered evocation of temporality, the images on Sadako's tape function in a way that aligns with what Marks (2000, 24-33) has termed 'archaeological' images. Marks draws from the Deleuzian concept of the optical image to pinpoint how intercultural films engage with multiple layers of cultural memory in deconstructive acts of historical excavation (25). In such cinema, archaeological images evoke multiple layers of the past, instead of a singular past with a secure place on an established historical continuum, refiguring time not as a homogenous line but as multilayered depth. As Marks suggests, archaeological images encourage us to relate to them via complex processes of memory, rather than by moving forward in time through a sequential linear narrative. As she states, such images reveal 'new history as it is being formed, the new combination of words and things that cannot be read in terms of the existing languages of sound and image but calls for new, as yet unformulated languages' (Marks, 2000, 31): a description that suggests the disruptive, plural power of counter-memory. Sadako's video seems to reconstruct history by harnessing and layering the signifiers of Japan's cultural past in its construction of childhood memories fractured by trauma. The uncanny temporal contortions of Sadako's video are thus manifested through its aesthetic properties in a way that disassembles the linear chronology of Japan's modern time consciousness.

This ideo-aesthetic rebellion is also encapsulated in the fractured, tortured movements of Sadako as she approaches her victims. Slow and rhythmic - especially in their accord with the staccato non-diegetic score 
- Sadako's movements suggest the measured discipline of traditional Noh dance, a style performed since the fourteenth century, which requires highly trained dancers and has become synonymous with a romanticized projection of culturally authentic Japan, as the oldest form of major theatre art still regularly performed (Faubion Bowers, 1974). Yet, Sadako's movements are also painfully spasmodic, rigid, and jerky, eerily defying the smooth continuity of both typical bodily movement and the fluid motions of Noh dance: an effect Nakata achieved by having the actress - seasoned Kabuki performer Rie Ino'o - walk backwards in fitful motions before playing the film in reverse (Fig. 14). These strange movements refract the style of Butoh, a form of performance art which seeks to rebel against highly codified, aristocratic modes of traditional Japanese performance such as Noh.

Butoh arose in the turbulent postwar period, introduced in 1959 by Tatsumi Hijikata and Kazuo Ohno, and sought to, in the words of Bonnie Stein, explore 'the dark truths that hid behind the Japanese social mask' (2001, 378). Essentially, the term can be interpreted as 'dance of darkness' or 'dance of the dark soul' (Vicky Sanders, 1988, 149). Butoh aimed to coopt and pervert the basic styles of traditional Noh and Kabuki - to resurrect and challenge them simultaneously - in an effort to resist the Western modes of dance and performance infiltrating Japanese culture postwar. In so doing, Butoh sought both to question Westernized modes of national progress and express the suppressed traumas of Japan's fractured postwar consciousness. Often, Butoh dancers such as Ohno would adorn the garb typical of Kabuki and Noh performers, such as kimonos (often the female version, in a defiance of gender boundaries), as well as heavy white face makeup reflective of both Kabuki and the wooden masks typically worn in Noh, an implication suggested by the performer's fixed facial expressions. As Sanders suggests, 'Butoh dancers use a fresh, sometimes nightmarish vocabulary of grimace and gesture that seems at once prehistoric and futuristic' $(1988,150)$. Butoh's movements can be characterized as an uncomfortable and deeply unsettling array of painful bodily contortions, which, in its multilayered avant-garde style, is a literal embodiment of trauma that rails against Japan's postwar progressive time consciousness (Fig. 14). Thus Butoh, like Sadako's degrading videotape, deploys the aesthetics of trauma to launch an ideo-aesthetic challenge to postwar fixations with progress and futurity.

In its powerful evocation of counter-memory, Sadako's tape collapses together the different modes of address that typically separate national history from personal memory. The viewer and other characters become enfolded in and are forced to sift through a past childhood trauma as if it were a broader cultural history, rather than the fractured memories of a 

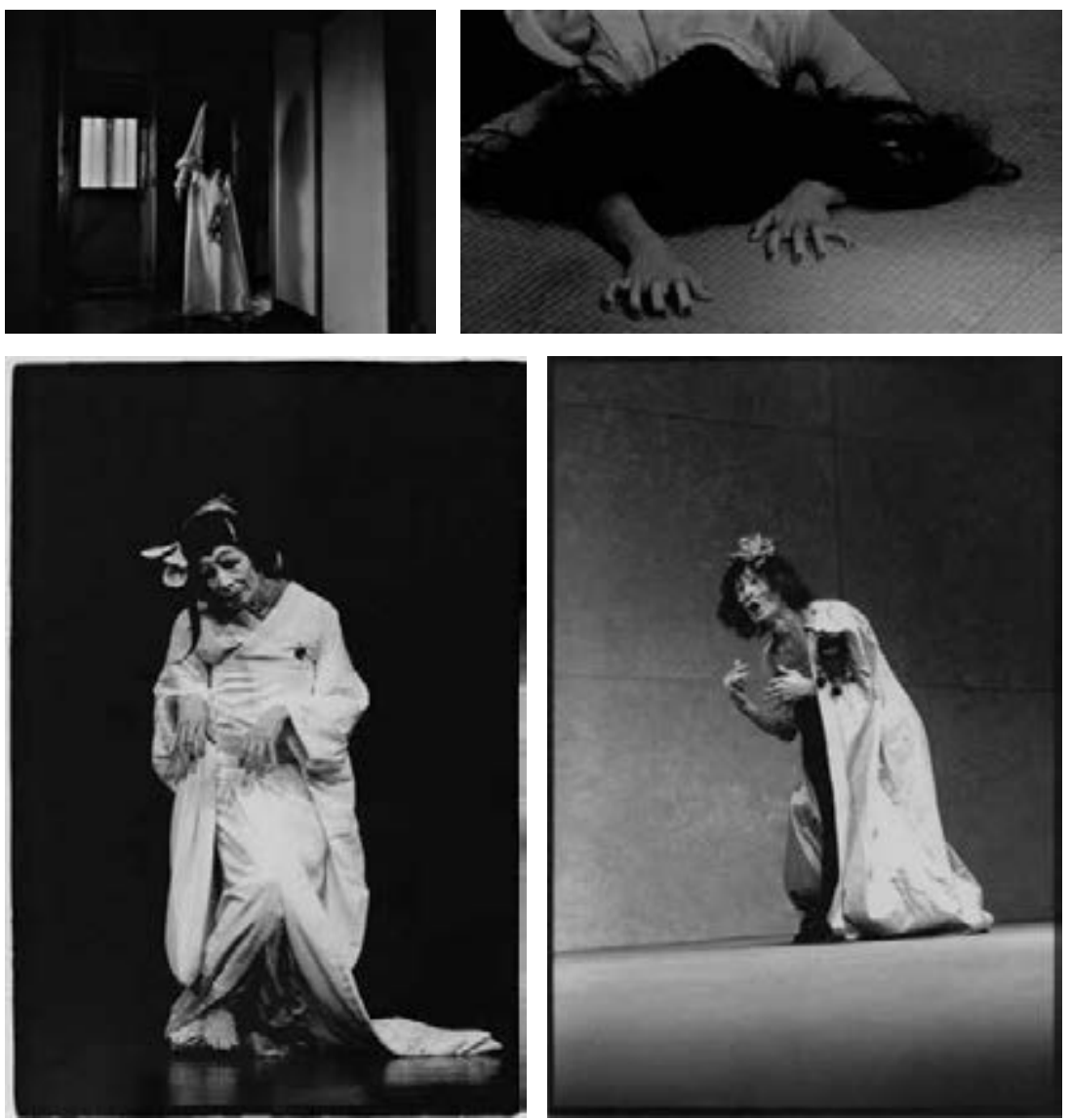

Figure 14. Top from left: RINGU 0 and crawling through the television in RINGU. Bottom: Kazuo Ohno performing Water Lilies (1987); photographs by Nourit Masson-Sekine (1988).

forgotten dead girl - an explicit evocation of prosthetic trauma. In defining counter-memory, Foucault proposes just such a replacement of 'objective' historical narratives with personal memories and genealogies (1977, 139-164). As a result of its prosthetic trauma, Sadako's tape powerfully conjures the 'insurrection of subjugated knowledges' $(2003,10)$ that Foucault asserts is the project of counter-memory. As Medina explains:

when it comes to knowledge of the past and the power associated with it, this battle involves resisting the 'omissions' and distortions of official histories, returning to lost voices and forgotten experiences, relating to the past from the perspective of the present in an alternative (out-of-themainstream) way. $(2011,13)$ 
Rebelling against the child's conventional function to embody national continuity and thus sustain ever-advancing national progress, Sadako instead harnesses her past trauma - inflicted by the very adults responsible for her care - to dismantle the imagined coherence and homogeneity of Japan's modern time consciousness. This ideo-aesthetic 'insurrection of subjugated knowledges' $(2003,10)$ rebels against homogenous narratives of Japanese history, while potently expressing the belated recognition in the late 1990 s that, while children as both ideological apparatus and as subjects have sustained celebrated mythologies of rapid postwar progress, they are also the long-unacknowledged victims of this pervasive entanglment of personal growth and national advance.

\section{Sadako's Fluctuation between Child and Adult}

In concert with the archaeological images on her tape, as I previously suggested, Sadako's 'growth' does not adhere to the strictures of linearity. For most of RINGU, Sadako's ghostly image takes the form of a small child: she appears as such in the video that bears her curse, and also in the intersubjective flashback to the moment she killed the journalist (a vision that briefly fills the whole screen as Sadako imposes her memory upon Reiko and Ryuji). Yet, towards the end of the film, when Reiko and Ryuji finally discover the well in which Sadako died and experience another intersubjective flash of Sadako's past - the moment that Ikuma attacked her and threw her down the well - Sadako appears eerily tall and stretched. Similarly, the monstrous creature who crawls through the television screen to murder Ryuji in the climactic scene is rendered abject through the unnatural contortions of her elongated, lean body, a corporeality that conflicts with that of the small girl depicted earlier in the film. Further obfuscating the unstable timeline of her existence, in RINGU 2, it is revealed that Sadako in fact remained alive in the well for 30 years, dying only a year or two before Reiko discovered her corpse - a disconcerting muddying of narrative time, as Sadako's body was depicted in an advanced state of decay in RINGU.

The prequel further unsettles the temporal continuum to which Sadako is bound. As intimated above RINGU o: BIRTHDAY (a title which points to the cycle's preoccupation with Sadako's development) is set 30 years before RINGU and RINGU 2 in the late 196os - a cultural moment in which both postwar progress, and Butoh dance, flourished - and depicts Sadako as a socially and mentally stunted nineteen-year-old girl who unknowingly places a deadly curse upon almost everyone she encounters. Yet, it is revealed that this seemingly innocent teenage Sadako is latently inhabited, and, at 
moments of fear or rage (kireru), taken over by, a second version of herself: the child incarnation of Sadako. This child Sadako, who constantly evades full capture in the visual field even of this film, seems to exist within the depths of the teenage Sadako's own psyche as a residue of Sadako's traumatic memories, while simultaneously possessing corporeal form in the film's present.

It is suggested that after Sadako murdered the journalist at Shizuko's demonstration of her psychic abilities - which, as in RINGU and RINGU 2, remains a powerful but elusive moment in the film's diegetic past -, Sadako split into two versions of the same self. Ikuma captured the version of Sadako that he believed harboured murderous inclinations, and locked her in the attic, injecting her with chemicals to ensure she did not develop on her own terms - a forceful allegory for the previous generation's culpability for the stultifying conditions surrounding childhood in Japan at the turn of the 21st century. It is only when this monstrous child reasserts herself inside the psyche of the soft and gentle teenage Sadako that she loses control of her psychic powers and kills or torments those around her. At the film's climax, frightened members of Sadako's theatre troupe track her down and brutally beat her, facilitating the child's complete takeover of Sadako's bent and broken body to wreak vengeance upon all of her aggressors, leaving none alive in her wake. It is after this massacre that Ikuma tosses his daughter(s) into the well. The child Sadako is thus a particularly threatening incarnation of the internal alien, existing outside of Sadako's being as a corporeal entity in the present while simultaneously lurking deep within her psyche as a partially obscured traumatic past. Echoing Sōseki's tale, at the conclusion of RINGU o, the internal alien restates her primacy within the psyche of the teenage Sadako, folding the process of growing up back onto itself at the very moment of her transition into adulthood.

The affects of this temporal looping are extended to the viewer throughout the film cycle: in a simulation of being engulfed by a long-latent childhood trauma, Sadako and her fractured memories function like an internal alien for the viewer as well. The films revolve around the implication that Sadako's traumatic images have the power to extra-diegetically infect the viewer's mind, for we have also been exposed to her videotape curse in the process of watching the film(s), a conceit invoked with further potency by the climactic realization in RINGU that Sadako has the ability to erupt through the screen which projects her image and enter the real space of the spectator. Sadako's temporal multiplicity underpins the prosthetic traumas of this internal alien, as it remains impossible to locate her at one particular developmental stage along the continuum from child to adult throughout the cycle. Between 
appearances, her corporeality seems to stretch and contract, unsettling the audience's temporal grasp by impelling them to question whether their previous perceptions of Sadako were accurate. Reflecting trauma's paradox of vision, in relating to the character of Sadako, we are unable to construct a coherent linear narrative of growth and development from the snippets of her past that we are offered, in a way that challenges the authority of our own gaze and powers of comprehension: we instead engage in an uncertain process of reflection and comparison between the image before us and earlier memories of what we may or may not have seen.

\section{Attentive Recognition and the Ideo-Aesthetics of the Internal Alien}

This stymied mode of recollection is in large part enacted by Sadako's evasion of full capture within the camera and viewer's gaze. In fact, the first time we see her in RINGU, it is via a darkened mirror reflection on the cursed videotape: as we watch the mirrored reflection of Shizuko brushing her hair, the mirror shifts for one moment from the left side of the wall to the right, and for this instant Sadako's image is briefly reflected, receding even as it appears. During Reiko and Ryuji's analysis of the tape, this shot is put under particular scrutiny, as Reiko pauses the tape in an attempt to capture that image and questions 'What is that?' In trying to 'capture' Sadako as a character by piecing together these brief, barely tangible images, the viewer undergoes a process of attentive recognition, a mode of perception outlined by Deleuze ${ }^{7}$ in relation to what he calls the 'optical image' - the inspiration for Marks's aforementioned archaeological image. During attentive recognition, the perceiver is forced to oscillate between the fragmented, incoherent image that the film presents, and the images that it brings to mind - whether these are memories drawn from earlier in the film, or from the perceiver's own prior experience, or her imagination, or an indiscernible combination of the three. After undergoing this psychic process, the viewer returns to the image so that the memories drawn forth can assist her attempt at comprehension. As Deleuze explains, images that incite attentive recognition are 'necessarily poorer and more rarefied' (1997a, 44) as we are shown 'pure descriptions which are unmade at the same time they are outlined' (1997a, 45) - a fitting description for the grainy, black-and-white image of Sadako receding into the shadowy depths reflected by the mirror.

Because Sadako's memories are emitted via her cursed video, the films amplify the rather uncanny affects of attentive recognition by diegetically 
foregrounding the entanglement of memories raised by optical media with an individual's own subjective processes of memory. For instance, in RINGU 2, a scene early in the film depicts a forensic scientist's attempt to reconstruct Sadako's face from the information garnered from her remains. The result is a plasticine model that is curiously devoid of distinguishing facial features, extending the first film's tension surrounding Sadako's unknowability. One of the investigators starts to take photographs of the model, and, with each flash of the camera, an uncanny face briefly overlays the blank plasticine replica, the texture and hue of a photographic negative. Yet the 'face' disappears with the light of the camera flash, and we are forced to question what it is we really saw and provide the image with substance by patching together our own vague memories or internal visualizations of Sadako's appearance. The vague and elusive 'memory' of Sadako's face is thus drawn forth by the flash of the camera, as optical media technology becomes a prosthetic vehicle for memory, working in a circuit with the subjective memories of other characters and the viewer.

The affective relationship between film and viewer ripples out to the deep ideological tensions the films express. As Ndalianis explains, 'our cognitive engagement with the ideological issues raised by horror films [...] rely on our sensory responses to horror' $(2012,20)$. The sensory effects of the films' aesthetics express an all-encompassing unsettling of Japanese progress that is played out via an anxiously belated rethinking of both growth and childhood. In a succinct example of such ideo-aesthetics, in the first film, a black-and-white, photographic negative effect occasionally intrudes upon the muted, realist colour palette of the main narrative, an effect which resembles the flash of Sadako's face described above. When Sadako's victims - almost always teenagers on the brink of adulthood - die, their terror-contorted faces are depicted using this chromatic shift, and throughout the cycle these images often abruptly erupt into the diegeses in concert with a piercing electronic scraping sound (the distorted sound of a camera flash, which also evokes a human scream and the high-pitched squeal of Sadako's tape). The jarring effect interrupts our smooth interaction with the linear narrative as we experience a sensory jolt. At the same time, this effect potently condenses the way this internal alien derails progressive temporal vectors, demonstrating that Sadako's curse shuts down the subjectivity of her victims, immobilizing their future potential as they become frozen as degraded mediated images in her archaeology of the past.

This same ideo-aesthetic effect contributes to the feelings of dread conjured by RINGU's final shot, a wide shot depicting Reiko driving toward a grey horizon with her son, Yoichi, in the car. Yoichi has watched Sadako's 
cursed tape, and is doomed to die unless Reiko shows someone else the tape, and she has chosen to show it to her father. As she drives towards the horizon, the voice of the child that she interviewed, yet calmly dismissed, at the beginning of the film is replayed, stating 'It never ends, it just goes on and on.' Just before the screen fades to black, the image of Reiko driving becomes a static, black-and-white image. This shift is almost imperceptible at first due to the dark sky, yet the film lingers for a moment on this static image before the screen blackens. RINGU thus leaves us on an unsettling evocation of stalled progress, mediated through the voice of a child we heard in the early moments of the film who understood all along that Sadako's curse is not conducive to linear resolutions. Thus, the film ends with the frisson of an eerily delayed recognition of the power of past childhood traumas to reconfigure narrative time from behind, a recognition that in turn unsettles the child's binding to growth, progress, and futurity.

Ultimately, throughout the RING cycle, few external temporal coordinates are offered to the viewer to help construct a linear pattern of growth for Sadako Yamamura: the instances from Sadako's past simply erupt into the film's diegetic present as grainy, sepia coruscations, overcoming the muted colour palette of the film's diegetic real - flashes of the past which briefly dominate the whole screen like a traumatic memory. As viewers, we become enfolded in the few eerie images that circulate around Sadako's childhood trauma, and are encouraged to engage with them via our own processes of attentive recognition. Marks suggests that this deeply personal process of engagement can be disturbing and even traumatic $(2000,48)$, as is the intention in RING: the boundaries between film and screen seem to waver as our memories interface with the floating memories of Sadako on-screen. This affect is enhanced by the aesthetics of technological decay and degradation that characterize Sadako's imaging of pastness, as her traumatic images intrude upon the films' narratives as though they have emerged from a layered, indiscernible combination of psychic and historical pasts beyond the diegetic realm of each film. The cyclical, repetitive way Sadako's images reverberate throughout all three films evokes the relentless repetition of her traumatic past: the films cycle around a traumatic event and impose the fragmented memories of it upon our consciousness without directly or coherently depicting it. These aesthetics thus simulate the affects of trauma, inciting 'a larger relation to the event that extends beyond what can simply be seen or what can be known [...] inextricably tied up with the belatedness and incomprehensibility that remain at the heart of this repetitive seeing' (Caruth, 1996, 92). Sadako's childhood trauma becomes our trauma: we too have now become cursed by the images on her tape - a recognition 
that occurs long after we are first exposed to it in the course of watching RINGU - as the prosthetic technologies Sadako uses to store and transmit her disjunctive memories also extend her trauma into our own corporeal and subjective experience. In turn, the ideo-aesthetics of Sadako's trauma subvert our own experiences and perceptions of both narrative progress and childhood growth, challenging the claustrophobic ideological binding of childhood to national progress and futurity in Japan at the millennial turn.

\section{The Ju-on Series}

While the temporal mechanics of the RING cycle may be complex, the JU-ON films extend RING's spiralling structure to disorienting extremes. JU-ON first appeared as two very popular television and direct-to-video movies in 2000, JU-ON: THE CURSE 1 and 2, before the theatrical release of JU-ON: THE GRUDGE 1 and 2 (Takashi Shimizu, 2002). The narratives of the theatrical releases follow on from these telemovies without a connective preamble for new viewers. In so doing, the theatrical releases render the brutal murder at the crux of the films as a particularly intangible traumatic event of the past, appearing only as brief and faded sepia intercuts that slice into the opening titles, without temporal or explanatory context. This terrible past event nevertheless shapes the trajectories of everything that occurs within each films' present diegeses.

The films centre on the spectres of a mother, Kayako, and her child, Toshio, who linger within the house in which they were brutally murdered by Kayako's husband and Toshio's father, Takeo. While the theatrical releases do not expose the reasons behind Takeo's murderous rage, the telemovies reveal that Takeo suspected his wife was having an affair with Toshio's classroom teacher. As is indicated by the intertitles that open almost all of the films - emphasizing the series' aesthetic of inescapable repetition - 'ju-on' denotes a curse that emerges when someone dies in the grip of a powerful rage, which gathers in the site of their death, in this case, the Saeki family's home. This curse involves the eternal repetition of the circumstances surrounding Toshio's and Kayako's deaths, enfolding any who come into contact with the house in a replaying of their trauma.

While in RING a videotape functions as the prosthetic vessel for the contagious spreading of the child's trauma, in JU-ON, people become prostheses for the curse's ever-extending grasp: those who have already been cursed tend to die in the grip of the powerful rage of Toshio and Kayako, creating new incarnations of the curse that extend beyond the bounds of 
the haunted house. The films thus depict a traumatic consequence of family breakdown and abuse, as the violent combustion of one family unit threatens to spread across the whole of Japanese society like a virus. The child, Toshio, is the embodied site of this traumatic collapse in contemporary societal structures and thus the primary vessel of the film's prosthetic trauma: Toshio drives most of the hauntings in the film, making contact with the viewer's sensorium by continually reliving his own trauma throughout the franchise. Diegetically, it is also Toshio who first draws the general public into the curse, as in the first film, ThE CURSE, his teacher visits the Saeki house because Toshio has not been attending school.

Anxiety surrounding the effects upon society of the ever-increasing incidence of school refusal (tôkôkyohi) was high in Japan at the time that the Ju-ON series was released: in a study of the phenomenon, Shoko Yoneyama points to data that demonstrates that school refusal increased dramatically throughout the 1990s, and, by 1997, one in 53 lower middle school students were officially recognized as tôkôkyohi $(2000,79)$. What is more, Yoneyama includes in her study statements made by students who explain their school refusal as a mode of resistance against Japan's intense compulsory schooling system: 'students come to juxtapose their self-hood and school as fundamentally incompatible' (2000, 89) as 'student accounts indicate that even if the "triggers" of tôkôkyohi might be specific to each individual student, it is ultimately the entire school system that is at fault' (2000, 92), a rebellion which is 'gradually causing a legitimation crisis in Japanese schools and society' (2000, 92). Refracting anxieties about the tôkôkyohi phenomenon, Toshio's absence from school heralds his monstrous resistance to the child's sociocultural function, a resistance that, via his contagious supernatural curse, threatens Japanese society with total dissolution.

While brief flashes of Kayako's murder, and also Takeo's drowning of the family's black cat, are depicted throughout the Ju-ON films, Toshio's death is not shown: the child's trauma is circled around in all three films but never overtly represented, it is 'not experienced in time' (emphasis in original, Caruth, 1996, 62), in both senses of the phrase, enforcing a break in coherent temporality. Throughout the series, Toshio is known to be missing, but his murder has not been confirmed, for his body has never been located. In fact, the drowning of the cat functions as a signifier for Toshio's unrepresented death: Takeo is shown drowning the cat in the bathtub as it yowls and hisses, and at certain points throughout the films, Toshio is pictured around the bathtub as well, at one point with his head over the rim, submerged in the water. In his ghostly form, Toshio emits a cat's squeal, further reinforcing the way the cat's death comes to stand in for Toshio's own, unwitnessed 
trauma. Toshio's cat sounds metonymize the trauma inflicted upon him by his father, while indicating how the child draws his spectral force from this trauma to impose it back upon the adult society that failed him.

\section{Toshio as Prosthetic Trauma}

In a subversion of traditional haunted-house narratives in which the haunting is tied to a particular space, anyone who comes into contact with the house in which Toshio and Kayako died, however tangentially, experiences the wholesale disintegration of linear timeframes within their everyday lives: as soon as characters have encountered the ghosts, their narratives branch away from their previously linear route to become a disorientating corkscrew in which phone calls, conversations, and events repeat, replay, and overlap. Echoing the mechanics of prosthetic trauma and the internal alien, some characters start to (re)experience the circumstances surrounding Kayako and Toshio's murder psychically, as the traumatic past of the child and his mother is restaged in the present experience of other characters, even though it is not a past that 'belongs' to them. Toshio frequently clings and attaches himself to the bodies of the central characters or the furniture that they use - such as beds, chairs, and tables - aestheticizing his spectral function as prosthetic trauma.

Furthermore, Toshio embodies the subjective and temporal dislocations of the internal alien's prosthetic trauma: in both the original telemovie and first theatrical film, he appears as a mute and abused living boy in the central narrative thread, yet he simultaneously wreaks havoc as a ghost, with white skin and darkly lined eyes, in successive scenes that have hazy temporal connections to the overarching narrative. Thus, like Sadako, Toshio distorts the boundaries between the spectral and the material in a defiance of the ontological categorization that would permit his reinstatement into a coherent linear narrative. As a result, Toshio clearly refracts moral panics about the strange-changed child (kodomo ga hen $\mathrm{da}$ ) so prevalent around the millennial turn, as outlined in Chapter Five. He is both the victim of a corrosive and neglectful school and family structure - the extent of his suffering is realized too late by both his teacher and the viewer in The Curse, a belated recognition that is rendered as agonizing tension throughout the film - yet he is simultaneously a monstrous villain possessed by fits of murderous kireru. Toshio's dual appearance reflects the temporal split enforced by his death: the vacillation between his appearance as he was just before he died and alternatively as a pale ghost circulates the gulf of the traumatic event without recalling it directly or situating it on a chronological 
continuum. Toshio himself remains forever stuck at a particularly traumatic temporal moment and will never grow up to enact the future for which he is the receptacle, a temporal blocking that is registered as a deeply uncanny portent for the collapse in narrative progress that is to follow his initial appearance in each film.

For instance, in The Grudge, social worker Rika finds Toshio hiding in a cupboard early in the film, and, because she sees him in the form of a bruised and battered living child, she reports his presence to the police. Toshio disappears while she is making the phone call, but later, when being interviewed at the station, she recognizes the child in a police photograph. She is told that the boy has been missing for six years and would have grown up a great deal in that time, yet Rika shivers in terror because she saw him as he appeared in the photograph. This moment is a turning point in the film, in which Toshio becomes a figure to fear as well as to pity. From this juncture, Toshio's haunting forces characters and the audience of THE GRUDGE to experience his own dropping out of the linear processes of progress and growth, as his hauntings rearrange temporality as an inescapable loop in which characters are literally haunted by their own doomed futures. In THE GRUDGE 2, for instance, characters Tomoka and Noritaka hear a mysterious banging noise seemingly coming from the wall of their apartment, which occurs at exactly the same time each night. Eventually, as their experience of temporality becomes increasingly unstable, Tomoka and Noritaka (and the viewer) come to learn that this mysterious sound has been a reverberation from the future all along, emanating from Noritaka's own corpse: Kayako's ghost strangles him with her supernaturally charged hair, leaving him hanging from the apartment's ceiling. The banging is caused by Toshio, who playfully swings Noritaka's body backwards and forwards so that his feet periodically hit the wall. Thus, Tomoka and Noritaka have been locked into a temporal cycle from which there is no escape, although this does not become clear to them until moments before their death, evoking the traumatic affect of belated recognition in particularly tangled ways.

\section{Seriality, Asynchronous Narratives, and the Spectator's Prosthetic Trauma}

The spectator's experience of the Ju-ON films echoes the characters' belated recognition that they are trapped within a doomed temporal loop. The films are constituted of separate, episodic segments that layer different representations of the same time period from the perspectives of various characters as they meet their demise at the hands of Kayako and Toshio: as 
in RING, time in JU-ON thus functions as cacophonous heterogeneity rather than as a homogenous line. The individual segments do not come together to form a coherent tapestry of narrative meaning, instead serving to enclose the audience, like the characters, into a preordained circle. A sense of mastery over the events is denied in our attempts to follow a storyline to its resolution, as we instead experience how the characters' stories intersect and double back upon each other before inevitably leading to their death. This temporal plurality is enhanced on a larger scale by the numerous different versions of JU-ON in existence (including three American remakes), which do not progress in linear succession: each film presents a different group of people coming into contact with the haunted house. These characters are usually tenuously connected to those from previous films (their storylines set after or before those of the previous film), and the spectator is tasked with detecting this diaphanous connective tissue, following disorienting circuits back and forth through time in charting the ever-expanding web woven by the curse. This decentred heterogeneity thus induces a process of attentive recognition on the part of the spectator which underpins the horrifying affects of the films themselves: as Ndalianis explains, "the pervasive intertextuality that's expressed through seriality [and] allusionism [...] requires the active engagement of the participant beyond the simple interaction with a story of character level' $(2012,10)$. While the films function as a series, consistently requiring viewers to draw forth their memories from previous films to make threads between the many different characters, when viewed chronologically, they do not gradually establish a linear master narrative, but render narrative time as increasingly plural and circuitous.

For instance, the final shot of THE CURSE 2 is a static exterior shot of the cursed house, overlaid with the chirpy voices of a group of teenage girls who have come to explore after hearing that the place is haunted. In the first theatrical release, THE GRUDGE, Toyoma, a detective involved in investigating Toshio's disappearance, arrives at the Saeki house intending to burn it down, an attempt to expel the curse once and for all. Yet, while he is in the house, he sees a group of teenage girls in one of the rooms, who are speaking the dialogue that constituted previous film THE CuRSE 2's final scene. His vision of the girls is suffused with a sepia tone that usually signals that the past is replaying - and, for viewers who have seen the previous film, it is - but Toyoma is in fact seeing the diegetic future: he recognizes one of the girls as his daughter, Izumi, yet, according to this film's diegesis, Izumi is currently a young child, not a teenager. Toyoma and the teenage Izumi's eyes meet for a moment, before the room becomes shrouded in shadow once more and the girls disappear. Toyoma is then claimed by the curse before he is able to burn down 
the house. The film's next segment jumps forward to this flash from the future, to focus on the experience of the teenage Izumi soon after she has entered the cursed house. Izumi remains haunted by the death of her father when she was a young child, and her anxiety has heightened since she entered the haunted house in which he died with her friends and was confronted with a vision of him from the past: the incident that the viewer has just experienced from the perspective of Toyoma. Thus, for the viewer, a haunting from the past turns out to reverberate from the future, before being promptly flipped back into a haunting from the past, as chronological progression is folded back on itself.

The end of JU-ON 2 draws out the ideological implications of the series' frightening narrative and aesthetic contortion of linear time into doomed cycles. Overarching the film is the story of an actress, Kyoko, who has been haunted by Toshio throughout the film. Kyoko, who has been performing in a horror film set in the haunted house (her name's similarity to the ghostly Kayako is clearly no coincidence), has become pregnant. The film's climax depicts the terrible birth: instead of birthing a human baby, it is a miniature Kayako who crawls from Kyoko's body, and the monstrous creature kills everyone else in the delivery room. The final scenes depict Kyoko walking through the streets of Tokyo hand-in-hand with her monstrous progeny - a child born as a ghost. Recalling Sadako (and thus inciting the viewer's sense of dread via intertextual allusion), the reborn ghost of Kayako is a small creature in a white gown, with long black hair completely covering her face. The film ends with this child pushing Kyoko down the stairs of the bridge on which they have been walking, leaving her surrogate mother on the stairs to die as she totters off alone, into the busy Tokyo street. Thus, the series ends on a literal 'rebirth' of the curse, a claustrophobic vision in which children emerge into life as the vessels for the perpetuation of unresolved traumas of the past. The Ju-ON films ultimately aestheticize the catastrophic fracture that occurs when the child breaks apart from the linear path from education to work that defines childhood in Japan: the horizon of the future falls away for all who encounter Toshio and his vengeful mother, as traumatic 'time with the ghost' replaces each character's existence within a homogenous, ever-advancing national time.

\section{Conclusion}

At the liminal juncture represented by the turn of the millennium - a moment which also signified the continuation of one 'Lost Decade' into another - children became Japan's long-unacknowledged victims, and subsequently threatened to violently break out of their proper ideological 
place, symbolic contortions that threatened disturbing domino effects upon Japan's national identity. As Ryuji says of Sadako in RINGU, 'our fear has taken on a life of its own'. The J-horror films that emerged at the millennial turn can be seen as a response to the cultural trauma of the Lost Decade, in which long-standing narratives of rapid national progress were suddenly destabilized. The child is a powerful receptacle for such tensions, as this vessel for national futurity defies its overdetermined classification to instead monstrously foreclose the possibility of sociocultural advancement. The child's eruption through subjective and temporal boundaries makes contact with the viewer's sensorium on a deep level through the mechanism of prosthetic trauma, which constitutes both an affect and narrative preoccupation of these films. This prosthetic trauma aestheticizes the disturbing intensity yet challenging incoherence of traumatic memories - counter-memories resistant to homogeneous historical discourse - as in our interface with the films, we confront decaying, illegible images that circulate around traumatic pasts without coherently depicting them, in ways that become entangled with our own subjective processes of memory.

While this prosthetic trauma resonates beyond national boundaries (as is indicated by J-horror's vast transnational popularity in the early 21st century), the internal alien triggers particularly potent reverberations within a Japanese context, as every Japanese adult has been subject to the claustrophobic ideological entwinement of childhood development and national progress. Furthermore, Japanese adults of the period were (and are) implicated in the belated recognition of the extent to which children have been oppressed in the quest for national progress and productivity. Thus, the prosthetic traumas raised by the millennial internal alien have the potential to incite a retroactive reconsideration of their domestic audience's own experiences of growth, schooling, and childhood in Japan. In turn, these figures dramatize questions of culpability surrounding the current generation's own part in the continuation of confining models of education and child development in service of national ideology.

Parallel to this extra-diegetic potential, the temporal dislocations of the uncanny child interrupt both narrative progress and character development, inciting frightening moments of belated recognition in a simulation of traumatic experience. Furthermore, the subversive plurality of these characters also entails the resurfacing of earlier modes of childhood in Japan, in which the child was not locked into position as a sociocultural (and economic) unit within linear constructions of national development. The J-horror uncanny child thus resists the redomestication of the child within the unitary discourse of linear national progress, deconstructing the 
temporal mechanics that underlie this mode of consciousness. Although these characters' distortions of homogenous temporality are deeply uncanny, by challenging the overdetermined entwinement of a child's 'growing up' with national progress they expose the extent to which the Lost Decade represented an opportunity to reimagine the child's position in Japan's national narrative.

\section{Works Cited}

Balmain, Colette. 'Inside the Well of Loneliness: Towards a Definition of the Japanese Horror Film.' Electronic Journal of Contemporary Japanese Studies. 3 (May 2006): n.p. Web. 30 Sep. 2014.

-.Introduction to Japanese Horror Film. Edinburgh: Edinburgh University Press, 2008. Print.

Benson-Allott, Caetlin. Killer Tapes and Shattered Screens: Video Spectatorship from VHS to File Sharing. Berkeley: University of California Press, 2013. Print.

Bergson, Henri Louis. Matter and Memory. Trans. Nancy M. Paul and W. Scott Palmer. New York: Dover Philosophical Classics, 2004. Print.

Bowers, Faubion. Japanese Theatre. Rutland: Charles E. Tuttle Co., 1974. Print.

Caruth, Cathy. Unclaimed Experience: Trauma, Narrative, and History. Baltimore: The John Hopkins University Press, 1996. Print.

-.'Introduction: Trauma and Experience.' Trauma: Explorations in Memory. Ed. Cathy Caruth. Baltimore: The John Hopkins Univeristy Press, 1995. Print.

Deleuze, Gilles. Cinema 2: The Time Image. 1985. Trans. Hugh Tomlinson and Robert Galeta. Minneapolis: The University of Minnesota Press, 1997a. Print.

Dona, Giorgia. 'Collective suffering and Cyber-memorialisation in Post-genocide Rwanda.' Trauma, Media, Art:New Perspectives. Ed. Mick Broderick and Antonio Traverso. Cambridge: Cambridge Scholars Press, 1999. Print.

Edelman, Lee. No Future: Queer Theory and the Death Drive. Durham: Duke University Press, 2004. Print.

Foucault, Michel. Language, Counter-Memory, Practice. Ed. Donald F. Bouchard. New York: Cornell University Press, 1977. Print.

—.'Society Must Be Defended': Lectures at the Collège de France 1975-1976. Trans. David Macey. New York: Picador. 2003. Print.

Hand, Richard J. 'Aesthetics of Cruelty: Traditional Japanese Theatre and the Horror Film.' Japanese Horror Cinema. Ed. Jay McRoy. Edinburgh: Edinburgh University Press, 2006. 18-29. Print.

Haque, D. 'Horrific Reproductions: Pathology and Gender in Koji Suzuki's Ring Trilogy.' The Scary Screen: Media Anxiety in The RING. Ed. Kristen Lacefield. Surrey: Ashgate Publishing Ltd., 2010. 191-205. Print. 
Kafu, Nagai. 'The Fox.' 1909. Autumn Wind and Other Stories. Ed. and Trans. Lane Dunlop. North Clarendon: Charles E. Tuttle Publishing Company, 1994.11-30. Print. Landsberg, Alison. Prosthetic Memory: The Transformation of American Remembrance in the Age of Mass Culture. New York: Columbia University Press, 2004. Print.

Lim, Bliss Cua. Translating Time: Cinema, the Fantastic and Temporal Critique. Durham: Duke University Press, 2009. Print.

Lowenstein, Adam. 'Ghosts in a Superflat Global Village: Globalization, Surrealism and Contemporary Japanese Horror Films.' Post-Script. 28.2 (2009): 59-72. EBSCO Host Humanities International Complete. Web. 30 Sep. 2014.

—.'Globalized Spectatorship: Ring Around the Superflat Global Village: J-Horror Between Japan and America.' Dreaming of Cinema: Spectatorship, Surrealism and the Age of Digital Media. New York: Columbia University Press, 2015· 79-116. Print.

Lury, Karen. The Child in Film. London: I.B. Tauris \& Co. Ltd., 2010. Print.

Marks, Laura U. The Skin of the Film: Intercultural Cinema, Embodiment and the Senses. Durhman: Duke University Press, 200o. Print.

McRoy, Jay. Nightmare Japan. Amsterdam: Rodopi, 2008. Print.

Medina, José. 'Toward a Foucaultian Epistemology of Resistance: Counter-Memory, Epistemic Friction, and Guerrilla Pluralism.' Foucault Studies 12 (2011): 8-35. EBSCO Host Humanities International Complete. Web. 30 Sep. 2014.

Miyao, Daisuke. The Aesthetics of Shadow: Lighting and Japanese Cinema. Durham: Duke University Press, 2013. Print.

Nakata, Hideo. Interview by Donald Totaro. 'The "Ring” Master: Interview with Hideo Nakata.' OffScreen.com, Canada Council for the Arts. July 200o. Web. 30 Sep. 2014.

Ndalianis, Angela. The Horror Sensorium: Media and the Senses. Jefferson: McFarland, 2012. Print.

Phu, Thy. 'Horrifying adaptations: RINGU, THE RING, and the cultural contexts of copying.' Journal of Adaptation in Film and Performance. 3.1 (2010): 43-58. Print.

Richards, Andy. Asian Horror. Herts: Kamera Books, 2010. Print.

Robertson, Jennifer. 'Furusato Japan: The Culture and Politics of Nostalgia.' International Journal of Politics, Culture and Society. 1.4 (1988): 494-518.JSTOR Arts and Sciences VI. Web. 30 Sep. 2014.

Sanders, Vicky. 'Dancing and the Dark Soul of Japan: An Aesthetic Analysis of Butoh.' Asian Theatre Journal 5.2 (1988): 148-163. JSTOR Arts and Sciences III. Web. 30 Sep. 2014.

Sōseki, Natsume. Ten Nights' Dreams. 1908. Trans. Takumi Kashima and Loretta R. Lorenz. London: Soseki Museum in London, 2000. Print.

Stein, Bonnie Sue. 'Butoh: Twenty Years Ago We Were Crazy, Dirty, and Mad.' Moving History/Dancing Cultures. Ed. Ann Dils and Ann Cooper Albright. Middletown: Wesleyan University Press, 2001. 376-383. Print. 
Suzuki, Koji. Ring. Trans. Robert B. Rohmer and Glynne Walley. New York: Vertical, 2004. Print.

Tateishi, Ramie. 'The Japanese Horror Film Series: Ring and Eko Eko Azarak.' Fear Without Frontiers: Horror Cinema Across the Globe. Ed. Steven Jay Schneider. Godalming: FAB Press, 2003. Print.

Wada-Marciano, Mitsuyo. 'J-Horror: New Media's Impact on Contemporary Japanese Horror Cinema.' Horror To the Extreme: Changing Boundaries in Asian Cinema. Ed.Jinhee Choi and Mitsuyo Wada-Marciano. Hong Kong: Hong Kong University Press, 2009. 15-39. Print.

Webber, Andrew Lloyd. The Phantom of the Opera. Lyrics by Charles Hart and Richard Stilgoe. Milwaukee: Hal Leonard, 1987.

Wee, Valerie.Japanese Horror Films and their American Remakes. London: Routledge, 2013. Print.

-.'Patriarchy and the Horror of the Monstrous Feminine: A Comparative Study of RIngu and The RIng.' Feminist Media Studies 11.02 (2011a): 151-165. Taylor and Francis Journals Complete. Web. 30 Sep. 2014.

-.'Visual Aesthetics and Ways of Seeing: Comparing Ringu and The Ring.' Cinema Journal 50.2 (2011b): 41-6o. JSTOR Arts and Sciences III. Web. 30 Sep. 2014.

Wetmore, Kevin J. 'Technoghosts and culture shocks: sociocultural shifts in American remakes of J-horror.' Post-script 28.2 (2009): 72-83. EBSCO Host Literary Reference Centre. Web. 30 Sep. 2014.

White, Eric. 'Case Study: Nakata Hideo's Ringu and Ringu 2.' Japanese Horror Cinema. Ed. Jay McRoy. Edinburgh: Edinburgh University Press, 2006. 38-51. Print.

Yoneyama, Shoko. 'Student Discourse on Tôkôyohi (School Phobia/Refusal) in Japan: Burnout or Empowerment.' British Journal of Sociology of Education 21.1 (2000): 77-94.JStOR Arts and Sciences IV. Web. 30 Jan. 2015.

\section{Filmography}

Dark Water [Honogurai mizu no soko Kara]. Dir. Hideo Nakata. 2002. Section 23 Films, 2005. DVD.

Eyes Without a Face [Les Yeux Sans Visage]. Dir. Georges Franju. Champs-Elysées Productions, 1960. Film.

Ju-ON: The Curse [Ju-ON]. Dir. Takashi Shimizu. 2000. Lionsgate Home Entertainment, 2003. DVD.

Ju-ON: The CURSE 2 [JU-ON 2]. Dir. Takashi Shimizu. 2000. Lionsgate Home Entertainment, 2003. DVD.

Ju-ON: The Grudge [Ju-ON]. Dir. Takashi Shimizu. 2002. Lionsgate Home Entertainment, 2005. DVD. 
Ju-ON: The Grudge 2 [Ju-ON 2]. Dir. Takashi Shimizu. 2002. Lionsgate Home Entertainment, 2006. DVD.

The Locker [Shibuya KaIdan]. Dir. Kei Horie. Bad Taste Visual Voice and Geneon Entertainment, 2004. Film.

One Missed Call [Chakushin ari]. Dir. Takashi Miike. 2003. Tokyo Shock, 2006. DVD.

Reincarnation [Rinne]. Dir. Takashi Shimizu. 2005. Lionsgate Home Entertainment, 2007. DVD.

RINGU. Dir. Hideo Nakata. 1998. DreamWorks Video, 2000. DVD.

Ringu o: Birthday [RIngu 0: Basudei]. Dir. Norio Tsuruta. 2000. Paramount Catalogue, 2013. DVD.

RINGU 2. Dir. Hideo Nakata. 1999. DreamWorks Video, 2005. DVD. 


\title{
Section Four
}

\author{
Trauma's Child:
}

The Uncanny Child in Transnational

Coproductions and Remakes 



\title{
7. The Transnational Uncanny Child
}

\begin{abstract}
Chapter Seven considers the Hollywood J-horror remakes and SpanishAmerican coproductions that emerged in the early 21st century as a response to the globally successful boom of uncanny child films. The chapter considers how this assemblage of films is self-consciously transnational, as the uncanny child becomes disconcertingly ungrounded from specific visions of national identity. In these films, the uncanny children stage direct confrontations with the child's shifting role in postmodern culture. Through their cultural hybridity, the uncanny children in transnational horror navigate tensions underlying not only shifting understandings of childhood but changing global cinema cultures in the early 2000 s.
\end{abstract}

Keywords: Transnational cinema, Childhood, Globalization, Deterritorialization, Cultural hybridity

Through their deployment of uncanny children who expose and trouble the child's overdetermined, sometimes paradoxical temporal function, all the films discussed in this book so far communicate with one another in profound ways. Previous chapters have outlined how the uncanny child emerges from culturally specific contexts as an embodiment and agent of trauma at the turn of the 21st century, aestheticizing a breach in linear narratives of personal and national identity. The uncanny child is thus a product of this unsettled moment of transition in which entrenched historical narratives seemed to waver, harnessing this liminality to problematize the child's imbrication in progressive temporal modes with specific cultural functions. Though these films emerge from and speak to culturally specific contexts, they exchange themes and aesthetics in a manner that helps them to envision new ways for the child to erupt through its symbolic bounds at the millennial turn, as traditional understandings of childhood's symbolic function started to come undone.

Balanzategui, J., The Uncanny Child in Transnational Cinema: Ghosts of Futurity at the Turn of the Twenty-First Century, Amsterdam University Press, 2018.

DOI: $10.5117 / 9789462986510 / \mathrm{CHO} 7$ 
For instance, the character design for child-ghost Santi of THE DEviL's BAсквоNE was inspired by the ghostly children of J-horror: ${ }^{1}$ his white, cracked skin and black, reflective eyes echo the traumatic aesthetics typical of the Japanese child-ghost, but reinscribed to refract Spanish cultural traumas about the Civil War's effects on childhood development. Del Toro's drawing from J-horror also points to the ways the film was positioned as both a culturally specific and transnationally digestible product. As Lázaro-Reboll points out, 'the film targeted not only the expanding Spanish and Latin American markets but also a wider international audience. The film was distributed through a truly global film cartel and pre-sold heavily to many major territories' (2007, 39). Lázaro-Reboll also suggests that 'the allegorical intentions of the film are neatly translated into American generic forms' $(2007,43)$ - and indeed, the eerie pairing of the child-ghost with the child seer who communicates with him echoes American films The Sixth SEnse and Stir of Echoes, analysed in Section One, both of which came out two years prior to BACKBONE. THE ORPHANAGE, another Spanish film discussed in Section Two, and a film that del Toro produced, was similarly successfully positioned for global audiences through a carefully tailored blend of cultural specificity and transnational legibility. As Lázaro-Reboll (2012) explains, not only did the film maximize 'the bankability and reputation of del Toro', with the tagline 'Produced by Guillermo del Toro' acting 'as a guarantee of access to international markets' (226), but the film 'displayed the production values usually associated with Hollywood film' (227) while recalling the themes and aesthetics of classic Anglophonic ghost films, in particular seminal creepy child film THE INNOCENTs (Jack Clayton, 1961). The uncanny child figure is at the core of both films' positioning for global markets, as is most strongly indicated by the influence of J-horror's child-ghosts upon del Toro - J-horror being another supposedly 'national' cinema thrust into the global mainstream during the millennial turn.

Similarly, while the uncanny children of J-horror modulate kaidan folklore and Japanese literary tropes, the generic focus on the child is also strongly influenced by American horror films of the 1970s and 1980s. In fact, Suzuki, author of the book series upon which the RING franchise is based, has suggested that Carol Anne from POLTERGEIST was a direct inspiration for Sadako, while director Nakata claims that classic monstrous child films THE EXORCIST and THE OMEN influenced his work (Anthony Enns, 2010, 31). Lowenstein reads the mediated circuits of transnational influence as a key preoccupation of RINGU's diegesis, suggesting that the film plays out an anxiety that 'the

1 In various interviews and discussions about the film del Toro has suggested the ways that 'J-horror intersects with The DeviL's BackBone' (del Toro, 2012). 
technologies that promise to erase boundaries between people scattered across the globe fulfil their promise - only too much so. It is not just the boundaries that are erased but the people themselves as well' $(2015,83)$. He proposes that RINGU and its American remake in fact suggest "a "superflat" global portrait: a simultaneously "Japanized” America and "Americanized" Japan that belongs to both nations but is not fully locatable in either' $(2015,84)$.

Furthermore, the Ju-ON cycle is distinctively marked by cultural hybridity, with the ghosts acting very much like the stalker/slasher killers of American horror: McRoy describes Ju-ON as a 'curious filmic hybrid, combining carefully chosen aesthetic trappings of western - particularly US - horror films with visual and narrative tropes long familiar to fans of Japanese horror cinema' $(2005,176)$. In addition, REINCARNATION (2005), another uncanny child Jhorror film directed byJu-ON's Shimizu, clearly echoes THE SHINING in its tale of a haunted hotel and a father driven to murder his family within its walls: throughout the film, 'Room 227' is prominently featured, a reference to THE SHINING's infamous Room 237, and the central ghost-girl's repeated declaration 'We'll be together forever' throughout the film recalls the Grady twins' 'Play with us forever and ever.' Thus, as in the Spanish films, the uncanny child trope in J-horror represents the locus for processes of transnational exchange: this is at the thematic and aesthetic core of these films while also being a key element transposed from an American into a Japanese cultural context. In turn, subsequent to the global popularity of the RING and JU-ON franchises, the child-focused J-horror cycle came to change the shape of the horror genre globally through both direct remakes from countries as diverse as America, Korea, and Turkey ${ }^{2}$, and films which drew from the themes and aesthetics of J-horror yet constructed original, often culturally specific, narratives, such as Australia's LAKe Mungo (Joel Anderson, 2008) and the Spanish-BritishBulgarian coproduction THE ABANDONED (Nacho Cerdà, 2007).

In fact, aside from the new subgenre known as torture porn, a fair proportion of Hollywood's horror output in the first decade of the 2000 s consisted of remakes of Japanese supernatural horror films. Such films include THE RING (Gore Verbsinki, 2002) and its sequel The RING Two (Hideo Nakata, 2005), The Grudge (Takashi Shimizu, 2004) and its two sequels The Grudge 2 (Shimizu, 2006) and 3 (Toby Wilkins, 2009), DARK WATER (Walter Salles, 2005), and One Missed CALL (Eric Valette, 2008). Contributing to this resurgence

2 Apart from the well-known cycle of American remakes canvassed in this chapter, there has, for instance, also been a Korean remake of RINGU - THE RING VIRUS (Dong-bin Kim, 1999) - and an unofficial Turkish remake of critically acclaimed J-horror film PULSE (Kiyoshi Kurosawa, 2001) called D@BBE (Hasan Karacadag, 2006) (which also draws heavily from RINGU). 
of supernatural horror films were Spanish-American coproductions THE OTHERs (Alejandro Amenábar, 2001) - which was, alongside THE RING, one of the most critically and commercially successful horror films of the early 21st century ${ }^{3}$ - DARKNESS (Jaume Balagueró, 2002), and Spanish-British coproduction FragiLE (Balageuró, 2005), starring American actress Calista Flockhart and distributed and promoted in the U.S. by Metro-Goldwyn Mayer. While these films share a subgeneric status as supernatural horror films, the thematic and aesthetic link which binds them is the uncanny child. Thus, the cycle of transnational horror films that emerged in the early years of the new millennium illustrates the extent to which American, Japanese, and Spanish supernatural horror films engage with one another through the traumatic temporal contortions wrought by their uncanny child figures. Chapter Seven presents a discussion of these remakes and transnational coproductions, outlining how these films can be considered transnational amongst broader discussions of the 'decline' of American horror in the early 21st century, while suggesting how these films self-consciously confront the implications of transnationality through their uncanny children.

\section{Transnational Horror Film}

The assemblage of uncanny child films that emerged alongside and subsequent to the more culturally specific American, Spanish, and Japanese cycles ${ }^{4}$ analysed in previous chapters are transnational in a number of different senses, despite being marketed as Hollywood products. ТнЕ ОтнERS, DARKNESS, and FrAGILE were developed by creative teams from Spain, while coproduced by American, Spanish, and, in the case of FragILE, British companies. ${ }^{5}$ The Grudge franchise and The RING 2 were codeveloped by

3 THE RING is currently among the 20 highest-grossing horror films of all time and is the most commercially successful horror remake. It received $72 \%$ on rottentomatoes.com, a website which aggregates the reviews of film critics, a relatively high score for a horror film (and particularly high for a Hollywood remake). THE OTHERs holds a review aggregate score of $83 \%$, and was the fourth highest-grossing horror film of the 2000 s.

4 Many of the films discussed in this chapter came after the influential American, Japanese, and Spanish films discussed in previous chapters: obviously, the J-horror remakes are based on, and subsequent to, the Japanese originals. However, the transnational cycle flourished alongside some of the more culturally specific films previously discussed, a condition which furthered the transnational potential and global popularity of these films: for instance, THE Devil's BACKBONE was released in the same year as The Others (2001), and The OrPhANAGE (2007) came at the tail end of this transnational horror boom.

5 The Others was coproduced by Cruise-Wagner Productions and Spanish companies Sogecine and Las Producciones del Escorpión, DARKNeSs by Castelao Producciones and U.S. 
creative teams based in both Japan and America. The first two GRUDGE films and THE RING 2 were directed by Takashi Shimizu and Hideo Nakata respectively - the directors of the Japanese originals - and THE GRUDGE franchise was largely filmed in Japan. The other J-horror remakes - THE RING, DARK WATER, and ONE Missed CALL - were developed by American creative teams; however, their screenplays are based on the Japanese originals and, in all cases except THE RING, the writers of the Japanese originals are acknowledged in the credits as having cowritten the screenplays. In addition, ONE Missed CALL was coproduced by Hollywood company Alcon Entertainment and the Japanese company that produced Takashi Miike's original film, Kadokawa Shoten. While not all of the J-horror remakes were coproduced by both Hollywood and Japanese companies, all of them function as self-conscious reinterpretations of the aesthetics and ideological preoccupations of the original Japanese films. Thus, they are transnational in the sense that they mediate the channel between cultures, and resist simple definition as American or Japanese products. All of these films are thus the types of films to which Christina Klein refers in her assertion that:

in recent years the once unambiguously 'American' horror film has been challenged by films that have been profoundly shaped by Hollywood, both directly and indirectly, but that cannot be classified as American in any simple way [...] the horror film is becoming - and is being recognized - as a transnational genre. $(2010,3)$.

In all cases, the films under discussion were codeveloped by production companies or creative teams across cultures, or, at the very least, function as interpretative bridges between national contexts, and are designed to be accessible to diffuse, global audiences.

Elizabeth Ezra and Terry Rowden describe such 'Hollywoodization' processes in wholly negative terms, referring to the 'homogenizing dynamic' of Hollywood film production:

the U.S. film industry has perhaps irreversibly committed itself to the production of empty and costly cinematic spectacles that, in order to maintain their mainstream inoffensiveness, must be subjected to increasingly thorough forms of cultural and ideological cleansing before being released into the global cinemascape. $(2006,2)$ 
In particular, the Hollywood remakes of J-horror films that dominated the horror genre in the early years of the new millennium faced widespread denigration in popular and academic commentary, and were considered to be an indication that the American horror genre was in crisis in the early 200os. As Steffen Hantke points out, most academic criticism focused on the American horror genre published in the first decade of the 21st century 'agree[s] with the notion, explicitly or implicitly, that the [horror genre] [...] is currently in a state of crisis' (Hantke, 2007, 199), as is evidenced in particular by Hollywood's 'indiscriminate plunder of Asian horror films - a practice that, as it confirmed the vitality, creativity, relevance, and intensity of horror film in other countries, made the lack of these qualities strikingly obvious in American cinema' (Hantke, 2010, ix). Disdain for American remakes of Asian horror films is also related to valid concerns surrounding the colonization and appropriation of national genres for Hollywood profits, as is suggested in the work of Balmain (2008), Lim (2009), and McRoy (2008).

Often implicit in the widespread vilification of Hollywood's practice of remaking J-horror films, however, is an anxiety about J-horror's disturbance to a distinctly American horror genre, as the explicit and visible process of global exchange that came to constitute the horror genre in the early 2ooos destabilized binary separations of 'American' and 'Japanese' national cinemas. As Klein points out, 'remakes severely problematize familiar notions of cinematic style and cultural identity' $(2010,7)$, as they are defined by their intertextual relationship with the original upon which they are based, and hybridize tropes and styles that were previously considered culturally specific. Some of the popular and scholarly anxieties about Hollywood's rampant remaking of Asian horror films in the early 21st century could thus arguably relate to the ways that transnational horror films suggest the destabilization of a clearly definable American product. ${ }^{6}$

The interplay between Hollywood 'homogeneity' and cultural specificity permeates all of these films: for instance, DARKNESS and THE GRUDGE are set in Spain and Japan respectively, and feature well-known Spanish and Japanese actors who were relatively unknown in a Hollywood context, such as Fele Martínez and Takako Fuji, alongside Hollywood stars such as Anna Paquin and Sarah Michelle Gellar. In addition, these films exhibit the distinctive styles of Balagueró and Shimizu, new within a Hollywood

6 For instance, film critic Joe Queenan decries J-horror remakes before stating 'western directors are trying to shoehorn Asian films into a culture that cannot fully accommodate them' (2008), while Joshua Rothkopf, states 'it's hard to know what's scarier - the fact that Asia keeps producing these movies or that Hollywood keeps remaking them' (2008). 
context at this time but recognizable to fans of Spanish and Japanese horror cinema. Furthermore, THE OTHERS was marketed internationally as a Hollywood production, as enhanced by the presence of Nicole Kidman as lead actress and her then-husband, Tom Cruise, as executive producer. ${ }^{7}$ Yet, THE ОтнеRS was considered to be a Spanish product in Spain (titled Los отROs), and won the best picture award at Spain's national film awards ceremony, The Goyas: the first English-language film to be bestowed with the award. The film was also, at the time, the highest-grossing Spanish film ever released. Ultimately, while a surface consideration of these films suggests Ezra and Rowden's 'homogenizing dynamic', their navigation of the circuits between cultures and spaces of belonging - as embodied by the culturally hybridized uncanny child - upsets straightforward assumptions of Hollywood cultural homogeneity.

The culturally ungrounded nature of these remakes and coproductions underwrites their themes and aesthetics, and, in particular, their construction of the uncanny child. This model of uncanny child, untethered from specific national contexts, comes to be a cipher through which ontologies of childhood and progress can be rewritten in the new millennium, heralding a globalized, postmodern era in which linear teleological frameworks and clearly defined national identities fall away. Ezra and Rowden suggest:

like postmodernism and poststructuralism, other discourses that have complicated the notion of unmediated representation, transnationalism factors heterogeneity into its basic semantic framework [...] Transnational cinema arises in the interstices between the local and the global [...] [and is] most "at home" in the in-between spaces of culture. $(2006,4)$

This characterization of cinema conceived and produced between national boundaries parallels the deterritorialized workings of the transnational uncanny child: deterritorialization being a Deleuzian term that expresses a 'coming undone' (Deleuze and Guattari, 2004, 354), a decontextualization from established ideological relations and structures ${ }^{8}$, which, in the very process of this coming undone - this 'movement of deterritorializaton' -, 'pushes the simulacra to a point where they cease being artificial images

7 The film attracted pronounced media attention for the collaboration between Kidman and Cruise because the film was released in the midst of their high-profile divorce.

8 Deleuze and Guattari first use the term to discuss the freeing of labour power from the original or specific means of production, and in their discussion of 'schizoanalysis' to mark a breaking loose of psychic energy from the heavy ideological anchor of the Oedipal complex (both conceptually and psychically). 
to become indices of the new world' (2004, 353-354). Deterritorialization, in the words of Adrian Parr, works to 'free up the fixed relations that contain a body all the while exposing it to new organisations' $(2013,69)$.

The term has 'deterritoralized' from Deleuze and Guattari's original context (as Deleuze endorses throughout his oeuvre), to become commonly used in discourse about globalization to chart how processes of cultural exchange release meanings and identities from clear and specific cultural grounding, yet inscribe them with new meaning in the course of this ungrounding. As globalization scholar John Tomlinson states 'deterritorialization is [...] the major cultural impact of global connectivity', and he uses the term to explore how this 'complex connectivity weakens the ties of culture to place' and enacts 'the dislodging of everyday meanings from their "anchors" in the local environment' (1999, 29). Transnational uncanny child films self-consciously express anxieties about this process of cultural deterritorialization. As McRoy emphasizes, transnational horror is an 'ideal forum for the metaphoric expression of concerns over an indiscrete (or hybrid) national, social or corporeal body' $(2008,93)$. In these transnational horror films, the uncanny child is deterritorialized from clear origins and is inscribed with a cultural hybridity: a condition of the processes of remaking and transnationally codeveloping films for vaguely defined global audiences. In turn, through their self-conscious transnationality, these films tend to engage in meta-textual encounters with the shifting ways in which cinema is produced and consumed in globalized, postmodern media culture.

As a result, in contrast with the films analysed in previous chapters, the transnational horror films of the new millennium displace a concern with the uncanny child's disruption to coherent narratives of national identity to contemplate the breakdown of the very notion of contained national identities. While Ezra and Rowden would read the more generalized construction of uncanny childhood which results from this preoccupation as a symptom of Hollywood's 'homogenizing dynamic', I see this process as a culmination of the uncanny child's conceptual relevance between the cultures of America, Spain, and Japan at the turn of the millennium, as the uncanny child is imbued with global resonance in the early 21st century as a figure who resists containment within the established ideological bounds of adult-centric discourse and culture. The supernatural disturbances of the uncanny children in all of these films emerge from displacement and alienation. The films pivot on an anxious expression of deterritorialization, as a sense of home and belonging gives way to the unhomely disquiet of the 'non-place', isolated or detached from the society beyond its bounds. The transnational uncanny child thus thematizes the disintegration of 
cultural belonging in ways both symbolic and direct. As Ezra and Rowden suggest, transnational cinema tends to foreground 'a sense of being out of place' as 'identities are necessarily deconstructed and reconstructed' and 'identification with a "homeland" is experienced and represented as a crisis' $(2006,7-8)$. It is this very sense of crisis that facilitates the uncanny child's deconstruction of enclosed cultural identities - based as they are on a tight historical continuum of past, present, and future - and opens a space for childhood's conceptual reformulation.

\section{'At The Back of Beyond':}

\section{Place in Spanish Coproductions and Japanese Remakes}

In the Spanish films discussed in Section Two, the uncanny child embodies the aesthetics and temporal disjunction of trauma to trouble historical narratives that distance the post-Civil War past from Spain's 'hyper-modern' present. However, in transnational films The OTHERs, DARKNess, and FrAGILE - performed in English and aimed at global audiences - specific Spanish historical narratives are no longer a viable source from which to draw. Instead, these films self-consciously reflect the culturally liminal conditions of their production. As is indicated by the film's opening title, THE OTHERS is set in an isolated mansion on the island of Jersey, a bailiwick off the coast of France that is a possession of The Crown in the Right of Jersey (thus, it is a self-governed entity with symbolic ties to the British Crown). Enhancing the geopolitical ambiguity of this setting, the mansion is cut off by dense woodlands and thick fog from the rest of the community and when the protagonist, Grace, ventures into the woods in order to seek help for herself and her children, her passage is blocked by disorienting fog.

In a setting which is similarly culturally interstitial, FRAGILE is set in a children's hospital on the Isle of Man that is soon to be shut down: a remote, inaccessible place that is in the throes of decay, dilapidation, and abandonment. The Isle of Man is itself a culturally ambiguous location in the Irish Sea between Great Britain and Ireland, with an independent parliament and government that directs most domestic matters but whose defence is the responsibility of the United Kingdom. In FrAGILE, the island hospital is inhabited by staff and patients from an array of different nationalities: while the actors perform in English, they speak in a range of different accents (Spanish, British, American, and Portuguese). The spatial and cultural liminality of the hospital underscores the film's horrors: as is exacerbated by the island location, the hospital is short-staffed and cut off from supplies. As one character proclaims early in the film, 'it is at the back of beyond', and, 
even when a helicopter arrives to transport the children to the mainland, a storm prevents its transit. The ghost in the film - strongly influenced by J-horror - is like a spectral force of cultural dislocation: she draws her power from the decaying hospital and the sick and dying children within it, and desperately tries to keep them in this isolated, dilapidated space. ${ }^{9}$

DARKNESS centres on an American family who have recently moved to an old, dilapidated house in Spain that has never been lived in. The house is on the rural outskirts of a city which is never specifically defined (the only geographical context is provided by the opening subtitle superimposed over an establishing shot of the house, which reads 'Spain'). The multicultural nature of the cast is evidenced through their varied accents, as their contrasting, contrived performances of American English further amplify the eerily ungrounded nature of the setting: the father is portrayed by Scottish actor Iain Glen, the mother by Swedish actress Lena Olin, and the two children are played by Canadian-New Zealand actress Anna Paquin and Swedish-Spanish actor Stephan Enquist. Diegetically reflecting the cultural ungroundedness of the film's production, the young protagonists experience a pervasive disquiet in their new environment which conflates their sense of cultural displacement with their fear of the child-ghosts in the eerie house.

Similarly, in translating the Japanese originals into Hollywood products, the J-horror remakes construct ambiguous settings that loosen the characters' roots in place, and similarly set the audience adrift in eerily undefined, hybridized, or isolated landscapes. In translating the Japanese originals into a globalized, Hollywood context, the echoes of the original Japanese locations reverberate in generalized terms. These films do not simply reconfigure the settings of the Japanese originals to resonate with American preoccupations in a straightforward process of cultural translation. Instead, these spaces refract an unsettling cultural emptiness that intensifies the lack of belonging and sense of unhomeliness that the characters experience.

As outlined in the previous chapter, in RINGU, the islands of the Izu peninsula on which uncanny child Sadako lived and died resonate with

9 In a manipulation of the generic expectations of the uncanny child cycle, all the characters (and the audience) are led to assume that this terrible ghost was a child who died in the hospital throughout the film. The twist, however, reveals that, in fact, the ghost was one of the nurses: so dependent was the woman's identity on her vulnerable patients that she kept her young charges ill to ensure that they remained confined in the isolated hospital. Eventually, this sadistic behaviour led to the death of her favourite patient, causing the nurse to lose her sense of purpose and to take her own life. Fragile thus self-consciously plays with and draws out the themes of the uncanny child cycle, placing the adult nurse's monstrously pathological dependence on the mythology of the weak, innocent, and vulnerable child at the core of the film's horrors. 
millennial Japanese anxieties about the troubling of long-valued paradigms of economic advancement and urbanization in what has become known as 'the Lost Decade'. By contrast, the remake THE RING is ostensibly set in Seattle - as we learn through protagonist Rachel's job at the Seattle PostIntelligencer - although the specifics of the city are barely referenced by either name or visual markers, as the city scenes largely take place within either Rachel's or her ex-partner Noah's apartments. By contrast to the original, in the remake, the island on which Samara (the film's version of Sadako) once lived is a fictional site called Moesko Island. The film retains the original's implications that the island has been left behind by mainland society: Moesko is a fishing village and farming community in a state of physical and economic deterioration. However, because the island is fictional, the specific contours of a historical narrative and cultural consciousness are stripped away, and the island becomes a generalized evocation of present-becoming-past. Furthermore, unlike Izu in RINGU, the rural area at which Samara was murdered - Shelter Mountain - is another fictional site that has unclear geographical relations to the film's other settings. Shelter Mountain's distance from Seattle is only indicated by the numerous montages of high-angle shots that depict Rachel travelling along densely forested roads to get there. Thus, like Moesko Island, the site where Samara's body decomposes in the well is a vaguely defined archetype of rural isolation, as is emphasized by the ironic name 'Shelter' Mountain, which serves to draw attention to the distinct unhomeliness of the space. As in the original, Shelter Mountain is now a tourist destination, but was an expansive, rural property when Samara was murdered.

The entwined vagueness and uncanniness of both locations is visually reinforced by a thick veil of fog, and cinematography suffused with a bluegrey filter, which evokes the sense that the spaces are underwater. Samara herself embodies this uneasy sense of deterritorialization. In contrast to Sadako, an illegitimate child whose taboo origins implicitly play a role in her murder, Samara is adopted from somewhere unknown across the ocean. Her supernatural curse, which defies rational explanation and containment, wreaks havoc on the previously secure identities of her adoptive parents, leading Samara's adopted mother to murder the child. Yet, even after Samara's death, her uncontainable curse torments her adoptive parents, eventually driving both to suicide. It is as if the child's curse emerges from the unknowability of her origins.

THE GRUDGE is set in Tokyo, like the Japanese original - the same location is even used for the haunted house - but the plot focuses primarily on a group of American expatriates unsettled in their new environment. The 
enigmatic powers of the uncanny child, Toshio - who is played by the same actor, Yuya Ozeki, as in the original - seem to ripple out from this cultural discord. The eeriness of the child is associated with the American characters' inability to communicate with him: when protagonist, Karen, first sees the child, she asks his name, to which he abrasively and gutturally replies 'Toshio', drawing out each syllable in a disconcerting way. This is the only discernible word that the child utters throughout the film. From this point on, Toshio is only ever heard issuing catlike wailing sounds, which, by contrast to the original, seem in the remake to underscore the ghost's incomprehensible speech to the non-Japanese speaking leads. The child's 'Japanese-ness' is thus emphasized as an uncanny occlusion of the channel of communication between him and the English-speaking progagonist. ${ }^{10}$ Thus, THE GRUdGe positions the turbulent flows between Japanese and American culture central to the narrative. As a result, Wee suggests that THE GRUdGe troubles the very definition of 'remake':

Labelling THE GRUDGE an American remake [...] has the effect of potentially oversimplifying the identity politics associated with and expressed within the film [...] this straightforward distinction between American Self/Oriental Other is complicated by THE GRUDGE's sometimes ambiguous status as simultaneously both inherently "Japanese" - it is directed by the same Japanese director who was responsible for the original film; it is set in Japan; and features many of the same Japanese characters as in the original - and an American remake, as signalled by the film's revised script; Hollywood financing, production, and distribution practices; and the inclusion of American/"foreign" characters. This somewhat "blurred" nature of the film's national/cultural origins and identity raises some interesting questions regarding THE GRUDGE's cultural politics. (emphasis in original, 2013, 139)

Indeed, as opposed to revolving around a clearly established and orientalist self/other binary (as some critics, such as McRoy [2005] and Lim [2009], have suggested), THE GRUDGE is characterized by a distinct instability of

10 This point is directly parodied in SCARY Movie 4 (David Zucker, 2006), in which Cindy (a caricature of THE GRUDGE's Karen) tries to communicate with Toshio using mock Japanese (a string of Japanese terms appropriated by American culture). The subtitles indicate that the boy has replied 'Your Japanese dishonours my ears', when, in fact, he too is simply listing Japanese words well-known in Western culture (such as sushi), and the names of transnational Japanese-based companies. The film thus plays with the troubled processes of cultural translation inherent to the 'horrors' of The GRUDGe. 
subject positions, largely as a result of the film's fractured, episodic structure (carried over from the Japanese originals). Throughout, the film fluidly shifts focus and identification between different characters, both American and Japanese. This structure also results in a continually shifting sense of what constitutes foreign/other and domestic/self. This fluctuating cultural identification is even reflected in the critical discourse surrounding the film: while Wee positions the American characters as foreign, Lim positions the Japanese space in which the film is set as foreign: 'The title word, grudge, describes not only the trauma-stained house but also the resentment the American expatriate harbors toward a foreign social space that, for its part, destroys rather than accommodates her' (2009, 217).

In fact, the film as a whole, its setting, and its various characters are not clearly situated on either side of the self/other, domestic/foreign divide. THE GRUDGE anxiously destabilizes this binary altogether, instead emphasizing the uneasy channels between enclosed national identities and modes of cultural belonging. Both Japanese and American characters fall prey to the ghosts, and none of the characters are able to resolve or suppress their supernatural curse. The subsequent films in the American GRUDGE franchise depict the curse extending its reach beyond Japan and into an apartment block in Chicago, a monstrously spectral representation of globalization and the dissolution of cultural boundaries.

\section{Deterritorialized Technologies and Temporalities}

In tandem with their ungrounded settings, these transnational uncanny child films - drawing on the prosthetic technologies of J-horror - tend to be fixated with anachronistic, malevolent, or faulty technologies that disturb narrative continuity and advancement. The diegetic emphasis on technological malfunction or flux is associated with the films' meta-textual consideration of the dynamics of transnational film production. As Brenda Walter suggests:

Through remakes and transformations, regional tales of vengeful ghosts and cursed pasts are culturally adapted, internationally disseminated, and instantaneously transmitted into our homes through digital devices and networks such as the Internet. The resulting transnational and transmedial matrix of fear blurs the boundaries between original and remake, foreign and native, sender and receiver, and creates a web of postmodern horror mediated by digital technology, one in which distant ghosts and curses might become our own. $(2014,17)$ 
Walter's characterization of 2000 s transnational horror points to how the technological anxieties of these films confront the global circuits that have increasingly underpinned film culture since the early 21 st century. The disembedding of cultural anxieties from their original contexts in these films parallels the extra-diegetic process of deterritorialization facilitated by globalized, digital, and on-demand access to cinema that was gaining popularity during this period. The tensions underlying this process are reflected in various ways by the films' diegetic technological preoccupations: in many of these coproductions and remakes, antiquated, inadequate technologies with staid groundings in the material ensure that the characters become disassociated from any sense of community, emphasizing the extent to which belonging in the global community of the 21st century is technologically determined and defies material roots. Yet, somewhat paradoxically, these films also tend to anxiously express the implications of all-encompassing technological shift, as images, stories, and people are deterritorialized from geopolitical and sociohistorical contexts. No longer circulating around specific national pasts, these films construct generalized evocations of technological antiquity and obsolescence that stand in for a sense of 'pastness' and historical consciousness.

For instance, THE OTHERS is ostensibly set in 1945, the year that WWII ended, yet the house has no electricity, and thus there are no radios or telephones to connect with the world beyond the mansion's grounds, so the characters remain unsure of the status of the war. Grace explains that her family learned to live without electricity because the 'Germans kept cutting it off', but we are given the sense that this lack of electricity actually relates to the children: both children suffer from potentially lethal photosensitivity - they cannot venture into the light, or they will break out in sores and blisters. As a result, the curtains are always closed and Grace traverses the house using gas lamps, which gives the film the aura of a Victorian - rather than a post-WWII - setting. The film's technological anachronism is crystallized in a scene in which Grace discovers a large box of Victorian-era postmortem photographs in one of the house's bedrooms. This technological collapsing together of time periods is entwined with the film's plot, as, unbeknownst to them, Grace and her children are already ghosts from a bygone era. Like the new housekeepers, who are in fact ghosts from the Victorian period and appear as corpses in one of the eerie 'Book of the Dead' photographs, progress has displaced Grace and her family in favour of the house's new occupants.

Similarly, THE RING, like the original film, centres on a cursed VHS videotape. However, in 2002, the year of the film's release, many audiences 
would have watched this film about a videotape curse on DVD or via digital film projection: DVD had replaced VHS as the dominant mode of home entertainment by 2001, and, by the time of THE RING's home entertainment release in 2003, the obsolescence of VHS was imminent (Benson-Allott, 2013, 1). Furthermore, while VHS remains the mode that is copied, exchanged, and shared in THE RING, 'by the time The RING came out, videotapes were no longer the most common platform for illicit viewing; that distinction had passed to DVD and the Internet' (Benson-Allott, 2013, 103). In fact, Benson-Allott rightly suggests that the complete lack of DVDs in Verbinski's film is 'an absence so unlikely it constitutes a structuring lack' $(2013,103)$. As will be seen in Chapter Nine, the strange lack of DVDs in the film is related to its fixation with the decay of analogue materiality and concomitant uprising of uncontainable, ephemeral digital images.

The conflicted technological anxieties of these films can be aligned with the rapid process of digitization that was, at the time, changing how films were disseminated and consumed, heralding a new level of cultural exchange and hybridity that made the destabilization of 'national cinema' paradigms clearly visible. In addition to DVD, accessing films online became increasingly popular following the rise of informal streaming and peer-to-peer file sharing in the early 2000s: as Ramon Lobato (2012) outlines, these illegal or grey digital circulations - which he calls 'shadow film economies'- had started to reshape film culture prior to the emergence of official streaming services such as YouTube (2005) and subscription video on demand services like Netflix (which started offering a streaming service in 2007). As Lobato suggests, during this period, we see 'industrial processes of distribution give way to amorphous practices of decentralised content sharing' (2012, 6), which also amounts to the decentring of the official practices of global cinema circulation such as national film festivals and clearly marked sections in home entertainment stores. These official distribution practices place relatively clear borders around national cinemas in ways not present with on-demand digital access to films nor online purchase of DVDs. In tandem, digital film projection, distribution, and recording became increasingly popular following the pioneering 1999 digital release of THE РнаNтом MENACE (Lucas). By 2011, celluloid was facing obsolescence as digital cinema and projection started to become the dominant mode of exhibition. ${ }^{11}$ Chuck Tyron contends that these technological shifts transformed the "very idea

11 See David Hancock (2011) and Nick Allen (2011). However, John Belton (2012) has demonstrated the transition from celluloid to digital projection was not necessarily a smooth or particularly rapid one, and accelerated significantly following the uptake of digital $3 \mathrm{D}$ in the mid 2000 . 
of the film text [...] turning a tangible artefact - a filmstrip - into digital code. As David Bordwell bluntly reminds us, "films have become files"' (emphasis in original, 2013, 2).

These developments helped to facilitate the rise of transnational horror cinema in the early 2000 s and drive its global popularity: for instance, Wada-Marciano points out that the global success of millennial J-Horror was strongly influenced by the efficient new digital production and distribution technologies being embraced by Japanese horror filmmakers and distributors at the time, which in turn helped J-Horror to challenge 'the long-standing flow of capital and culture, i.e. the centrality of Hollywood' $(2009,15)$. The global success of J-Horror of course in turn led to the production of transnational remakes such as THE GRUDGE. In addition, this context of technological change influenced the films' thematic fixations with loosening cultural ties and detachments from precise historical contexts. In their writing on transnational horror, Dana Och and Kirsten Strayer point out that 'contemporary horror media highlights the limitations of keeping [cultural] considerations discretely separated. [...] Indeed, what we see in contemporary horror is a constant flow of affinities and ideas, in which histories and styles become flattened, mutated' (2014, 1-2). Walter further suggests such a combined cultural and technological deterritorialization, a 'frameless and formless abjection' incarnated by digital media, in which:

terrifying images and horrifying tales circulate from one region and home to another along a digital web and are culturally reshaped in an ever-spinning fractal of tropes and transformations, both changing and being changed by the cultures they encounter, in a seemingly perpetual circuit of ghastly transmissions. $(2014,28)$

Transnational uncanny child films mediate these entwined technological and conceptual contortions, as film is displaced from its material, geo-spatial contexts in simultaneity with the loosening of the ligatures of national cinemas and identities.

\section{The Culturally Hybrid Uncanny Child}

That the uncanny children are the locus for these anxieties about combined technological and cultural deterritorialization is evidenced through their cultural hybridity and obscure origins. Samara wears a white gown like her predecessor, Sadako, and her face is usually shrouded in lank dark 
hair, although the specific cultural implications of the onryō, Kabuki, Noh, and Butoh are only distant reverberations within this child character. Unlike Sadako, Samara does not directly engage with anxieties surrounding the child's growth during Japan's Lost Decade. As a result, her age is unambiguous: in contrast to her Japanese predecessor, Samara is clearly defined as a child throughout. Samara retains Sadako's relentless pursuit of vengeance, the key semantic function of the Japanese onryo (vengeful ghost), which is aligned with Sadako's ideo-aesthetic rebellion against Japanese ideologies of progress. However, Samara's quest for revenge is depicted as monstrously motiveless and inscrutable now that the character is unhinged from Japanese culture. While her white dress is clearly modelled after her progenitor's onryō-esque gown, Samara's outfit, now a white prairie dress worn with leather T-Bar sandals and white socks, is visually reinscribed to situate her alongside the terrible children of American film culture, such as Rhoda of THE BAD SEED and Regan from THE EXORCIST, who wear similar outfits symbolic of traditional Western childhood purity and innocence (a visual construction that serves to highlight their perversion of these qualities).

While visually appearing as a hybrid of American and Japanese uncanny children, a brief glimpse of Samara's birth certificate maintains her vague links to Japan: the document is written in kanji, yet this kanji is virtually indiscernible and is not translated or explained. Balmain suggests that the birth certificate is an indication of the film's problematic exoticization of Samara's 'Japanese-ness' - a sign of her 'oriental alterity and implacable foreignness' $(2004,72)$. I contend that this vague and quickly passed over suggestion of Japanese origins functions as a meta-textual reference to the original film that adds another layer to Samara's hybrid unknowability, further muddying the audience's and protagonist's grasp on her origins rather than clarifying her existence or situating her within a clear cultural context. It is not Samara's Japanese otherness that monstrously contaminates the world into which she is brought, but her resistance to a single, legible history and cultural tradition. Underlying her monstrosity is the fact that she has no stakes in the future of Japanese nor American culture, for she is untethered from both.

Similarly, the two children of THE ОтнеRS are self-consciously situated alongside a long history of supernatural British cinema, appearing and behaving like stereotypical visions of Victorian British childhood: in particular, they are clearly modelled on Miles and Flora from THE INNOCENTS (1961), Clayton's film version of Henry James's The Turn of the Screw. Yet this self-aware grounding in British narrative traditions is interrupted 
by the fact that the film is an American-Spanish coproduction, and is not set in Britain, but on the island of Jersey (on which English is the dominant language, but French and the indigenous language of Jèrrais are also spoken). This isolated location is continually emphasized throughout the film. Furthermore, while THE OTHERs self-consciously upholds a vaguely British-Victorian style - largely through its child characters - the colour palette, rather than evoking the dark, shadowy foreboding of the Victorian Gothic, is reminiscent of the soft golden light and chiaroscuro effects of tenebrism, a style associated with significant Spanish painters of the seventeenth century such as Velasquez and Ribera. Indeed, the film's Spanish-Basque cinematographer Javier Aguirresarobe names such artists - along with Goya - as his central inspirations (Aguirresarobe, 2014). The felt deterritorialization from the film's British influences enhances the sense that Grace, her children, and their household represent a generalized evocation of the historical past detached from a culturally specific narrative.

\section{Conclusion}

Exemplifying the cultural flows and tangle of influences of globalized media culture, the themes and aesthetics of American, Spanish, and Japanese child characters discussed in previous chapters reverberate within these transnational figures, but are deterritorialized to refract the cultural 'between-ness' of transnational cinema. As a result, these figures function as prisms through which anxieties surrounding conceptual and technological change can be illuminated. The embodied site of cultural exchange, the transnational uncanny child becomes bound up in a self-conscious consideration of how the rise of digital media incites a wavering of the boundaries separating national cinemas and traditions, and a concomitant muddying of clear conceptions of national identity. Due to their cultural hybridity, these child characters resist being embedded in secure historical narratives, and, as a result, their growth is unshackled from concepts of national progress and futurity - a process explored in this book's final chapters. The transnational uncanny child thus becomes a complex embodiment of childhood's shifting role in early 21st century society, a cultural moment in which historical meaning and technologies were in flux. 


\section{Works Cited}

Aguirresarobe, Javier. 'Javier Aguirresarobe, ASC, AEC: Interviews with ASC Members.' Theasc.com, American Society of Cinematographers. Feb. 2014. Web. 30 Sep. 2014.

Allen, Nick. 'Hollywood Says Goodbye to Celluloid.' The Telegraph.com, Telegraph UK. 25 Dec. 2011. Web. 30 Sep. 2014.

Balmain, Colette. Introduction to Japanese Horror Film. Edinburgh: Edinburgh University Press, 2008. Print.

—.'Lost in Translation: Otherness and Orientalism in The Ring.' Diagesis: The Journal of the Association for Research into Popular Fictions Special Horror Edition (2004): 69-77. Web. 30 Sep. 2014.

Belton, John. 'Digital 3D Cinema: Digital Cinema's Missing Phase.' Film History 24 (2012): 187-195. Print.

Benson-Allott, Caetlin. Killer Tapes and Shattered Screens: Video Spectatorship from VHS to File Sharing. Berkeley: University of California Press, 2013. Print.

Del Toro, Guillermo. Interview by Ryan Turek. 'On the Set: Guillermo del Toro, Jessica Chastain on the Mysteries of MAMA.' Shocktillyoudrop.com, Shock Till You Drop. 23 Oct. 2012. Web. 30 Sep. 2014.

Deleuze, Gilles and Guattari, Félix. Anti-Oedipus. 1984. London: Continuum, 2004. Print.

Enns, Anthony. 'The Horror of Media: Technology and Spirituality in the RINGU Films.' The Scary Screen: Media Anxiety in The RING. Ed. Kristen Lacefield. Surrey: Ashgate Publishing Ltd., 2010. 29-44. Print.

Ezra, Elizabeth and Rowden, Terry. eds. Transnational Cinema: The Film Reader. London: Routledge, 2006. Print.

Hancock, David. 'The End of an Era Arrives as Digital Technology Displaces 35mm Film in Cinema Projection.' Technology.IHS, IHS Technology. 15 Nov. 2011. Web. 30 Sep. 2014.

Hantke, Steffen, ed. 'They Don't Make 'Em Like They Used To: On the Rhetoric of Crisis and the Current State of American Horror Cinema.' American Horror Film: The Genre at the Turn of the Millennium. Jackson: The University Press of Mississippi, 2010. vii-xxxii. Print.

-.Academic Film Criticism, the Rhetoric of Crisis, and the Current State of American Horror Cinema: Thoughts on Canonicity and Academic Anxiety.' College Literature 34.4 (2007): 191-202. EBSCO Host Humanities International Complete. Web. 30 Sep. 2014.

James, Henry. The Turn of the Screw. 1898. Ed. David Bromwich. London: Penguin Classics, 2011. Print. 
Klein, Christina. 'Globalization and Transnational U.S.-Asian Genres.' American Horror Film: The Genre at the Turn of the Millennium. Ed. Steffen Hantke. Jackson: The University of Mississippi Press, 2010. 3-14. Print.

Lázaro-Reboll, Antonio. Spanish Horror Film. Edinburgh: Edinburgh University Press, 2012. Print.

—.'The Transnational Reception of El espinazo del diablo (Guillermo del Toro 2001).' Hispanic Research Journal 8.1 (2007): 39-51. Maney Online. Web. 30 Sep. 2014.

Lim, Bliss Cua. Translating Time: Cinema, the Fantastic and Temporal Critique. Durham: Duke University Press, 2009. Print.

Lobato, Ramon. Shadow Economies of Cinema: Mapping Informal Film Distribution. London: BFI/Palgrave Macmillan, 2012. Print.

Lowenstein, Adam. 'Globalized Spectatorship: Ring Around the Superflat Global Village: J-Horror Between Japan and America.' Dreaming of Cinema: Spectatorship, Surrealism and the Age of Digital Media. New York: Columbia University Press, 2015. 79-116. Print.

McRoy, Jay, ed. 'Case Study: Cinematic Hybridity in Shimizu Takashi's Ju-ON: THE Grudge.' Japanese Horror Cinema. Edinburgh: Edinburgh University Press, 2005. 175-184. Print.

-.Nightmare Japan. Amsterdam: Rodopi, 2008. Print.

Och, Dana and Strayer, Kirsten, eds. Transnational Horror Across Visual Media: Fragmented Bodies. New York: Routledge, 2014. Print.

Parr, Adrian, ed. The Deleuze Dictionary: Revised Edition. Edinburgh: Edinburgh University Press, 2013. Print.

Queenan, Joe. 'Bring on the Creepy Girls.' The Guardian.com, The Guardian News and Media. 22 Feb 2008. Web. 30 Sep. 2014.

Rothkopf, Joshua. 'One Missed Call.' TimeOutNewYork.com, Time Out. 8 Jan. 2008. Web. 30 Sep. 2014.

Tomlinson, John. Globalization and Culture. Chicago: The University of Chicago Press, 1999. Print.

Tyron, Chuck. On-demand Culture: Digital Delivery and the Future of Movies. New Brunswick: Rutgers University Press, 2013.

Wada-Marciano, Mitsuyo. 'J-Horror: New Media's Impact on Contemporary Japanese Horror Cinema.' Horror To the Extreme: Changing Boundaries in Asian Cinema. Ed. Jinhee Choi and Mitsuyo Wada-Marciano. Hong Kong: Hong Kong University Press, 2009. 15-39. Print.

Walter, Brenda S. Gardenour. 'Ghastly Transmissions: The Horror of Connectivity and the Transnational Flow of Fear.' Transnational Horror Across Visual Media: Fragmented Bodies. Ed. Dana Och and Kirsten Strayer. New York: Routledge, 2014. 17-29. Print. 
Wee, Valerie.Japanese Horror Films and their American Remakes. London: Routledge, 2013. Print.

\section{Filmography}

The Abandoned. Dir. Nacho Cerdá. Castelao Producciones, 20o6. Film.

The BAd Seed. Dir. Mervyn LeRoy. 1956. Warner Home Video, 2011. Blu-ray DVD. D@BBE. Dir. Hasan Karacadag. J-Plan, 20o6. Film.

DARKNESS. Dir. Jaume Balagueró. 2002. Dimension Films, 2005. DVD.

DARK WATER. Dir. Walter Salles. Buena Vista Home Entertainment, 2005. DVD.

The Devil's Backbone [El espinazo Del diablo]. Dir. Guillermo del Toro. 2001.

The Criterion Collection, 2001. Blu-ray DVD.

The Exorcist. Dir. William Friedkin. 1973. Warner Home Video, 2013. Blu-ray DVD. Fragile [Frágiles]. Dir. Jaume Balagueró. 2005. Phase 4 Films, 2010. DVD.

The Grudge. Dir. Takashi Shimizu. Sony Pictures Home Entertainment, 2005. DVD.

The Grudge 2. Dir. Takashi Shimizu. Sony Pictures Home Entertainment, 2007. DVD.

The Grudge 3. Dir. Toby Wilkins. Sony Pictures Home Entertainment, 2009. DVD.

The Innocents. Dir. Jack Clayton. 1961. Criterion Collection Home Entertainment, 2014. Blu-ray DVD.

Ju-ON: The Grudge [Ju-ON]. Dir. Takashi Shimizu. 2002. Lionsgate Home Entertainment, 2005. DVD.

Lake Mungo. Dir. Joel Anderson. Mungo Productions, 2008. Film.

One Missed CALl. Dir. Eric Valette. Warner Home Video, 2008. DVD.

The OMen. Dir. Richard Donner. 1976. Twentieth Century Fox, 2007. Blu-ray DVD.

The Orphanage [El orfanato]. Dir. Juan Antonio Bayona. 2007. New Line Home Video, 2008. Blu-ray DVD.

The Others [Los otros]. Dir. Alejandro Amenábar. 2001. Optimum Home Entertainment, 2011. Blu-ray DVD.

Poltergeist. Dir. Tobe Hooper. 1982. Warner Home Video, 2008. DVD.

Pulse [KaIro]. Dir. Kiyoshi Kurosawa. Magnolia Pictures Company, 2001. Film.

Reincarnation [RINne]. Dir. Takashi Shimizu. 2005. Lionsgate Home Entertainment, 2007. DVD.

RINGU. Dir. Hideo Nakata. 1998. DreamWorks Pictures, 2000. DVD.

The Ring. Dir. Gore Verbinski. 2002. DreamWorks Pictures, 2013. Blu-ray DVD.

The RING 2. Dir. Hideo Nakata. 2005. DreamWorks Pictures, 2013. DVD.

The Ring Virus. Dir. Dong-Bin Kim. ADFD, 1999. Film.

Scary Movie 4. Dir. David Zucker. Dimension Films, 2006. Film.

The Sixth Sense. Dir. M. Night Shyamalan. 1999. Hollywood Pictures Home Entertainment, 2000. DVD. 
The Shining. Dir. Stanley Kubrick. 1980. Warner Bros. Entertainment Inc., 2007. Blu-ray DVD.

Star Wars Episode I: The Phantom Menace. Dir. George Lucas. Lucasfilm, 1999. Film.

Stir of EchoEs. Dir. David Koepp. 1999. Lionsgate Home Entertainment, 200o. DVD. 


\title{
8. Progress and Decay in the 21st Century
}

\author{
The Postmodern Uncanny Child in The Others (Alejandro
} Amenábar, 2001)

\begin{abstract}
Chapter Eight outlines the specific ways that transnational uncanny child characters trouble entrenched cultural investments in teleological progress via the theoretical framework of Dylan Trigg's 'aesthetics of decay'. The chapter argues that these child figures unravel the process of growing up and transform it into one of 'becoming', a Deleuzian term that designates a process of change that resists teleological goals and end-states. The analysis in this chapter centres on one of the most influential and critically successful films of the early 2000s, THE OTHERs (Alejandro Amenábar, 2001), which thematizes the decline of traditional, modernist conceptions of the child.
\end{abstract}

Keywords: Aesthetics of decay, Progress, The Others, Decline, Postmodernity, Modernity, Uncanny child

As has been explored throughout this book in the context of specific cultural conditions, the millennial turn represented a global pause in the unquestioned progression of history, forcing a reconsideration of the mechanics of sociohistorical time. This is crystallized in globally pervasive anxieties about institutional collapse, such as the $\mathrm{Y}_{2} \mathrm{~K}$ Bug: a particularly potent incarnation of millennial disquiet that characteristically hinged on the fear that technological malfunction would unsettle coherent temporality on a mass scale. As Joseph Natoli puts it:

Is the new millennium a fresh start, a fresh winding of the clock? Or, is it more what we fear it is: a painful reminder of what might have been, of a

Balanzategui, J., The Uncanny Child in Transnational Cinema: Ghosts of Futurity at the Turn of the Twenty-First Century, Amsterdam University Press, 2018.

DOI: 10.5117/9789462986510/CHo8 
time when future time was hopeful and not already wearied, redundant, bearing more of what has already been packaged than what is new and inconceivable? $(1998,13)$

In transnational remakes and coproductions, the child becomes implicated in this anxious uncertainty as to what the new millennium represents, as the previously naturalized relationship between past, present, and future starts to unravel and specific historical narratives are displaced. Baudrillard characterizes millenarism as a challenge to established conceptions of historical time, for, unlike historicism, 'which continually shifts the stakes to a hypothetical end, [millenarism] is characterized by a fatal exigency, a fatal strategy of time which wants to shoot straight ahead to a point beyond the end' (1994, 8). For Baudrillard, the turn of the millennium represents the final breaking apart of linear time, a mode of temporality that has buttressed teleological conceptions of cultural progression since the Enlightenment: the millennial turn is thus 'our non-Euclidean fin de siècle' in which 'the future no longer exists' $(1994,11)$.

This shift in conceptualizations of futurity at the turn of the 21st century obviously has strong implications for the child - the 'emblem of futurity's unquestioned value' (Edelman, 2004, 3) - and indeed, concerns about the child's ideological function in the new millennium suffused the beginning of the 21st century. All of the films discussed in this book so far express such anxieties, deploying the uncanny child trope to consider specific cultural and historical implications of millennial shift. Yet, by stripping back cultural specificity and self-consciously considering the form and function of the uncanny child, transnational remakes and coproductions instead consider in more general terms what the uncanny child figure suggests about the shifting ideological status of childhood at the beginning of the 21st century, and, more precisely, what the postmodern disintegration of linear historicity and progress means for childhood's conceptual apparatus.

\section{Childhood and the Decline of Progress and Futurity}

As Jack Zipes elucidates, cultural critics of childhood became fixated with what the symbolic contortions associated with millennial transition meant for children in the early 200os, wondering:

Are they being made more violent, sexual, and sick by the images of brutality, sex and horror on the big and little screens of television, the Internet, and the cinema? Are the new digital technologies transforming 
literacies and the way children read so that they are no longer reflective and capable of sustained reading? How does advertising affect the brains of children from infancy through their teens? What are they actually imbibing? What are they learning if they are learning? What do they do with that experience? $(2009,2)$

Similarly, Paula Fass questions, 'I wonder [...] whether the particular, romantic, Western vision of the sentimental child may not have outgrown its usefulness, to become so cliché ridden that it can no longer cover the needs of children' $(2007,255)$. These scholars are concerned with how concepts of the child were reinscribed by the cultural and technological shifts heralded by the beginning of the 21st century, and latent in their commentary is the understanding that unquestioned investment in progress and futurity is no longer a viable narrative to enforce upon the child's growth.

Echoing Baudrillard, Zygmunt Bauman suggests - in a quote positioned at the opening of Zipes's own consideration of the status of childhood in postmodern culture - that "Progress", once the most extreme manifestation of radical optimism and a promise of universally shared and lasting happiness, has moved all the way to the opposite, dystopian and fatalistic pole of anticipation' $(2007,10)$. Bauman points to a change in the way progress is conceptualized with the beginning of the 21st century, as looking to the future became an exercise no longer associated with positive change. As Svetlana Boym puts it, at the close of the 2oth century, 'optimistic belief in the future became outmoded' $(2007,7)$. With the arrival of the long-awaited 'future' represented by the 21st century came only more uncertainty and violence, as signified most potently by the 11 September 2001 terrorist attacks on the United States and subsequent Iraq war. Phillip Hammond expounds: 'in the absence of any confident vision of the future, $9 / 11$ further intensified an already heightened sense of vulnerability and fear. In Baudrillard's terms, the attack could indeed be said to have revealed the "internal fragility" of the system' $(2007,4)$.

In this context, the alignment of growing up with social progress that anchors modernist understandings of childhood becomes an ominous pairing fraught with anxious anticipation. As Jenks points out, throughout modernity:

the metaphoricity through which the discourse of childhood speaks is predicated on the absent presence of a desired tomorrow, with 'growth,' 'maturation' and 'development' writ large at the level of individual socialization. [...] by way of children, we have, through modernity, dreamt of futures, and in so doing we have both justified and sought justification 
for modernity's expansionist urges in the post-Darwinian conflation of growth and progress. $\left(2005,105^{-106}\right)$

However, with the decline of modernity throughout the second half of the 2oth century and the emergence of the uncertainties of the distinctly post- or, to use Bauman's terms, 'liquid' modern 21st century, 'group affiliations' and aspirations no longer have such an influence over individual identities (Jenks, 2005, 107), and, as a result 'the new experience of history, at both the individual level and the level of institutions, is one of discontinuity rather than of continuity' $(2005,107)$.

As we have seen in Chapter Seven, the uncanny children in transnational remakes and coproductions embody troubling detachments from cultural belonging. At the same time, however, this development represents a compelling movement away from previous models of childhood, in which the child's growing up is made to serve adult-centred narratives of personal, historical, and national advancement. Despite the anxieties of childhood scholars such as Zipes and Fass, this postmodern shift in our understandings of progress unsettles the previously unquestioned binding of childhood to the needs of adult politics in potentially generative ways. Threatening and often monstrous in their affront to traditional modes of national identification and progress, the uncanny children of early 21st century transnational horror nevertheless represent a productive symbolic reconfiguration of childhood, playing out in dramatic fashion the obsolescence of the innocent, romantic, or to use Fass's term, 'sentimental' child.

\section{The Uncanny Child and the Aesthetics of Decay}

The specific manner by which the transnational uncanny child deconstructs the traditional, teleological conception of progress is to expose progress's entwinement with decline. In so doing, the child figure envisages a cultural moment in which all that was once familiar - all the quotidian elements of the society that was in the zoth century - suddenly become unfamiliar in the 21st, so that temporal progression itself becomes a vehicle for the uncanny. This process can be elucidated via Dylan Trigg's 'aesthetics of decay': an aesthetic study of 'the ontological value of [...] decay' (2006, xxix) partly inspired by Walter Benjamin's own study of decaying ruins. Throghout his book The Aesthetics of Decay, Trigg critiques what he calls a 'fixed image' of progress, suggesting that decline and its outward manifestation, decay, can reveal to us an altered perception of time passing outside of progressivist narratives of historical, economic, and technological advance. 
As intimated above, the sense that society had approached the end of historical development as we know it suffused the late 1990s and early 2000s, a phenomenon which Baudrillard characterizes thus:

now we encounter strange, altered, random, and chaotic events that Historical Reason no longer recognizes as its own. Even if, by analogy with past events, we think we recognize them, they no longer have the same meaning. The same incidents (wars, ethnic conflicts, nationalisms, the unification of Europe) do not have the same meaning when they arise as part of a history in progress as they do in the context of a history in decline. Now, we find ourselves in a vanishing history, and that is why they appear as ghost events to us. $(2008,161)$

Expressing a similar sentiment, Jörn Rüsen explicitly links the 21st century decline of history with globalization and postmodernism:

at the turn of the twenty-first century the term 'history' brings extremely ambivalent associations to mind [...] whether in reference to [...] postmodernism, or to the challenge to Western dominance by decolonization and multiculturalism, 'history' as we know it has been declared to be dead, outdated, overcome, and at its end. (2007, vii)

Anxieties about the decline of history are an extension of postmodern discourse that has circulated throughout the latter half of the 2oth century, cohered in Lyotard's work on the decline of the metanarrative, which famously outlines how 'the grand narrative has lost its credibility, regardless of what mode of unification it uses' $(1983,37)$.

However, the beginning of the 21st century brought with it a renewed fixation with the decline of historical continuity, as incredulity towards the metanarrative became not just a reified component of academic discourse, but a felt condition that suffused global popular culture. As Niles Tomlinson points out, "historically, degeneration is a discourse intimately braided with fin-de-siecle, millennial or end-time anxiety about transformation, revelation, and apocalypse' $(2010,185)$. While fixations with decline and apocalypse usually manifest as pessimistic anxieties about the fall of society - as in Baudrillard's work - the millennial fixation with decline also marks apprehension for the emergence of new symbolic structures. As Lois Zamora elucidates in her examination of the conceptual underpinnings of apocalypse myths, 'apocalypse projects the patterns of creation, growth, decay, renewal, catastrophe onto history, 
encompassing the beginning and the end of time within its vision' (1988, $89)$.

Trigg's aesthetics of decay provide an optique through which to conceptualize this early 21st century entanglement of decay and growth, decline and emergence. While Trigg does not explicitly analyse the millennial turn, his book, published in 2006, offers a rethinking of temporal continuity that can effectively be applied to the tangling of endings and beginnings that characterized the transition into the 21st century, suggesting the generative potential of history's 'decline'. Trigg suggests that what he calls the 'fixed' or 'rational' mode of progress is inevitably bound to the ideological structures of the past, as our visions of futurity are constructed out of epistemological structures with roots in the past, bound together under the umbrella term, 'reason' (what Baudrillard refers to as 'Historical Reason'). Thus, even though rational progress infers a continual process of positive change, the values and conceptual apparatus underlying rational progress are fixed, determined by modernist ideologies of scientific enlightenment, human endeavour, and national histories. As Trigg conceives it, fixed progress is a process of continual deferment in which the present remains incomplete, but is sustained by the promise that this epistemic incompleteness will eventually be filled by an imagined, 'nostalgic' future (a term that exposes how investment in futurity is actually shaped by the past): "The nostalgia for the future informs the endurance of the unfinished present and makes that present bearable. In political terms, the failed promise that the next term of government will bring about improvement relies on the same logic' $(2006,229)$. The cultural logic that sustains our hopes for the future emerges from the rational structures of the past, providing cultures and nations with a sense of historical continuity. Furthermore, through progress, the past is fulfilled with meaning that serves the needs of the present. Trigg's assertion thus accords with Edelman's suggestion that our sociocultural usage of the child to maintain temporal continuity is at its core conservative and stultifying because 'it works to affirm a structure, to authenticate social order, which it then intends to transmit to the future in the form of its inner Child' (Edelman, 2004, 3).

As I have outlined in previous chapters, the child is inevitably bound up with various 'fixed images' of progress. Symbolically embedded in the figure of the child are the incongruent temporal vectors of progress: childhood represents a lost past suffused with adult nostalgia and retrospective longing - and, in fact, childhood only attains such symbolic value through the adult's retrospective view - while the child as social actor represents the vehicle through which we conceptualize and shape the course of futurity. 
The child's temporal function is thus to provide narrative clarity to rational progress, facilitating a sense of intergenerational (or social) and psychic (or personal) development. The child thus embodies a form of temporal continuity that makes meaning of the past and future, while domesticating radical change in the present. As Jenks points out, throughout modernity, the child has functioned as 'a "promise" of unimagined action, but also an extension of our own plans and a hedge against our own action as yet incomplete. Such a commitment has, for several generations, enabled us to indulge in pleasant reveries concerning tomorrow' $(2005,104)$. Thus, the child's temporal function, aligned as it is with a fixed image of progress, is adult-centric, fulfilling the needs of the adult's present: childhood gives meaning to the adult's past, while the child is tasked with realizing a future that emerges from the adult's present and promises to anneal its gaps. As Jenks puts it, 'what could not be achieved today could be set in train for tomorrow' $(2005,107)$ through the child.

Trigg suggests that rational progress comes undone in the decaying ruins of society: formerly quotidian spaces which now exist in a state of disuse and decay, but have not been considered of enough historic value to sanctify and preserve in the form of a monument. As Trigg outlines, 'in the continuity of its disbanding, the ruin rewards us with insight, and so creates a space in which the end of rationality converges. Thinking alongside the ruin means recognizing its ability to evaluate progress' (2006, xvii-xix). In temporal terms, 'these ruins are close enough to the present to mirror an alternative past/present/future. A derelict factory testifies to a failed past but also reminds us that the future may end in ruin' (2006, xxvii). While the preservation of a space or site as a historical monument entails the solidification of a particular narrative of history, the abandoned, decaying spaces of society capture a temporal admixture of past, present, and future not clarified via temporal narratives of advance: a building that was not long previously a component of a city- or townscape - formerly unnoticeable through its unproblematic belonging to the present - is rendered visible through dropping out of use and becoming outmoded. Such structures thus impel us to conceptualize the continual transition of the present into pasts that are not captured within historical narratives. As Trigg explains:

unlike the enforcement of a political agenda through the conservation of the monument, the ruin frees us from an already formed definition of history. [...] The false arrangement of the past, whereby the surplus remains are discarded, presenting history as an ordered, self-contained, and rationalistic project, is overruled by the emergence of the past in the ruin, as fragmented and incomplete. $(2006,238)$ 
These decaying spaces resist the conventional sense that the past 'makes sense' to us in light of the progress that has been made and continues to drive the present, and that, in a similar manner, in the future, the dreams of the present will be fulfilled due to the onwards march of progress. Instead, the ruin incarnates 'the preservation of a past, manifest not by the fulfilment of that past, but through its decay' (my emphasis, Trigg, 2012, 269).

In transnational horror films, the uncanny child, her degraded technologies, and the forgotten, decaying spaces in which she lurks are united in energizing this liminal moment of transition, in which progress appears to be moving towards its apparent opposite: decay. As Trigg elucidates, 'the ruin is in a process of constant becoming-toward. It moves' (emphasis in original, 2006, 236) - the ruin is compelling in that it is 'becoming-toward' dissolution, as futurity becomes not a fantastical distant horizon, but just as palpable within this (soon-to-be)non-structure as the recent past, as is represented by the decaying building's former function as a factory, a hospital, or school. Thus, like the uncanny child, the ruin perceptually draws the temporal polarities of past and future together, resulting in an eerily unmediated sense of progress stripped of its fixity and optimism. Hereby, in their entwinement, the uncanny child and her decaying, unhomely spaces capture the temporal quality at the heart of the uncanny: as Anthony Vidler explains, for Freud the unheimlich 'was more than a simple sense of not belonging; it was the fundamental propensity of the familiar to turn on its owners, suddenly to become defamiliarized, derealized, as if in a dream' $(1992,7)$.

As will be illuminated via my analysis of THE OTHERs in this chapter - and THE RING in the next - in transnational uncanny child films of the early 21st century, the eerie sense that homely space has turned on its (adult) owners is entwined with the realization that the child has dissociated herself from the adult-centric mode of rational progress, to expose its uncanny underside: decline. This process entails a symbolic defamiliarization of all that was taken for granted throughout the 2oth century - its technologies, spaces, and modernist conceptual apparatus - a self-conscious shift in historical and temporal consciousness. Furthermore, because these children are exposed to be at a point of flux between growth and decay, life and death, they conflate and confuse beginnings and endings in a way that expresses the upheavals of millennial shift.

A recurring motif of these films is the decaying body of a child alongside a building or technology in the throes of abandonment and/or decay, both of which are rendered aesthetically and narratively powerful via the very process of decline in which they are caught. Progress is realized not as a 
continual advancement forward - a growing 'up' - but an unsettlingly liminal space of transition between states, with no triumphant end state. As a result, these films impel us to experience temporal progression as the eerie splitting of the present into both lost pasts and futures, in a self-aware stripping away of progressive historical metanarratives. No longer interacting with contained national identities and histories, these uncanny children thus instead engage with the very epistemologies of progress and change, and in so doing conceptually transform the process of 'growing up' to one of 'becoming', a term ubiquitous throughout the work of Deleuze. Deleuze uses this term in a diverse range of contexts across his oeuvre, but it is essentially a generative process of 'passage, change' (1997a, 17), which he links directly to entrenched notions of history in Negotiations: 'History amounts only to the set of preconditions, however recent, that one leaves behind in order to "become," that is, to create something new' (1997b, 171). As Cliff Stagoll explains, 'becoming is the pure movement evident in changes between particular events. [...] Rather than a product, final or interim, becoming is the very dynamism of change, situated between heterogenous terms and tending towards no particular goal or end-state' $(2013,26)$. The becomings of the uncanny children in these films - most commonly typified as their becoming-corpse and becoming-ghost - harness this 'non-linear dynamic process of change' (Marcel Swiboda, 2013, 30) to express the ontological contortions of technological transition and history in flux. In various ways, the children resist simple representation as either a ghost or a living child, a dichotomy that structures almost all of the films discussed in previous chapters. In THE OTHERS and THE RING, we are instead privy to the child's processes of becoming between these states.

Emma Uprichard points out that children constantly mediate a tension between being and becoming: they exist as social actors, or 'beings', in the present, yet are also continually 'becoming' adults, as their status as adults-in-the-making continually looms over their conceptualization (2008, 303-313). The transnational uncanny child subverts this processual becoming, in which the process of change according to which the child is defined points towards a fulfilled end point in the future: namely, adulthood. Being caught in the throes of death and decay, these children will never fulfil futurity's promise of becoming an adult - thus, nor do they promise to anneal the gaps in the adult's present - but instead linger at a point of continual transition to a corpse, dust, a ghost, a memory. They thus derail the quotidian and adult-centric mode of becoming to which Uprichard refers, and transform it into a becoming stripped of a vision of futurity set in place by adults of the present. As a result, the transnational uncanny child disassembles 
the ontology of rational progress. This process represents a self-reflexive extension of all the films previously analysed in this book, in which the uncanny child challenges specific modes of personal and national progress.

\section{'Sooner or later she'll see them. Then everything will be different': The Decline of Modernity in THE OTHERS}

THE OTHERS is one of the most successful horror films of the 21st century, and received significant attention at major film award ceremonies, a rare display of critical appreciation for a horror film. In addition to winning major awards at Spain's Goyas and other prominent ceremonies such as the London Film Critics and Saturn Awards, the film was nominated for major awards at both the British Film Academy Awards and the Golden Globes. ${ }^{1}$ The lasting cultural impact of THE OTHERs is signalled by the extent to which it has been referenced, parodied, and otherwise circulated throughout popular culture: it has been spoofed in SCARY Movie 3 (David Zucker, 2003) and SpANish Movie (Javier Ruiz Caldera, 2009); inspired a Hindi remake, WHO ARE WE? (Ravi Sharma Shanka, 2004); and was a major reference in THE Simpsons Halloween episode, 'Treehouse of Horror XXV' (Matthew Faughnan, 2014). The film coheres many of the refrains of the uncanny child cycle into a compelling reflection on how our entwined understandings of childhood, progress, and historical time underwent a profound shift in the early 21st century.

THE OTHERS is suffused with the aesthetics of spatiotemporal dislocation and unhomeliness, a self-conscious refraction of the film's distinctly liminal, transnational production context - as I outlined in the previous chapter, the film is a Spanish-American coproduction set on the Isle of Jersey, an island off the coast of France that is a self-governing possession of the British Crown. The entire film takes place within a moment of transition from homely space into unhomeliness, a point of spatial flux the film aligns with the temporal shift from present into pastness. The children, Anne and Nicholas, embody this eerie vision of progress founded not on advancement and futurity, but on becoming and decline. As Trigg explains, 'our ability to be aroused

1 The film won eight Goyas, including Best Film and Best Director; was nominated for six Saturn awards, winning Best Horror Film, Best Actress (Nicole Kidman), and Best Supporting Actress (Fionnula Flanagan); won the London Film Critics Award for Best Actress of the Year (Nicole Kidman); was nominated for a Golden Globe Award for Best Actress in a Drama (Nicole Kidman); and received a BAFTA nomination for Best Original Screenplay and won the award for Best Actress in a Leading Role (Nicole Kidman). 
by the ruin' - and thus to experience progress's form undomesticated by teleological trajectories of history - is 'dependent upon our sensitivity to the polarized tension between the homely and the unhomely' $(2006,138)$. In The OTHERs, this continual tension also underlies the sense that the rational structures to which protagonist Grace clings in order to make sense of her existence are captured in a state of dissolution: not only does the house turn on its owner, but so too do all the ideological assumptions for which it stands, as both are simultaneously exposed to be in the process of fading into the past. ${ }^{2}$ The family is thus haunted by the future, not the past. These themes are all tied to the fact that Grace and her children are ghosts, but are not yet aware of their spectral status. Unbeknownst to them (and the audience, until the final ten minutes, if the twist ending works as intended), they have already dropped out of the onwards march of historical progression, and are spectres of a past that is being replaced with a new present, as represented by the new family who are moving into the house. Grace's children sense these intruders throughout the film and refer to them as 'the others'.

\section{Historical Uncertainty and the Post-WWII Period}

This stripping away of rational progress is emphasized by the setting of the film. As the opening subtitle informs us, the film takes place in 1945, the year WWII ended: a symbolic moment of conceptual transition that represents both the beginning of the modern epoch's decline, and the gradual emergence of postmodernity from modernity's smouldering remnants. As J. T. Fraser suggests ' $[\mathrm{p}]$ ostmodernism is a post-Second World War phenomenon. It may best be described as a reflection of changes which are so rapid as to make their integration into the recent past and onrushing future impossible' $(1996,5)$. Fraser's expression of a temporality that does not seem to naturally synthesize into historical time suggests why Amenábar (who wrote as well as directed the film) uses the post-WWII period to work through the temporal uncertainty of the early 21st century. The post-WWII period is often positioned as the nebulous beginnings of postmodernity due to a sense that these years saw the beginning of modernity's degeneration. As Rein Staal puts it: 'The aspirations that had inspired the founders of modern thought - the conquest of nature through science, indeed the conquest of human nature through science and the emancipation of power from moral

2 Notably, the house is a grand, late Victorian-era mansion - symbolic of a zenith of the modern period - in actuality, the Palacio de los Hornillos, built in 1904, is in Las Frugas, Cantabria. 
restraint - had been achieved beyond anyone's wildest dreams, and they had turned to ashes before that success could be enjoyed' (2008, 35). THE OTHERS retrospectively confronts the epistemic uncertainty nascent in the post-WWII period, positioning it as a symbolic parallel to the unsettling of historical progression represented by the millennial turn.

Because the film is set in an isolated mansion on the Isle of Jersey - the only setting depicted in the film - the direct and immediate implications of WWII are eerily intangible and distanced, unable to be arranged into historical meaning. That WWII is continually represented as an event that does not 'belong' to the film's characters expresses the film's transnationality: Spain did not participate in WWII, and was officially nonbelligerent. The Channel Islands, of which Jersey is a part, were occupied by the German forces throughout the war, and were liberated on 9 May 1945. Significantly, the film does not provide a date in 1945 for its setting, so the current status of the war and occupation is left unclear. Enhancing this uncertainty, Grace refers to the presence of Germans in vague terms: at first she fears 'the others' haunting the property may be German spies. The lack of a clear chronological relationship to the end of the war and the liberation of the Channel Islands renders the precise political and historical context of the diegesis ungraspable and subversively liminal, as the film resists contextual tethering along a trajectory from war to victory.

Just as the audience is not offered precise historical context, nor do the characters seem to be aware of their grounding in historical time. Early in the film, Grace explains to the housekeepers that her husband, Charles, went to war a year and a half ago, yet she has had no news 'since the war ended'. The children believe their father is still fighting in the war, and their vague awareness of the war's significance is only measured through its scale and distance: 'our father is fighting in a war in France, you know', Anne proclaims, while Nicholas corrects 'It's a World War', to which Anne replies 'I know, but he's in France.' When the children ask their mother about their father, she tells them that he shall return 'when the war's over', contradicting her earlier suggestion that it has already ended. Nicholas replies: 'Why did he go to war? I mean, nobody's done anything bad to us', further reinforcing the family's detachment from their sociopolitical context. Even when Charles mysteriously emerges from the woods surrounding the mansion halfway through the film, both his own status and that of the war remains obscure: as the housekeeper suggests, 'he doesn't really know where he is'. The audience is none the wiser, as it remains unclear whether Charles is a traumatized living man, or a spectre caught forever in the war, having died on the battlefield. He disappears as quickly and inexplicably as 
he reemerges, explaining to Grace that he must return 'to the front', which prompts the following exchange:

Grace: The war's over.

Charles: The war's not over.

Grace: What are you talking about?

Hovering at this point of confusion and disagreement, the dialogue again leaves the temporal stage of the war in doubt, eventually leading Grace to cry out in frustration 'Why did you go to that stupid war that had nothing to do with us?'

The specifics of historical trauma are thus replaced in THE OTHERS with the temporal and ideological uncertainty of a liminal moment between clearly definable historical stages. In turn, the film's unsteady grasp on postwar historical consciousness pointedly marks the beginning of the decline of modern thought. Reflecting this transitory temporal context, the house itself is situated not as a stable site but as transitional space, with many of the myriad rooms depicted with the furniture packed away, covered in sheets, and unused, creating insecurity as to whether these belongings have long been packed up due to disuse, in readiness to move, or have simply never been unpacked. As the plot emphasizes, both of these vectors - imminent unhomeliness and imminent homeliness - are coexistent in this interstitial zone in which modernist discourse has started to unravel: Grace and the children's hold on their home may be coming undone now that they are spectres, but the new family are only just settling in.

\section{Uncanny Childhood and the Decline of Adult Discourse}

Anne and Nicholas are the threads that bind Grace to this isolated space dislocated from cultural belonging and historical trajectories. The children are photosensitive: bright light would cause their skin to blister and rupture, so the house is kept in a state of constant darkness (as is emphasized by the lack of electricity). Because the curtains are constantly pulled closed to protect the children, natural light very rarely enters the house, and, as a result, it is frequently unclear throughout the film as to whether it is night or day. Fog continually obscures the spatial boundaries of the house in exterior shots, whereas shadow and darkness render the internal structure of the house unclear: the walls of rooms and hallways are frequently obscured, as a dull halo of gas lamp light is all that illuminates the characters in the shot. We are thus not offered coherent spatial coordinates with which 
to comprehend the house or the characters' position in space, and it is the children's vaguely defined condition that necessitates this constant shroud of shadow. The children thus unsettle the status of homeliness, as the spatial familiarity, security, and identity that make a house a 'home' are not apparent in this claustrophobic, uneasy space.

In order to deal with this spatiotemporal aimlessness, Grace adheres to artificially constructed rituals that provide her existence with a sense of coherence and direction. When the mysterious new servants arrive (as we later learn, they are in fact ghosts from the Victorian era, having died in 1891), Grace is quick to instruct them of the exact times at which she and the children must have their meals and other facets of their schedule, an insistence on strict timekeeping matched by her precise way of dealing with the vast darkness of the house's rooms and hallways. Grace has keys for every room, and instructs the servants on the rules of locking one room before passing into the next, an orderly spatial traversal which mirrors her insistence on chronological coherence. Grace's adherence to socially constructed rituals is also indicated by her awareness of the weekly visiting schedules of the priest and postman, which constitute her only tenuous connections with the world beyond her property. Grace's devotion to these rituals also represents her only means of maintaining a chronological sense of time within the darkened house. Grace is introduced through her attachment to chronology: the film's opening shot is an extreme close-up of her screaming in horror, but upon checking her watch, she breathes a sigh of relief. Despite Grace's relief when she looks at her watch, from the beginning of the film the temporal structures to which Grace clings have already dissolved. Her relief, after all, is founded on her inability to confront her trauma: she is buoyed by her mistaken belief that she did not actually go through with the act of killing herself and her children.

The children's incitement of a temporally insecure unhome through their 'condition' is entwined with their burgeoning resistance to the ideological structures that their mother holds dear - beliefs aggrandized by Grace's devout Roman Catholicism. ${ }^{3}$ Throughout the film, we witness scenes of Grace teaching her children regimented lessons from the Bible, yet both children later admit to the housekeeper that they do not entirely believe what they have been taught in these lessons. The children are also depicted reading

3 Grace's oppressive Roman Catholicism also vaguely signals the Spanish contexts that echo throughout the film, as this discourse goes hand-in-hand with Franco-era fascism, and is often depicted as such in Spanish film (most infamously in the works of Luis Buñuel, such as VIRIDIANA $[1960])$. 
out lessons about traditional family units, half-heartedly dictating the text from their readers: 'We all live in a house with our families. The family is usually made up of parents, children, and their grandparents. We must be obedient and kind towards other members of our family.' Reflecting Trigg's notion of a fixed image of progress, these lessons perpetuate a conservative, intergenerational model of temporal continuance in which futurity emerges from the structures and institutions of the past, the master figure of which is the nuclear family unit. As Jenks points out, 'the modern family has become the basic unit of social cohesion in advancing capitalism, and though loving and supportive in its self-image it has become the very epitome of the rational enterprise. [...] The modern family enabled the modern State to invest in "futures"' $(2005,105)$. The children's conceptual entwinement with this formally sanctified mode of temporal progression is also signalled by a message written on the blackboard which appears throughout the film: 'Thank God for Their Growth in Faith and Love.'

Yet the children - Anne in particular - continually challenge the structures and assumptions upon which the 'rational enterprise' is founded. Following the mysterious reemergence of their father, the children ask their mother to where one's soul goes when one has died fighting in a war. The following exchange ensues:

Grace: That depends on whether you fought on the side of the goodies or the baddies. Your father, he fought for England on the side of the goodies.

Anne: How do you know who the goodies and the baddies are?

Grace: That's enough questions. Eat your food.

Anne immediately proceeds to bring up the subject of the mysterious 'others' that she has perceived lurking in the house once again - exposing the entwinement of these intruders with the child's resistance to her mother's teachings - but Grace angrily dismisses Anne, insisting that the child be silent, leading Anne to run from the dinner table. As the housekeeper tells the frustrated girl in the adjacent kitchen: 'There are things your mother doesn't want to hear. She only believes in what she was taught. But don't worry, sooner or later, she'll see them. And then everything will be different.'

The child, and the ghosts from the future that she perceives, thus embody a challenge to her mother's belief system: while the child in modern discourse is tasked with continuing the adult's present into futurity, Anne represents the decline of her mother's reality. As Trigg suggests: 
decline is the imminent fall of a narrative already aware of its limitations. Decay is the outward manifestation of decline, which allows subjectivity to recognize itself in that narrative. If not seen as pernicious in their own right, decay and decline are an anathema to the progressive march of reason. $(2006,84)$

Anne's awareness of the limitations of her mother's rigid discourse heralds the imminent collapse of this discourse, and its subsequent transition from present into pastness. In charting Grace's gradual recognition that she and her children are dead, the film entwines Grace's belated recognition of trauma with a realization that all the ideological structures that buttress her identity are collapsing. This is the uncanny point at which she recognizes herself within a narrative of decline, rather than advancement, as crystallized in the realization that 'her' home is in fact no longer 'hers': both her identity and her home are thus caught at a moment of defamiliarization.

This sense of modernity in decline is captured in a recurring motif throughout the film in which Grace enters various rooms of the house and rips the sheets off of the belongings stored inside. In one of the film's key set pieces, Grace searches for the 'intruders' in a room that Anne provocatively labels the 'junk room'. Inside the room is a large assemblage of objects covered in white sheets, and thus unclear in their individual forms and properties. The objects themselves seem like the ghosts haunting the room - a point further suggested by the fact that, moments before this sequence, Anne declares that ghosts 'go around in white sheets'. Grace hears indiscernible whispering, but this eerie murmuring seems to emanate not from spectres, but from the ghostly objects that surround her as she nervously traverses the room. As the whispers crescendo to a pronounced moaning sound, Grace is startled and backs into a set of outstretched hands, before ripping the sheet off in terror to reveal a full-sized Virgin Mary statue. She then proceeds to frantically pull off the sheets covering various other objects in the room, including a coat stand, which teeters frantically with the force of its unveiling, and two mirrors, the second of which Grace nervously stares into. The 'junk' thus represents the source of terror in this scene, rather than any supernatural occurrence.

As Grace looks in the mirror, the camera captures her from behind, before slowly dollying into her reflection to focus on the door that is slowly creaking closed behind her: both Grace and the camera shift focus from her reflection to the events taking place behind her back. Grace's identity is thus decentralized, placed off-centre, and eventually blurred in favour of the activities of the 'ghosts' behind her, who in fact presage Grace's own 
displacement into the past. The objects in the 'junk room' represent the flotsam and jetsam of modern consciousness, caught at a point of decline marked by the post-WWII period. Likewise, the intruders are not actually the film's ghosts: the spectres are Grace herself, her children, and the objects with which she surrounds herself. Near the end of the film, in a scene immediately prior to the grand reveal that Grace and her children are ghosts, Grace is once again seen in the junk room. Yet this time, in her desperate quest to locate the curtains that the 'ghosts' have removed from the windows - which finally serves to bathe the house and its dark corners in light - Grace is seen carelessly pushing, throwing, and smashing the objects that embody her threatened belief system.

\section{The Parallel Perversion of Growing Up and Rational Progress}

In a similar manner to the eerie ghosts of modernity represented by the objects in the junk room, the children embody a point at which development and grow th are revealed to be decline and decay. Initially, Anne and Nicholas appear to be traditional models of pure and innocent childhood, pale blank slates primed to be filled with adult knowledge and to enact its continuity into the future. They thus seem to embody the promise that meaning will soon be restored to their mother's identity, to the film itself, and to this uncanny period of time that is yet to be inscribed with historical meaning: an expectation signalled by the statement 'Thank God for Their Growth in Faith and Love.' Yet it gradually becomes clear that Anne and Nicholas actually herald the outmodedness of their mother's modernist, adult-centric understanding of childhood's function. Rather than ensuring the continuance of Grace's beliefs and genes into the future, the children - particularly Anne - are harbingers for their mother's obsolescence.

Aestheticizing Anne's embodiment of decline is a scene two-thirds into the film, which echoes the earlier sequence in the junk room. In the scene, Anne tries on a dress that her mother has made for her, intended for the child's first communion. Anne's first communion represents another of Grace's religious and temporally bound rituals, which, in this case, serves to mark the holy confirmation, and thus utter enculturation of Anne's identity into her mother's ideologies. Temporally, the communion represents a way for Grace to quantify Anne's growth and consecrate a symbolic transition from irrational infant child into the adult's 'age of reason' - the traditional purpose of the first communion. However, importantly, Anne is already a ghost at this point, exposing the communion's status as an empty ritual seeking to affix temporal and rational coordinates where none exist. Significantly, 
although Anne tries on the dress, following the horrors of this scene, outlined below, the child never actually goes through with the ritual. The sequence represents the film's key horror set piece and has become the most referenced moment of THE OTHERS.

As Anne wears the dress, we see Anne and her mother's reflection in the mirror as they admire her mother's creations - both the child and the dress she wears. Yet, as her mother gently places the veil over the child's face and Anne stands frozen in place, admiring her reflection, her ghostliness - and her similarity to the immobile objects in the junk room - is eerily suggested. When Grace briefly leaves the child alone in the room, the editing becomes uncomfortably disorienting. At first, the child is filmed from behind, her mirror image captured but not her body. When the camera does cut back to the child in real space, the rules of cinematographic continuity are broken as the camera jumps across the 180-degree line, unsettling the audience's grasp of how the child relates to the space. This is followed by a flurry of jump cuts between a full frontal shot of Anne apparently standing before the mirror, a shot of her mirror image (however, the darkness and strangeness of the angles make it difficult to discern which is the real child and which is her mirror image), and a shot from a higher angle depicting Anne standing in an unexpected position in the room. As Nicola Diamond points out, this disorienting series of shots 'happens so fast, taking the viewer by surprise, and this affects the viewer pre-reflectively. The disruption of body identity affects our sense of spatial orientation and renders a state of das Unheimlich that we share for a split second' (2014, 95). The sequence creates the fleeting impression that there are multiple Annes in the room, visually expressing the breaking apart of the child's traditional function and her dispersal into decay and pastness, even as her actions speak of growth and futurity - throughout the scene, she is pretending to enact her wedding dance.

When Grace returns to the room, Anne is again captured from behind, singing the same nursery rhyme-esque melody that she has hummed throughout the scene. However, as the camera closes in on the child, now a crumpled figure on the floor playing with a marionette, Grace and the audience become privy to the withered, wrinkled nature of the hand that protrudes from the lacy white sleeve of the gown. Anne's gentle humming enhances the eeriness of the contrast, as childish sweetness is swiftly rendered uncanny. As the camera revolves around the figure's body to capture her frontally, it becomes evident that the face beneath the veil is no longer that of a child, but of an old woman. She continues to speak in Anne's sweet voice, yet moves in unnatural, stilted movements not unlike the puppet with which she plays: a parallel which emphasizes the sense of 
uncanny doubling and becoming-other that permeates this sequence. The scene frighteningly articulates the child's untethering from clearly marked temporal coordinates of growing up - a process which functions in tandem with the film's lack of clearly defined cultural and historical context - as the pure, untarnished body of the child is suddenly imaged in a state of elderly decay, a juxtaposition amplified through the disjuncture between the childish voice and the gnarled face and hands. Exposed in this scene are the true horrors of the child's ghostliness: the child is no longer fixed on a progressive timeline, and instead conflates the usually opposed polarities of growth and decay.

Horrified, Grace desperately grabs at the child's dress, trying literally to unveil Anne as she did the objects in the junk room. When Grace violently removes the veil, her shock is at first registered in her mirror image, before a reverse shot captures both Grace in real space and Anne - once more appearing as a child - standing before her. Grace repeatedly screams 'you're not my daughter!', her abject horror expressing her terrified resistance towards the collapse of her intergenerational continuance. The uncanniness of this sequence is only enhanced by its narrative explanation, revealed later in the film: the child-ghost, depicted at a moment that marks a symbolically significant point in her 'growth', suddenly merges with an elderly medium attempting to make contact with her from the future, a medium that the new occupants have hired to make contact with the ghosts haunting 'their' house. The child's function as vessel for futurity and historical continuity thus unravels, as the child's body becomes synonymous with the 'untimely' quality of the decaying ruin: 'having fallen from (active) time, the ruin becomes disjoined from time. The untimeliness is evident in how past, present, and future conspire to converge in the ruin' (Trigg, 2006, 131).

\section{'We're not dead!': Subverting the Narrative Structure of the Ghost Story}

This disjoining from historical time culminates in the climactic scene, in which Grace and her children realize that they are spectres. Finally confronting the 'intruders', the family come across a husband, wife, and two spiritualists (including the elderly medium who previously possessed Anne) sitting at a large table in the drawing room conducting a séance. At this point, the past and future finally reach a point of collision, which in fact represents a crashing into the diegesis of the film's 'real' present. In some shots, only the family sitting at the table are visible, and the only evidence of Grace and the children's presence is the shuddering of the table and a flurrying of the papers on which the medium is writing. In alternative shots, Grace and 


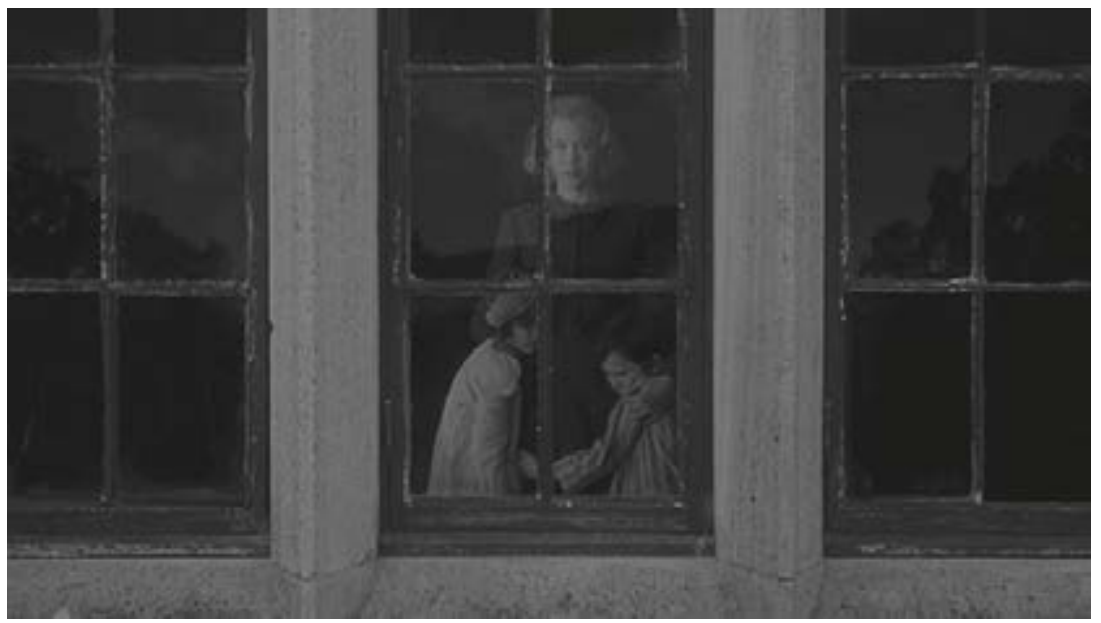

Figure 15. Grace and the children haunt the new occupants in the final image of the family in THE OtHERS.

the children once more appear in the frame, violently shaking the table and moving the papers - desperate acts that only serve to emphasize their lack of visibility in the present. 'We're not dead!' the children and their mother repeatedly cry out: the desperate last cries of a former present, incarnating in traumatic form the moment at which the present diegesis of the film reveals itself to be the past. Grace and the children are becoming-past as a new present takes their place, an image of progress which foregrounds not advancement, but the decline and displacement of the previous mode of being. As her world becomes unhomely, Grace is finally forced to question her beliefs, saying to the children when they ask her about how their (non) existence fits into the dichotomies of heaven, limbo, and hell: 'I'm not even sure if there is a limbo. I'm no wiser than you are.' The adult character no longer has dominion over the children's epistemic reality now that they are untethered from the narratives of intergenerational and historical continuation that the adult had set in place.

The film impels the audience to experience this uncanny defamiliarization of progress by subverting the typical trajectory of the ghost story. In one of the film's final scenes, Grace and her children repeatedly whisper, 'This house is ours.' The whispering accompanies floating shots of the now empty rooms of the house. This is thus an eerie vision of space devoid of its occupants, rendered anonymous for it is no longer semiotically anchored as the characters' home. Exposing their flailing grasp on the space, Grace and her children use the word house in their frantic recitations, emptying the structure of its homeliness in tandem with a montage of deterritorialized, 
floating shots that no longer have a subject on which to focus. This sequence echoes a motif typical to the ghost story, except that now we are haunted not by the reemergence of a past that disturbs the status of the present and the flow of temporal progress - as in all the films previously discussed in this book -, but by the gradual displacement of a past in progress's wake. This is succinctly captured in the final shot of the family, in which we finally see Grace and her children from the living child Victor's point of view: as Victor stares up from the grounds of the mansion, the family appear as eerily transparent, static figures in the top-floor window, who gradually fade away and disappear (Fig. 15). This shot references an image typically featured in the first third of ghost films, as Grace and her two children gaze ominously through the window, watching as the new occupants flee the house that Grace no longer owns, but haunts. This shot underscores the viewer's realization that 'the others' of the title are the characters with which we have identified for the duration of the film, not the 'intruders'. ${ }^{4}$

From this point, the camera pulls away from the house - the grounds now bathed in a bright light that had been elusive for the duration of the film - and follows the car of the living family as they leave the property. Although we are at first given the impression that we, the audience, will follow this car out along the road, and thus rejoin the forward march of historical progress, in fact the camera stops at the gate as the car leaves the grounds. As the car continues beyond the gate and moves out of frame, the final shot lingers on the 'For Sale' sign which hangs on the gate, before fading to black. Instead of releasing us from the displaced past in the final shot, the film thus hovers at the point of becoming spatially represented by the unsold, haunted house, no longer belonging to the dead previous occupants, but yet to be grounded in the present by new owners and colonized with new life and meaning.

4 To be specific, the final shot in THE OTHERs echoes an early scene from The InNocents, in which Miss Giddens wanders the grounds of the mansion before noticing a spectral figure staring down at her from the tower. Similarly, in THE HAUnTING when Eleanor walks around the grounds of the mansion in which she is staying, she constantly senses something looking down at her from the uppermost window, as depicted in low-angle shots depicting her anxious gaze staring up at the windows that bear down on her. THE CHANGELING, discussed in Chapter One, also features a scene in which John walks in his front yard only to have shards of stained glass fall at his feet from the attic window. A tense shot constructs his perspective as he stares up at the window, expecting to see someone watching him. This scene facilitates his exploration of the attic in which the child, Joseph, died. THE OTHERs is strongly influenced by all of these films, and this final scene plays upon the eerie, intertextual realization that we and the three central characters have in fact been on the 'other' side of the window throughout the film. 


\section{Conclusion}

Ultimately THE OTHERS aestheticizes Trigg's characterization of the eerie sensation in which the 'aftermath' of rational history becomes evident to us within the unoccupied, decaying structure, in which:

the emergence of decline becomes the figure which defines time and space. Accordingly, as the content of history loses its privileged certainty, so too does the form. Conjoined with the incongruity between the present stage of things and the remains that linger, an anticipatory waiting emerges. The beginning of history and the end of history converge, the boundaries ambiguous. In the wavering space in between, temporal uncertainty forms. (2006, 194-195)

In its subversion of the traditional ghost story arc, THE OTHERs emphasizes this site of decline, which challenges history's accepted form. The decay of the house that Grace and her children inhabit is imminent, as is the gradual dissolution of their own identities - the house is caught at a point of becoming-unhomely, becoming-ruin, just as Grace and her children are caught at a point of becoming-ghost. The audience identifies not with the 'present' characters who move forwards through historical time, but with the spectral remains of this past that lingers. We are thus locked into an anticipatory waiting between a present that has passed and a future that becomes present, with the diegetic present functioning as an unsettled slip-zone in between. The ambiguity of the historical setting - between the final stages of WWII and the beginning of the postwar period - confounds historical progress by intermingling beginnings and endings in a similar manner. This temporal uncertainty is embodied by the child whose growing up has become her decay, another conflation of beginnings and endings that aestheticizes the eerie encounter with progress stripped of its teleological function. Thus, via its detachment from specific national narratives of history and progress, THE OTHERs deploys the uncanny child to work through the liminality of the early 2ooos, as the 2oth century was displaced by a long-awaited new epoch: a felt transition in which the present became past, inciting an uncanny defamiliarization of all that once was in the face of the future becoming-present. 


\section{Works Cited}

Baudrillard, Jean. The Illusion of the End. Trans. Chris Turner. Stanford: Stanford University Press, 1994. Print.

—.'The Millennium, or the Suspense of the Year 200o.' Trans. Julie Witwer. The Jean Baudrillard Reader. Ed. Steve Redhead. New York: Columbia University Press, 2008. 153-170. Print.

Bauman, Zygmunt. Liquid Life: Living in the Age of Uncertainty. Cambridge: Polity, 2007. Print.

Boym, Svetlana. 'Nostalgia and its Discontents.' The Hedgehog Review 9.2 (2007): 7-18. EBSCO Host Humanities International Complete. Web. 30 Sep. 2014.

Deleuze, Gilles. Cinema 2: The Time Image. 1985. Trans. Hugh Tomlinson and Robert Galeta. Minneapolis: The University of Minnesota Press, 1997a. Print.

—.Negotiations, 1972-199o. Trans. Margin Joughin. New York: Columbia University Press, 1997b. Print.

Diamond, Nicola. 'The Body, Emotion and Cinema: Perspectives on Cinematic Experiences of das Unheimlich and Estranged Body States in THE OTHERs.' Media and the Inner World: Psycho-cultural Approaches to Emotion, Media and Popular Culture. Ed. Caroline Bainbridge and Candida Yates. New York: Palgrave Macmillan, 2014. 82-98. Print.

Edelman, Lee. No Future: Queer Theory and the Death Drive. Durham: Duke University Press, 2004. Print.

Fass, Paula S. Children of a New World: Society, Culture, and Globalization. New York: New York University Press, 2007. Print.

Fraser, J.T. 'An Embarrassment of Proper Times: A Foreword.' Time: The Modern and Postmodern Experience. By Helga Nowotny. Trans. Neville Plaice. Cambridge: Polity Press, 1996. 1-6. Print.

Hammond, Philip. Media, War and Postmodernity. London: Routledge, 2007. Print. Jenks, Chris. Childhood. $2^{\text {nd }}$ Ed. New York: Routledge, 2005. Print.

Lyotard, Jean-François. The Postmodern Condition: A Report on Knowledge. 1979. Trans. Geoff Bennington and Brian Massumi. Minneapolis: University of Minnesota Press, 1983. Print.

Natoli, Joseph. Speeding to the Millennium: Film and Culture, 1993-1995. Albany: State University of New York Press, 1998. Print.

Rüsen, Jörn. Time and History: The Variety of Cultures. New York: Berghahn Books, 2007. Print.

Staal, Rein. 'The Forgotten Story of Postmodernity.' First Things December (2008): 35-39. EBSCOhost Academic Search Complete. Web. 30 Sep. 2014.

Stagoll, Cliff. 'Becoming.' The Deleuze Dictionary Revised Edition. Ed. Adrian Parr. Edinburgh: Edinburgh University Press, 2013. 25-27. Print. 
Swiboda, Marcel. 'Becoming + Music.' The Deleuze Dictionary Revised Edition. Ed. Adrian Parr. Edinburgh: Edinburgh University Press, 2012. 27-29. Print.

Tomlinson, Niles. 'Of Horse Blood and TV Snow: Abhuman Reproduction in THE RING.' The Scary Screen: Media Anxiety in The RING. Ed. Kristen Lacefield. Surrey: Ashgate Publishing, 2010. 175-190. Print.

Trigg, Dylan. The Aesthetics of Decay: Nothingness, Nostalgia, and the Absence of Reason. New York: Peter Lang, 20o6. Print.

-.The Memory of Place: A Phenomenology of the Uncanny. Athens: Ohio University Press, 2012. Print.

Uprichard, Emma. 'Children as "Beings and Becomings": Children, Childhood and Temporality.' Children and Society 22 (2008): 303-313. Wiley Online Library. Web. 30 Sep. 2014.

Vidler, Anthony. The Architectural Uncanny: Essays in the Modern Unhomely. Cambridge: Massachusetts Institute of Technology, 1992. Print.

Zamora, Lois Parkinson. 'Apocalypse.' Dictionary of Literary Themes and Motifs: A-J. Ed. Jean-Charles Seigneuret. Westport: Greenwood Publishing, 1988. 87-96. Print. Zipes, Jack. Relentless Progress: The Reconfiguration of Children's Literature, Fantasy and Storytelling. New York: Routledge, 2009. Print.

\section{Filmography}

The Changeling. Dir. Peter Medak. 1980. HBO Home Video, 2005. DVD.

The Haunting. Dir. Robert Wise. Argyle Enterprises, 1963. Film.

The InNocents. Dir. Jack Clayton. 1961. Criterion Collection Home Entertainment, 2014. Blu-ray DVD.

The Others [Los отros]. Dir. Alejandro Amenábar. 2001. Optimum Home Entertainment, 2011. Blu-ray DVD.

The Ring. Dir. Gore Verbinski. 2002. DreamWorks Pictures, 2013. Blu-ray DVD.

Scary Movie 3. Dir. David Zucker. Dimension Films, 2003. Film.

Spanish Movie. Dir. Javier Ruiz Caldera. Telecino Cinema, 2009. Film.

'Treehouse of Horror XXV.' The Simpsons: Season 26, Episode 4. Dir. Matthew

Faughnan. Gracie Films and $20^{\text {th }}$ Century Fox Television, 2014.

VIRIDIANA. Dir. Luis Buñuel. Unión Industrial Cinematográfica (UNINCI), 1961. Film. Who Are We? [Hum Kaun Hai?]. Dir. Ravi Sharma Shankar. 4U2C Film, 2004. Film. 


\title{
9. 'Round and round, the world keeps spinning. When it stops, it's just beginning'1
}

\author{
Analogue Ghosts and Digital Phantoms in The RING (Gore \\ Verbinski, 2002)
}

\begin{abstract}
The final chapter considers the impact of the shift from analogue to digital media upon the preoccupations and aesthetics of millennial uncanny child films. Via an analysis of The RING (Gore Verbinski, 2002), Chapter Nine contends that this paradigmatic technological shift has deep intersections with the ideological tangling of beginnings and endings characterized by the millennial turn. These intersections are embodied by the uncanny child in THE RING who eerily conflates decay and growth.
\end{abstract}

Keywords: Digital, Analogue, The Ring, Obsolescence, Trauma, Uncanny child

The highest-grossing horror remake in history, THE RING, laid the template for subsequent American remakes of Japanese horror films, while demonstrating their commercial viability. In fact, THE RING is among the top 20 highest-grossing horror films of all time, ${ }^{2}$ and Kristen Lacefield suggests that it 'nearly single-handedly revived a moribund sector of the film industry that had once been dominated by tired film franchises such as HALLOWEEN, FRIDAY THE $13^{\mathrm{TH}}$ and SCREAM' $(2010,1)$ - although I contend that, in fact, THE RING achieved this in tandem with the other influential uncanny child films discussed throughout this book. Not only was THE RING one of the most commercially and critically successful horror films of the new

1 The lyrics to the eerie, nursery rhyme-esque song Samara sings throughout THE RING.

2 See 'The 20 Highest Grossing Horror Films of All Time' (Lynch, 2017).

Balanzategui, J., The Uncanny Child in Transnational Cinema: Ghosts of Futurity at the Turn of the Twenty-First Century, Amsterdam University Press, 2018. DOI: 10.5117/9789462986510/CHog 
millennium, but it sparked a veritable body of fertile critical discourse. Many insightful scholarly and popular analyses of THE RING were produced in the aftermath of the film's release, evidence of the film's potent confrontation of the uncertainties of the early 21 st century. ${ }^{3}$

In translating RINGU from Japanese to Hollywood horror, THE RING self-reflexively builds upon the original film's ambiguous postmodern anxieties about the power of media technologies to erase or displace human subjectivity. That THE RING draws out and embellishes the uncertainties of Nakata's film - analysed in Chapter Six - is of course one symptom of the process of remaking, as Verbinski and his team consciously reconfigured the culturally specific themes and aesthetics of the original in order to transform a low-budget, national horror film into a globally accessible, blockbuster Hollywood product: a process which necessitates the augmentation and clarification of the anxieties of the original, but a simultaneous effacement of their cultural specificity.

THE RING's centralization of postmodern tensions is also bound to the period of technological flux between analogue and digital audiovisual media in which the film was produced and released. As Lacefield suggests:

its reluctance to embody the transition to the digital realm offers an important indication of the film's technological anxiety and resistance [...] it seems likely that the VHS tape, with its perceived degradation of quality and impending obsolescence, offers Verbinski an opportunity to forge a technological link from the past to the present, thus reinforcing a temporal/historicist trajectory that is identical to the one Samara herself accomplishes - via videotape - from beyond the watery sepulchre of the well that houses her remains. $(2010,13)$

THE RING thus functions like 'a cathode ray tube or movie screen onto which gets played our anxieties over technological change' (Lacefield, 2010, 20-21). While the original prefigured the impending obsolescence of the VHS tape with eerie prescience, Verbsinki's film presents a supernatural curse that harnesses a technology already well on the decline. As I highlighted in Chapter Seven, most home viewers would have watched this film about an

3 Primary among these is Lacefield's The Scary Screen (2010), an illuminating collection of essays that considers the ways in which both the Japanese RINGU and the American remake express cultural anxieties surrounding technological and conceptual change. Most other works on THE RING emphasize the processes of adaptation and exchange between the original and the remake: for insightful studies, see Balmain (2004), Holm (2011), Lowenstein (2015), Meikle (2005), Phu (2010), and Wee (2013). 
analogue videotape curse on the new digital home entertainment technology, DVD (or via the illegal peer-to-peer torrenting or grey streaming websites that were becoming popular in the early 200os). This results in a shift in preoccupations between Nakata's and Verbinski's films, as ghost-child Samara becomes overtly implicated in the undulations of technological decline and progress.

THE RING emphasizes the manner by which Samara and her cursed videotape disrupt the ontological structures to which the adult protagonists blindly adhere in their fruitless quest to resolve the mysteries of the curse and the tape. Thus, Samara's unsettling of conventional (adult) wisdom becomes the primary theme of the film. Wee aptly points out that:

by emphasizing reason, information, and knowledge, and subsequently undermining their power and consequence, the film reflects a declining confidence and security in humanity's ability to harness our intellect to control and determine our reality and destiny. What THE RING dramatizes is the failure and inconsequence of humanity's ongoing reliance on logic, science, and reason against a destructive supernatural force. $(2013,95)$

I suggest that Samara's status as a child deepens the implications of this challenge to human - adult - discourse, as she draws to the surface many of the anxieties that have ambiguously surged through the uncanny child cycle. As Lacefield elucidates, 'Samara is deconstruction with a vengeance' $(2010,15)$ : this uncanny child is a frightening embodiment of, and icon for, the postmodern child who simultaneously contaminates the processes of growing up and progress, challenging adult epistemological structures and narratives wholesale.

In a narrative device not seen in the original film, in THE RING, anyone who watches Samara's cursed videotape without copying it and showing it to someone else not only dies after seven days, but suffers in a way that precisely echoes Samara's own trauma throughout that week. The seven-day period in THE RING represents the length of time Samara herself was stuck alive in the well before finally dying (an element not made explicit in the original). The images on Samara's video, each of which evokes painful cathexis points around which her trauma revolves, infect each of her victim's minds and leave painful marks on their bodies, as the trauma of Samara's own death invades and overcomes their lives. Thus, Samara literalizes the uncanny child's associations with the aesthetics of trauma, becoming a self-reflexive archetype of uncanny childhood written in broad, apocalyptic strokes: Samara is a truly monstrous embodiment of childhood trauma, knowingly 
harnessing her own trauma in order to terrorize her victims. Significantly, THE RING emphasizes that this trauma is eerily ungrounded from adultcentred personal and cultural narratives. Samara's trauma is not entwined with the deep, inner psychic turmoil of the adult protagonists, as was the case in the American films discussed in Section One - in fact, she reverses this relationship, imposing traumatic images that are distinctly her own into the minds of her victims, images that are horrifying in their unknowability and otherness. Nor is Samara's trauma associated with specific national histories or identities, as in the Spanish or Japanese films analysed in Sections Two and Three - as I suggested in Chapter Seven, Samara's unknowable origins and cultural hybridity are at the core of her monstrosity. In fact, the adult characters' persistent attempts to ground Samara's trauma in psychological causes or legible sociocultural realities is depicted as their failure, an unproductive means of domesticating Samara's power by sublimating her into a vulnerable, victimized child. It is in this way that Samara represents a powerful embodiment of postmodernity: through her ungrounded trauma, the obsolescence of modernist adult discourse is exposed.

\section{Analogue Aesthetics and Corporeal Decay}

In his insightful essay, Niles Tomlinson suggests that THE RING revolves around the fear that 'while technology has become infinitely flexible, the human itself has become "ponderous", an ossified relic trapped by its own conservative ontological categories and traditions, and made vulnerable by its insistence on its own exceptionality' $(2010,188)$. Tomlinson suggests that the film constructs a semantic parallel between the impending 'extinction' of human beings in the face of technological progress and the equivalent decline of the horse - an organic machine with intimate links to human endeavour, having been bred, cultivated, and trained over thousands of years in order to support the transport and agricultural requirements of human culture. Indeed, in THE RING, unlike in Nakata's original, horses are a central theme: Samara's adopted parents were horse breeders, until Samara mysteriously drove the horses to kill themselves by careening into the ocean. The horses' bodies appear in Samara's cursed videotape and one of the film's key horror set pieces depicts a horse throwing itself from a ferry in a panic when it encounters protagonist Rachel, who has become infected by Samara's curse. An extreme close-up of a horse's eye is a key motif of both the cursed videotape and the film itself.

Tomlinson suggests that the horses are a key clue to the film's core preoccupations, allegorically illuminating THE RING's millennial contemplation 
of how progress no longer centres around the human being (2010, 188-189). As he outlines, the film engages with a contemporary cultural awareness (and fear) that technological advance in the form of advanced computer and biotechnologies had seemingly broken loose from human intellect and DNA, displacing the primacy of organic human 'code' and endeavour. To build upon Tomlinson's argument, I contend that it is incredibly significant that the film positions the child as the agent of this dismantling of a human-centred model of progress. Furthermore, the technologies with which the film is fixated, VHS and analogue television, are defined, not by their associations with technological advance and futurism, but by their decline. Thus, Samara embodies not just an 'infinitely flexible' technology, but, more specifically, the eerie flux between analogue and digital media technologies: she draws to light not the human being's impotence in the face of a generalized technological domination, but the adult's inability to navigate technological change without resorting to a teleological vision of progress. Refusing to be an 'emblem of futurity's unquestioned value' (Edelman, 2004, 4), Samara instead expresses the becomings of decay in overtly technological terms. Samara's videotape curse and her supernatural embodiment of analogue technology make visible the conceptual contortions underlying the shift from analogue to digital technologies.

As Lacefield points out, Verbinski was inspired to make the film after a degraded VHS copy of RINGU ended up on his desk: 'it was really poor quality, but actually that added to the mystique' he explains (cited in Lacefield, 2010, 6). In The RING, the decaying aesthetics of the degraded analogue video pervade the entire film, even bleeding through the boundaries which demarcate the fictional diegesis: the opening DreamWorks logo is not accompanied by the usual bright orchestral soundtrack, but by the buzzing hum of analogue noise, and is interrupted by the juddering and grain of television static. As Lowenstein suggests, 'the result is that the DreamWorks logo, with its iconic American connotations attached to production partner Steven Spielberg, shows signs that it has become possessed by Japanese media infection - which of course, it has' $(2015,99)$. In addition, the quivering of the image gives rise to a fleeting glimpse of the 'ring' symbol, which is briefly superimposed over the moon/O of the DreamWorks logo, transforming it into a flickering circle of white light against a black background. This is the key motif of both the film itself (featured on posters and DVD covers) and Samara's curse ('before you die, you see the ring', explains protagonist Rachel, a line which is also the film's promotional tagline). This 'ring' was the last image Samara saw before finally dying in the well (in the form of the dim reverberations of sunlight creeping through the cracks in the 
well's cover), and is also the last image her victims perceive before their death. It is the first and final image on Samara's cursed videotape, and also bookends the film itself, serving to reinforce that, despite our investment in a two-hour supernatural mystery narrative, no resolution has been achieved. Rachel has failed to abate Samara's curse, having only figured out how to perpetuate it - by copying the tape and passing it on - thus deferring the death of herself and her son, Aidan. As a result, despite the illusion of narrative progression and closure - a central expectation of the classical Hollywood paradigm that is not as pivotal to the Japanese original -, the final scene, in which Rachel and Aidan copy Samara's videotape in order to show it to an unwitting victim, reinforces the realization that we are still at the same point of disequilibrium established at the film's beginning. Like the horses and pervasive analogue aesthetics, this emphasis on ring imagery is a new addition to Verbinski's film that was not present in the Japanese original (which was titled 'ring' due to the telephone ring Sadako's victims hear when her spectre calls to announce their impending death). In Verbinski's film, the flickering, analogue ring becomes Samara's calling card, metonymizing her malevolent use of her own personal trauma to disallow rational, linear progress.

In another contrast to RINGU, when Samara erupts from the television screen to kill her victims, she remains suffused in the analogue grain and grey-blue hue of her tape's images even after she enters her victim's 'real' space, and she continues to jitter, flicker, and skip monstrously in the manner of the degraded images. Thus, the ghost-child's transposition of analogue aesthetics into the real space inhabited by her victims is a central component of her frightening aesthetic. Benson-Allott suggests that the film revolves around a belated acknowledgement of the distinct eeriness of analogue technology, and in particular the videocassette, a physical cavity in which images perpetually lurk in material form, waiting to be activated:

THE RING was [...] the first film to be able to reveal (revel in) the horror of the videocassette, because it was the first produced after the rise of DVD, the new, impotent way to bring movies home. [...] In short, the studios could not afford to admit how damned eerie the videocassette was until they possessed another way to sell old movies to home viewers. (2010, 135-137).

While Samara does indeed monstrously expose the eerie power of the VHS tape and analogue aesthetics, the decay of analogue images and technologies is more specifically fetishized in the depiction of her monstrosity, in 
amplified and more generalized ways than in RINGU. The degradation of the analogue image is intertwined with the monstrous decomposition of Samara's own physical form - unlike Sadako, when Samara emerges through the screen, she is figured as a mouldering corpse, with her wet, putrefying skin constantly threatening to slide off her body.

Similarly, when Rachel finally locates the child's corpse in the well at the film's climax, Samara at first floats to the surface of the water looking the very image of a pure, untarnished child, complete with a white dress and soft pale skin (not unlike Anne and Nicholas in The OTHERs). ${ }^{4}$ Parallel to the equivalent scene in RINGU, upon seeing the child's body, Rachel's eyes well with tears and she embraces the corpse tenderly: the film's monster seems thoroughly tamed through the adult's pitying gaze. Yet, as soon as Rachel grasps the child's body, Samara rapidly decomposes before her eyes. The corpse's putrefaction echoes abject scenes from Samara's video - in particular an extreme close-up of swarming maggots - as maggots overtake the child's skin. The child's skin turns from pure white to a rusted brown, before her flesh becomes black as it rapidly melts from her bones, resembling the magnetic tape of a VHS cassette burning and melting. ${ }^{5}$ The child's decomposing body aestheticizes both the decline of the innocent, vulnerable child - as Samara reclaims her monstrous agency by collapsing the adult's romanticized vision of her - and the terrible antithesis to 'growing up'. Furthermore, through this monstrous fetishization of corporeal and technological decay, Samara makes eerily tangible the physical qualities of analogue media lost in the immaterial circuits of digital technology. She dramatically emphasizes the degradation of this formerly quotidian audiovisual technology and defamiliarizes it - and thus renders it distinctly threatening and uncanny - through its decline.

\section{The Becomings of Technological Transition: Analogue Decline/Digital Emergence}

In addition to fetishizing the entwined aesthetics of technological and corporeal decay, Samara also portends the uprising of digital technologies from analogue's degenerating remains. The outmodedness of the adult

4 This is in stark contrast to this moment in RINGU, in which Reiko feels under the water to grasp Sadako's skeleton.

5 This link is reinforced in the sequel, when Rachel burns Samara's cursed videotape and the image recalls the scene of Samara's decomposition. The burning tape is accompanied by an eerie screeching which melds a human scream with the sound of the tape coiling and melting. 
characters is drawn to light in the face of this technological flux: the adults' failure to adapt to the uncertainties of technological becoming is ultimately their undoing. When Noah and Rachel are first studying Samara's tape, Noah notes that it does not have a control track. As he explains, the control track consists of numbers that are:

put on the tape whenever it's recorded. Which means, [by not having a control track] theoretically, there shouldn't be any images [on Samara's tape]. [...] When you record a tape, the makeup of the tracks is like a signature for whatever did the recording, like a camcorder, VCR, whatever. So the control track can tell us where it came from. But to not have one, I mean, that's like being born without fingerprints. ${ }^{6}$

This slippage between biological and technological codes - that which identifies the origins of a videotape and that which identifies a human articulates the way Samara conflates anxieties about the shifting ideological status of childhood with those surrounding technological flux. Just as her tape's images were formed without the 'real' physical staging of the scenes, or the technologically determined processes necessary to record them onto the videocassette's magnetic tape, nor was she 'born' with the symbolic fingerprints of an identifiable lineage and genetic code, which would ground her in a secure narrative of intergenerational and historical continuation.

Throughout the film, Noah and Rachel fruitlessly try to affix Samara with material, rational grounding in tandem with solidifying her origins. Rachel's research into Samara's curse is conducted mainly in dusty libraries, as she sifts through large leather-bound historical texts and newspaper records, and is only once seen searching the internet (and notably, she prints out her findings). She also analyses the tape using a huge analogue playback and recording device - as the technician states, 'the big box here's a warhorse. Totally analogue' - which she uses to print out shots from the tape on paper, further materializing the tape's images. Notably, Rachel herself works at a newspaper, another material media mode threatened with obsolescence with the uprising of digital media. Near the end of the film, after failing to resolve the video's mysteries Rachel and Noah return to the Shelter Mountain cabin where Rachel first found the tape, at which point

6 As Benson-Allott points out, a control track just tells a videotape how fast to scan the images, but nevertheless, 'Noah's anthropomorphic mischaracterization of this technology actually tells the spectator how THE RING reads its videotape. For Noah, Samara's tape either has no origins (was never recorded, does not exist) or is capable of obscuring its origins' $(2013,116)$. 
Noah cries out in exasperation as he grasps hold of various objects in the room 'There's a reason that we're here! There's something in this room! It's in this phone! It's in this television!' Rachel and Noah's subsequent attempt to locate Samara's corpse - the tangible remnants of her identity - in the well underneath one of the cabins represents a related grasping for her form through emplacing her in material reality. Yet in the scene in which Rachel finally locates Samara's body, which directly follows Noah's desperate clutching of the objects in the cabin, this climactic moment towards which the plot has been driving quickly crumbles before our eyes with Samara's corporeal disintegration. As in RINGU, excavating and burying Samara's remains is promptly revealed to be a false resolution to Samara's curse.

The adult's flailing investment in materiality is crystallized in the iconic scene in which Samara emerges from Noah's television screen, killing him even though he helped Rachel to find the child's corpse and bury her body. As the image of Samara on-screen breaks free from its material housing, Noah is unable to do anything apart from stare in horror and back away. In contrast to RINGU, the grey-blue hue and static that suffuses Samara even after she crawls out of the television emphasizes that this is the mediated image which defies the boundaries of the frame - not just the ghost herself - as is reinforced in a moment in which she evades physical grounding and skips forward via a burst of static, a deterritorialization of bodily movement that knocks Noah backwards with the force of his shock. Unlike the equivalent character Ryuji of RINGU - a mathematics professor - Noah is a filmmaker and analogue video expert (at one point Rachel proclaims that he reads 'Video Geek Magazine'), underscoring his attachment to analogue technology and subsequent inability to adapt to Samara's rerouting of the mechanics of the mediated image. Samara emerges from Noah's screen surrounded by his technological paraphernalia, and, as he backs away from her, he falls into a cabinet of videocassettes and analogue recording equipment, smashing its contents. After Noah's death, in her hopeless desperation to understand Samara's motives, Rachel breaks open the cavity of the videotape screaming 'What do you want from me!' as she unfurls the tape inside, still searching for a material core to Samara that she can hold, touch, and unravel.

Samara's monstrous capability for wanton image proliferation is repeatedly highlighted throughout the film. For instance, she is able to produce telekinetic x-rays - referred to as 'projected thermography' - imprinting images from her mind directly onto the film. On a videotape that Rachel finds in Samara's family home depicting her sessions with a psychiatrist, the doctor says to the child, 'Let's talk about the pictures. How did you make them?' to which Samara replies 'I don't make them. I just seem them, and 
then, they just are.' Another of Samara's images - a large tree seemingly burnt into the wood of the barn in which she spent much of her childhood - resembles a giant Japanese woodblock (the carved wooden base used for woodblock printing), a link reinforced by the fact that the image depicts a Japanese maple tree. The tree bears clear signs of the physical labour necessary to create the image even though it was 'burnt' directly from Samara's mind onto the wood.7 That each of these images gesture to long-standing, highly specialized processes underscores Samara's monstrous eradication of the material, technological, and cultural contexts involved in the creation of these images, suggesting the coiling of tensions related to the deterritorialized transnational exchange of images, the child's lack of clear origins, and her eerie embodiment of technological flux.

THE RING thus pairs the adult protagonists' fixation with material grounding - a cleaving to materiality that parallels their adherence to rationality and logic - with Samara's monstrous ability to defy material processes in her creation and propagation of images. While the adult characters are fatally slow to comprehend Samara's monstrous empowerment of the image, Rachel's young son, Aidan, shares her ability, telekinetically communicating with Samara through the sharing of mind-images throughout the film. Thus, Samara, and to a lesser extent Aidan, project in embodied form an anxiety that Dominik Schrey associates with the technological flux of the early 21st century: 'even media formats with a strong tradition like the book (as a material object) or cinema (as a specific "dispositif") are now perceived to be threatened by obsolescence and seem to be outpaced by their increasingly ephemeral digital successors' $(2014,27)$. As Schrey suggests, the transition from analogue to digital media has incited a pervasive cultural 'longing for what is assumed to be lost in the continuing process of digitisation' (2014, 28): the sense of belonging to material realities associated with both the material creation and physical degradation of non-digital images. Laura Marks characterizes such analogue nostalgia as a 'retrospective fondness for the "problems" of decay and generational loss that analog video posed'

7 Of course, the maple tree image references the film's Japanese origins, and the anxieties associated with this image are underscored by the fact that woodblock printing has a lengthy, culturally specific legacy involving master craftsmen that Samara has deterritorialized in her own, mentally projected image. Furthermore, Lowenstein (2015) intriguingly connects the maple tree, which actually stands beside the well in which Samara died, to atomic blast imagery, referencing a striking shot after Rachel watches the cursed tape, in which the tree is suddenly bathed in a bright light which searingly projects the redness of the leaves. He suggests deep links between the Japanese and American films in relation to post-WWII trauma, which he suggests lurks within the 'mediated unconscious' of both films (102). 
$(2002,152)$ which expresses a 'longing for analog physicality' not attainable with digital media $(2002,153)$. Samara expresses a fetishization of the decay of analogue physicality so extreme that it becomes monstrous, while simultaneously insinuating the terrible deterritorialization of the image post analogue. In THE RING, the adult characters are simply unable to keep pace with Samara's boundless image proliferation, a monstrous amplification of fears that, with the rapid emergence of digital media and the subsequent 'loss' of the image's physical and indexical contexts, we will become swamped by a flurry of images projected across various formats, effacing the material referents and cultural backgrounds of the images with which we are confronted. THE RING thus works through the tensions that Thomas Elsaesser points to in his analysis of anxieties surrounding digital media, a sense that 'the digital image is not part of cinema or film history, and the reason seems to be an absence: the lack of "roots" and "texture", which is to say, materiality and indexicality' $(1998,31)$.

Yet this is not to say that the film maps a clear (albeit anxious) path from analogue decay to digital deterritorialization through its uncanny child. In order for her curse to perpetuate, Samara requires that her tape be copied and passed on - a fetishization of a material process of viral image sharing that seems disjunctive given that Samara is able to project her images directly into the minds of others. Furthermore, Samara's curse always reaches its climactic point via an analogue television screen spatially rooted in someone's home: while Samara's monstrous eruption through the screen incarnates her defiance of this boundary, she still relies on the analogue television set to emerge into her victim's reality. Furthermore, as I suggested earlier, Benson-Allott points out that the film is marked by a strange absence of DVDs $(2013,103)$. Thus, the film gives charge to the point of transition between technological states, a moment in which the decline of analogue technology portends the rampant propagation of digital images. This eerie conflation of analogue decay and a monstrously exaggerated expression of digital proliferation is projected by Samara's form as she approaches her victims: diegetically, it is ambiguous as to whether she has any physical substance (as did her predecessor, Sadako), or if she is purely an endlessly circulated mediated image fulfilling a preprogrammed function. Extra-diegetically, it is clear that this monstrous image of analogue decay has been created with digital special effects technologies.

Thus, Samara embodies the unstable moment of becoming between analogue and digital visual media technologies. As Kim Knowles points out, in the early 21st century much popular and critical discourse has considered the shift from analogue to digital, but such analyses: 
tend to overlook the more complex dialectical relationship between the old and the new [...] in the heady rush to embrace and theorize the 'new', we have neglected to consider the wider cultural, economic and ideological implications of recent technological change, including the ever-changing notion of the 'old' and its precarious position in both culture and society. $(2011,2)^{8}$

Samara's amalgamation of analogue decay and digital emergence captures the uncanny limanilty of impending obsolescence, making visible the processes whereby a current technological mode becomes-past in simultaneity with a new format claiming dominance. Joel Dinerstein asserts that ideological investment in technological advance is typically 'synonymous with faith in the future' $(2006,569)$ because technology functions 'as an "autonomous" aspect of cultural production illuminating the road to a utopian future that will not require social or political change' $(2006,571)$. Thus, technological development offers a teleological vision of futurity and progress that does not necessarily require cultural and sociohistorical grounding. Yet Samara monstrously disrupts this simple alignment of technological development with faith in futurity, by twinning her own corporeal decay - and thus perversion of growth and futurity - with the point of becoming inherent in technological change, embodying not advance but the turbulent conceptual upheavals involved in comprehensive technological transition.

\section{Samara's Challenge to Adult Discourse}

Ultimately, Samara's powerful technological becoming is depicted as a direct affront to adult knowledge and understanding throughout the film. The anxiety surrounding the child's breaking loose from material and cultural grounding - and from adult discourse wholesale - is particularly highlighted in the scenes which depict her psychiatric sessions. Like Samara's curse, these sessions have been recorded on VHS videotapes, but by the psychiatrists in charge of her care. Unlike Samara's tape, these tapes not only have control tracks, but are obsessively marked by session numbers which place them in linear sequence, technologically imposing linear temporal continuity upon the child while aestheticizing the disciplinary, medical gaze to which Samara

8 The field of media archaeology has since started to examining this gap, addressing what James Newman describes as 'the complexity of obsolescence as a lived experience, and the ecology of contemporary media as one in which old and new rub along together, each informing one another and bestowing meanings upon one another' $(2012,87)$. 
was subjected while alive. In Discipline and Punish, Foucault suggests that the medical gaze intends to "position the constitution of the individual as a describable, analysable object. [...] a case which at one and the same time constitutes an object for a branch of knowledge and a hold for a branch of power' $(1995,191)$. The tapes of Samara's psychiatric sessions clearly function in this way, representing the adult's quest to forcibly re-situate the child into his own, rational discourse: to excise her of her irrational power and reinscribe her as a comprehensible, controllable object of the adult gaze.

The session video that is depicted in the film positions the viewer in parallel with the faceless psychiatrist, a seemingly omnipotent figure whose gaze is synonymous with that of the camera recording the session. Emphasizing Samara's colonization by the adult's gaze, she appears not just in front of the psychiatrist in physical space, but on the screen of the television monitor which sits upon his desk. She is thus captured in a layered mise en abyme of adult frames: the psychiatrist's gaze and that of the camera recording her session; the television monitor on his desk; the diegetic television screen on which Rachel watches the session tape in this scene; by Rachel's own gaze; and finally, she is contained by the viewer's own screen and gaze in our real space (Fig. 16).

The Droste effect created by this layering of frames emphasizes how the child is obsessively captured within the boundaries of the adult's gaze in an attempt to counteract her own empowerment of the mediated image. As well as being filmed, surveyed, and interviewed, Samara is also shown with electrocardiogram (ECG) monitors attached to her torso and head, as the medical gaze becomes inscribed upon the girl's body. In fact, the ECG cords trail off from her body to make it seem as though she is tied to or 'plugged in' to the wall of her padded cell. Throughout the video, she sits meekly in the middle of the room, passively averting the psychiatrist's all-encompassing gaze. The psychiatrist talks to her in condescending tones, saying 'you love your Mummy and Daddy? Don't you? And you don't want to hurt anyone, do you?' When we first witness this video, Samara sadly replies, 'But I do, and I'm sorry, it won't stop', her voice suffused with guilt as she seems to be, under the adult's penetrative watch, a powerless victim of her pathology, from which the adult promises to save her. Indeed, interspersed with the images from the videotape are close-ups of Rachel's face as she reacts to the session, watching the child with pity and shaking her head in dismay. After Rachel recovers Samara's corpse just prior to the twist in the final minutes of the film, Rachel sighs '[Samara] just wanted to be heard. Sometimes children yell or cry or draw pictures.' Thus, despite all that she has experienced, Rachel sublimates Samara's powerful images within the 
realm of rational adult knowledge, positioning them as fragmented cries for help borne of a naive childish psyche, to be interpreted and responded to by the superior knowledge of the adult.

However, Samara comes to overpower this penetrative and patronizing adult gaze. Her own uncanny cursed tape, made up of ambiguous and surrealist ${ }^{9}$ images with no coherent flow, stands in stark opposition to the clinical, explanatory session tapes - the two videotapes thus express the competing discourses of the adult and the child. Samara symbolically ejects the clinical adult gaze from her body on her cursed videotape, in an extreme-close up showing an ECG cable being pulled violently out of her throat and through her mouth. Later in the film, Rachel herself is forced to echo this evacuation of adult discourse when she also violently regurgitates an ECG cable. As it finally starts to dawn on Rachel in the film's final moments that the child possesses a power that she has failed to appreciate and is unable to subdue, brief images of Samara's psychiatric session are replayed: it is implied that Rachel is remembering the video, as the images from the session tape take over the screen and the audience too is impelled to recall these moments from earlier in the narrative. Yet this time, the diegetic camera recording the sessions has been eradicated, removing the smaller image of Samara on the psychiatrist's television screen from the frame and thus undermining the power of his gaze. Samara is now filmed in direct close-up. The child utters the same words that she spoke in response to the psychiatrist's questioning earlier in the film ('You don't want to hurt anyone, do you?'): 'I do, and I'm sorry. It won't stop.' This time, instead of passively avoiding eye contact, she stares directly at the camera and viewer - harshly enunciating the words as a direct threat, rather than a helpless, guilt-riddled admission. The 'victimized' child's unacknowledged agency and power is thus finally unveiled.

This replaying of the scene stripped of the mise en abyme of adult gazes and frames - which served to position the actual Samara as a tiny, blurred figure in the background of the image - incarnates the adult's belated recognition of the child's true intentions and power (Fig. 16). Samara subverts the assumption that she is the hopeless victim of her pathology, exposing that her wrath is wilful and unstoppable despite the subjugating efforts of the adults who purport to care for her. The scene thus crystallizes the horrifying process at the heart of THE RING's depiction of progress in disarray. The adults' recalcitrance to come to terms with the child's power indicates

9 Lowenstein (2015) studies the film's surrealist aesthetics, and suggest that surrealism functions as an intertextual link between the Japanese and American versions. 


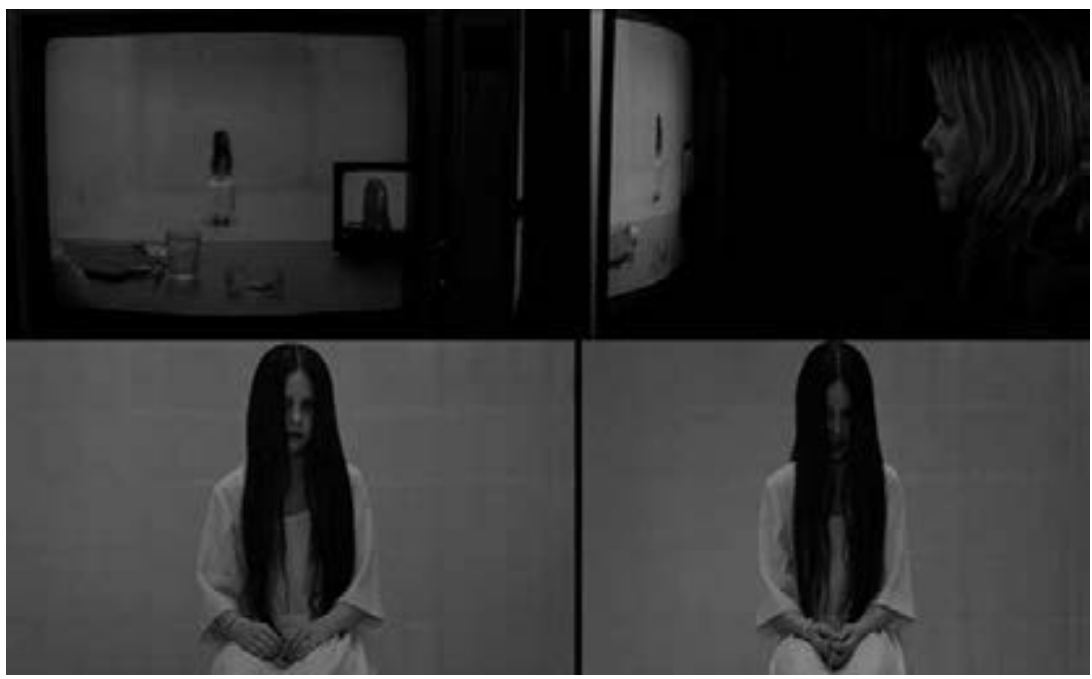

Figure 16. Samara is captured by a mise-en-abyme of adult gazes when her session tape is first depicted (top) and the replaying of the tape at the end of the film with the eradication of adult frames (bottom) in THE RING.

their inability to grasp the powerful becomings of the child freed from modernist adult discourse: her simultaneous analogue/corporeal decay and becoming-digital heralds the obsolescence of the linear teleologies of growing up and rational progress, and thus the decline of the adult's unquestioned dominion over the cultural function and personal trajectories of childhood.

\section{Conclusion}

As is exemplified by The OTHERS and The RING, when the uncanny child is deterritorialized from clear and specific cultural grounding, she becomes implicated in broad anxieties associated with the conceptual and technological shifts of the early 21 st century. Thus, instead of working through traumas of the adult protagonist's own mind or submerged beneath specific sociohistorical narratives - as is the case with the films analysed in this book's previous sections - the transnational uncanny child's association with trauma is consciously developed on the child's own terms, presenting a vision of childhood which disassembles the previously unquestioned ideological braiding of growing up with optimistic, 'fixed' images of progress and futurity. As a result, these films suggest a burgeoning rethinking of the child's symbolic function in the early years of the 21st century. 
Although frightening, these child characters play out a dramatic break from the concept of the passive, innocent child waiting to be moulded by adult ideology, suggesting that this model of childhood is becoming outmoded - a coming undone that is expressed by these figures' embodiments of decline and decay, and subsequent subversions of futurity and rational progress. As is emphasized in varying contexts throughout the work of Deleuze, Edelman, and Trigg, it is just such uncomfortable dislocations from existing ideological frameworks - interruptions to the process whereby we craft visions of the future that reflect and serve our own image, the conditions of the adult's present - that open a space for conceptual change. As Deleuze theorist Elizabeth Grosz puts it:

political and cultural struggles are all, in some sense, directed to bringing into existence futures that dislocate themselves from the dominant tendencies and forces of the present. [...] The more we affirm the value of the nick, the cut, or rupture, the more we revel in the untimely and the more we make ourselves untimely. $(2004,14)$

The uncanny children of transnational horror films revel in such deterritorialized spaces of 'untimely' becoming, unhinged as they are from fixed sociohistorical trajectories and teleologies. Rather than re-territorializing this figure into linear narratives that serve the needs of the adult's present, THE OTHERs and THE RING sustain the subversive qualities of this temporal rupture. By dramatically playing out millennial anxieties about the decline of rational progress through the child, these films position the collapse of modernist, adult-centric discourse as a terrifying opportunity for the uncanny child's chronological disjunction to reign supreme. In so doing, these films not only point to the ontological tensions associated with shifting understandings of childhood in the early 21st century, but to the generative potential represented by the conceptual untethering of childhood from growing up and fixed images of progress.

\section{Works Cited}

Balmain, Colette. 'Lost in Translation: Otherness and Orientalism in THE RING.' Diagesis: The Journal of the Association for Research into Popular Fictions Special Horror Edition (2004): 69-77. Web. 30 Sep. 2014.

Benson-Allott, Caetlin. Killer Tapes and Shattered Screens: Video Spectatorship from VHS to File Sharing. Berkeley: University of California Press, 2013. Print. 
—." "Before You Die, You See the Ring”: Notes on the Imminent Obsolescence of VHS.' The Scary Screen: Media Anxiety in THE RING. Ed. Kristen Lacefield. Surrey: Ashgate Publishing, 2010. 116-140. Print.

Dinerstein, Joel. 'Technology and its Discontents: On the Verge of the Posthuman.' American Quarterly 58.3 (2006):569-595.JSTOR Arts and Sciences. Web. 30 Jan. 2015 .

Edelman, Lee. No Future: Queer Theory and the Death Drive. Durham: Duke University Press, 2004. Print.

Elsaesser, Thomas. 'Truth or Dare: Reality Checks on Indexicality, or the Future of Illusionism.' Cinema Studies into Visual Theory? Ed. Anu Koivunnen and Astrid Soderbergh Widding. Turku, Finland: D-Vision, 1998. 31-50. Print.

Foucault, Michel. Discipline and Punish: The Birth of the Prison. Trans. Alan Sheridan. London: Vintage, 1995. Print.

Grosz, Elisabeth. The Nick of Time: Politics, Evolution, and the Untimely. Durham: Duke University Press, 2004. Print.

Holm, Nicholas. 'Ex(or)cising the Spirit of Japan: Ringu, The Ring, and the Persistence of Japan.' Journal of Popular Film and Television 39.4 (2011): 183-192. Proquest International Index to Performing Arts. Web. 30 Sep. 2014.

Knowles, Kim. 'Analog Obsolescence and the "Death of Cinema" Debate: The Case of Experimental Film.' Proceedings of the Media in Transition 7 Conference: Unstable Platforms: The Promise and Perils of Transition, 13-15 May 2011. Ed. Brad Seawell. Cambridge: Massachusetts Institute of Technology, 2011. Print.

Lacefield, Kristen, ed. 'Introduction: Media Anxiety and the RING Phenomenon.' The Scary Screen:Media Anxiety in The RING. Surrey: Ashgate Publishing, 2010. 1-28. Print.

Lowenstein, Adam. 'Globalized Spectatorship: Ring Around the Superflat Global Village: J-Horror Between Japan and America.' Dreaming of Cinema: Spectatorship, Surrealism and the Age of Digital Media. New York: Columbia University Press, 2015. 79-116. Print.

Marks, Laura U. Touch: Sensuous Theory and Multisensory Media. Minneapolis: The University of Minnesota Press, 2002. Print.

Meikle, Denis. The Ring Companion. London: Titan Books, 2005. Print.

Newman, James. Best Before: Videogames, Supersession and Obsolescence. London: Routledge, 2012. Print.

Phu, Thy. 'Horrifying adaptations: RINGU, THE RING, and the cultural contexts of copying.' Journal of Adaptation in Film and Performance 3.1 (2010): 43-58. Print.

Schrey, Dominik. 'Analogue Nostalgia and the Aesthetics of Digital Remediation.' Media and Nostalgia: Yearning for the Past, Present and Future. Ed. Katharina Niemeyer. Basingstoke: Palgrave Macmillan, 2014. 27-38. Print. 
'The 20 Highest Grossing Horror Films of All Time.' BusinessInisder.com.au, John Lynch. 2017. Web. 30 Dec. 2017.

Tomlinson, Niles. 'Of Horse Blood and TV Snow: Abhuman Reproduction in THE RING.' The Scary Screen: Media Anxiety in The RING. Ed. Kristen Lacefield. Surrey: Ashgate Publishing, 2010. 175-190. Print.

Trigg, Dylan. The Aesthetics of Decay: Nothingness, Nostalgia, and the Absence of Reason. New York: Peter Lang, 20o6. Print.

Wee, Valerie. Japanese Horror Films and their American Remakes. London: Routledge, 2013. Print.

\section{Filmography}

The Others [Los otros]. Dir. Alejandro Amenábar. 2001. Optimum Home Entertainment, 2011. Blu-ray DVD.

Ringu. Dir. Hideo Nakata. 1998. DreamWorks Video, 2000. DVD.

The RING. Dir. Gore Verbinski. 2002. DreamWorks Pictures, 2013. Blu-ray DVD. 


\title{
Conclusion
}

\begin{abstract}
The conclusion reflects upon how the millennial turn represented a moment of historical uncertainty and transition, and incited a renewed consideration of what the child 'means' to existing cultural and epistemological frameworks of futurity and progress.
\end{abstract}

Keywords: Uncanny child, Futurity, Children's culture, Millennial turn

The myriad uncanny children who stared out from and erupted through our screens during the millennial turn herald our shifting sense of what the child means to adult-sanctioned narratives of personal and national identity. By harnessing the temporally dissonant mechanisms of traumatic experience, these figures endow the innocent and benign 'sleep of reason', which Rousseau famously placed at the core of our understandings of childhood, with potent, monstrous charge. To return to the words of Goya, 'the sleep of reason produces monsters'. It is this deeply uncanny subversion of childhood innocence that structures all of the films analysed throughout this book. These children do not simply vacillate between innocence and its opposite, evil. Instead, they enact a dialectic movement between heimlich to unheimlich from within the bounds of childhood's traditional definition - as innocent, naïve other to adulthood's knowledgeable, powerful rationality - exposing the uneasiness usually veiled beneath conventional understandings of the child.

To emphasize the implications of this shift, I return to the work of Edelman and Stockton outlined in the Introduction. Edelman suggests doing away with our value in the child for the way it affirms current social structures and politics: 'we are no more able to conceive of a politics without a fantasy of the future than we are able to conceive of a future without the figure of the child' $(2004,11)$. Yet the transnational, millennial uncanny child cycle unravels the child's entwinement with this narrow fantasy of the future. As Stockton suggests, 'there are other ways to circumvent "the child." One

Balanzategui, J., The Uncanny Child in Transnational Cinema: Ghosts of Futurity at the Turn of the Twenty-First Century, Amsterdam University Press, 2018.

DOI: $10.5117 / 9789462986510 / \mathrm{CONC}$ 
could explore the elegant, unruly contours of growing that don't bespeak continuance' $(2009,13)$. The uncanny children of this transnational body of films enact the very 'moving suspensions and shadows of growth' (2009, 13) to which Stockton refers. In various ways, all of the figures discussed in this book empower the ideo-aesthetic properties of past traumas, a process that functions as a denial of 'futurity's unquestioned value' (Edelman, $2004,4)$, while serving narratively and aesthetically to underscore the adult protagonist's - and viewer's - disastrously belated recognition of the power, knowledge, and insight of the child. As a result, uncanny child characters refuse to fit within adult-centric models of childhood and temporal continuity, turning the very traumas inflicted upon them as a result of such ideology back upon adult society to rail against the child's overdrawn conceptual function.

Thus, the uncanny child plays out a burgeoning awareness of the impending obsolescence of long-standing modernist understandings of childhood that subjugate the child as 'innocent' and 'naïve', and which, as justified by this posited emptiness, force her to fit our own visions of social development and futurity. Yet, as Jenks suggests:

to abandon a shared category of the child is to confront a daunting paradox. If as adults we do just that, what happens to the concept of 'childhood', through which we, as adults, see ourselves and our society's past and future? If [...] the concept of 'childhood' serves to articulate not just the experience and status of the young within modern society but also the projections, aspirations, longings and altruism contained within the adult experience then to abandon such a conception is to erase our final point of stability and attachment to the social bond. In a historical era during which issues of identity and integration are, perhaps, both more unstable and more fragile than at any previous time such a loss would impact upon the everyday experience of societal members with disorienting consequences. $(2005,135)$

These films express the feelings of dread and fear that accompany an everheightening realization at the turn of the millennium that the child - one of our key means of conceptualizing the relations between self and society, the individual and the collective, growth and cultural progress - can no longer function as an empty vessel for adult meaning. But these films also start to work through ways forward, by challenging hierarchical binaries of child and adult. The transnational films discussed in Section Four signal a period of baroque embellishment and self-reflexivity within the uncanny 
child cycle. However, this by no means marked the end of the movement, but instead evidenced the start of a self-aware consideration of the significance of this trope as the 21st century progressed. Sequels, remakes, and reboots of many of the films discussed throughout this book have proliferated throughout the first two decades of the 21st century, including a remake of Poltergeist (Poltergeist [Gil Kenan, 2015]), three sequels to Insidious (Insidious: CHAPTER 2 [James Wan, 2013], Insidious: ChAPTER 3 [Leigh Whannell, 2015] and Insidious: The LAst Key [Adam Robitel, 2018]), two American sequels to The RING (The RING Two [Hideo Nakata, 2005] and RINGS [F. Javier Gutiérrez, 2017]), and three Japanese sequels to the original Ring cycle (SADAKO 3D [Tsutomu Hanabusa, 2012], SADAKo 3D 2 [Hanabusa, 2012], and a RING and Ju-ON crossover, SADAKO vs KAYAKo [Kōji Shiraishi, 2016]), to name but a few.

Yet, beyond the franchises these millennial uncanny child figures sparked, in the 2010 a recurring preoccupation with the power of children's culture has emerged in supernatural horror cinema, a theme that extends upon uncanny child cinema of the millennial turn. These films include Don'т BE Afraid of the Dark (Troy Nixey, 2010, US/Mexico), Mama (Andrés Muschietti, 2013, Canada/Spain/US) - both of which were produced by Guillermo del Toro - Intruders (Juan Carlos Fresnadillo, 2011, US/Spain/Britain), Sinister (Scott Derrickson, 2012, US/Britain), and ThE BABADOoK (Jennifer Kent, 2014, Australia/Canada). In all of these films, a bogeyman of the child's imagination, initially belittled or dismissed by the adult characters, comes to represent a direct threat not just to the children, but to the adult characters as well. These films thus enact a shift in the traditional power balance between children and their adult guardians, whereby 'childish' fears become adult ones - a subversion of the very connotations of childishness.

All of these films play out the fear that the supposedly fictional, 'childish' bogeymen of children's culture are slipping into the adult real in insidious ways, and that it is their very depiction in children's art and stories which functions as the channel for this slippage. Such a fixation is captured by some of the taglines of these films, which include 'Fear is Never Just Make Believe' (Don't Be Afraid of the Dark), 'The Nightmare is Real' (INTRUders), 'Once you see him, nothing can save you' (SINISTER), and 'If it's in a word, or in a book, you can't get rid of The Babadook' (THE BABADOOK). These films suggest that adult culture's dismissal of the power of children's culture will be our undoing, allowing bogeymen to creep into our realities right under our noses, empowered through our very denial of their existence. This is made explicit in a recurring line in THE BABADOOK: 'The more you deny me, the stronger I get.' The sleep of reason produces monsters, but they overtly 
become monsters not simply of childhood, but shared between child and adult, suggesting a renunciation of the empty inscrutability of childhood 'innocence' and thus the beginnings of a breakdown in the overdetermined binary separation between child and adult realms. This continuing popcultural preoccupation is further suggested by the recent emergence of self-reflexively nostalgic horror texts such as IT (Muschietti, 2017) and the Netflix television show STRANGER Things (The Duffer Brothers, 2016-2017) that are child-centred - in terms of perspective, character, and culture - yet are ostensibly aimed at adult audiences. In different ways, all of these texts suggest the continued vitality and cultural magnitude of the uncanny child figure in the 2010 s.

Ultimately, the millennial turn represented a felt moment of historical uncertainty and transition that incited a renewed consideration of what the child 'means' to existing social and conceptual frameworks - that is, adult, frameworks - of meaning and identity. Traumatized and victimized, the child figures that emerged during this period are captured breaking loose from their subjugated position, harnessing the powerful incoherence and temporal dissonance of their trauma to unseat the primacy of adult knowledge. The continued cultural fixation with uncanny children at the end of the second decade of the 21st century suggests the important cultural work this figure continues to perform. Initially a vision of cultural otherness that frighteningly exposed the tangled closeness and distance of child-adult conceptual relations, the uncanny child is gradually unravelling the very assumptions upon which this unbalanced dichotomy is constituted.

\section{Works Cited}

Edelman, Lee. No Future: Queer Theory and the Death Drive. Durham: Duke University Press, 2004. Print.

Jenks, Chris. Childhood. $2^{\text {nd }}$ Ed. New York: Routledge, 2005. Print.

Rousseau, Jean-Jacques. Emile, Or on Education. 1763. Sioux Falls: NuVision Publications, 2007. Print.

Stockton, Kathryn Bond. The Queer Child, or Growing Sideways in the Twentieth Century. Durham: Duke University Press, 2009. Print.

\section{Filmography}

The BABAdook. Dir. Jennifer Kent. Causeway Films, 2014. Film. Don't Be Afraid of the Dark. Dir. Troy Nixey. Miramax, 2010. Film. Insidious: Chapter Two. Dir. James Wan. FilmDistrict, 2013. Film. 
Insidious: Chapter Three. Dir. Leigh Whannell. Blumhouse Productions, 2015. Film.

Insidious: The Last Key. Dir. Adam Robitel. Blumhouse Productions, 2018. Film. Intruders. Dir. Juan Carlos Fresnadillo. Antena 3 Films, 2011. Film.

IT. Dir. Andrés Muschietti. Warner Bros. Pictures, 2017. Film.

Mama. Dir. Andrés Muschietti. Universal Pictures, 2013. Film.

Poltergeist. Dir. Gil Kenan. $20^{\text {th }}$ Century Fox, 2015. Film.

RINGS. Dir. Javier Gutiérrez. Parkes + MacDonald Image Nation, 2017. Film.

The Ring Two. Dir. Hideo Nakata. 2005. DreamWorks Pictures, 2013. DVD.

SADAKo 3D. Dir. Tsutomu Hanabusa. Kadakowa Pictures, 2012. Film.

SADAKo 3D 2. Dir. Tsutomu Hanabusa. Kadakowa Pictures, 2013. Film.

SADAKo vs KaYAKo. Dir. Kōji Shiraishi. Kadakowa, 2016. Film.

Sinister. Dir. Scott Derrickson. Alliance Films, 2012. Film.

Stranger Things. Dir. Matt and Ross Duffer. Netflix, 2016-2017. Television Program.

\section{Artworks}

Goya y Lucientes, Francisco José. The Sleep of Reason Produces Monsters. 1799. Etching, aquatint, drypoint, and burin. The Metropolitan Museum of Art, New York. 



\section{Works Cited}

Abe, Kobo. Inter Ice Age 4. Trans. Dale Saunders. 1958. New York: Perigee Books, 1981. Print.

Akinari, Ueda. Ugetsu Monogatari, or Tales of Moonlight and Rain. 1776. Trans. and

Ed. Leon M. Zolbrod. London: George Allen \& Unwin Ltd., 1974. Print.

Akutagawa, Ryunosuke. Kappa. 1927. Trans. Geoffrey Bownas. London: Peter Owen Publishers, 2009. Print.

Aldana Reyes, Xavier. Spanish Gothic: National Identity, Collaboration and Cultural Adaptation. London: Palgrave Macmillan, 2017. Print.

Allen, Nick. 'Hollywood Says Goodbye to Celluloid.' The Telegraph.com, Telegraph UK. 25 Dec. 2011. Web. 30 Sep. 2014.

Allison, Anne. Permitted and Prohibited Desires: Mothers, Comics and Censorship in Japan. Berkeley: University of California Press, 1996. Print.

-.Precarious Japan. Durham: Duke University Press, 2013. Print.

Aguilar, Paloma. 'Justice, Politics and Memory in the Spanish Transition.' The Politics of Memory: Transitional Justice in Democratizing Societies. Ed. Alexandra de Brito, Carmen Gonzaléz-Enríquez, and Paloma Aguilar. Oxford: Oxford University Press, 2001. 92-118. Print.

Aguirresarobe, Javier. 'Javier Aguirresarobe, ASC, AEC: Interviews with ASC Members.' Theasc.com, American Society of Cinematographers. Feb. 2014. Web. 30 Sep. 2014.

Arai, Andrea G. 'Notes to the Heart: New Lessons in National Sentiment and Sacrifice from Recessionary Japan.' Global Futures in East Asia: Youth, Nation and the Economy in Uncertain Times. Ed. Ann Anagost, Andrea Arai, and Hai Ren. Stanford: Stanford University Press, 2013. 174-196. Print.

-.The Strange Child: Education and the Psychology of Patriotism in Recessionary Japan. Stanford: Stanford University Press, 2016. Print.

—.'The Wild Child in 199os Japan.' Japan After Japan: Social and Cultural Life from the Recessionary 199os to the Present. Ed. Tomiko Yoda and Harry Harootunian. Durham: Duke University Press, 2006. Print.

Ariès, Philippe. Centuries of Childhood: A Social History of Family Life. Trans. Robert Baldick. New York: Alfred A. Knopf, 1962. Print.

Balmain, Colette. 'Inside the Well of Loneliness: Towards a Definition of the Japanese Horror Film.' Electronic Journal of Contemporary Japanese Studies 3 (May 2006): n.p. Web. 30. Sep. 2014.

—.Introduction to Japanese Horror Film. Edinburgh: Edinburgh University Press, 2008. Print. 
-.'Lost in Translation: Otherness and Orientalism in The RING.' Diagesis: The Journal of the Association for Research into Popular Fictions Special Horror Edition (2004): 69-77. Web. 30 Sep. 2014.

—.'Oriental Nightmares: The "Demonic" Other in Contemporary American Adaptations of Japanese Film.' Something Wicked This Way Comes: Essays on Evil and Human Wickedness. Ed. Colette Balmain and Lois Drawmer. Amsterdam: Rodopi, 2009. Print.

Baudrillard, Jean. The Illusion of the End. Trans. Chris Turner. Stanford: Stanford University Press, 1994. Print.

—.'The Millennium, or the Suspense of the Year 200o.' Trans. Julie Witwer. The Jean Baudrillard Reader. Ed. Steve Redhead. New York: Columbia University Press, 2008. 153-170. Print.

Bauman, Zygmunt. Liquid Life: Living in the Age of Uncertainty. Cambridge: Polity, 2007. Print.

Bays, Jan Chozen. Jizō Bodhisattva: Guardian of Children, Travelers and Other Voyagers. Boston: Shambhala Publications, 2002. Print.

Bello, Walden. 'The Hashimoto Controversy and Japan's Failure to Come to Terms with its Past.' Foreign Policy in Focus, Institute for Policy Studies. 22 May 2013. Web. 27 Oct. 2014.

Belton, John. 'Digital 3D Cinema: Digital Cinema's Missing Phase.' Film History 24 (2012): 187-195. Print.

Benson-Allott, Caetlin. Killer Tapes and Shattered Screens: Video Spectatorship from VHS to File Sharing. Berkeley: University of California Press, 2013. Print.

—." "Before You Die, You See the Ring": Notes on the Imminent Obsolescence of VHS.' The Scary Screen: Media Anxiety in THE RING. Ed. Kristen Lacefield. Surrey: Ashgate Publishing, 2010. 116-140. Print.

Bergson, Henri Louis. Matter and Memory. Trans. Nancy M. Paul and W. Scott Palmer. New York: Dover Philosophical Classics, 2004. Print.

Besas, Peter. Behind the Spanish Lens: Spanish Cinema under Fascism and Democracy. London: Arden Press, 1988. Print.

Bettelheim, Bruno. The Uses of Enchantment: The Meaning and Importance of Fairy Tales. 1976. New York: Vintage Books, 2010. Print.

Blake, Linnie. Wounds of Nations: Horror Cinema, Historical Trauma and National Identity. Manchester: Manchester University Press, 2008. Print.

Blakemore, Bill. 'Kubrick's Shining Secret: Film's Hidden Horror is the Murder of the Indian.' The Washington Post, 12 July (1987): 1-6. Web. William Blakemore. com. 30 Sep. 2014.

Blum, Virginia. Hide and Seek: The Child between Psychoanalysis and Fiction. Champaign: The University of Illinois, 1995. Print.

Bowers, Faubion.Japanese Theatre. Rutland: Charles E. Tuttle Co., 1974. Print. 
Boym, Svetlana. 'Nostalgia and its Discontents.' The Hedgehog Review 9.2 (2007): 7-18. EBSCO Host Humanities International Complete. Web. 30 Sep. 2014.

Britton, Andrew. 'Blissing Out: The Politics of Reaganite Entertainment (1986).' Britton on Film: The Complete Film Criticism of Andrew Britton. Ed. Barry Keith Grant. Detroit: Wayne State University Press, 2009. 97-154. Print.

Bruhm, Steven. 'Nightmare on Sesame Street: or, the Self Possessed Child.' Gothic Studies 8.2 (2006): 98-210. EBSCO Host Humanities International Complete. Web. 30 Sep. 2014.

Buse, Peter and Stott, Andrew, eds. Ghosts: Deconstruction, Psychoanalysis, History. Houndsmills: Macmillan Press, 1999. Print.

Caruth, Cathy. Unclaimed Experience: Trauma, Narrative, and History. Baltimore: The John Hopkins University Press, 1996. Print.

-.'Introduction: Trauma and Experience.' Trauma: Explorations in Memory. Ed. Cathy Caruth. Baltimore: The John Hopkins Univeristy Press, 1995. Print.

Carr, Raymond. Modern Spain, 1875-1980. New York: Oxford University Press, 1980. Print. Carroll, Noël. The Philosophy of Horror, or Paradoxes of the Heart. New York: Routledge. 1990. Print.

Carter, Jimmy. 'The Crisis of Confidence.' 1979. The 1970s. Ed. Neil Hamilton. New York: Fact on File Inc., 2006. 356-357. Print.

'China protests at Japanese PM's latest WW2 shrine tribute.' TheGuardian.com, The Guardian News and Media. 17 Oct. 2014. Web. 30 Dec. 2014.

Clover, Carol. Men, Women and Chainsaws: Gender in the Modern Horror Film. Princeton: Princeton University Press, 1992. Print.

Coerr, Eleanor. Sadako. Illust. Ed Young. New York: G.P. Putnam's Sons, 1993. Print. -.Sadako and the Thousand Paper Cranes. 1977. New York: Puffin Books, 1999. Print. Cornyetz, Nina and Vincent, J. Keith. 'Japan as Screen Memory: Psychoanalysis and History.' Perversion and Modern Japan: Psychoanalysis, literature, culture. Ed. Nina Cornyetz and J. Keith Vincent. London: Routledge, 2010. 1-21. Print. Cousins, Mark. The Story of Film. London: Pavilion, 2013. Print.

Creed, Barbara. The Monstrous-Feminine: Film, Feminism, Psychoanalysis. London: Routledge, 1993. Print.

Deleuze, Gilles. Cinema 2: The Time Image. 1985. Trans. Hugh Tomlinson and Robert Galeta. Minneapolis: The University of Minnesota Press, 1997a. Print.

—.The Logic of Sense. 1969. Trans. Mark Lester. Ed. Constantin V. Boundas. London: Continuum, 2004. Print.

—.Negotiations, 1972-199o. Trans. Margin Joughin. New York: Columbia University Press, 1997b. Print.

Deleuze, Gilles and Guattari, Félix. Anti-Oedipus. 1984. London: Continuum, 2004. Print. Deleyto, Celestino. 'Rewriting Spain: Metafiction and Intertextuality in Saura's Carmen.' Journal of Hispanic Research 2.2 (1994): 237-247. Print. 
Del Toro, Guillermo. Interview by Mark Kermode. 'Guillermo del Toro.' The Guardian.com, The Guardian News and Media. 21 Nov. 2006. Web. 22 May 2015.

--.Interview by Ryan Turek. 'On the Set: Guillermo del Toro, Jessica Chastain on the Mysteries of Mama.' Shocktillyoudrop.com, Shock Till You Drop. 23 Oct. 2012. Web. 30 Sep. 2014.

Derrida, Jacques. The Gift of Death. Trans. David Willis. Chicago: The University of Chicago Press, 1996. Print.

Diamond, Nicola. 'The Body, Emotion and Cinema: Perspectives on Cinematic Experiences of das Unheimlich and Estranged Body States in The Others.' Media and the Inner World: Psycho-cultural Approaches to Emotion, Media and Popular Culture. Ed. Caroline Bainbridge and Candida Yates. New York: Palgrave Macmillan, 2014. 82-98. Print.

Dinerstein, Joel. 'Technology and its Discontents: On the Verge of the Posthuman.' American Quarterly 58.3 (2006):569-595.JSTOR Arts and Sciences. Web. 30 Jan. 2015.

D'Lugo, Marvin. Guide to the Cinema of Spain. Westport: Greenwood Publishing Group. 1997. Print.

Doak, Kevin. Dreams of Difference: The Japan Romantic School and the Crisis of Modernity. Berkeley: University of California Press, 1994. Print.

Doi, Takeo. The Anatomy of Dependence: The Key Analysis ofJapanese Behaviour. 1971. New York: Kodansha America, 2001. Print.

Dona, Giorgia. 'Collective suffering and Cyber-memorialisation in Post-genocide Rwanda.' Trauma, Media, Art: New Perspectives. Ed. Mick Broderick and Antonio Traverso. Cambridge: Cambridge Scholars Press, 1999. Print.

Edelman, Lee. No Future: Queer Theory and the Death Drive. Durham: Duke University Press, 2004. Print.

Elsaesser, Thomas. 'Truth or Dare: Reality Checks on Indexicality, or the Future of Illusionism.' Cinema Studies into Visual Theory? Ed. Anu Koivunnen and Astrid Soderbergh Widding. Turku, Finland: D-Vision, 1998. 31-50. Print.

Enns, Anthony. 'The Horror of Media: Technology and Spirituality in the RINGU Films.' The Scary Screen: Media Anxiety in THE RING. Ed. Kristen Lacefield. Surrey: Ashgate Publishing Ltd., 2010. 29-44. Print.

Evans, Peter. 'Marisol: The Spanish Cinderella.' Spanish Popular Cinema. Ed. Antonio Lázaro-Reboll and Andrew Willis. Manchester: Manchester University Press, 2004. 129-151. Print.

Ezra, Elizabeth and Rowden, Terry, eds. Transnational Cinema: The Film Reader. London: Routledge, 2006. Print.

Faiola, Anthony. 'Youth Violence Has Japan Struggling For Answers.' The Washington Post.com, The Washington Post. 9 Aug. 2004. Web. 30 Sep. 2014.

Fass, Paula S. Children of a New World: Society, Culture, and Globalization. New York: New York University Press, 2007. Print. 
Faulkner, Sally. A History of Spanish Film: Cinema and Society 1910-2000. London: Bloomsbury Academic, 2013. Print.

'Fertility Rate Total (Births Per Woman).' Worldbank.org. The World Bank. 2015. Web. 30 Jan. 2015.

Field, Norma. 'The Child as Laborer and Consumer: The Disappearance of Childhood in Contemporary Japan.' Children and the Politics of Culture. Ed. Sharon Stephens. Princeton: Princeton University Press, 1995. Print.

Figal, Gerald. Civilization and Monsters: Spirits of Modernity in Modern Japan. Durham: Duke University Press, 1999. Print.

Fitzgerald, Bridget. 'Children of Lesbian and Gay Parents: A Review of the Literature.' Marriage and Family Review. 29.1 (1999): 57-75. Taylor \& Francis Online. Web. 30 Sep. 2014.

Fletcher III, W. Miles and von Staden, Peter W. 'Epilogue: retrospect and prospects: the significance of the 'lost decades' in Japan.' Asia Pacific Business Review 18.2 (2012): 275-279. Taylor and Francis Journals Complete. Web. 30 Sep. 2014.

Foucault, Michel. Discipline and Punish: The Birth of the Prison. Trans. Alan Sheridan. London: Vintage, 1995. Print.

—.Language, Counter-Memory, Practice. Ed. Donald F. Bouchard. New York: Cornell University Press, 1977. Print.

—.'Society Must Be Defended': Lectures at the Collège de France 1975-1976. Trans. David Macey. New York: Picador, 2003. Print.

Fraser, J.T. 'An Embarrassment of Proper Times: A Foreword.' Time: The Modern and Postmodern Experience. By Helga Nowotny. Trans. Neville Plaice. Cambridge: Polity Press, 1996. 1-6. Print.

Freeley, Dustin. 'The Monstrous Child: Replacement and Repetition in THE ShInING.'Monstrous Children and Childish Monsters: Essays on Cinema's Holy Terrors. Ed. Markus P.J. Bohlmann and Sean Moreland. Jefferson: McFarland, 2015. 160-172. Print.

Freud, Sigmund. 'Analysis of a Phobia in a Five Year Old Boy.' 1925. The Standard Edition of the Complete Psychological Works of Sigmund Freud, Volume X. Two Case Histories: 'Little Hans' and the 'Rat Man.' Trans. Alix and James Strachey. London: Vintage, 2001. 5-21. Print.

—.'Beyond the Pleasure Principle.' 1920. The International Psychoanalytical Library, No. 4. Ed. Ernest Jones. Trans. C. J. M. Hubback. London: The International Psychoanalytic Press, 1922. 1-84. Print.

—.Civilization and Its Discontents. 1930. Trans. David McLintock. New York: Penguin Books, 2002. Print.

—.'Screen Memories.' 1899. The Uncanny. Trans. David McLintock. New York: Penguin Books, 2003a. 1-22. Print. 
—.'The Uncanny.' 1919. The Uncanny. Trans. David McLintock. New York: Penguin Books, 2003b. 121-176. Print.

Goodman, Roger. Children of the Japanese State: The Changing Role of Child Protection Institutions in Contemporary Japan. Oxford: Oxford University Press, 200o. Print. Gould, Steven Jay. Questioning the Millennium: A Rationalist's Guide to a Precisely Arbitrary Countdown. New York: Harmony Books, 1997. Print.

Graham, Helen. 'Popular Culture in the "Years of Hunger."' Spanish Cultural Studies. Ed. Helen Graham and Jo Labanyi. Oxford: Oxford University Press, 1995. 237-245. Print.

Graham, Helen and Labanyi, Jo, eds. 'Culture and Modernity: The Case of Spain.' Spanish Cultural Studies. Oxford: Oxford University Press, 1995 1-20. Print.

Grosz, Elisabeth. The Nick of Time: Politics, Evolution, and the Untimely. Durham: Duke University Press, 2004. Print.

Halbwachs, Maurice. On Collective Memory. 1925. Ed. and Trans. Lewis A. Coser. Chicago: University of Chicago Press, 1992. Print.

Hammond, Philip. Media, War and Postmodernity. London: Routledge, 2007. Print. Hancock, David. 'The End of an Era Arrives as Digital Technology Displaces 35mm Film in Cinema Projection.' Technology.IHS, IHS Technology. 15 Nov. 2011. Web. 30 Sep. 2014.

Hand, Richard J. 'Aesthetics of Cruelty: Traditional Japanese Theatre and the Horror Film.' Japanese Horror Cinema. Ed. Jay McRoy. Edinburgh: Edinburgh University Press, 2006. 18-29. Print.

Hantke, Steffen, ed. 'They Don't Make ‘Em Like They Used To: On the Rhetoric of Crisis and the Current State of American Horror Cinema.' American Horror Film: The Genre at the Turn of the Millennium. Jackson: The University Press of Mississippi, 2010. vii-xxxii. Print.

-.Academic Film Criticism, the Rhetoric of Crisis, and the Current State of American Horror Cinema: Thoughts on Canonicity and Academic Anxiety.' College Literature 34.4 (2007): 191-202. EBSCO Host Humanities International Complete. Web. 30 Sep. 2014.

Haque, D. 'Horrific Reproductions: Pathology and Gender in Koji Suzuki's Ring Trilogy.' The Scary Screen: Media Anxiety in The RING. Ed. Kristen Lacefield. Surrey: Ashgate Publishing Ltd., 2010. 191-205. Print.

Hardcastle, Anne. 'Ghosts of the Past and Present: Hauntology and the Spanish Civil War in Guillermo del Toro's The DeviL's BAсквоNE.' Journal of the Fantastic in the Arts 15 (2005): 119-131. EBSCO Host Humanities International Complete. Web. 30 Sep. 2014.

Harwood, Sarah. Family Fictions: Representations of the Family in 1980 s Hollywood Cinema. London: Macmillan Press, 1997. Print. 
Haughton, Hugh. 'Introduction.' The Uncanny. By Sigmund Freud. Trans. David McLintock. New York: Penguin Books, 2003. vii-lx. Print.

Hearn, Lafcadio. Kwaidan: Stories and Studies of Strange Things. 1904. New York: Start Publishing LLC, 2012. Print.

Hess, Noel. 'THe SHIning: All Work and No Play...' International Journal of Psychoanalysis 91.2 (2010): 409-414. Wiley Online Library. Web. 30 Sep. 2014.

Higginbotham, Virginia. Spanish Film Under Franco. Texas: University of Texas Press, 1988. Print.

Hoile, Christopher. 'The Uncanny and the Fairy Tale in Kubrick's The SHining.' Literature/Film Quarterly 12.1 (1984):5-12. EBSCO Host Communication and Mass Media Complete. Web. 30 Sep. 2014.

Holm, Nicholas. 'Ex(or)cising the Spirit of Japan: Ringu, The Ring, and the Persistence of Japan.' Journal of Popular Film and Television 39.4 (2011): 183-192. Proquest International Index to Performing Arts. Web. 30 Sep. 2014

Hopewell, John. Out of the Past: Spanish Cinema After Franco. London: BFI, 1986. Print.

Houtman, Carol. 'Questions of Unreliable Narration in The Sixth Sense.' Scope: An Online Journal of Film Studies Nov. 2004: n.p. Web. 30 Sep. 2014.

Hultqvist, Kenneth and Dahlberg, Gunilla. eds. Governing the Child in the New Millennium. New York: RoutledgeFalmer, 2001. Print.

Igarashi, Yoshikuni. Bodies of Memory: Narratives of War in Postwar Japanese Culture, 1945-1970. Princeton: Princeton University Press, 2000. Print.

Ikeda, Yoshiko. 'Child Abuse and Child Abuse Studies in Japan.' Pediatrics International 37.2 (1995): 240-247. Wiley Online Journal. Web. 30 Sep. 2014.

James, Henry. The Turn of the Screw. 1898. Ed. David Bromwich. London: Penguin Classics, 2011. Print.

Jameson, Fredric. 'Historicism in The SHINING.' Signatures of the Visible. New York: Routledge, 1992. 82-98. Print.

'Japan PM Shinzo Abe visits Yasukuni WW2 Shrine.' BBC.com, BBC World News. 26 Dec. 2013. Web. 30 Sep. 2014.

'Imperial Rescript on Education making slow, contentious comeback.' JapanTimes. co.jp, Japan Times. 12 Apr. 2017. Web. 21 Apr. 2017.

Jenks, Chris. Childhood. $2^{\text {nd }}$ Ed. New York: Routledge, 2005. Print.

-.'The Pacing and Timing of Children's Bodies.' Governing the Child in the New Millennium. Ed. Kenneth Hultqvist and Gunilla Dahlberg. New York: RoutledgeFalmer, 2001. 68-84. Print.

Jenkins, Philip. Moral Panic: Changing Concepts of the Child Molester in Modern America. New Haven: Yale University Press, 1998. Print.

Jenner, Karen, ed. The 'Evil Child' in Literature, Film and Popular Culture. New York: Routledge, 2013. Print. 
-.Evil Children in the Popular Imagination. New York: Palgrave Macmillan, 2016. Print. Kafu, Nagai. 'The Fox.' 1909. Autumn Wind and Other Stories. Ed. and Trans. Lane Dunlop. North Clarendon: Charles E. Tuttle Publishing Company, 1994.11-30. Print. Kakuchi, Suvendrini. 'Youth murder shocks Japan.' AsiaTimes.com, Asia Times. 15 July 2003. Web. 25 Oct. 2013.

Kawakami, Ryoichi. Gakkō Hōkai [School Collapse]. Tokyo: Bungei Shunju, 1999. Print. Kendrick, James. 'A Return to the Graveyard: Notes on the Spiritual Horror Film.' American Horror Film: The Genre at the Turn of the Millennium. Ed. Steffen Hantke. Jackson: The University Press of Mississippi, 2010. 142-159. Print

Kermode, Mark. 'Review of Ringu.' Sight and Sound, BFI. 30 Sep. 200o. Web. 30 Sep 2014.

Kessen, William. 'The Child and Other Cultural Inventions.' The Child and Other Cultural Inventions. Ed. Frank S. Kessel and Alexander W. Siegel. New York: Praeger Publishers, 1983. 26-39. Print.

Kilker, Robert. 'All Roads Lead to the Abject: The Monstrous Feminine and Gender Boundaries in Stanley Kubrick's The SHINING.' Literature/Film Quarterly 34.1 (2006):54-64. Proquest International Index to Performing Arts. Web. 30 Sep. 2014. Kincaid, James. Erotic Innocence: The Culture of Child Molesting. Durham: Duke University Press, 1998. Print.

Kinder, Marsha. Blood Cinema: The Reconstruction of National Identity in Spain. Berkeley: The University of California Press, 1993. Print.

—.'Carlos Saura: The Political Development of Individual Consciousness.' Film Quarterly 32.3 (1979): 14-25.JSTOR Arts and Sciences III. Web. 30 Sep. 2014

—.'The children of Franco in New Spanish Cinema.' Quarterly Review of Film Studies 8.3 (1983): 57-76. Taylor \& Francis Journals Complete. Web. 30 Sep. 2014. King, Stephen. The Shining. London: Hodder \& Stoughton Ltd., 1977. Print.

Kinoshita, Chika. 'The Mummy Complex: Kurosawa Kiyoshi's Loft and J-Horror.' Horror To the Extreme, Ed. Jinhee Choi and Mitsuyo Wada-Marciano. Hong Kong: Hong Kong University Press, 2009. 103-123. Print.

Klein, Christina. 'Globalization and Transnational U.S.-Asian Genres.' American Horror Film: The Genre at the Turn of the Millennium. Ed. Steffen Hantke. Jackson: The University of Mississippi Press, 2010. 3-14. Print.

Klein, Melanie. The Psychoanalysis of Children. 1932. Trans. Alix Strachey. New York: Delacorte Books, 1975. Print.

Kline, Stephen. Out of the Garden: Toys, TV, and Children's Culture in the Age of Marketing. London: Verso, 1995. Print.

Knowles, Kim. 'Analog Obsolescence and the "Death of Cinema” Debate: The Case of Experimental Film.' Proceedings of the Media in Transition 7 Conference: Unstable Platforms: The Promise and Perils of Transition, 13-15 May 2011. Ed. Brad Seawell. Cambridge: Massachusetts Institute of Technology, 2011. Print. 
Kord, T.S. Little Horrors: How Cinema's Evil Children Play on Our Guilt. Jefferson: McFarland, 2016. Print

Kosawa, Heisaku. 'Two Kinds of Guilt Feelings: The Ajase Complex.' 1931. Freud and the Far East: Psychoanalytic Perspectives on the People and Culture of China, Japan and Korea. Ed. and Trans. Salman Akhtar. Plymouth: Rowman \& Littlefield Publishers, Inc., 2009. Print. 61-70. Print.

Kristeva, Julia. Powers of Horror: An Essay on Abjection. Trans. Leon S. Roudiez. New York: Columbia University Press, 1982. Print.

Labanyi, Jo. 'Memory and Modernity in Democratic Spain: The Difficulty of Coming to Terms with the Spanish Civil War.' Poetics Today 28.1 (2007): 89-116. JSTOR Arts and Sciences III. Web. 30 Sep. 2014.

Lacan, Jacques. 'The Mirror Stage as Formative of the Function of the $I$ as Revealed in Psychoanalytic Experience.' 1949. Écrits: A Selection. Trans. Alan Sheridan. London: Routledge, 2001. 1-6. Print.

LaCapra, Dominick. History in Transit: Experience, Identity, Critical Theory. Ithaca: Cornell University Press, 2004. Print.

La Caze, Marguerite. 'The Mourning of Loss in The Sixth Sense.' PostScript: Essays in Film and the Humanities 21.3 (2002): 111-121. Web. 30 Sep. 2014.

Lacefield, Kristen, ed. 'Introduction: Media Anxiety and the Ring Phenomenon.' The Scary Screen: Media Anxiety in The RING. Surrey: Ashgate Publishing, 2010. 1-28. Print.

Lamb, Lynzee. 'Tokyo Theme Park Offering Creepy Sadako 3D 2 Menu.' Anime News Network, Anime News Network, 28 July 2013. Web. 30 Sep. 2014.

Landry, Jess. 'SADA Ko 3D: Super Scary Fun Time Challenge Extreme! Part 1.' Dirge Magazine, Dirge Magazine. 21 Apr. 2015. Web. 1 May 2015.

Landsberg, Alison. Prosthetic Memory: The Transformation of American Remembrance in the Age of Mass Culture. New York: Columbia University Press, 2004. Print.

Laplanche, Jean. 'Notes on Afterwardsness.' Essays on Otherness. Ed. John Fletcher. London: Routledge, 1999. 264-269. Print.

Lavik, Erlend. 'Narrative Structure in The Sixth Sense: A New Twist in Twist Movies?' The Velvet Light Trap 58 (2006): 55-64. Project Muse. Web. 30 Sep. 2014. Lázaro-Reboll, Antonio. Spanish Horror Film. Edinburgh: Edinburgh University Press, 2012. Print.

—.'The Transnational Reception of El espinazo del diablo (Guillermo del Toro 2001).' Hispanic Research Journal 8.1 (2007): 39-51. Maney Online. Web. 30 Sep. 2014. Leggott, Sarah. 'Representing Spain's $20^{\text {th }}$-century Trauma in Fiction: Memories of War and Dictatorship in Contemporary Novels by Women.' Trauma, Media and Art: New Perspectives. Ed. Mick Broderick and Antonio Traverso. Cambridge: Cambridge Scholars Publishing, 2010. 120-131. Print. 
Lennard, Dominic. Bad Seeds and Holy Terrors: The Child Villains of Horror Film. Albany: State University of New York Press, 2015. Print.

Lev, Michael A. 'Beheading Arrest Plunges Japan Into Despair About Its Kids.' ChicagoTribune.com, Chicago Tribune. 4 July 1997. Web. 30 Sep. 2014.

Lim, Bliss Cua. Translating Time: Cinema, the Fantastic and Temporal Critique. Durham: Duke University Press, 2009. Print.

Link, Stan. 'The Monster and the Music Box: Children and the Soundtrack to Horror.' Music in the Horror Film: Listening to Fear. Ed. Neil Lerner. New York: Routledge, 2010. 38-54. Print.

Litke, Mark. 'Juvenile Crime No Longer Rare in Japan.' ABC News.com, American Broadcasting Corporation. 28 Nov. 2003. Web. 30 Sep. 2014.

Litman, Frances. 'Introduction.' Focus on the Family: New Images of Parents and Children in the 1980's. Ed. Clifford Baden. Boston: Wheelock College Center for Parenting Studies, 1980. 5-16. Print.

Lobato, Ramon. Shadow Economies of Cinema: Mapping Informal Film Distribution. London: BFI/Palgrave Macmillan, 2012. Print.

Locke, John. An Essay on Human Understanding. 1689. Ed. Kenneth P. Winkler. Indianapolis: Hackett Publishing Company, 1996. Print.

Low, Morris. 'Technological Culture.' The Cambridge Companion to Modern Japanese Culture. Ed. Yoshio Sugimoto. Melbourne: Cambridge University Press, 2009. 130-146. Print.

Lowenstein, Adam. 'Ghosts in a Superflat Global Village: Globalization, Surrealism and Contemporary Japanese Horror Films.' Post-Script 28.2 (2009): 59-72. EBSCO Host Humanities International Complete. Web. 30 Sep. 2014.

—.'Globalized Spectatorship: Ring Around the Superflat Global Village: J-Horror Between Japan and America.' Dreaming of Cinema: Spectatorship, Surrealism and the Age of Digital Media. New York: Columbia University Press, 2015 · 79-116. Print.

- Shocking Representation: Historical Trauma, National Cinema and the Modern Horror Film. New York: Columbia University Press, 2005. Print.

Lury, Karen. The Child in Film. London: I.B. Tauris \& Co Ltd., 2010. Print.

Lyotard, Jean-François. The Postmodern Condition: A Report on Knowledge. 1979. Trans. Geoff Bennington and Brian Massumi. Minneapolis: University of Minnesota Press, 1983. Print.

Marks, Laura U. The Skin of the Film: Intercultural Cinema, Embodiment and the Senses. Durhman: Duke University Press, 200o. Print.

-.Touch: Sensuous Theory and Multisensory Media. Minneapolis: The University of Minnesota Press, 2002. Print.

Martin-Jones, David. Deleuze and World Cinemas. London: Continuum International Publishing Group, 2011. Print. 
McGowan, Todd. 'Looking for the Gaze: Lacanian Film Theory and its Vicissitudes.' Cinema Journal 42.3 (2003): 27-47.JSTOR Arts and Sciences III. Web. 30 Sep. 2014. McRoy, Jay, ed. 'Case Study: Cinematic Hybridity in Shimizu Takashi's Ju-on: The Grudge.' Japanese Horror Cinema. Edinburgh: Edinburgh University Press, 2005. 175-184. Print.

-.Nightmare Japan. Amsterdam: Rodopi, 2008. Print.

Medina, José. 'Toward a Foucaultian Epistemology of Resistance: Counter-Memory, Epistemic Friction, and Guerrilla Pluralism.' Foucault Studies 12 (2011): 8-35. EBSCO Host Humanities International Complete. Web. 30 Sep. 2014.

Meikle, Denis. The Ring Companion. London: Titan Books, 2005. Print.

Merino, Eloy E. and Song, Rosi H, eds. Traces of Contamination: Unearthing the Francoist Legacy in Contemporary Spanish Discourse: Lewisburg: Bucknell University Press, 2005. Print.

Merish, Lori. 'Cuteness and Commodity Aesthetics: Tom Thumb and Shirley Temple.' Freakery: Cultural Spectacles of the Extraordinary Body. Ed. Rosemarie Garland Thomson. New York: New York University Press, 1996. 185-206. Print.

Merlock Jackson, Kathy. Images of Children in American Film: A Sociocultural Analysis. Metuchen: The Scarecrow Press Inc., 1986. Print.

Miyao, Daisuke. The Aesthetics of Shadow: Lighting and Japanese Cinema. Durham: Duke University Press, 2013. Print.

Muir, Bob. 'Latest SADAKo 3D marketing flooding the streets with Sadako.' Japanator, Modern Method. 5 Aug. 2012. Web. 30 Sep. 2014.

Mulvey, Laura. 'Visual Pleasure and Narrative Cinema.' Screen 16.3 (1975): 6-18. Oxford University Press Journals. Web. 30 Sep. 2014.

Murphy, Bernice. The Suburban Gothic in American Popular Culture. New York: Palgrave Macmillan, 2009. Print.

Nakamura, Naofumi. 'Railway Systems and Time Consciousness in Modern Japan.' Japan Review 14 (2002): 13-38. JSTOR Arts and Sciences III. Web. 30 Sep. 2014.

Nakata, Hideo. Interview by Donald Totaro. 'The "Ring” Master: Interview with Hideo Nakata.' OffScreen.com, Canada Council for the Arts. July 2000. Web. 30 Sep. 2014 .

Napier, Susan. The Fantastic in Modern Japanese Literature. Tokyo: The Nissan Institute/Routledge Japanese Studies, 1995. Print.

Narváez, Rafael F. Embodied Collective Memory: The Making and Unmaking of Human Nature. Lanham: University Press of America, 2013. Print.

Nasu, Masamoto. The Children of the Paper Crane: The Story of Sadako Sasaki and Her Struggle with A-Bomb Disease. Trans. Elizabeth W. Baldwin. London: Routledge, 1991. Print.

Natoli, Joseph. Speeding to the Millennium: Film and Culture, 1993-1995. Albany: State University of New York Press, 1998. Print. 
Ndalianis, Angela. The Horror Sensorium: Media and the Senses. Jefferson: McFarland, 2012. Print.

Newman, James. Best Before: Videogames, Supersession and Obsolescence. London: Routledge, 2012. Print.

Och, Dana and Strayer, Kirsten, eds. Transnational Horror Across Visual Media: Fragmented Bodies. New York: Routledge, 2014. Print.

Ōe, Kenzaburō. 'Aghwee the Sky Monster.' 1964. Teach Us to Outgrow Our Madness. Trans. John Nathan. New York: Grove Press, 1994. 221-328. Print.

- The Pinch Runner Memorandum. 1976. Trans. Michiko N. Wilson and Michael K. Wilson. London: Routledge. 1994. Print.

'Osaka Mayor Toru Hashimoto: Sex slaves in World War Two were necessary to "maintain discipline" for Japanese army.' The Independent.co.uk, The Independent UK. 14 May 2013. Web. 30 Sep. 2015.

Paul, William. Laughing Screaming: Modern Hollywood Horror and Comedy. New York: Columbia University Press, 1994. Print.

Parr, Adrian, ed. The Deleuze Dictionary: Revised Edition. Edinburgh: Edinburgh University Press, 2013. Print.

Pavlović, Tatjana; Alvarez, Inmaculada; Blanco-Cano, Rosana; Grisales, Anita; Osorio, Alejandra and Sánchez, Alejandra. 100 Years of Spanish Cinema. Oxford: Wiley-Blackwell, 2009. Print.

Pavlović, Tatjana. Despotic Bodies and Transgressive Bodies: Spanish Culture from Francisco Franco to Jesús Franco. New York: State University of New York Press, 2003. Print.

Perriam, Chris. 'El espíritu de la colmena (Víctor Eríce, 1973).' Burning Darkness: A Half Century of Spanish Cinema. Ed.J.R. Resina. New York: SUNY Press, 2008. 61-82. Print. Petley, Julian. 'The Monstrous Child.' The Body's Perilous Pleasures: Dangerous Desires and Contemporary Culture. Ed. Michele Aaron. Wiltshire: Edinburgh University Press, 1999. 87-105. Print.

Phu, Thy. 'Horrifying adaptations: Ringu, The RING, and the cultural contexts of copying.' Journal of Adaptation in Film and Performance 3.1 (2010): 43-58. Print. Platt, Brian. 'Japanese Childhood, Modern Childhood: The Nation-State, the School, and $19^{\text {th }}$-Century Globalization.' Journal of Social History 38.4 (2005): 965-985. JSTOR Arts and Sciences VII. Web. 30 Sep. 2014.

Powell, Anna. Deleuze and the Horror Film. Edinburgh: Edinburgh University Press, 2006. Print.

Queenan, Joe. 'Bring on the Creepy Girls.' The Guardian.com, The Guardian News and Media. 22 Feb, 2008. Web. 30 Sep. 2014.

Rauer, Julie. 'Persistence of a Genetic Scar: Japanese Anime, Manga, and Otaku Culture Fill an Open National Wound.' AsianArt.com: The on-line journal for the study and exhibition of the arts in Asia. 13 June 2005. n.p. Web. 30. Sep. 2014. 
Reagan, Ronald. 'State of the Union Address, 1982.' The Public Papers of President Ronald W. Reagan. Ronald Reagan Library and Museum Archives, n.d. Web. 20 Dec. 2015. Reynolds, Jack. Chronopathologies: Time and Politics in Deleuze, Derrida, Analytic Philosophy, and Phenomenology. Lanham: Lexington Books, 2012. Print.

Richards, Andy. Asian Horror. Herts: Kamera Books, 2010. Print.

Robertson, Jennifer. 'Furusato Japan: The Culture and Politics of Nostalgia.' International Journal of Politics, Culture and Society 1.4 (1988): 494-518. JSTOR Arts and Sciences VI. Web. 30 Sep. 2014.

Rothkopf, Joshua. 'One Missed Call.' TimeOutNewYork.com, Time Out. 8 Jan. 2008. Web. 30 Sep. 2014.

Rousseau, Jean-Jacques. Emile, Or on Education. 1763. Sioux Falls: NuVision Publications, 2007. Print.

Royle, Nicholas. The Uncanny. Manchester: Manchester University Press, 2003. Print. Rüsen, Jörn. Time and History: The Variety of Cultures. New York: Berghahn Books, 2007. Print.

Sanders, Vicky. 'Dancing and the Dark Soul of Japan: An Aesthetic Analysis of Butoh.' Asian Theatre Journal 5.2: 1988. 148-163. JSTOR Arts and Sciences III. Web. 30 Sep. 2014.

Savage, Kirk. Monument Wars. Berkeley: University of California Press, 2009. Print. Scahill, Andrew. The Revolting Child in Horror Cinema: Youth Rebellion and Queer Spectatorship. New York: Palgrave Macmillan, 2015. Print.

Schober, Adrian. Possessed Child Narratives in Literature and Film: Contrary States. New York: Palgrave Macmillan, 2004. Print.

Schrey, Dominik. 'Analogue Nostalgia and the Aesthetics of Digital Remediation.' Media and Nostalgia: Yearning for the Past, Present and Future. Ed. Katharina Niemeyer. Basingstoke: Palgrave Macmillan, 2014. 27-38. Print.

Schwartz, Hillel. Century's End: An Orientation Manual Toward the Year 20oo. New York: Currency Doubleday, 1996. Print.

Shin, Chi-Yu. 'The Art of Branding: Tartan "Asia Extreme" Films.' Horror to the Extreme: Changing Boundaries in Asian Cinema. Ed. Jinhee Choi and Mitsuyo Wada-Marciano. Hong Kong: Hong Kong University Press, 2009. 85-100. Print.

Shor, Juliet B. Born to Buy: The Commercialized Child and the New Consumer Culture. New York: Scribner, 2004. Print.

Sobchack, Vivian. 'Bringing it all Back Home: Family Economy and Generic Exchange.' American Horrors: Essays on the Modern American Horror Film. Ed. Gregory A. Waller. Champaign: University of Illinois Press, 1987. 163-194. Print. Sōseki, Natsume. Ten Nights' Dreams. 1908. Trans. Takumi Kashima and Loretta R. Lorenz. London: Soseki Museum in London, 2000. Print.

Staal, Rein. 'The Forgotten Story of Postmodernity.' First Things December (2008): 35-39. EBSCOhost Academic Search Complete. Web. 30 Sep. 2014. 
Stagoll, Cliff. 'Becoming.' The Deleuze Dictionary Revised Edition. Ed. Adrian Parr. Edinburgh: Edinburgh University Press, 2013. 25-27. Print.

Stamp Lindsey, Shelley. 'Horror, Femininity and Carrie's Monstrous Puberty.' Journal of Film and Video 43.4 (1991): 33-44. Print.

Steedman, Carolyn. Strange Dislocations: Childhood and the Idea of Human Interiority 1780-1930. London: Virago Press, 1995. Print.

Stein, Bonnie Sue. 'Butoh: Twenty Years Ago We Were Crazy, Dirty, and Mad.' Moving History/Dancing Cultures. Ed. Ann Dils and Ann Cooper Albright. Middletown: Wesleyan University Press, 2001. 376-383. Print.

Stockton, Kathryn Bond. The Queer Child, or Growing Sideways in the Twentieth Century. Durham: Duke University Press, 2009. Print.

Stone, Rob. Spanish Cinema. London: Routledge, 2002. Print.

Stuchlíková, Zuzana. 'Japan's Lost Decade: On the Development of The Japanese Economy in the 1990s.' Journal of International Relations 4: 2012. 129-152. HeinOnline Law Journal Library. Web. 30 Sep. 2014.

Suttmeier, Bruce. 'Speculations of Murder: Ghostly dreams, poisonous frogs and the case of Yokoi Shoichi.' Perversion and Modern Japan: Psychoanalysis, Literature, Culture. Ed. Nina Cornyetz and J. Keith Vincent. Oxon: Routledge, 2010. 22-39. Print.

Sutton, Damien. Photography, Cinema, Memory: The Crystal Image of Time. Minneapolis: The University of Minnesota Press, 2009. Print.

Suzuki, Koji. Ring. Trans. Robert B. Rohmer and Glynne Walley. New York: Vertical, 2004. Print.

Swiboda, Marcel. 'Becoming + Music.' The Deleuze Dictionary Revised Edition. Ed. Adrian Parr. Edinburgh: Edinburgh University Press, 2012. 27-29. Print.

Tanaka, Stefan. 'Childhood: Naturalization of Development in a Japanese Space.' Cultures of Scholarship. Ed. Sarah C. Humphreys. Ann Arbor: The University of Michigan Press, 1997. 21-56. Print.

-.New Times in Modern Japan. Princeton: Princeton University Press, 2004. Print.

Tateishi, Ramie. 'The Japanese Horror Film Series: Ring and Eko Eko Azarak.' Fear Without Frontiers: Horror Cinema Across the Globe. Ed. Steven Jay Schneider. Godalming: FAB Press, 2003. Print.

Thatcher, Margaret. Interview by Douglas Keay. Woman's Own 31 Oct. (1987): 8-10. Print.

'The 20 Highest Grossing Horror Films of All Time.' BusinessInisder.com.au, John Lynch. 2017. Web. 30 Dec. 2017.

Thrailkill, Jane F. 'Sigmund Freud, Pedophile Priests, and Shyamalan's Filmic Fairy Tale (The Sixth Sense).' Critical Approaches to the Films of M. Night Shyamalan: Spoiler Warnings. Ed. Jeffrey Weinstock. New York: Palgrave Macmillan, 2010. 139-158. Print. 
Tomlinson, John. Globalization and Culture. Chicago: The University of Chicago Press, 1999. Print.

Tomlinson, Niles. 'Of Horse Blood and TV Snow: Abhuman Reproduction in THE RInG.' The Scary Screen: Media Anxiety in The RING. Ed. Kristen Lacefield. Surrey: Ashgate Publishing, 2010. 175-190. Print.

Trefalt, Beatrice. Japanese Army Stragglers and Memories of the War in Japan, 1950-75. London: RoutledgeCurzon, 2003. Print.

Trigg, Dylan. The Aesthetics of Decay: Nothingness, Nostalgia, and the Absence of Reason. New York: Peter Lang, 2006. Print.

—. The Memory of Place: A Phenomenology of the Uncanny. Athens: Ohio University Press, 2012. Print.

Tudor, Andrew. Monsters and Mad Scientists: A Cultural History of the Horror Movie. Hoboken, NJ: Wiley-Blackwell, 1991. Print.

Tyron, Chuck. On-demand Culture: Digital Delivery and the Future of Movies. New Brunswick, NJ: Rutgers University Press, 2013.

Underwood, Ted. 'Romantic Historicism and the Afterlife.' PMLA. 117.2 (2002): 237-251.JSTOR Arts and Sciences III. Web. 30 Sep. 2014.

Uno, Kathleen. Passages to Modernity: Motherhood, Childhood, and Social Reform in Early Twentieth Century Japan. Honolulu: University of Hawai'i Press, 1999. Print.

Uprichard, Emma. 'Children as "Beings and Becomings": Children, Childhood and Temporality.' Children and Society 22 (2008): 303-313. Wiley Online Library. Web. 30 Sep. 2014.

Valis, Noël. The Culture of Cursilería:Bad Taste, Kitsch and Class in Modern Spain. Durham: Duke University Press, 2002. Print.

Viala, Jean and Masson-Sekine, Nourit. Butoh: Shades of Darkness. Clarendon: Tuttle Publishing, 1988. Print.

Vidler, Anthony. The Architectural Uncanny: Essays in the Modern Unhomely. Cambridge: Massachusetts Institute of Technology, 1992. Print.

Wada-Marciano, Mitsuyo. Japanese Cinema of the Digital Age. Honolulu: University of Hawai'i Press, 2012. Print.

-.'J-Horror: New Media's Impact on Contemporary Japanese Horror Cinema.' Horror To the Extreme: Changing Boundaries in Asian Cinema. Ed. Jinhee Choi and Mitsuyo Wada-Marciano. Hong Kong: Hong Kong University Press, 2009. 15-39. Print.

Walsh, Fintan. Male Trouble:Masculinity and the Performance of Crisis. New York: Palgrave Macmillan, 2010. Print.

Walter, Brenda S. Gardenour. 'Ghastly Transmissions: The Horror of Connectivity and the Transnational Flow of Fear.' Transnational Horror Across Visual Media: Fragmented Bodies. Ed. Dana Och and Kirsten Strayer. New York: Routledge, 2014. 17-29. Print. 
Wang, Ya-huei. 'Archetypal Anxieties in Stanley Kubrick's The SHIning.' k@ta 13.1 (2011): 112-122. Web. 30 Sep. 2014.

Warner, Marina. Managing Monsters: Six Myths of Our Time. London: Vintage, 1994. Print.

Webber, Andrew Lloyd. The Phantom of the Opera. Lyrics by Charles Hart and Richard Stilgoe. Milwaukee: Hal Leonard, 1987.

Wee, Valerie.Japanese Horror Films and their American Remakes. London: Routledge, 2013. Print.

-.'Patriarchy and the Horror of the Monstrous Feminine: A Comparative Study of RINGU and The RING.' Feminist Media Studies 11.02 (2011a): 151-165. Taylor and Francis Journals Complete. Web. 30 Sep. 2014.

-.'Visual Aesthetics and Ways of Seeing: Comparing Ringu and The Ring.' Cinema Journal 50.2 (2011b): 41-6o.JSTOR Arts and Sciences III. Web. 30 Sep. 2014.

Weinstein, David E., Kashyap, A. K., and Hamada, Kōichi.Japan's Bubble, Deflation and Long-term Collapse. Cambridge: MIT Press, 2011. Print.

Weinstock, Jeffrey, ed. 'Introduction: The Spectral Turn.' Spectral America: Phantoms and the National Imagination. Madison: University of Wisconsin Press, 2004. 3-17. Print.

Wetmore, Kevin J. 'Technoghosts and culture shocks: sociocultural shifts in American remakes of J-horror.' Post-script 28.2 (2009): 72-83. EBSCO Host Literary Reference Centre. Web. 30 Sep. 2014.

Wetsch, Elisabeth. 'Kobe School Killer.' Crimezzz.net, Elisabeth Wetsch. 2005. Web. 30 Sep. 2014.

White, Eric. 'Case Study: Nakata Hideo's Ringu and RINGU 2.' Japanese Horror Cinema. Ed. Jay McRoy. Edinburgh: Edinburgh University Press, 2006. 38-51. Print.

Williams, Tony. Hearths of Darkness: The Family in the American Horror Film. London: Associated University Presses, 1996. Print.

Willis, Andrew. 'From the Margins to the Mainstream: Trends in Recent Spanish Horror Cinema.' Spanish Popular Cinema. Ed. Antonio Lázaro-Reboll and Andrew Willis. Manchester: Manchester University Press, 2004. 237-249. Print.

—.'Spanish Horror and the Flight from Art Cinema.' Defining Cult Movies: The Cultural Politics of Oppositional Taste. Ed. Mark Jancovich, Antonio Lázaro-Reboll, Julian Stringer, and Andy Willis. Manchester: Manchester University Press, 2003. 71-83. Print.

Wood, Christopher. The bubble economy: The Japanese economic collapse. London: Sidgwick and Jackson, 1992. Print.

Wood, Robin. 'An Introduction to the American Horror Film.' Planks of Reason: Essays on the Horror Film. Ed. Barry Keith Grant and Christopher Sharret. London: Scarecrow Press, 1985. 164-200. Print. 
—.'The American Family Comedy: From Meet Me In St Louis to The Texas Chainsaw Massacre.' Wide Angle 3.2 (1979): 5-11. Print.

—.'Yet Another Terrible Child.' London Times Education Supplement 11 February (1977): 86-9o. Print.

Wright, Sarah. The Child in Spanish Cinema. Manchester: Manchester University Press, 2013. Print.

Yoneyama, Lisa. Hiroshima Traces: Time, Space and the Dialectics of Memory. Berkeley: University of California Press, 1999. Print.

Yoneyama, Shoko. 'Student Discourse on Tôkôyohi (School Phobia/Refusal) in Japan: Burnout or Empowerment.' British Journal of Sociology of Education 21.1 (2000): 77-94. JStor Arts and Sciences IV. Web. 30 Jan. 2015.

Zamora, Lois Parkinson. 'Apocalypse.' Dictionary of Literary Themes and Motifs: A-J. Ed. Jean-Charles Seigneuret. Westport: Greenwood Publishing, 1988. 87-96. Print. Zipes, Jack. Relentless Progress: The Reconfiguration of Children's Literature, Fantasy and Storytelling. New York: Routledge, 2009. Print.

Žižek, Slavoj. Looking Awry: An Introduction to Jacques Lacan Through Popular Culture. Cambridge: MIT Press, 1992. Print. 



\section{Filmography}

The Abandoned. Dir. Nacho Cerdá. Castelao Producciones, 20o6. Film.

Ana And the Wolves [AnA y los Lobos]. Dir. Carlos Saura. Elías Querejeta Producciones Cinematográficas S.L., 1973. Film.

An Angel has Appeared. [Ha llegado un Angel]. Dir. Luis Lucia. 1961. Richard Bradley distribuciones, 2009. DVD.

Audrey Rose. Dir. Robert Wise. Sterobcar Productions, 1977. Film.

A RAY of Light [Un RAYo DE LUZ]. Dir. Luis Lucia. 196o. Tribanda Pictures, 2009. DVD.

The BAbadook. Dir. Jennifer Kent. Causeway Films, 2014. Film.

The Bad Seed. Dir. Mervyn LeRoy. 1956. Warner Home Video, 2011. Blu-ray DVD.

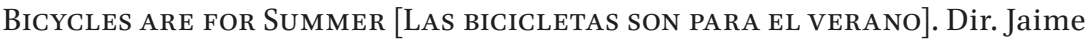
Chávarri. In-Cine Compañía Industrial Cinematográfica, 1984. Film.

The Changeling. Dir. Peter Medak. 1980. HBO Home Video, 2005. DVD.

The Children. Dir. Tom Shankland. Vertigo Films, 2008. Film.

Child's Play. Dir. Tom Holland. United Artists, 1988. Film.

Cousin Angelica [LA Prima AngéLICA]. Dir. Carlos Saura. Elías Querejeta Producciones Cinematográficas S.L., 1974. Film.

D@BbE. Dir. Hasan Karacadag. J-Plan, 20o6. Film.

The Dark Hour [La hora fría]. Dir. Elio Quiroga. Eqlipse Producciones Cinematográficas S.L., 2006. Film

DARKNESS. Dir. Jaume Balagueró. 2002. Dimension Films, 2005. DVD.

DARK WATER. Dir. Walter Salles. Buena Vista Home Entertainment, 2005. DVD.

Dark Water [Honogurai Mizu no soko Kara]. Dir. Hideo Nakata. 2002. Section 23 Films, 2005. DVD.

The Death of Mikel [La muerte de Mikel]. Dir. Imanol Uribe. Aiete Films S.A., 1984. Film.

The Devil's Backbone [El espinazo del diablo]. Dir. Guillermo del Toro. The Criterion Collection, 2001. Blu-ray DVD.

Don't Be Afraid of the Dark. Dir. Troy Nixey. Miramax, 2010. Film.

Dовотнy Mills. Dir. Agnés Merelet. Euroimages Fund of the Council of Europe, 2008. Film.

Eugenia de Montijo. Dir. José López Rubio. Manuel del Castillo, 1944. Film. EXIstenZ. Dir. David Cronenberg. Alliance Atlantis Communications, 1999. Film. The EXorCist. Dir. William Friedkin. 1973. Warner Home Video, 2013. Blu-ray DVD. Eyes Wide Shut. Dir. Stanley Kubrick. Warner Bros., 1999. Film.

Eyes Without a Face [Les Yeux Sans Visage]. Dir. Georges Franju. Champs-Elysées Productions, 1960. Film. 
FALLEN. Dir. Gregory Hoblit. Atlas Entertainment, 1999. Film.

Fight Club. Dir. David Fincher. Fox 2000 Pictures, 1999. Film.

Fragile [Frágiles]. Dir. Jaume Balagueró. 2005. Phase 4 Films, 2010. DVD.

Frankenstein. Dir. James Whale. Universal Pictures, 1931. Film.

The Gift. Dir. Sam Raimi. Lakeshore Entertainment, 2000. Film.

Ghost Story of Yotsuya [Tôkaidô Yotsuya KaIdan]. Dir. Nobuo Nakagawa.

Shintoho Film Distribution Committee, 1959. Film.

The Grudge. Dir. Takashi Shimizu. Sony Pictures Home Entertainment, 2005. DVD.

The Grudge 2. Dir. Takashi Shimizu. Sony Pictures Home Entertainment, 2007.

DVD.

The Grudge 3. Dir. Toby Wilkins. Sony Pictures Home Entertainment, 2009. DVD. Halloween. Dir. John Carpenter. Compass International Pictures, 1979. Film.

Hara-Kiri: Death of A Samurai [Ichimei]. Dir. Takashi Miike. Sedic International, 2011. Film.

The Haunting. Dir. Robert Wise. Argyle Enterprises, 1963. Film.

The Haunting. Dir. Jan de Bont. DreamWorks SKG, 1999. Film.

The Heifer [La vaQuilla]. Dir. Luis García Berlanga. In-Cine Compañía Industrial Cinematográfica, 1985. Film.

House of Voices [SAint Ange]. Dir. Pascal Laugier. Castel Film Romania, 2004. Film.

House on Haunted Hill. Dir. William Malone. Dark Castle Entertainment, 1999. Film.

The Hunt [La CAzA]. Dir. Carlos Saura. Elías Querejeta Producciones Cinematográficas S.L., 1966. Film.

In a Glass Cage [Tras el CRISTAL]. Dir. Agustí Villaronga. T.E.M. Productores S.A., 1987. Film.

InÊS DE CASTRO. Dir. José Leitão de Barros. Faro Producciones Cinematográficas, 1944. Film.

The InNocents. Dir. Jack Clayton. 1961. Criterion Collection Home Entertainment, 2014. Blu-ray DVD.

Insidious. Dir. James Wan. 2010. Icon Film Distribution, 2011. Blu-ray DVD.

Insidious: Chapter Two. Dir. James Wan. FilmDistrict, 2013. Film.

Insidious: Chapter Three. Dir. Leigh Whannell. Blumhouse Productions, 2015.

Film.

Insidious: The Last Key. Dir. Adam Robitel. Blumhouse Productions, 2018. Film. InTruders. Dir. Juan Carlos Fresnadillo. Antena 3 Films, 2011. Film.

Iт. Dir. Andrés Muschietti. Warner Bros. Pictures, 2017. Film. Jaws. Dir. Steven Spielberg. Universal Pictures, 1975. Film. Julia's Eyes [Los ojos De Julia]. Dir. Guillem Morales. Antena 3 Films, 2010. Film. 
Ju-on: The Curse [Ju-ON]. Dir. Takashi Shimizu. 2000. Lionsgate Home Entertainment, 2003. DVD.

Ju-ON: The CURSE 2 [Ju-ON 2]. Dir. Takashi Shimizu. 2000. Lionsgate Home Entertainment, 2003. DVD.

Ju-ON: The GRudge [Ju-ON]. Dir. Takashi Shimizu. 2002. Lionsgate Home Entertainment, 2005. DVD.

Ju-ON: The Grudge 2 [Ju-ON 2]. Dir. Takashi Shimizu. 2002. Lionsgate Home Entertainment, 2006. DVD.

KWAIDAn [KaIdAn]. Dir. Masaki Kobayashi. Bungei, 1964. Film.

Lake Mungo. Dir. Joel Anderson. Mungo Productions, 2008. Film.

The Legion’s For Me! [¡A Mí LA LEgion!]. Dir. Juan de Orduña. Compañía Industrial Film Español S.A. (CIFESA), 1942. Film.

Let the Right One In [LÅt DEn RÄtte komma IN]. Dir. Tomas Alfredson. Sandrew Metronome Distribution Sverige AB, 2008. Film.

The Locker [ShibuYa KaIdan]. Dir. Kei Horie. Bad Taste Visual Voice and Geneon Entertainment, 2004. Film.

The Madness of Love [Locura de amor]. Dir. Juan de Orduña. Compañía Industrial Film Español S.A. (CIFESA), 1948. Film.

Magnolia. Dir. Paul Thomas Anderson. New Line Cinema, 1999. Film.

Mama. Dir. Andrés Muschietti. Universal Pictures, 2013. Film.

Martyrs of the Philippines [Los úlitmos de Filipinas]. Dir. Antonio Román. Alhambra-Cea, 1945. Film.

The Matrix. Dir. Lily and Lana Wachowski. Warner Bros., 1999. Film.

The Miracle of Marcelino [Marcelino pan y vino]. Dir. Ladislao Vajda. Chamartín Producciones y Distribuciones, 1955. Film.

The Nameless [Los Sin nombre]. Dir. Jaume Balagueró. 1999. Miramax Echo Bridge, 2005. DVD.

Night of the Howling Beast [LA Maldición DE LA Bestia]. Dir. Miguel Iglesias. Profilmes, 1975 .

The OMen. Dir. Richard Donner. 1976. Twentieth Century Fox, 2007. Blu-ray DVD. On a Paper Crane: Tomoko's Adventure [Tsuru ni notte: Tomoko no bouken]. Dir. Arihara Seiji. Peace Anime, 1994. VHS Videotape.

One Missed CALl. Dir. Eric Valette. Warner Home Video, 2008. DVD.

One Missed Call [Chakushin ARi]. Dir. Takashi Miike. 2003. Tokyo Shock, 2006. DVD.

Onibaba. Dir. Kaneto Shindô. Kindai Eiga Kyokai, 1964. Film.

The Orphanage [El orfanato]. Dir. Juan Antonio Bayona. 2007. New Line Home Video, 2008. Blu-ray DVD.

The Other. Dir. Robert Mulligan. Twentieth Century Fox, 1972. Film. 
The Others [Los otros]. Dir. Alejandro Amenábar. 2001. Optimum Home Entertainment, 2011. Blu-ray DVD.

Painless [Insensibles]. Dir. Juan Carlos Medina. Les Films d'Antoine, 2012. Film. PAn's Labyrinth [El Laberinto Del Fauno]. Dir. Guillermo del Toro. Estudios Picasso, 2006. Film.

Pirates of the Caribbean: At World's End. Dir. Gore Verbinski. Walt Disney Pictures, 2007. Film.

Peppermint Frappé. Dir. Carlos Saura. Elías Querejeta Producciones Cinematográficas S.L., 1967. Film.

Poltergeist. Dir. Tobe Hooper. 1982. Warner Home Video, 2008. DVD.

Poltergeist. Dir. Gil Kenan. $20^{\text {th }}$ Century Fox, 2015. Film.

Princess Mononoke [Mononoke-hime]. Dir. Hayao Miyazaki. Studio Ghibli, 1997. Film.

Pulse [Kairo]. Dir. Kiyoshi Kurosawa. Magnolia Pictures Company, 2001. Film.

Race [RAZA]. Dir. José Luis Sáenz. Cancilleria del Consejo de la Hispanidad, 1942. Film.

Raise Ravens [Cría cuervos]. Dir. Carlos Saura. 1976. The Criterion Collection, 2007. DVD.

Reincarnation [Rinne]. Dir. Takashi Shimizu. 2005. Lionsgate Home Entertainment, 2007. DVD.

RINGU. Dir. Hideo Nakata. 1998. DreamWorks Video, 2000. DVD.

Ringu o: Birthday [Ringu o: Basudei]. Dir. Norio Tsuruta. 2000. Paramount Catalogue, 2013. DVD.

RINGU 2. Dir. Hideo Nakata. 1999. DreamWorks Video, 2005. DVD.

The Ring. Dir. Gore Verbinski. 2002. DreamWorks Pictures, 2013. Blu-ray DVD.

The Ring Two. Dir. Hideo Nakata. 2005. DreamWorks Pictures, 2013. DVD.

The Ring Virus. Dir. Dong-Bin Kim. ADFD, 1999. Film.

RINGs. Dir. Javier Gutiérrez. Parkes + MacDonald Image Nation, 2017. Film.

Room 237. Dir. Rodney Ascher. Highland Park Classics, 2012. Film.

Rosemary's Baby. Dir. Roman Polanski. William Castle Productions, 1968. Film.

SADA Ko 3D. Dir. Tsutomu Hanabusa. Kadakowa Pictures, 2012. Film.

SADAKo 3D 2. Dir. Tsutomu Hanabusa. Kadakowa Pictures, 2013. Film.

SADAKo vs KaYAKo. Dir. Kōji Shiraishi. Kadakowa, 2016. Film.

Scared Silent: Ending and Exposing Child Abuse. Dir. Melissa Jo Peltier, Perf.

Oprah Winfrey. Arnold Shapiro Productions, 1992. TV Movie.

SCARy Movie 3. Dir. David Zucker. Dimension Films, 2003. Film.

SCARY Movie 4. Dir. David Zucker. Dimension Films, 2006. Film.

Sinister. Dir. Scott Derrickson. Alliance Films, 2012. Film.

The Sixth Sense. Dir. M. Night Shyamalan. 1999. Hollywood Pictures Home Entertainment, 2000. DVD. 
The Shining. Dir. Stanley Kubrick. 1980. Warner Bros. Entertainment Inc., 2007. Blu-ray DVD.

Shiver [Eskalofrío]. Dir. Isidro Ortiz. A Punto la Postpo, 2008. Film.

Spanish Movie. Dir. Javier Ruiz Caldera. Telecino Cinema, 2009. Film.

The Spirit of the Beehive [El espíritu de la colmena]. Dir. Víctor Eríce. 1973. The Criterion Collection, 2006. DVD.

Star Wars Episode I: The Phantom Menace. Dir. George Lucas. Lucasfilm, 1999. Film.

Stigmata. Dir. Rupert Wainwright. Metro-Goldwyn Myer, 1999. Film.

Stir of Echoes. Dir. David Koepp. 1999. Lionsgate Home Entertainment, 200o. DVD.

Stranger Things. Dir. Matt and Ross Duffer. Netflix, 2016-present (at time of print). Television Programme.

The Thirteenth Floor. Dir. Josef Rusnak. Columbia Pictures, 1999. Film.

Thizeen Ghosts. Dir. Steve Beck. Warner Bros, 2001. Film.

Tombs of the Blind Dead [La Noche Del terror ciego]. Dir. Amando de Ossorio. Interfilme, 1972.

'Treehouse of Horror XXV.' The Simpsons: Season 26, Episode 4. Dir. Matthew Faughnan. Gracie Films and $20^{\text {th }}$ Century Fox Television, 2014.

Ugetsu [Ugetsu monogatari]. Dir. Kenji Mizoguchi. Daiei Studios, 1954. Film. VAmpyros Lesbos. Dir. Jesús Franco. CCC Telecine, 1971. Film.

Village of the Damned. Dir. Wolf Rilla. Metro Goldwyn Myer British Studios, 1960. Film.

VIRIDIANA. Dir. Luis Buñuel. Unión Industrial Cinematográfica (UNINCI), 1961. Film. What Lies Beneath. Dir. Robert Zemeckis. DreamWorks SKG, 200o. Film.

Who Are We? [Hum Kaun Hai?]. Dir. Ravi Sharma Shankar. 4U2C Film, 2004. Film. Who Can Kill a Child? [¿QuiÉn PUede Matar a Un niÑo?]. Dir. Narciso Ibáñez Serrador. 1976. Dark Sky Films, 2007. DVD. 



\section{Artworks}

Goya y Lucientes, Francisco José. The Sleep of Reason Produces Monsters. 1799. Etching, aquatint, drypoint, and burin. The Metropolitan Museum of Art, New York.

Fg2. Children's Peace Monument. 2005. Photograph. Wikimedia Commons. Web. 30 Jan. 2015 .

Hongo, Shin. Statue of Mother and Children During the Storm. 196o. Bronze. Hiroshima Peace Park, Hiroshima City.

Ishikawa, Kouyou. Charred mother and child after the Operation Meetinghouse bombing. 1945. Photograph. C. Peter Chen, World War II Database. Web. $3^{0}$ Sep. 2014.

Kikuchi, Kazuo and Ikebe, Kiyoshi. Children's Peace Monument. 1958. Bronze and concrete. Hiroshima Peace Park, Hiroshima City.

Parker, Lewan. The Statue of Sadako Sasaki. 2015. Photograph.

Robertson, Corporal Angus. A Member of a Marine Patrol on Saipan found this family of Japs hiding in a Hillside Cave. 1944. Photograph. National Archives and Records Administration, Archives.gov. Web. 30 Sep 2014.

Sūshi, Sawaki. Yūrei. 1737. Picture scroll. Yōkai zukan. Ed. Natsuhiko Kyōgoku and Katsumi Tada. Tokyo: Kokusho Kankōkai, 200o. Print. 



\section{Music}

Gob. 'Paint it Black' (Rolling Stones Cover). Comp. Mick Jagger and Keith Richards. How Far Shallow Takes You. Nuttwerk America, 1998. CD.

The Rolling Stones. 'Paint it Black.' Comp. Mick Jagger and Keith Richards. Aftermath. ABKCO Records, 2002. CD. 



\title{
Film Index (by Country)
}

\author{
Australia \\ The BABADooK (Jennifer Kent, 2014, Australia/Canada), 285, 286, 307. \\ LAKe Mungo (Joel Anderson, 2008), 221, 239, 309.
}

\section{Bulgaria}

The Abandoned (Nacho Cerdá, 2006, Spain/U.K./Bulgaria), 221, 239, 307.

\section{Canada}

The Babadook (Jennifer Kent, 2014, Australia/Canada), 285, 286, 307.

The Changeling (Peter Medak, 1980, Canada/U.S.), 12, 30, 35, 36, 40, 42, 53-56, 58-59, 64, 66-70, $72,74,82,90,261$, 264,307 .

EXISTEnZ (David Cronenberg, 1999, Canada/U.K.), 69, 90, 307.

Mama (Andrés Muschietti, 2013, Canada/Spain/U.S.), 285, 287, 309.

Sinister (Scott Derrickson, 2012, U.S./U.K./Canada), 285, 287, 310.

\section{France}

DoRothy Mills (Agnés Merlet, 2008, Ireland/France), 15n, 207.

Eyes Without a Face [Les Yeux Sans Visage] (George Franju, 1960), 197, 215, 307.

House of Voices [SAint Ange] (Pascal Laugier, 2004), 15n, 308.

Painless [Insensibles] (Juan Carlos Medina, 2012, Spain/France/Portugal), 97n, 118, 310.

\section{Germany}

VAMPYros Lesbos (Jesús Franco, 1971, Spain/Germany), 107n, 118, 311.

\section{India}

Who Are We? [Hum Kaun Hai?] (Ravi Sharma Shankar, 2004), 250, 264, 311.

\section{Ireland}

DoRothy Mills (Agnés Merlet, 2008, Ireland/France), 15n, 207.

\section{Japan}

DARK WATER [Honogurai MiZU NO SOKo KARA] (Hideo Nakata, 2002), 185, 215, 221, 239, 307.

GHost Story of Yotsuya [Tôkaidô YotsuYa KAIDAN] (Nobuo Nakagawa, 1959), 157, 158n, 6o, 182, 308.

The GRudge (Takashi Shimizu, 2004, U.S./Japan), 159, 182, 221, 222, 223, 224, 229, 230, 231, 234, 239, 308.

The Grudge 2 (Takashi Shimizu, 2006, U.S./Japan), 221, 222, 223, 231, 239, 239, 308.

The Grudge 3 (Toby Wilkins, 2009, U.S./Japan), 221, 222, 223, 231, 308.

HARA-Kiri: DeAth of A SAmurai [IChimei] (Takaski Miike, 2011), 157, 182, 308.

Ju-on: The Curse [Ju-ON] (Takashi Shimizu, 2000), 206, 207, 208, 215, 309.

JU-ON: The CURSE 2 [JU-ON 2] (Takashi Shimizu, 2000), 206, 210, 215, 309.

JU-ON: The Grudge [Ju-ON] (Takashi Shimizu, 2002), 30, 159, 182, 206, 209, 210, 215, 239, 309.

JU-ON: The GRUdGe 2 [JU-ON 2] (Takashi Shimizu, 2002), 206, 216, 309.

KWAIDAN [KAIDAN] (Masaki Kobayshi, 1964), 157, 158, 182, 309.

The LOCKer [ShibUYA KAIDAN] (Kei Harie, 2004), 185, 216, 309.

On a Paper Crane: Tomoko's Adventure [Tsuru ni notte: Tomoko no bouken (Arihara Seiji, 1994), 172n, 182, 309 .

One Missed CALl (Eric Valette, 2008, U.S./Japan), 221, 223, 239, 309. 
One Missed Call [Chakushin Ari] (Takashi Miike, 2003), 185, 309.

Onibaba (Kaneto Shindô, 1964), 158, 182, 309.

Princess Mononoke (Hiyao Miyazaki, 1997), 175n, 183, 310.

Pulse [KaIRo] (Kiyoshi Kurosawa, 2001), 221n, 239, 310.

REINCARNATION [RINNE] (Takashi Shimizu, 2005), 185, 216, 221, 239, 310.

RINGU (Hideo Nakata, 1998), 15, 18, 27, 155, 156, 157, 159, 173, 175, 183, 185, 190, 191-206, 212, 216, 220 ,

221, 228, 229, 239, 266, 269, 270, 271, 273, 282, 310.

RINGU 2 (Hideo Nakata, 1999), 156n, 183, 193, 201, 202, 204, 216, 310.

RingU 0: BIRTHDAY [RINGU 0: BASUDEI] (Norio Tsuruta, 2000), 192, 197, 20of, 201, 202, 216, 310.

SADAKO 3D (Tsutomu Hanabusa, 2012), 156n, 183, 285, 287, 310.

SADAKO 3D 2 (Tsutomu Hanabusa, 2013), 183, 285, 287, 310.

SADAKO VS KAYAKO (Kōji Shiraishi, 2016), 285, 287, 310.

Ugetsu [Ugetsu Monogatari] (Kenji Mizoguchi, 1953), 157, 183, 311.

\section{South Korea}

The Ring Virus [Hangul] (Dong-bin Kim, 1999), 221n, 239, 310.

\section{Mexico}

The Devil's Backbone (Guillermo del Toro, 2001, Spain/Mexico), 15, 27, 96, 97n.2, 99, 101, 117, 121, $122,132,133-138,143,144,149,15^{0}, 220,222$ n.4, 239, 307.

Don't Be Afraid of the Dark (Troy Nixey, 2010, U.S./Mexico), 285, 286, 307.

Pan's Labyrinth [El LABERINTO DEL FAUNo] (Guillermo del Toro, 2006, Spain/Mexico), 97n, 118, 310.

VIRIDIANA (Luis Buñuel, 1961, Spain/Mexico), 108, 119, 254, 264, 311.

\section{Portugal}

Tombs of the Blind Dead [La noche del terror Ciego] (Amando de Ossorio, 1972, Spain/

Portugal), 107n, 118, 311.

Painless [Insensibles] (Juan Carlos Medina, 2012, Spain/France/Portugal), 97n, 118, 310.

\section{Spain}

The Abandoned (Nacho Cerdá, 2006, Spain/U.K./Bulgaria), 221, 239, 307.

ANA AND THE Wolves [ANA Y LOS LOBAS] (Carlos Saura, 1973), 107, 117, 307.

An Angel has Appeared [Ha Llegado Un ANGel] (Luis Lucia, 1961), 105, 106, 117, 141f, 150, 307.

A RAY OF Light [UN RAYo SE LUZ] (Luis Lucia, 1960), 141f, 150, 307.

BiCYCLES ARE FOR SUMMER [LAS BICICLETAS SON PARA EL VERANO] (Jaime Chávarri, 1984), 114n, 117, 307.

Cousin Angelica [La prima Angélica] (Carlos Saura, 1974), 107, 117, 307.

The Dark Hour [LA hora Fría] (Elio Quiroga, 2006), 97n, 117, 307.

DARKNESS (Jaume Balagueró, 2002, U.S./Spain), 222, 224, 228, 239, 307.

Death of Mikel [La MUerte de Mikel] (Imanol Uribe, 1984), 114n, 117, 307.

The Devil's Backвone (Guillermo del Toro, 2001), 15, 27, 96, 97n.2, 99, 101, 117, 121, 122, 132, 133-138,

$143,144,149,150,220,222$ n. 4, 239, 307.

Eugenia de Montijo (José López Rubio, 1944), 7n, 117, 307.

Fragile [Frágiles] (Jaume Balagueró, 2005, Spain/U.K.), 222, 223, 227, 228, 239, 308.

The Heifer [LA VAQUilla] (Luis Garciá Berlanga, 1985), 114n, 117, 308.

The Hunt [LA CAZA] (Carlos Saura, 1966), 108, 118, 308.

In a Glass Cage [Tras el Cristal] (Agusti Villaronga, 1987), 114, 118, 308.

INÊS DE CASTRo (José Leitão de Barros, 1944), 104n, 118, 308.

INTRUDERS (Juan Carlos Fresnadillo, 2011, U.S./Spain/U.K.), 285, 287, 308.

Julia's Eyes [Los ojos DE Julia] (Guillem Morales, 2010), 101n, 118, 308.

The Legion's For Me! [¡A Mí LA Legion!] (Juan de Orduña, 1942), 103n, 118, 309.

The Madness of Love [Locura De AMOR] (Juan de Orduña, 1948), 104n, 118, 309.

Mama (Andrés Muschietti, 2013, Canada/Spain/U.S.), 285, 287, 309.

Martyrs of the Philippines [Los úlitmos de Filipinas] (Antonio Román, 1945), 103n, 118, 309. 
Night of the Howling Beast [La maldición de bestia] (Miguel Iglesias, 1975), 107n, 118, 309.

The NAmeless [Los Sin NOMBre] (Jaume Balagueró, 1999), 27, 30, 96, 99, 118, 121, 132, 138-144, 150, 309 .

The Orphanage [El orfanato] (Juan Antonio Bayona, 2007), 27, 30, 96, 99, 101n, 102n, 118, 22, 132, $135,138,140,144-148,151,220,222,239,309$.

The Others [Los otros] (Alejandro Amenábar, 2001, Spain/U.S.), 6, 16, 30, 99, 100, 101n, 118, 222, $225,227,232,235,236,239,241,248,249,250-253,258,260 f, 261 \mathrm{n}, 262,264,271,279,280,282,310$

Painless [Insensibles] (Juan Carlos Medina, 2012, Spain/France/Portugal), 97n, 118, 310.

Pan's Labyrinth [El LABerinto Del Fauno] (Guillermo del Toro, 2006, Spain/Mexico), 97n, 118, 310.

Peppermint Frappé (Carlos Saura, 1967), 108, 118, 310.

RACE [RAZA] (José Luis Sáenz de Heredia, 1941) 104-105, 118, 310.

RAise Ravens [CRía CUERvos] (Carlos Saura, 1976), 107, 108, 109, 111, 118, 121, 122, 125-131, 138, 145n, $151,310$.

SHIVER [ESKAlOFRÍo] (Isidro Ortiz, 2008), 97n, 118, 311.

Spanish Movie (Javier Ruiz Caldera, 2009), 250, 264, 311.

The Spirit of the Beehive [El espíritu DE LA COLMENA] (Victor Erice, 1973), 107, 108, 109, 111, 118, $121,122,125^{-131}, 133,138,141,151,311$.

Tombs of the Blind Dead [La noche del terror Ciego] (Amando de Ossorio, 1972, Spain/ Portugal), 107n, 118, 311.

VAmpyros Lesbos (Jesús Franco, 1971, Spain/Germany), 107n, 118, 311.

Viridiana (Luis Buñuel, 1961, Spain/Mexico), 108, 119, 254, 264, 311.

Who Can Kill A Child? [¿QuiÉn PUde MataR A Un niño?] (Narciso Ibáñez Serrador, 1976), $109-111,119,143,151,311$.

\section{Sweden}

LET The Right ONE IN [LÅT DEN RÄTte KOMMA IN] (Tomas Alfredson, 2008), 15n, 309.

\section{Turkey}

D@BBE (Hasan Karacadag, 2006), 221, 239, 307.

U.K.

The Abandoned (Nacho Cerdá, 2006, Spain/U.K./Bulgaria), 221, 239, 307.

The ChILdRen (Tom Shankland, 2008), 15n, 307.

EXIstenz (David Cronenberg, 1999, Canada/U.K.), 69, 90, 307.

Eyes Wide Shut (Stanley Kubrick, 1999, U.S./U.K.), 69, 90, 307.

Fragile [Frágiles] (Jaume Balagueró, 2005, Spain/U.K.), 222, 223, 227, 228, 239, 308.

The Haunting (Robert Wise, 1963), 54, 65, 261n, 264, 308.

The InNocents (Jack Clayton, 1961), 220, 235, 239, 261n, 264, 308.

INTRUDERS (Juan Carlos Fresnadillo, 2011, U.S./Spain/U.K.), 285, 287, 308.

The Shining (Stanley Kubrick, 1980, U.S./U.K.), 31, 35, 36, 42-45, 47, 48, 50, 52, 53, 55, 56-6o, 65, 68,

$69,70,74,82,83,86,90,221,240,311$.

Sinister (Scott Derrickson, 2012, U.S./U.K.), 285, 287, 310.

The Village of the Damned (Wolf Rilla, 1961), 43, 65, 311.

U.S.

AUdrey Rose (Robert Wise, 1977), 40n, 64, 307.

The BAd Seed (Melvyn LeRoy, 1956), 10-11, 30, 43, 235, 239, 307.

The Changeling (Canada/U.S, Peter Medak, 1980), 12, 30, 35, 36, 40, 42, 53-56, 58-59, 64, 66-70, $72,74,82,90,261 n, 264,307$.

Child's Play (Tom Holland, 1988), 42, 64, 307.

DARK WATER (Walter Salles, 2005), 221, 223, 239, 307.

Don't Be Afraid of The Dark (Troy Nixey, 2010, U.S./Mexico), 285, 286, 307.

DARKNESS (Jaume Balagueró, 2002, U.S./Spain), 222, 224, 228, 239, 307.

The Exorcist (William Friedkin, 1973), 11, 30, 38, 43, 64, 67, 220, 235, 239, 307. 
Eyes Wide Shut (Stanley Kubrick, 1999, U.S./U.K.), 69, 90, 307.

FALLEN (Gregory Hoblit, 1999), 69, 90, 308.

Fight Club (David Fincher, 1999), 69, 90, 308.

Frankenstein (James Whale, 1931), 127-130, 141, 150, 308.

The Gift (Sam Raimi, 200o), 68n, 90, 308.

The Grudge (Takashi Shimizu, 2004, U.S./Japan), 159, 182, 221, 222, 223, 224, 229, 230, 231, 234, 239, 308.

The Grudge 2 (Takashi Shimizu, 2006, U.S./Japan), 221, 222, 223, 231, 239, 239, 308.

The GRudge 3 (Toby Wilkins, 2009, U.S./Japan), 221, 222, 223, 231, 308.

HALLOWEEN (John Carpenter, 1979), 62n, 65, 265, 308.

The Haunting (Jan de Bont, 1999), 69n, 90, 308.

House on Haunted Hill (William Malone, 1999), 68n, 90, 308.

INSIDIOUS (James Wan, 2010), 67, 82-87, 88, 90, 285, 286, 287, 308.

INSIDIOUS: CHAPTER Two (James Wan, 2013), 285, 286, 308.

Insidious: CHAPTER ThreE (Leigh Whannell, 2015), 285, 287, 308.

INSIDIOUS: THE LAST KEY (Adam Robitel, 2018), 285, 287. 308.

INTRUDERS (Juan Carlos Fresnadillo, 2011, U.S./Spain/U.K.), 285, 287, 308.

IT (Andrés Muschietti, 2017), 286, 287, 308.

JaWs (Steven Spielberg, 1975), 67, 90, 308.

Magnolia (Paul Thomas Anderson, 1999), 69, 90, 309.

Mama (Andrés Muschietti, 2013, Canada/Spain/U.S.), 285, 287, 309.

MATrix, The (Lily and Lana Wachowski, 1999), 69, 90, 309.

The OMEN (Richard Donner, 1976), 11, 30, 43, 44, 65, 220, 239, 309.

ONe Missed CALL (Eric Valette, 2008, U.S./Japan), 221, 223, 239, 309.

THE OTHER (Robert Mulligan, 1972), 40n, 65, 309.

The Others [Los otros] (Alejandro Amenábar, 2001, Spain/U.S.), 6, 16, 30, 99, 100, 101n, 118, 222,

$225,227,232,235,236,239,241,248,249,25^{0}-253,258,26$ of, 261n, 262, 264, 271, 279, 280, 282, 310.

Pirates of the Caribiean: At World's End (Gore Verbinski, 2007), 101, 118, 310.

Poltergeist (Tobe Hooper, 1982), 12, 30, 35, 36, 40, 42, 59-61, 65, 68, 70, 72, 74, 82, 83, 90, 220, 239, $285,287,310$.

Poltergeist (Gil Kenan, 2015), 285, 287, 310.

The Ring (Gore Verbinski, 2002), 6, 16, 31, 159, 183, 221, 222, 223, 229, 232, 233, 239, 248, 249, $265^{-279,280,282,285,310 .}$

The Ring Two (Hideo Nakata, 2005), 221, 223, 239, 285, 287, 310.

RINGS (F. Javier Gutiérrez, 2017), 285, 287, 310.

Room 237 (Rodney Ascher, 2012), 46n, 65, 310.

Rosemary's BABY (Roman Polanski, 1967), 11, 31, 310.

Scared Silent: Ending And Exposing Child Abuse (Melissa Jo Peltier, 1992), 70, 90, 310.

SCARY Movie 3 (David Zucker, 2003), 250, 264, 310.

SCARY Movie 4 (David Zucker, 2006), 23on, 239, 310.

The Shining (Stanley Kubrick, 1980, U.S./U.K.), 31, 35, 36, 42-45, 47, 48, 50, 52, 53, 55, 56-6o, 65, 68, $69,70,74,82,83,86,90,221,240,311$.

The Simpsons: Season 26, Episode 4 (Matthew Faughnan, 2014), 250, 264, 311.

SINISTER (Scott Derrickson, 2012, U.S./U.K./Canada), 285, 287, 310.

The Sixth Sense (M. Night Shyamalan, 1999), 15, 18, 31, 67, 8, 69, 70, 71-78, 81, 82, 88, 90, 101, 220, $239,310$.

Star Wars: Episode I - The Phantom Menace (George Lucas, 1999), 67, 90, 240, 311.

STIGMATA (Rupert Wainwright, 1999), 69, 90, 311.

Stir of Echoes (David Koepp, 1999), 67-70, 78, 79, 80-81, 82, 88, 90, 220, 240, 311.

Stranger Things (Matt and Ross Duffer, 2016-), 286, 287, 311.

THI3EEN GHosts (Steve Beck, 2001), 68n, 91, 311.

The Thirteenth Floor (Josef Rusnak, 1999), 69, 91, 311.

What Lies BenEATH (Robert Zemeckis, 2000), 68n, 91, 311. 


\section{Index}

21st Century (see also millennium/the millennial), 9, 15, 16, 17, 19, 23, 26, 27, 69, 82, 88, 97, $100,101,102,121,148,158,159,160,163,175 \mathrm{n}$, 202, 212, 219, 222, 224, 226, 232, 241-250, 266, 274, 275, 279, 280, 285, 286.

Abandoned, The (Nacho Cerdá, 2006), 221, 239, 307 .

abjection/the abject, $39,47,49,72,77,78,83,86$, 156, 201, 234, 259, 271.

and hieroglyphs, 49 .

horror, 259.

and in-between, 47 .

space, $78,188$.

and spectral realm, 39 .

Academy Awards, 97n, 158n.

adult, the/adulthood, 9, 10, 12, 13, 14, 15, 17, 19, 21, $22,23,24,25,26,27,35^{-40}, 45,48,49,50,5^{1}$, $5^{2}, 53,56,57,58,59,61,62 \mathrm{n}, 67,69,70,71,72$, $73,74,75,76,77,78,79,80,81,82,83,84,85$, $86,87,88,95,96,102 \mathrm{n}, 105,110,123,126,128$, $129,130,131,132,133,134,138,139,143,145 \mathrm{n}$, $146,147,148,149,160,162,163,168,174,177$, $178,186,188,192,194,201,202,204,208,212$, 226, 228n, 244, 246, 247, 248, 249, 253, 255, $260,267,268,269,271,272,273,274,275,277$, $278,279,280,283,284,285,286$.

and 'age of reason,' 257 .

and the child/childhood (see also the child/

childhood), 10, 11, 13, 15, 17, 22, 23, 36, 37,

$38,39,48,52,55,69,70,72,75,77,81,85$, $95,105,144,146,147,163,202,247,278$.

discourse, 25, 57, 75, 253, 268, 276, 278, 279 . and the 'inner child' $13,24,70,76-77,79,81$,

$84,85,87,88,96,246$.

and childhood memory, 37, 81, 95 .

and futurity, 27, 131, 255 .

Japanese, 212.

nostalgia, 12, 81, 246.

and patriarchy, 61,67 .

and teenagers, 204.

unconscious/repressed psyche, $35,36-40$,

$45,49,53,55,70,72,73,77,81,83,95,163$. and trauma, 12, 35, 57, 73, 74-77, 88, 96, 279.

allegory, 97n, 100, 111, 112, 121, 123, 124, 125, 128, $129,132,133,134,135,136,137,138,140,141$, $142,143,144,145,147,148,158,186,193,202$, 221, 268 .

allegorical moments, 121, 123, 124, 125, 128,

$133,134,135,136,137,138,147,148,186$.

and historical trauma, 112, 124, 145, 158.

and horror genre, 112 .

of national narrative, 100, 124.

and uncanny child, 124.
Almodóvar, Pedro, 114.

American cinema (see also Hollywood; and transnational cinema), 9, 12, 15, 16, 17, 19, 67, $69,88,95,98,159,163,185,189,210,219,220$, 221, 222, 223, 224, 230, 231, 235, 236, 250, 265, 266n, 268, 274n, 285 .

in the 1980 s (see also American horror film), 163 .

in 1999,67 .

co-productions, 16, 19, 27, 36n, 219, 222, 225, $236,242,244,250$.

and Freud, 98.

and Japanese cinema, 221, 224.

and horror genre (see American horror cinema).

as pervasive, 15 .

remakes/reboots (see also transnational cinema), 155, 157, 159, 210, 221, 224, 230, 265,266 n.

and transnational/cross-cultural cinema, 16 . and uncanny child/children, 15, 19, 88, 235 .

American horror film (see also American cinema; Hollywood; and psychoanalysis), $9,12,15,26,35,38,6$ on, 68, 159, 221, 222, $223,224$.

of the 1980 s, $9,12,15,35,36,38$.

decline of, 222, 224.

as ideological conflict, 38 .

and J-horror, 220.

and uncanny child/uncanny childhood, 12, 15, 26,163 .

and uncanny child films (see uncanny child film)

American national identity (see also American cinema; American horror film; history;

Hollywood; and national identity), 16, 19, 23, 41, 42, 6o, 61, 68, 74, 221, 227, 230.

accents, 227 .

and American culture, 19, 42, 55, 23 on.

'Americanization' (see also ‘Hollywoodization'), 221.

centralization to narrative, 230.

and the child/childhood (see also the child/ childhood), 88, 162.

cultural anxieties, 16 .

cultural translation, 228.

and the family, 41, 228.

historical metanarrative, 6o, 76 .

history, 76 .

and Hollywood (see American cinema and

Hollywood).

and ideology, 41.

interest in ghosts, 69 .

and law, 76 .

at the millennial turn, 17 . 
national anthem, 60 .

and patriarchy, 61.

sociocultural structures, 74 .

American Latino Media Arts Awards, 101.

Amsterdam Fantastic Film Festival, 101.

ANA AND THE WOLVES [ANA Y LOS LOBAS]

(Carlos Saura, 1973, Spain), 107, 117, 307.

analogue (see also digital), 15, 156, 193, 194, 233,

$265,266,267,268-176,279$.

aesthetics, 156, 194, 268, 270 .

and decay, 233, 267, 268, 269, 270, 271, 272, $275,276,279$.

and digital (see also digital), 266267,269 , 272.

ghosts, 265 .

materiality, 233

and the millennial turn, 156 .

noise, 269 .

nostalgia, 274 .

television, 269, 275 .

transition to digital (see also digital), 15 , $265,269,274$.

video, 194, 267, 273.

Arai, Andrea, 175n, 176, 177, 178, 289 .

Ariès, Philippe, 74-75, 89, 289.

art film, 101, 107-109, 122, 124, 125, 132, 137, 158 .

art-horror (see horror genre).

child-centered, 111-113.

and cultural trauma, 109, 124.

exchange with horror genre, 132.

in Franco-era, 121.

and period drama, 157 .

BAD SeEd, The (Melvyn LeRoy, 1956), 10-11, 30, $43,235,239,307$.

Benjamin, Walter, 123, 124, 149, 244.

Baudrillard, Jean, 242, 243, 245, 246, 263, 290.

Benson-Allott, Caetlin, 193, 213, 233, 237, 270,

272n, 275, 280, 290.

Berlin International Film Festival, 108.

Blake, Linnie, 113, 115, 16o, 179, 190.

Blum, Virginia, 35, 62, 290.

Bruhm, Steven, 13, 28, 28, 62, 291.

Buñuel, Luis, 108, 119, 254n, 264, 311.

Cannes Film Festival, 108, 158.

Carroll, Noël, 19, 28, 291.

Carter, Jimmy, 40, 62, 291.

Caruth, Cathy, 24-26, 28, 37, 53, 62, 73, 89, 110, $111,115,122,125,127,128,136,149,188,191,193$, 205, 207, 213, 291.

Cerdà, Nacho,221, 239, 307.

Changeling, The (Peter Medak, 1980), 12, 30, $35,36,40,42,53-56,58-59,64,66-70,72$, $74,82,90,261 \mathrm{n}, 264,307$.

child, the/childhood (see also the adult/adulthood; the family; futurity; progress; trauma; the uncanny child/uncanny childhood; and uncanny child film cycle) and abuse, 24, 45, 70, 175, 176, 208. and the adult/adulthood (see the adult/ adulthood), 10, 11, 13, 15, 17, 22, 23, 36, 37, $38,39,48,52,55,69,70,72,75,77,81,85$, $95,105,144,146,147,163,202,247,278$. and aesthetics of decay, 241, 244, 246. and the adult unconscious, $17,35,38,5^{\circ}$. as betweenness, 10, 11, 14, 18, 22, 23, 24, 37, $38,39,43,44,46,47,52,55,57,69,72,88$, $124,125,126,135,137,144,145,146,147$, $156,161,208,236$.

as blank slate, $9,10,11$.

children of Franco (see also Spanish cinema; Spanish history; Spanish national identity), 104, 125, 131, 149. cine con niño (see also Spanish cinema), 105-106, 110, 130, 134, 140.

as collective progress, 14 .

as consumer, 41,42 .

and cuteness, 9, 10, 11, 38, 39, 52, 79 .

definition, 23.

and the family (see also family), 9, 41, 42, 45, $59,104,105,169,175,176,208,255$.

and Freud (see also Sigmund Freud), 13, 19, $23,25,35,36,37,38,39,74,162,163$.

and futurity (see also futurity; and progress), 14, 15, 21, 22, 27, 123, 168, 169, $185,206,242,249,258,259$.

gaze, $84,85,125,126,127 \mathrm{f}, 135 \mathrm{f}, 136,137,138$, $139,140,142,147,261$.

as ghost or spectre, 18, 123, 130, 16o, 187, 188, $251,257,259,270$.

and the gothic (see also gothic), 12, 95 . growing sideways, 21-22.

and hieroglyphs, 49, 50, 51, 52, 71, 79, 83 . as horror trope (see also horror genre), 11 as internal alien, $160,161,162,163,178,185$, 188, 202, 203, 204, 208, 212.

and lack of reason, 10, 13 .

"lost child" trope, 83, 141, 147 .

and the millennium (see also millennium/ millennial), 9, 12, 16, 17, 62, 67, 157, 211, $225,226,242,284$.

as monstrous (see also Gilles Deleuze), 10, $16,25,27,42,58,110,114 \mathrm{n}, 115,122,123$, $166,178,202,211,220,267,271,283$.

and national trauma, 27, 104, 112, 131, 155 .

and secrets, $23,37,39,40,51,52,53,54,57$, $69,70,72,79,82,132,163,192$.

as seer (see also Gilles Deleuze and uncanny child film), 121, 123, 125, 126, 128, 130, 131, 132, 143, 144, 147, 220. as sleep of reason, $10,25,27,283,285$. symbolic function/construct, 9, 15, 18, 21, 219, 279 .

temporal vectors, 13, 18, 23, 204, 246, 253 . as uncanny other, $9,10,12,13,18,20,23,24$, $37,38,39,42,47,55,57,61,74,75,76,83$, $84,85,95,126,188,230,231,235,159,268$, 283,286 . 
vessel-for-evil trope, 12. as work in progress, 14.

Children's Peace Monument (Hiroshima Peace Park), 172, 173, 183, 313 .

Child's Play (Tom Holland, 1988), 42, 64, 307. CoUsin ANGELICA [LA PRIMA ANGÉLICA] (Carlos Saura, 1974, Spain), 107, 117, 307.

Creed, Barbara, 50, 62, 291.

D@BBE (Hasan Karacadag, 2006), 221, 239, 307.

DARKNESS (Jaume Balagueró, 2002), 222, 224, $228,239,307$.

Dark Water [Honogurai Mizu No Soko KARA] (Hideo Nakata, 2002), 185, 215, 221, 223, 239, 307.

déjà vu, $54-55,73,77,79-80$.

Deleuze, Gilles, 20, 26, 57, 86, 123, 125, 126, 128, $129,135,136,142,194,203,225,249,280$. any-space-whatever, 129, 131, 134, 135, 136, $139,143,144,145,149$.

cinema of seeing, 128 . crystal of time, 135,136 .

definition of monstrosity, 123,136 . deterritorialization (see also globalization; and transnational cinema, 134, 225, 226, 229, 231, 232, 234, 236, 260, 273, 274, 275, 279 .

child seer (see also the child/childhood; and uncanny child film cycle), 123, 125, 126, 128, 130, 131, 132, 143, 144, 147, 220. encompassing situation, 125, 130, 140. sensory-motor-schema, 86 . pure optical situation, 125,128 . time-image, $26,57,86,123$.

Derrida, Jacques, 39, 62, 292.

deterritorialization (see also Gilles Deleuze; and globalization), 134, 225, 226, 229, 231, 232, 234, 236, 260, 273, 274, 275, 279.

Devil's BACKBONE, The (Guillermo del Toro, 2001), 15, 27, 96, 97n.2, 99, 101, 117, 121, 122, $132,133-138,143,144,149,150,220,222$ n. 4 , 239,307 .

digital, 16, 156, 159, 193, 231, 232, 233, 234, 236, $242,265,266,267,269,271,272,274,275$, 276,279 .

and analogue decay, 274, 279 .

becoming-, 279 .

cinema, 233 .

and deterritorialization, 234, 275 .

emergence/rise of, 233, 236, 269, 271, 272, $275,276$.

and film, 231, 234 .

and globalization, $23^{2}$.

and home viewing, 159, 232, 267.

and J-Horror, 234.

media, 234, 236, 266, 272, 274, 275 .

millennial transition, 156 .

phantoms, 265 .

and postmodern horror, 231. production, 234 .

storage, $16,156,193$.

technologies, 16, 159, 233, 234, 242, 266, 267, 269, 271.

transition from analogue, $16,156,193,233$, 234, 266, 267, 269, 272-273, 274 .

Edelman, Lee, 14, 21, 22, 28, 97, 106, 115, 123, 138, $144,149,185,213,242,246,263,269,280,281$, $283,284,286,292$.

Enlightenment, the, 9, 242.

Eríce, Victor, 107, 108, 118, 121, 122, 125, 131, 151, 311.

Exorcist, The (William Friedkin, 1973), 11, 30, $38,43,64,67,220,235,239,307$.

Eyes Without a Face [Les Yeux Sans Visage] (George Franju, 1960), 197, 215, 307.

FALLEN (Gregory Hoblit, 1999), 69, 90, 308. family (see also the child/childhood; and the adult/adulthood), 9, 10, 11, 41, 42, 44, 53, 54, $56,59,61,75,78,81,83,85,86,87 \mathrm{f}, 104,105$, 131, 144, 168, 169, 175, 176, 183, 207, 208, 221, 228, 232, 251, 252, 253, 255, 259, 261, 273. in the $195 \mathrm{os}, 86,87 \mathrm{f}$. in the 1980 s, 45,175 . in the $1990 \mathrm{~s}, 169$. American, 41, 228. and the child (see also the child/childhood), 9, 41, 42, 45, 59, 104, 105, 169, 175, 176, 208,255 .

fractured unit, 42, 207 .

and Freud, 42.

and ideology, 41, $25^{2}$.

Japanese, 175,176 .

melodrama genre, 10 .

modern, 176, 266.

nuclear, 11, 41, 45, 59, 86, 104, 105, 255.

patriarchal, 104.

and the school, 9 .

Festival international du film fantastique de Gérardmer, 101.

film festivals, 101, 108, 111n, 158, 233.

Foucault, Michel, 186, 200, 213, 277, 281, 293.

Fragile [FrÁgiles] (Jaume Balagueró, 2005), 222, 223, 227, 228, 239, 308.

FRANKENSTEIN (James Whale, 1931), 127-130, $141,150,308$.

fin-de-siècle (see also millennium), 17n, 69, 242,245 .

Franco, Francisco (see also history; memory; Spanish cinema; Spanish history; Spanish national identity; and trauma), 27, 95-98, 102-106, 107-109, 110, 11, 112, 113, 114, 115, 121, $122,123,125^{-131}, 134,138,141,142,144,148$, 149, 254n.

children of Franco (see also child/childhood), 104, 125, 131, 149. 
and the child/childhood, 27, 95-97, 104, 105, $106,107,109,110,111,112,121,122,123,125$, $130,131,134,144,148,149$.

and censorship, 100, 102, 107, 109, 131 .

Francoist aesthetic, 111, 131.

Francoist discourse, 27, 113, 121, 125 .

Francoist regime, 95, 96, 98, 100, 102, 103, $105,107,121,122,126,148$.

propaganda, 95, 96, 103, 125 .

and ideology/mythology, 97, 103, 104, 105, $106,129,144$.

and national progress, $27,95,96,97,102,105$, $112,115,123,125,128,129,130,134$.

Nationalism, 102, 103, 105, 106, 123 .

illness and death, 97, 100, 105, 107, 109, 113, $114,125,126-127,128,129$.

Freud, Sigmund (see also horror genre; psychoanalysis; the uncanny), 12, 13, 19, 20, $22,23,24,25,35,36,37,38,39,42,48,49$, $50,54,55,57,71,74,88,95,96,98,132,162$, $163,248$.

adult psyche, 49,88 .

and childhood, $13,19,23,25,35,36,37,38$, $39,74,162,163$.

'inner child,' 24.

Little Hans, 49, 50, 71.

Oedipal complex, $5^{\circ}$.

psychoanalysis, $24,35,163$.

on trauma, $37,54,57,95,96$.

and the uncanny, 12, 22, 23, 39, 132, 248 .

futurity (see also the adult/adulthood; the child/childhood; and progress), 14, 15, 17, 19, $21,22,27,40,61,69,123,131,138,144,163,165$, $168,169,178,185,199,205,206,212,236,241$, $246,248,249,250,255,258,269,276,279$, $280,283,284$.

and the adult/adulthood, 14, 21, 27, 61, 131 . and the child/childhood (see also the child/

childhood), 14, 15, 21, 22, 27, 123, 168, 169, $185,206,242,249,258,259$.

embodiment of, 15, 17, 168, 259 .

and the millennium, 17, 69, 242.

national, 163, 169, 206, 212, 236.

nostalgic, 246.

and progress, 14, 19, 21, 165, 178, 199, 205, 206, 236, 243, 276, 279, 283 .

\section{GHOSt StoRy of YotsuYa [TôKaidô Yotsuya} KAIDAN] (Nobuo Nakagawa, 1959), 157, 158n, $60,182,308$.

globalization (see also deterritorialization; and transnational cinema), $15,17,18,156,219$, 225, 226, 228, 231, 232, 236, 238, 245 . cultural exchange, 224, 226, 236. and deterritorialization, 232. and digital transition, 232. global transition, $15,17,18,156$. and Hollywood, 222, 223, 225, 226, 228, 266. and media culture, 226, 236. and millennial turn, 220.

and postmodernism/postmodern era, 225, 226,245 .

and transnational cinema, 15, 16, 219, 220, 221, 222, 223, 227, 231, 232, 234.

gothic, the (see also horror genre; and the uncanny child film cycle), 10, 12, 20, 68, 75, 95, 97, 100, 101, 236.

and childhood, 12, 95 .

Goya artwork, 10.

and supernatural horror, 68, 75, 95, 97 . millennial boom, 68 .

Spanish gothic (see also Spanish horror cinema), 95n, 100, 101.

Victorian, 236.

Goya, Francisco, 10, 30, 236, 283, 287, 313 .

Goya Awards, The, 225, 250.

Graham, Helen, 96, 104, 116, 294.

Grudge, The (Takashi Shimizu, 2004), 159, 182, $221,222,223,224,229,230,231,234,239,308$.

Grudge 2, The (Takashi Shimizu, 2006), 221, 222, 223, 231, 239, 239, 308.

Grudge 3, The (Toby Wilkins, 2009), 221, 222, $223,231,308$.

Halbwachs, Maurice, 98, 116, 94.

Halloween (John Carpenter, 1979), 62n, 65, $265,308$.

HARA-KiRi: DeATH OF A SAMURAi [ICHIMEI] (Takaski Miike, 2011), 157, 182, 308.

Haunting, The (Robert Wise, 1963), 54, 65, 261 , $264,308$.

Hiroshima Memorial Museum, 173.

Hiroshima Peace Park and Museum, 172, 183.

history (see also Japanese history; Japanese national identity; memory; Spanish history; Spanish national identity; and trauma), 13, $18,21,41,60,75,76,95,96,98,99,100,103$, $104,106,124,133,141,146,148,149,163,186$, $187,191,197,198,199,201,235,241,244,245$, 246, 247, 249, 251, 262, 275 .

American (see also American national identity), 76 .

of children's culture, 41.

and collective memory (see also Spanish national identity), 98,99 .

cultural, 199.

decline of, 245, 246.

film, 101, 265, 275 .

Hiroshima, 165, 171.

historical narrative, 76 .

historical uncertainty, 251, 283, 286.

Iwo Jima Monument, 60 .

national history, 98,149 .

nostalgia, 10, 55, 79, 84, 104, 192, 194, 196, 244, 272.

Personal memory, 13, 199. and postmodernism, 243. reconstructing, 198. 
and spectator, 124,137 .

and teleological narratives, 96, 103, 124, 130,

$141,144,148,151$.

Hollywood (see also American cinema; and transnational cinema), 16, 26, 27, 29, 99, 101, $159,190,196 \mathrm{n}, 198,219,220,221,222,223,224$, 225, 226, 228, 230, 266, 270.

blockbusters, 101, 159, 266.

classical style, 16, 26, 196n.5, 270., as cultural homogeneity, 224, 225, 226. continuity editing, 26 .

as genre, 16 .

'Hollywoodization,' 223-226.

horror (see also horror genre), 159, 190, 221. and J-horror, 27, 219, 221, 223, 224, 228, 266. transnational remakes(see also transna-

tional cinema), 16, 27, 159, 219-226, 228

horror genre (see also American horror film; gothic; J-horror; psychoanalysis; Spanish horror film; uncanny; and uncanny child films), 11, 12, 15, 16, 20, 61, 62, 67, 68, 100, 101, $112,124,132,157,189,221$.

allegorical moment, 121, 123-125, 128, 132,

$133,134,135,136,137,138,147$.

and art film/art-house horror, 112.

as collective nightmares, 20

definition of, 14, 16, 20, 22, 23.

and demonic possession, 11 .

and evil child trope, 12,13 .

shift from family melodrama, 10.

and the gothic, 68, 96, 100-101.

and ghost narrative, 19, 59, 71 .

and the millennial turn, $21,55-178,189,191$,

$212,220,265,285$.

and the monstrous child, 10, 16, 27, 220.

and mutant child seer (see also uncanny

child film), 132,133, 140, 143 .

and national trauma, 112, 185 .

franchises, $68,155,156 \mathrm{n}, 185,207,220,221$, $222,223,231,265,285$.

and music, 54, 55, 79, 80, 173 .

progressive function, 20.

and psychoanalysis, $23,24,163$.

remakes, $16,27,163,210,219-234,242,244$ 265 .

as 'return of the repressed', 84, 122, 132 .

and the sensorium, 190.

and soundscape, 194, 197

slasher subgenre, 68 .

supernatural subgenre, $12,15,26,27,68,158$,

$187,221,222,235,270,285$.

theory of, 11, 12, 15, 16, 20, 61-62, 67, 68, 224. transnational renaissance, $15,101$.

uncanny child subgenre (see uncanny child film).

Hunt, The [La CazA] (Carlos Saura, 1966), 108, $118,308$. ideo-aesthetics (see also J-horror), 190, 193, 198, 199, 201, 203, 204, 206, 235, 284.

In a Glass CAGe [Tras el CRISTAL] (Agusti Villaronga, 1987), 114, 118, 308

INÊS DE CASTRo (José Leitão de Barros, 1944), 104n, 118, 308.

INNOCENTS, THE (Jack Clayton, 1961), 220, 235 239, 261n, 264, 308.

Insidious (James Wan, 2010), 67, 82-87, 88, 9o, $285,286,287,308$.

International Horror Guild, 101.

Jackson, Kathy Merlock, 10n, 11, 16, 29, 299. Japanese cinema (see also Japanese history; Japanese national identity; and J-horror), 15 , $16,27,155,157,158,159,196,220,221,223,224$, $225,265,268$.

folktale films, 158, 198 .

and horror genre (see also J-horror), 15, 16, $27,57,156,157-160,221,225,265$.

and Japanese theatre, $158,196,199$.

and Kabuki and Noh, 156, 158, 196, 197, 199, 235 .

Kurosawa, Kiyoshi, 157, 221n, 239, 310.

and Lost Decade, $155 \mathrm{~m}, 157$.

Miike, Takashi, 157, 182, 185, 216, 223, 308, 309.

Shimizu, Takashi, 27, 30, 157, 159, 169, 182, $185,206,215,216,221,223,224,239,308$, 309, 210.

Japanese history (see also history; Japanese national identity), $167,186,187,191,196,198$, 201.

Lost Decade, 27, 155, 159, 164-167, 174, 175 , $186,193,211,212,213,229,235$.

Hiroshima, 165, 171, 172, 173.

Meiji Restoration, $161,163,165,167,168,169$, $170,171,186,188$.

and Modernity, 158, 161, 163, 165, 167, 168, $175,198$.

and World War II, 27, 155, 157, 158, 164, 167, $165,166,171$.

Japanese national identity (see also history; memory; national identity; Spanish history; Spanish cinema; Spanish national identity; and trauma), 27, 155, 157, 159, 164, 171, 212. bubble economy, 159, 164, 166.

and the child/childhood (see also the child/ childhood; the uncanny child; and the uncanny child film cycle), 9, 17, 19, $27,155,157,159,160,161,163,167-171$, 171-175-178, 185-188, 192, 193-194, 198, 199, 201, 202, 204, 206, 211-213, 220-222, 234-236.

collapse of progress, 164, 191.

and counter-memory,186, 196, 198, 199, 200. as historical narrative, $185,186,187,196$, $213,229$. 
internal alien (see also J-horror), 160-163, 178,185 .

Japanese-ness, 230, 235 .

and the Lost Decade (see Japanese history).

and the millennium (see also millennium/ millennial), 194, 206, 208, 229.

and nostalgia, 194, 196, 198.

post-World War II, 27, 155, 157, 158, 167 . postwar consciousness, 171-175, 186, 199, 153 .

and prosthetic trauma (see trauma). strange-changed child, 175-178, 208.

Jenks, Chris, 13, 14, 24, 28, 243, 244, 247, 255, $263,284,286,295$.

J-horror (see also millennium; the uncanny child/childhood; the uncanny child film cycle; horror genre; Japanese cinema; Japanese history; Japanese national identity; trauma), 16, 27, 57, 155, 156, 157, 158, $159,160,161,162,163,166,167,169,173,178$, $185,186,187,188,189,190,191,192,193,212$, 217, 220, 221, 223, 224, 228, 231, 234. and adult female ghosts, 160 . and art-horror, 157, 158, 160 .

and Butoh (see also Japanese cinema), 156, 199, 201, 235 .

child/children, $161,162,163,166,167,173,187$, 188,189 .

and counter-memory, $185,186,196,198,199$, $200,212$.

and digital technology, 16o, 229, 232.

and the horror sensorium, 185, 189-191, 192, 195, 207, 212.

and ideo-aesthetics, 190, 193, 198, 199, 201, $203,204,206,235,284$.

and the internal alien, $185,188,202,203$, 204, 208, 212.

kaidan, 158, 160, 220.

and Lost Decade, 27, 155, 159, 165, 167, 186, $193,212,229,235$.

millennial, 16o, 161, 163, 185, 187, 188, 189 .

as movement, 159,167 .

as national cinema, 157, 159, 220.

onryō and yūrei, 16o, 161, 197, 235.

prosthetic technologies, 206, 231.

remakes, 27, 219, 222n, 223, 224n, 228.

and uncanny child/children, $155,157,159$, $160,162,163,166,178,185,186,188,190$, 212, 219, 220, 221, 231.

Ju-ON: The Curse [Ju-ON] (Takashi Shimizu, 2000), 206, 207, 208, 215, 309.

JU-ON: The CURSE 2 [JU-ON 2] (Takashi Shimizu, 2000), 206, 210, 215, 309.

Ju-ON: The Grudge [Ju-ON] (Takashi Shimizu, 2002), 30, 159, 182, 206, 209, 210, 215, 239, 309 .

Ju-ON: The GRUdGe 2 [Ju-ON 2] (Takashi Shimizu, 2002), 206, 216, 309 .
Kendrick, James, 67, 68, 89, 296.

Kincaid, James, 20, 24, 28, 70, 81, 89, 296.

Kinder, Marcia, 104, 108, 116, 131, 149, 296.

King, Stephen, 42, 47, 49, 63, 296.

Klein, Christina, 223, 224, 238, 296.

Kristeva, Julia, 47, 50, 51, 63, 297.

Kubrick, Stanley, 12, 31, 35, 36, 42, 43, 44, 47, 62, $63,64,65,69,90,307,311$.

KWAIDAN [KAIDAN] (Masaki Kobayshi, 1964), $157,158,182,309$.

Labanyi, Jo, 96, 108n, 111n, 114, 133, 150, 297.

Lacan, Jacques, 23n, 48, 50, 63, 71n, 137, 297.

Landsberg, Alison, 98, 99, 116, 123, 150, 185, 186, $187,188,190,214,297$.

Lázaro-Reboll, Antonio, 99n, 100, 101, 108, 109, $110,133,140,150,220,238,297$.

Lennard, Dominic, 10n1, 12n.2, 16, 29, 41-42, $64,298$.

Locke, John, 9, 29, 298.

Lowenstein, Adam, 25, 112, 121, 123, 124, 125, 128, 132, 137, 142, 147, 149, 16on, 171, 192n, 193, 220, 266n, 169, 274n, 278n.

Lury, Karen, 16, 160, 163, 176, 192.

Marks, Laura U., 195, 198, 203, 205, 214, 274, 281, 298.

Martin-Jones, David, 111n, 116, 126, 150, 298.

McGowan, Todd, 137, 138, 147, 150, 299.

McRoy, Jay, 16o, 18o, 192n, 197n, 214, 221, 224, 226, 230, 299.

memory (see also history; and trauma), 37, 70, $81,84,89,95,96,98-100,111,114,122,129$, $136,141,146,148,162,166,174,185^{-188,190,}$ 195, 196, 198, 199, 200, 201, 204, 205, 212, 249. and childhood, 37,70 .

collective/cultural, 89, 95, 96, 98-100, 121, $148,186,198$.

counter-, 185, 196-200.

and law, 146.

personal, 199 .

politics of, 111 .

prosthetic, 185, 187, 190.

and Spanish national identity, 122.

traumatic, 114, 195, 196, 205.

metanarratives, 14, 6o, 76, 76, 103, 125, 129, 245 .

millennium/millennial (see also 21st Century; and globalization), 9, 12, 16, 17, 15 n.6, 27, 62, $67,68,69,70,82,88,95,97,99,101,102,111$, $112,115,121,122,123,124,132,155,156,157,158$, $160,161,163,178,184,185,191,192,202,211$, 219, 222-224, 226, 239, 241, 242, 245, 248, $252,265,268,280,283,285,286$.

anxieties, 17, 68, 69, 163, 229, 28o,

fin-de-siècle, 17n, 69, 242, 245 .

turn, 9, 12, 16, $2127,62,67,69,88,102,155$, 156, 178, 185, 186, 189, 191, 194, 202, 206, $208,211,212,219,220,224,226,241,242$, $245,246,252,265,283,284,286$. 
and the child/childhood, 9, 12, 16, 17, 62, 67, $157,211,225,226,242,284$.

and digital (see also digital), 156 .

and horror film (see also horror genre), 16 ,

$18,20,22,23,27,99,101,102,111,112,121$, $123,124,155,220,222,224$.

and J-horror (see also Japanese cinema; Japanese history, and Japanese national identity), $155,156,157,160,161,163,185$, $187,188,189,212,234$.

and Spanish cinema (see also Spanish cinema; Spanish history; and Spanish national identity), 95, 97, 98, 99, 101, 111, $115,121,122,123,132$.

and transnational cinema (see also transnational cinema), 222, 240. and uncanny child film (see also the uncanny and uncanny child films), 12, $15,16,18,20,70,82,88,97,112,115,124$, $132,155,220,265,283,285$.

modernity, 9, 97, 102, 106, 114, 115, 123, 141, 158, $161,163,163,165,167,168,169,175,241,243$, $244,247,250,251$. and the child/childhood, 167-169, 247 . the decline of, 250, 251.

and ghosts, 257 .

hypermodernity, 114, 115, 123, 141.

and postmodernity (see also postmodernism), 251.

premodernity, 198.

shift to, 161-162, 165 .

monstrosity, 10, 11, 20, 43, 123, 136, 235, 268, 270.

and the child, 11.

Deleuze's definition (see also Gilles Deleuze), 123,136 .

NAmeless, The [Los SIN NOMbre] (Jaume Balagueró, 1999), 27, 30, 96, 99, 118, 121, 132, 138-144, 150, 309.

Napier, Susan, 161, 162, 163, 164, 181, 299. national identity (see also American national identity; Japanese national identity; memory; Spanish national identity; and trauma), 17, 19, 27, 29, 60, 61, 89, 96, 99, 112, $113,115,124,124,132,141,148,155,157,159$, $163,164,165,171,174,212,219,224,226,236$, 283 .

and collective memory, 95, 98, 99, 100. and cultural/historical trauma, 19, 27, 112. and national narrative, 105,115 .

and national progress, 19, 27, 96, 112, 115, 124, $155,163,164,165,212,236$. and national time, 132,171 . and transnational hybridity, 27, 219, 226.

Natoli, Joseph, 68, 89, 241, 263, 299.

Ndalianis, Angela, 185, 189, 190, 204, 210, 214, 300.
OMEN, The (Richard Donner, 1976), 11, 30, 43, 44, 65, 220, 239, 309.

On a Paper Crane: Tomoko's Adventure [TSURU NI NOTTE: TOMOKO NO BOUKEN (Arihara Seiji, 1994), 172n, 182, 309.

One Missed CALl (Eric Valette, 2008), 221, 223, 239, 309.

Onibaba (Kaneto Shindô, 1964, Japan), 158, $182,309$.

OrPhanage, The [El orfanato] (Juan Antonio Bayona, 2007), 27, 30, 96, 99, 101n, 102n, 118, 22, 132, 135, 138, 140, 144-148, 151, 220, 222, 239, 309 .

Others, The [Los otros] (Alejandro Amenábar, 2001), 6, 16, 30, 99, 100, 101n, 118, $222,225,227,232,235,236,239,241,248$, 249, 250-253, 258, 26of, 261n, 262, 264, 271, $279,280,282,310$.

"Paint it Black" song (Rolling Stones, 1966), 79, $81,91,315$.

PAN'S LABYRINTH [El LABERINTO DEL FAUNo] (Guillermo del Toro, 2006), 97n, 118, 310.

Peppermint Frappé (Carlos Saura, 1967), 108, $118,310$.

Phantom of the Opera, The, musical (Andrew Lloyd Webber, 1986), 197, 215, 304.

Poltergeist (Tobe Hooper, 1982), 12, 30, 35, 36, $40,42,59-61,65,68,70,72,74,82,83,90$, 220, 239, 285, 287, 310 .

postmodernism, $27,219,225,226,231,241,242$, 243, 244, 251, 266, 267, 268.

anxieties, 266.

and the child/ childhood, 27, 219, 241, 243, 267 .

emergence of, 251 .

and globalization, 225, 245 .

horror (see also horror genre), 231.

media culture, 226 .

and millennium, 225.

and progress, 242, 243, 244.

Prince Juan Carlos de Borbón, 107.

progress (see also the child/childhood; and futurity), 14, 17, 19, 21, 22, 25, 27, 95, 96, 97, $102,106,114,115,123,124,125,128,129,130$, $141,155,156,157,160,161,162,163,164,165$, $166,167,168,170,174,175,177,178,185,186$, 187, 191, 193, 196, 197, 198, 199, 201, 204, 205, 206, 209, 210, 212, 213, 225, 232, 235, 236, 241, $242,243,244,245,246,247,248,249,250$, $251,253,255,257,258,259,260,216,263$, $264,267,268,269,270,276,278,279,280$, 283,284 .

and the child/childhood, 14, 21, 39, 105, 112, $144,148,149,155,156,161-162,166,169$, $174,175,185,186,191,204,205,206,209$, $212,213,219,225,242,243,244,246$.

decline of, 242, 244, 248 . and decay, 241, 244, 248, 256, 259. 
and futurity, 14, 17, 19, 27, 123, 163, 165, 178, $199,205,206,236,242,243,246,248$, 250,255 .

historical, 17, 19, 22, 67, 68, 123, 144, 261, 262. and linearity, $18,21,57,58,76,98,106,136$, $186,189,191,197,219,242$.

national, $17,101,105,110,112,121,133,158,171$, $173,175,187,196,212,219,227,232,236$, 244, 246, 249 .

technological, 244, 249.

psychoanalysis (see also horror genre; Sigmund Freud), 23, 24, 35, 36, 163 .

and childhood, 23,35 .

Freudian, 23, 24, 163 .

and horror cinema, 23, 24, 163 .

in Japan, 163 .

RAISE RAVENS (Carlos Suara, 1976), 107, 108, 109, $111,118,121,122,125^{-131}, 138,145$ n, 151, 310.

RAZA [RACE] (José Luis Sáenz de Heredia, 1941) 104-105, 118, 310.

Reagan, Ronald, 41, 59 .

Reincarnation [RINne] (Takashi Shimizu, 2005), 185, 216, 221, 239, 310.

Ring (Koji Suzuki, 1991, novel), 157, 159n, 181, 192, $215,220,302$.

RING, THE (Gore Verbinski, 2002), 6, 16, 31, 159, $183,221,222,223,229,232,233,239,248,249$, $265^{-279,280,282,285,310 .}$

Ring Two, The (Hideo Nakata, 2005), 221, 223, $239,285,287,310$.

RINGU (Hideo Nakata, 1998), 15, 18, 27, 155, 156, $157,159,173,175,183,185,190,191-206,212$, 216, 220, 221, 228, 229, 239, 266, 269, 270, 271, $273,282,310$.

RINGU 2 (Hideo Nakata, 1999), 156n, 183, 193, 201, 202, 204, 216, 310.

Ringu 0: BIRThDAY [RINGU o: BASUdei] (Norio Tsuruta, 2000), 192, 197, 20of, 201, 202, 216, 310.

Ringu - The Ring Virus (Dong-bin Kim, 1999), 221n, 239, 310.

Rosemary's BAby (Roman Polanski, 1967), 11, $31,310$.

Rousseau, Jean-Jacques, 10, 29, 283, 286, 301.

SADAKo 3D (Tsutomu Hanabusa, 2012), 156n, $183,285,287,310$.

SADAKO 3 D 2 (Tsutomu Hanabusa, 2013), 183, $285,287,310$.

San Sebastian Film Festival, 108

Saura, Carlos, 107, 108, 117, 118, 121, 122, 125, 131, 136, 151, 307, 308, 110.

Scahill, Andrew, 11, 12, 16, 21, 29, 301.

SCARy Movie 3 (David Zucker, 2003), 250, 264, 310.

Schober, Adrian, 12n, 16, 29, 38-39, 64, 301.

Serrador, Narciso Ibáñez, 109, 110, 119, 143, 151, 311.
Shining, The (Stanley Kubrick, 1980), 31, 35, 36, $4^{2-45}, 47,48,5^{0}, 5^{2}, 53,55,5^{6-60}, 65,68$, $69,70,74,82,83,86,90,221,240,311$.

Shining, The, novel (Stephen King, 1977), 42, 47, $63,296$.

Shor, Juliet B., 41, 64, 301.

Sixth Sense, The (M. Night Shyamalan, 1999), $15,18,31,67,8,69,70,71-78,81,82,88,90$, 101, 220, 239, 310.

Sleep of Reason Produces Monsters, The (painting) (see also Francisco Goya), 10, 30, 287,313 .

Star Wars: Episode I - The Phantom Menace (George Lucas, 1999), 67, 90, 240, 311.

Stigmata (Rupert Wainwright, 1999), 69, 9o, 311.

Stir of Echoes (David Koepp, 1999), 67-70, 78, $79,80-81,82,88,90,220,240,311$.

Sobchack, Vivian, 61, 64, 301.

Spanish cinema (see also Francisco Franco, horror genre; Spanish horror film; Spanish history; Spanish national identity), 12, 95, 96, 97, 99, 101, 102, 103, 105, 107, 108, 109, 100, $111,112,113,114-115,121,122$.

aesthetic of repression (see also Francisco Franco), 111, 131.

and art film, 96, 101, 107, 108, 109, 111-113, $122,132$.

and censorship, 108.

and collective memory, 95, 98-100, 122, $133,186$.

co-productions, 16, 19, 27, 99, 107, 219, 221, $222,225,227,236,250$.

cine con niño (child-centred cinema), 105-106, 110, 111-113, 130, 134, 140.

José María Carcía Escudero, 108.

Escuela Oficial de Cine, 108.

under Franco, 102-103, 105, 107.

and horror genre (see also Spanish horror film), 100-102.

Ley Miró legislation, 100.

Marisol, 105-106, 140, 141 f.

and millennium, 121.

New Spanish Cinema, 107-109.

and Spanish Civil War, 99, 102, 103-105, 106, $107,109,110,112,113,114,125,133,134$, 136,138 .

temporal belatedness, 97, 113, 122 .

Spanish history (see also Francisco Franco; history; memory; Spanish cinema; Spanish horror film; Spanish national identity; and trauma), 95, 96, 98, 99, 100, 104, 114, 122, 125, 133, 134, 140, 141, 142, 148, 149, 227.

Civil War, 26, 95, 96,97, 102, 103, 106, 107, 109, $111,121,122,124,128,131,132,136$.

Francoist regime (see Francisco Franco). pact of forgetting, 113 .

Historical Memory Law, 122, 146. 
Spanish Socialist Worker's Party, 113. transition period, 101, 113-115, 140. and trauma, 95, 114, 133, 138, 144, 148. years of hunger, 102.

Zapatero, Josè Luis, 122.

Spanish horror film (see also horror genre; Spanish cinema; uncanny child/childhood), $15,26,27,88,95,96,98-100,100-102$,

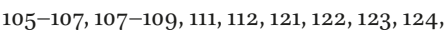
$132,155,159$.

allegorical moment (see horror genre), 121, $123-125,128,132,133,134,135,136,137$, 138,147 .

as art-house horror, $96,101,111,112,113,114 \mathrm{n}$, $125,132$.

and cultural trauma (see also Spanish national identity), 111, 112, 129, 178 . and collective memory, 98-100, 122, 186. as exploitation cinema, 100, 111, 113. and Freudian trauma, 95, 96. gothic supernatural, 95, 97, 101. repressed spectres, 96, 102, 133 . and the uncanny child (see also uncanny child film), 15, 57, 95, 97, 99, 101, 121, 122, $138,148,149$.

Spanish national identity (see also Francisco Franco; history; national identity; Spanish history; Spanish cinema; Spanish national identity; and trauma), 95-98, 99, 112, 113, $132,148$.

Association for the Recuperation of Historical Memory, 121.

and the child/childhood (see the child/ childhood), 112, 132 .

and the Civil War (see Spanish history). collective cultural memory, 89, 95, 96, 99, $121,122,148$.

cultural rupture, 115, 123, 129, 136, 148 . cultural unity, 103, 148.

and the family, 104, 105.

Forum for Memory, 122.

and Francoism(see Francisco Franco).

as historical metanarrative, 99, 103, 105, 125,129 .

historical trauma, 95, 96, 124, 133, 158, 253 .

'the two Spains,' 102, 148.

'Spanishness,' 103.

Spanish Civil War Memory Project, 122.

Spanish cultural discourse, 104, 115, 121.

Spanish model, 114.

and the transition period, 101,113-115.

SPIRIT OF THE BEeHIVE, The [El ESPÍRITU DE LA COLMENA] (Victor Erice, 1973), 107, 108, 109, 111, 118, 121, 122, 125-131, 133, 138, 141, $151,311$.

Stamp Lindsey, Shelley, 10n, 29, 302.

Statue of Mother and Children During the Storm

(Hiroshima Peace Park), 172, 183, 313.

Steedman, Carolyn, 36, 64, 302.
Stockton, Kathryn Bond, 21, 22, 29, 37, 45, 57, 64, $88,283,284,286,302$.

Sukuki, Koji, 157, 159n, 181, 192, 215, 220, 302.

Tanaka, Stefan, 161n, 167, 168-171, 181, 302.

temporality, $9,13,18,19,21,22,23,24,25,26,27$, $36,38,47,55,57,58,59,62,67,68,70,76,79$, $85,86,88,97,106,111 n, 112,113,114,122,123$, $125,129,130,134,135,139,145,146,147,148$, $149,156,163,164,167,168,171,185,186,187$, 189, 192, 194, 197, 198, 201, 202, 203, 204, 205, 206, 207, 208, 209, 210, 212, 213, 222, 227, 231, 241, 242, 244, 246, 247, 248, 249, 250, 251, $253,254,255,257,259,261,262,266,276$, $280,283,284,286$.

and adulthood, $23,36,76$.

and the a-temporal, 83 .

and childhood, 13, 22, 36, 70, 120, 146, 171.

cinematic time, 26,57 .

and Deleuze (see also Gilles Deleuze), 26, 57 . and deterritorialization, 231.

as liminal, 156 .

linear time, 18,164 .

and millennial horror, 112 .

national time, 132, 168, 171, 185, 211.

and national/historical progression, 22, 68, 167-168.

'out of joint,' 26,57 .

plurality, 186, 194, 210.

and spatiality, 88, 106, 123, 149, 164, 189, 254.

as temporal belatedness, 97,113 .

and trauma, 24, 47, 114, 129, 130, 134, 185, 186, 222, 227, 286.

vectors, 13, 18, 23, 204.

Thirteenth Floor, The (Josef Rusnak, 1999), $69,91,311$.

transnational cinema (see also globalization; and Hollywood), 15, 16, 17, 27, 97, 99, 158, 219, 221, 224, 226, 227, 231, 232, 234, 236, 241, 242, 244, 248, 249, 250, 268, 274, 280, 284.

as cultural hybridity, 219, 221, 226, 236, 268 . and deterritorialization, 232, 236, 274, 280 . and Hollywood, 16, 99.

and horror, 222, 224, 226, 232, 234, 244, 248, 280.

as global exchange, 224 .

and globalization, 158, 227 .

and remakes, 16,27, 234, 242, 244.

trauma (see also child/childhood; adult/adult-

hood; American national identity; Japanese national identity; memory; Spanish national identity), 18, 19, 20, 24, 25, 26, 27, $35,37,45,46,47,53^{-} 5^{6}, 5^{6-59}, 67,71-78$, $82,84,87,88,95-97,99,102,109,112,113,114$, $121-125,127,128,129,132,133,134,136,137$, $138,139,140,144-148,155,171,178,185,186$, 185-191, 191-201, 205, 208-211, 212, 267-268. and the adult/adulthood, 35, 74 . 
and the child, $12,18-19,24-27,35,36,37$, $5^{2}-59,67,70,77,80,84,96,97,102 \mathrm{n}, 110$, $111-112,122,126,127,128-134,136-148$, $155,162,173,176,178,185-209,211-212$, $219,220,227,267-268,279,284,286$.

and horror sensorium, 185, 189-191.

breach in mind, 122,136 .

childhood, $267,62 \mathrm{n}, 74,87,102 \mathrm{n}, 141,145 \mathrm{n}$, 199, 202, 205, 267 .

collective, 107, 113 .

historical, 19, 20, 27, 57, 95, 96, 112, 121, 124, $132,133,15^{8}, 253$

national, 27, 102, 104, 112, 131, 133, 155, 185 .

prosthetic, 185-190, 191 192, 200, 202, 207, 208-209, 212.

and the viewer, $77-78$.

Trigg, Dylan, 241, 244, 246, 247, 248, 250, 255, $259,262,264,280,282,303$.

\section{Ugetsu [Ugetsu Monogatari] (Kenji}

Mizoguchi, 1953), 157, 183, 311.

uncanny, the (see also Sigmund Freud; psychoanalysis; the uncanny child/childhood; and uncanny child film cycle) binaries, 13, 284, 286.

child (see also child/childhood; and uncanny child film), 9, 12-16, 20-24, $27,35-39,50,57,70,81,219,220,226$, $231,234,242,248,285$.

embodiment of trauma, 18, 187, 199 .

Freudianism, 19, 23, 24, $35-38,54,57,74$, $95,96,98,162,163$.

heimlich and unheimlich, 12, 22-23, 38, 39, $139,248,258,283$.

and horror film (see also uncanny child film), 222.

otherness, $12,13,18,24,38,39,42,57,61,75$, $83,85,88,235,268,286$.

as postmodern, $27,219,241,242,244,266$, $267,268$.

uncanny child, the/uncanny childhood (see also the child/childhood; psychanalysis; Sigmund Freud; the uncanny; and uncanny child film cycle)

aesthetics of decay, 241, 244, 246.

cathartic eruptions, $27,121$.

and Francoist discourse, 27,113, 121, 125 .

and Freud, 12, 19, 22, 23, 24, 25, 36, 39, 42, 57, $88,95,132,162,248$.

and futurity, 14, 17, 21, 61, 69, 163, 178, 212, $242,248,249,280,284$.

and historical trauma, 19, 27, 57, 124, 158 . and horror film, 9-12, 15-16, 20-23, 26-27, $35^{-3} 6,38,40,42,43,57,61,62,67-68,79$, $88,95,160-163,166-169,173,178,185^{-191}$, 193, 194, 204, 212, 219-234, 244, 248, 250, $265-266,280,285$.

of the millennial turn, $16,17,95,101,102,156$, $178,206,212,219,246,252,283,285,286$. postmodern, 27, 219, 225, 241, 242, 244, 266, 267,268 .

return of the repressed, $20,84,122,132$.

theorizing, 20-21.

transnational, $15,16,18,212,219,221$, $222-223,225,226-227,231,234,236$, $241,242,244,248,249,274,279,28$ o, 283,284 .

uncanny child film cycle (see also the child/ childhood; the uncanny; and uncanny child/childhood), 9, 12, 13, 14, 15, 16, 20, 21, $22,24,27,35,36,38,39,50,57,59,67,70$, $81,82,95 \mathrm{n}, 99,101 \mathrm{n}, 114 \mathrm{n}, 156,219,222,226$, 228n, 231, 234, 248, 250, 265, 267, 283, 285 . in the 1980 s, $12,15,35,36,38-40,43,59,61$, $62,68,70,81,82,88$.

and art film, 96, 122, 124, 132, 124, 156 .

in American horror cinema, 9, 12, 15, 38, 163, 220, 221, 222, 224.

and the child seer, 126, 140, 144, 147, 220. and cultural hybridity, 219, 221, 226, 234, $236,268$.

and cuteness, 9, 10, 38, 39, 52, 79 .

as deconstructing childhood, 19, 36, 212.

ghost-child, 22.

and the gothic, 20, 95 .

in Japanese horror cinema, 221.

as millennial cycle, 20, 285 .

paradoxes, 38,53 .

psychic entanglement, 43-47.

repressed trauma, 73 .

in Spanish horror cinema, 26, 27, 88, 95, 97, $121,123,124,132,159$.

syntactic, 53 .

and temporality, $9,26,55,57,58,79,83,148$, $163,187,213$.

uncanny child trope, 15, 16, 82, 242 .

Underwood, Ted, 74, 90, 303.

United Nations Convention on the Rights of the Child, 41, 175 .

USA Academy of Science Fiction, Fantasy and Horror Films, 101.

Venice Film Festival, 158.

Village of the Damned, The (Wolf Rilla, 1961), 43, 65, 311 .

ViridianA (Luis Buñuel, 1961), 108, 119, 254, $264,311$.

Wada-Marciano, Mitsuyo, 156n, 157, 158, 159, 16on, 192n, 234.

Warner, Marina, 13, 30, 75, 90, 304.

Wee, Valerie, 16, 30, 16o, 161, 182, 215, 231, 239, $267,282,304$.

Weinstock, Jeffrey, 19, 30, 69, 90, 302, 304.

Western society, 35, 36, 69, 158, 163, 165, 168, 171, 175, 197, 199, 23on, 243, 245 . and adult unconscious, 35 . and capitalist progress, 178 . 
and the child (see also childhood), 35, 235 . and Freud, 36 .

and identity, 163 .

Imperialism, 169 .

and Japan, 165, 167-169, 171, 199.

and masculinity, 69 .

modernity, 114, 175 .

and national progress, 199.

and technology, 167 . and trade, $161,167$.

Who CAN KILl A ChILD? (Narciso Ibáñez Serrador, 1976), 109-111, 119, 143, 151, 311.

Wood, Robin, 10, 16, 30, 304.

World War II (see also history; and Japanese history), 27, 6o, 123, 125, 128, 155, 157, 158 164-166, 167, 171, 232, 251, 252, 257, 262, 274n.

Wright, Sarah,99, 104-105, 106, 111n, $112 \mathrm{n}$. 



\title{
Film Culture in Transition
}

\author{
General Editor: Thomas Elsaesser
}

Thomas Elsaesser, Robert Kievit and Jan Simons (eds.)

Double Trouble: Chiem van Houweninge on Writing and Filming, 1994 ISBN paperback 9789053560259

Thomas Elsaesser, Jan Simons and Lucette Bronk (eds.)

Writing for the Medium: Television in Transition, 1994

ISBN paperback 9789053560549

Karel Dibbets and Bert Hogenkamp (eds.)

Film and the First World War, 1994

ISBN paperback 9789053560648

Warren Buckland (ed.)

The Film Spectator: From Sign to Mind, 1995

ISBN paperback $97890535^{6} 131$ 7; ISBN hardcover 9789053561706

Egil Törnqvist

Between Stage and Screen: Ingmar Bergman Directs, 1996

ISBN paperback 978905356137 9; ISBN hardcover 9789053561713

Thomas Elsaesser (ed.)

A Second Life: German Cinema's First Decades, 1996

ISBN paperback $97890535^{6} 172$ o; ISBN hardcover 9789053561836

Thomas Elsaesser

Fassbinder's Germany: History Identity Subject, 1996

ISBN paperback 978905356059 4; ISBN hardcover 9789053561843

Thomas Elsaesser and Kay Hoffmann (eds.)

Cinema Futures: Cain, Abel or Cable? The Screen Arts in the Digital Age, 1998 ISBN paperback 978905356282 6; ISBN hardcover 9789053563120

Siegfried Zielinski

Audiovisions: Cinema and Television as Entr'Actes in History, 1999

ISBN paperback 978905356313 7; ISBN hardcover 9789053563038 
Kees Bakker (ed.)

Joris Ivens and the Documentary Context, 1999

ISBN paperback 978905356389 2; ISBN hardcover 9789053564257

Egil Törnqvist

Ibsen, Strindberg and the Intimate Theatre: Studies in TV Presentation, 1999 ISBN paperback $97890535^{6} 35^{\circ}$ 2; ISBN hardcover $97890535^{6} 3717$

Michael Temple and James S. Williams (eds.)

The Cinema Alone: Essays on the Work ofJean-Luc Godard 1985-2000, 2000 ISBN paperback 978905356455 4; ISBN hardcover 9789053564561

Patricia Pisters and Catherine M. Lord (eds.)

Micropolitics of Media Culture: Reading the Rhizomes of Deleuze and Guattari, 2001

ISBN paperback 978905356472 1; ISBN hardcover 9789053564738

William van der Heide

Malaysian Cinema, Asian Film:Border Crossings and National Cultures, 2002 ISBN paperback 978905356519 3; ISBN hardcover 9789053565803

Bernadette Kester

Film Front Weimar: Representations of the First World War in German Films of the Weimar Period (1919-1933), 2002

ISBN paperback $97890535^{6} 597$ 1; ISBN hardcover $97890535^{6} 5988$

Richard Allen and Malcolm Turvey (eds.)

Camera Obscura, Camera Lucida: Essays in Honor of Annette Michelson, 2003 ISBN paperback 9789053564943

Ivo Blom

Jean Desmet and the Early Dutch Film Trade, 2003

ISBN paperback 978905356463 9; ISBN hardcover 9789053565704

Alastair Phillips

City of Darkness, City of Light: Émigré Filmmakers in Paris 1929-1939, 2003 ISBN paperback 978905356634 3; ISBN hardcover 9789053566336 
Thomas Elsaesser, Alexander Horwath and Noel King (eds.)

The Last Great American Picture Show: New Hollywood Cinema in the 197os, 2004

ISBN paperback 978905356631 2; ISBN hardcover 9789053564936

Thomas Elsaesser (ed.)

Harun Farocki: Working on the Sight-Lines, 2004

ISBN paperback 978905356635 o; ISBN hardcover 9789053566367

Kristin Thompson

Herr Lubitsch Goes to Hollywood: German and American Film after World War I, 2005

ISBN paperback 978905356708 1; ISBN hardcover 9789053567098

Marijke de Valck and Malte Hagener (eds.)

Cinephilia: Movies, Love and Memory, 2005

ISBN paperback 978905356768 5; ISBN hardcover 9789053567692

Thomas Elsaesser

European Cinema: Face to Face with Hollywood, 2005

ISBN paperback 978905356594 0; ISBN hardcover 9789053566022

Michael Walker

Hitchcock's Motifs, 2005

ISBN paperback 978905356772 2; ISBN hardcover 9789053567739

Nanna Verhoeff

The West in Early Cinema: After the Beginning, 2006

ISBN paperback 9789053568316 ; ISBN hardcover $97890535683^{2} 3$

Anat Zanger

Film Remakes as Ritual and Disguise: From Carmen to Ripley, 2006 ISBN paperback 978905356784 5; ISBN hardcover $978905356785^{2}$

Wanda Strauven

The Cinema of Attractions Reloaded, 2006

ISBN paperback 978905356944 3; ISBN hardcover 9789053569450 
Malte Hagener

Moving Forward, Looking Back: The European Avant-garde and the Invention of Film Culture, 1919-1939, 2007

ISBN paperback 978905356960 3; ISBN hardcover 978905356961 o

Tim Bergfelder, Sue Harris and Sarah Street

Film Architecture and the Transnational Imagination: Set Design in 1930 s European Cinema, 2007

ISBN paperback 978905356984 9; ISBN hardcover 9789053569801

Jan Simons

Playing the Waves: Lars von Trier's Game Cinema, 2007

ISBN paperback 978905356991 7; ISBN hardcover 9789053569795

Marijke de Valck

Film Festivals: From European Geopolitics to Global Cinephilia, 2007 ISBN paperback 978905356192 8; ISBN hardcover 9789053562161

Asbjørn Grønstad

Transfigurations: Violence, Death, and Masculinity in American Cinema, 2008 ISBN paperback 978908964010 9; ISBN hardcover 9789089640307

Vinzenz Hediger and Patrick Vonderau (eds.)

Films that Work: Industrial Film and the Productivity of Media, 2009 ISBN paperback 978908964013 o; ISBN hardcover 9789089640123

François Albera and Maria Tortajada (eds.)

Cinema beyond Film: Media Epistemology in the Modern Era, 2010

ISBN paperback 978908964083 3; ISBN hardcover 9789089640840

Pasi Väliaho

Mapping the Moving Image: Gesture, Thought and Cinema circa 1900, 2010 ISBN paperback 978908964140 3; ISBN hardcover 9789089641410

Pietsie Feenstra

New Mythological Figures in Spanish Cinema:Dissident Bodies under Franco, 2011

ISBN paperback 978908964304 9; ISBN hardcover 9789089643032 
Eivind Røssaak (ed.)

Between Stillness and Motion: Film, Photography, Algorithms, 2011 ISBN paperback 978908964212 7; ISBN hardcover 9789089642134

Tara Forrest

Alexander Kluge: Raw Materials for the Imagination, 2011

ISBN paperback 978908964272 1; ISBN hardcover 9789089642738

Belén Vidal

Figuring the Past:Period Film and the Mannerist Aesthetic, 2012

ISBN 978908964282 o

Bo Florin

Transition and Transformation: Victor Sjöström in Hollywood 1923-1930, 2012 ISBN 9789089645043

Erika Balsom

Exhibiting Cinema in Contemporary Art, 2013

ISBN 9789089644718

Gilles Mouëllic

Improvising Cinema, 2013

ISBN 97890896445517

Christian Jungen

Hollywood in Canne\$: The History of a Love-Hate Relationship, 2014 ISBN 9789089645661

Michael Cowan

Walter Ruttmann and the Cinema of Multiplicity: Avant-Garde Film - Advertising-Modernity, 2014

ISBN 9789089645852

Temenuga Trifonova

Warped Minds: Cinema and Psychopathology, 2014

ISBN 9789089646323

Christine N. Brinckmann

Color and Empathy: Essays on Two Aspects of Film, 2014

ISBN 9789089646569 
François Albera and Maria Tortajada (eds.)

Cine-Dispositives: Essays in Epistemology Across Media, 2015

ISBN 9789089646668

Volker Pantenburg

Farocki/Godard:Film as Theory, 2015

ISBN 9789089648914

Paul Cuff

A Revolution for the Screen: Abel Gance's NAPOLÉON, 2015

ISBN 9789089647344

Scott Loren and Jörg Metelmann (eds.)

Melodrama After the Tears: New Perspectives on the Politics of Victimhood, 2015 ISBN 9789089646736

Steve Choe

Sovereign Violence: Ethics and South Korean Cinema in the New Millennium, 2016

ISBN 9789089646385

Melis Behlil

Hollywood is Everywhere: Global Directors in the Blockbuster Era, 2016 ISBN 9789089647399

Thomas Elsaesser

Film History as Media Archaeology: Tracking Digital Cinema, 2016 ISBN 978946298057 o

Michael Walker

Modern Ghost Melodramas: 'What Lies Beneath', 2017

ISBN 9789462980167

Steffen Hven

Cinema and Narrative Complexity: Embodying the Fabula, 2017

ISBN 9789462980778

Alexandra Seibel

Visions of Vienna: Narrating the City in 1920 and 1930 Cinema, 2017 ISBN 9789462981898 
Rossella Catanese

Futurist Cinema: Studies on Italian Avant-garde Film, 2018

ISBN 9789089647528

Adrian Martin

Mysteries of Cinema: Reflections on Film Theory, History and Culture 1982-2016, 2018

ISBN 9789462986831

Paula Albuquerque

The Webcam as an Emerging Cinematic Medium, 2018

ISBN $97894629855^{8} 2$

Ilka Brasch

Film Serials and the American Cinema, 1910-1940, 2018

ISBN 9789462986527

Jessica Balanzategui

The Uncanny Child in Transnational Cinema: Ghosts of Futurity at the Turn of the Twenty-first Century, 2018

ISBN 9789462986510 
